UNIVERSIDADE DE SÃO PAULO

INSTITUTO DE GEOCIÊNCIAS

PALEOPLUVIOSIDADE NO NORTE DE MINAS GERAIS DURANTE O GLACIAL TARDIO E HOLOCENO COM BASE EM REGISTROS DE ESPELEOTEMAS

\author{
Nicolás Misailidis Stríkis \\ Orientador: Prof. Dr. Francisco William da Cruz Júnior \\ DISSERTAÇÃO DE MESTRADO \\ Programa de Pós-Graduação em Geoquímica e Geotectônica
}

São Paulo 
UNIVERSIDADE DE SÃO PAULO

INSTITUTO DE GEOCIÊNCIAS

\section{PALEOPLUVIOSIDADE NO NORTE DE MINAS GERAIS DURANTE O GLACIAL TARDIO E HOLOCENO COM BASE EM REGISTROS DE ESPELEOTEMAS}

Nicolás Misailidis Stríkis

Dissertação de mestrado apresentada junto ao Instituto de Geociências da Universidade de São Paulo na Área de Geoquímica dos Processos Exógenos para a obtenção do título de Mestre em Geociências. 
Autorizo a reprodução e divulgação total ou parcial deste trabalho, por qualquer meio convencional ou eletrônico, para fins de estudo e pesquisa, desde que citada a fonte

Ficha catalográfica preparada pelo Serviço de Biblioteca e Documentação do Instituto de Geociências da Universidade de São Paulo

Stríkis, Nicolás Misailidis

Paleopluviosidade no norte de Minas Gerais durante o Glacial tardio e Holoceno com base em registros de espeleotemas / Nicolás Misailidis Stríkis. - São Paulo, 2011.

124 p.: Il. + 4 anexos

Dissertação (Mestrado) : IGc/USP

Orient.: Cruz Júnior, Francisco William da

1. Minas Gerais: Paleoclimatologia 2. Minas Gerais: Espeleotemas 3. Minas Gerais: Quaternário 4. Minas Gerais: Sedimentologia 5. Geoquímica I. Título 


\section{AGRADECIMENTOS}

Antes de tudo, agradeço aos meus pais Pedro Carlos Stríkis e Maria Laura Misailidis Lerena por me mostrarem a ciência. Agradeço aos meus irmãos Nadejada, Frederico, Yadza e Laura por sempre estarem ao meu lado e por darem todo o suporte para que eu pudesse seguir com o meu trabalho. Agradeço também a minha morena, Daniele.

Aos meus orientadores Chico Bill e Ivo Karmann. A eles pela oportunidade de trabalhar com a paleoclimatologia, pelas discussões científicas e pelas cervejas que se seguiam no curso dessas disucussões, que sem dúvida abriram as nossas mentes.

Agradeço ao Dr. Luiz Mancini, um grande amigo, e porque não, um professor. A todos os companheiros do laboratório que acima de tudo, são grandes amigos: Eline Barreto Alves, Marcos Saito de Paula (Xang), Valdir Felipe Novelo (para alguns Valdirene), Thaize Segura Baroni, Sheila Schuindt (Sertão), James Apaestegui, Maria Carolina A. Catunda (Obelix). Galera, valeu mesmo, "tamo junto". Agradeço também ao Osmar Antunes Junior, pelas análises de laboratório, pelo companheirismo e claro, pelas discussões sobre química.

Aos espeleólogos norte mineiro Ronaldo Sarmento (Capitão Caverna) e Hamilton dos Reis Sales. A vocês meus sinceros agradecimentos. Agradeço também a todos os Pé na Lama (GEPELGrupo de Espeleologia Pé na Lama) do oeste de Minas Gerais: Leonordo Lepesqueur, Jaqueline Alves da Silva, Thomáz Thosio e toda a galera cavernera. Ao geólogo Augusto Auler pelo auxílio nos trabalhos de campo e pela contribuição nas discussões cientifícas.

Aos meus companheiros e amigos de sala Bruno Lagler (Meninão) e Lucas Padoan de Sá Godinho (Rejeito) que sempre ajudaram a conferir um clima de descontração e completa bagunça ao ambiente de trabalho.

Ao geólogo Xianfeng Wang do Lamont-Doherty Earth Observatory da Univerisidade de Columbia pelo auxílio nas datações e também pelo companheirismo e ao Prof. Dr. Lawrence Edwards da Universidade de Minnesota pela importante cooperação laboratorial, possibilitando a realização das análises geocronológicas. 


\section{RESUMO}

STRIKIS, N. M. Paleopluviosidade no norte de Minas Gerais durante o glacial tardio e Holoceno com base em registros de espeleotemas. 2011. 124. f. Dissertação (mestrado) - Instituto de Geociências, Universidade de São Paulo, São Paulo.

A partir de registros isotópicos $\left(\delta^{18} \mathrm{O}\right.$ e $\left.\delta^{13} \mathrm{C}\right)$, das razões elementos traços/Ca e das taxas de crescimento de espeleotemas precisamente datados pelo método U-Th, foi possível realizar a reconstituição das mudanças de paleopluviosidade e de feições paleoambientais da região do norte do estado de Minas Gerais, com alta resolução para os últimos 28 mil anos.

A interpretação do sinal climático embutido nos registros isotópico dos espeleotemas estudados são baseados em estudos prévios da série histórica de monitoramento das estações do IAEA-GNIP, em complemento com simulações das variações do $\delta^{18} \mathrm{O}$ da chuva através de modelos climáticos computacionais, os quais indicam o fator "amount effect" como o principal mecanismo atuante na variação da composição isotópica das chuvas sobre a região. As variações de pluviosidade estão associadas à atividade da Zona de Convergência do Atlântico Sul (ZCAS), as quais foram utilizadas na reconstituição da variabilidade espacial do Sistema de Monções Sulamericano (SMSA) e da atuação das forçantes de insolação, oceânicas e variabilidade solar na modulação das mudanças climáticas na região desde o último período glacial.

O registro paleoclimático do norte de Minas indica semelhança com as variações de pluviosidade da região nordeste do Brasil durante o período glacial entre 28 e 19 ka A.P., devido a mudanças na insolação de verão e/ou por influência da expansão do gelo no clima dos trópicos. Nesse período o registro isotópico mineiro indica condições relativamente secas, que contrastam com clima relativamente úmido registrado na região sudeste do país, assim como nas regiões tropicais dos altiplanos andinos. O padrão antifásico entre as regiões localizadas a leste e a oeste da ZCAS sugere uma migração para sudoeste do eixo de maior precipitação, relacionada ao fortalecimento da circulação meridional tipo Hadley e intensificação da alta da Bolívia. No período analisado, a intensificação da circulação zonal estabelecida entre a Alta da Bolívia e o Cavado do Nordeste estaria primariamente relacionada à maior convergência de umidade na Amazônia devido às baixas temperaturas da superfície do mar (TSM's) no Atlântico norte durante fases de maior expansão do gelo, quando a alta subtropical do Atlântico Norte e os ventos alísios de nordeste estariam mais fortalecidos.

Eventos milenares de aumento de intensidade das Monções Sul-americanas durante o Glacial tardio, deglacial e Holoceno registrados em Minas Gerais são sincrônicos aos eventos abruptos frios documentados nas zonas de altas latitudes do Hemisfério Norte, a exemplo dos eventos Heinrich $(2,1)$, Young Dryas, 8.2 ky e eventos Bond $(6,5,4,2)$. Da mesma forma, durante os eventos quentes Dansgaard-Oescheger 2 e Bølling-Allerød foram registradas reduções da paleoprecipitação. Portanto, o bom acoplamento entre a atividade do SMSA no norte de Minas com as variações da temperatura da superfície do mar do Atlântico norte indica que, independente dos mecanismos responsáveis pelo desencadeamento de tais eventos, as mudanças na intensidade das Monções Sul-americanas se dão principalmente por teleconexão estabelecidas com condições climáticas nas zonas de altas latitudes do Hemisfério Norte, mais especificamente por alterações do gradiente de TSM do Oceano Atlântico.

Ao longo do Holoceno, foi observado que o tempo de duração dos eventos abruptos de pluviosidade é mais longo durante o Holoceno Inferior e Médio e mais curto durante o Holoceno Superior. Essa relação sugere mudanças das condições de contorno do clima no transcorrer do Holoceno, possivelmente relacionadas à diminuição da cobertura de gelo no Hemisfério Norte a partir de 7 mil anos, que levou desativação da circulação termohalina que caracteriza os eventos Bond no hemisfério norte.

Palavras-chave: Minas Gerais, paleoclima, paleopluviosidade, Monções Sul-americana, Holoceno, deglacial, eventos milenares, espeleotemas, isótopos, Quaternário. 


\begin{abstract}
STRIKIS, N. M. Paleo-precipitation variations in northern Minas gerais during the later Glacial Period and Holocene from speleothem records. 2011. 124. f. Dissertação (mestrado) - Instituto de Geociências, Universidade de São Paulo, São Paulo.

Relative changes in paleo-precipitation and also in paleoenvironment features were reconstructed for northern Minas Gerais State, central-eastern Brazil, during the last 28 ka B.P. The reconstruction is based on high resolution stable isotope $\left(\delta^{18} \mathrm{O}\right.$ e $\left.\delta^{13} \mathrm{C}\right)$, trace element ratios and growth rate records of speleothems precisely dated by U-Th method.

The interpretation of climatic changes from the studied oxygen isotope records is taken into account the data from IAEA-GNIP monitoriting stations and from climate model simulations of $\delta^{18} \mathrm{O}$ in precipitation, which points out to the amount effect as the dominant isotope fractionation factor controlling the $\delta^{18} \mathrm{O}$ variations in meteoric water. The precipitation variations, associated to the activity of South American Convergence Zone (ZCAS), are used to reconstruct the spatial variability of South American Convergence Zone (SMSA) since last glacial period because of a forcing by insolation, ocean conditions e solar variability.

The record from Northern Minas Gerais indicate similarities with precipitations variation documented in speleothem records from Northeastern Brazil from 28 to 19 ka B.P., because of changes in summer insolation and/or influence of glacial boundary conditions on tropical precipitation. In this period, higher $\delta^{18} \mathrm{O}$ values of speleothems suggest the dominance of dryer conditions over the region, in contrast with the wetter climate recorded in other regions of South America such as southeastern Brazil and Andes Altiplano that are today located to the west of the ZCAS's axis of activity. This antiphased pattern within the same continent suggest a migration of ZACS mean position to southwest due to intensification of Bolivian High and Nordeste Low upper level features in response to changes in Hadley and Walker circulation cells. Theses changes were primarily related to colder Sea Surface Temperatures in Atlantic ocean and increased rainfall over western Amazon region.

Millennial-scale events of increase in monsoon precipitation during the Glacial, deglacial, and Holocene in northern Minas are synchronous with abrupt cold events recorded in the high latitude areas of North Hemisphere (N.H.), like Heinrich $(2,1)$, Young Dryas, 8.2 ky and Bond events. In the same way, dry periods in northern Minas were recorded during the DansgaardOescheger 2 and Bølling-Allerød N.H. warm events. The coupling between the rainfall due to South America Monsoon System with sea surface temperature variation in the North Atlantic, points out to a teleconnection mechanism with climate conditions in North Atlantic ocean such the TSM gradient with the South Atlantic basin. Differences in duration of abrupt events of changes in precipitation between early and late Holocene are associated larger amplitude of TSM's that characterize the Bond events over Atlantic Ocean. These differences were triggered by the stepwise ice melting after 7 thousand years ago.
\end{abstract}

Key words: Minas Gerais, paleoclimate, paleoprecipitation, South América Monsoon, Holocene, deglacial, millenial events, speleothems, isotopes, Quaternary. 


\section{LISTA DE FIGURAS}

Figura 2. 1 - Localização da área de estudo bem como o contexto das unidades carbonáticas e províncias cársticas do território brasileiro.

Figura 2.2 - Valores de $\delta^{13} \mathrm{C}$ dos carbonatos da Formação Sete Lagoa do Jacaré, rocha encaixante da caverna Lapa Sem Fim. As amostras TIR25 representam rocha do conduto e as demais (LSF A, B e C) amostras de rochas coletadas em um perfil vertical na entrada da caverna e apresentam valores muito enriquecidos em ${ }^{13} \mathrm{C}$.

Figura 2.3 - Estimativa de espessura do reservatório da zona vadosa sobre a caverna Lapa Grande. O contorno em verde representa a projeção da planta baixa sobre o relevo. Fonte Google Earth março/2011.-------------- 7

Figura 2.4 - Perfil longitudinal do desnível terreno sobre a caverna Lapa Sem Fim. A linha tracejada ilustra a projeção horizontal do perfil da caverna considerando o pequeno desnível vertical observado. A espessura de aproximadamente $25 \mathrm{~m}$ corresponde à área do Salão Cristiane, próximo ao final da caverna. Fonte Google Earth março/2011.

Figura 2.5 - Comparação das séries históricas dos valores dos acumulados anuais de Montalvânia (caverna Lapa Grande) e de Brasília de Minas (município próximo da caverna Lapa Sem Fim) entre os anos de 1974 e 2010. As séries temporais foram construídas com base nos dados de estações meteorológicas disponibilizados pela agência nacional de águas (ANA). Em ambas as regiões, as médias dos totais acumulados anuais giram em torno de 940 mm. As barras cinza representam anos de forte El-Niño.

Figura 2.6 - Distribuição de TSM em ${ }^{\circ} \mathrm{C}$ baseado em medições de radiação de ondas longas $\left(\mathrm{W} / \mathrm{m}^{2}\right)$ para os meses de Dezembro a Fevereiro (quadro a esquerda) e de Junho a Agosto (quadro a direita). Notar aumento da TSM do Atlântico equatorial oeste durante o período de pico das Moções Sul-americanas. Modificado de Mechoso et al. (2004).

Figura 2.7 - Distribuições pluviométricas mensais nas estações meteorológicas nos municípios de Montalvânia (a) e Brasília de Minas (b), o último localizado a $20 \mathrm{~km}$ de Luislândia. Dados pluviométricos obtidos pela ANA (www2.ana.gov.br). (c) mapas com as médias do total acumulado anual de precipitação média vertical climatológica dos fluxos médios de umidade (proveniente das reanálises do NCEP-NCAR) para os meses de DJA (figura superior) e JJA (figura inferior). Adaptado de Vera et al. (2006).

$-10$

Figura 2.8 - Mapa climático da precipitação da América do Sul entre 1979-2000 (Xie e Ankin, 1997). Para a região do norte de Minas Gerais, as maiores médias de precipitação ocorrem em DJF (verão austral), devido atuação das monções Sul-americanas. Os números indicados no mapa correspondem às seguintes localidades estudadas: 1 Caverna Lapa Grande, Montalvânia-MG; 2 - Caverna Lapa Sem Fim, Luislândia-MG e outras regiões estudadas paleoclimaticamente; 3 -Espeleotemas do oeste da Bahia (Wang et al. 2007; 2009), 4 - Espeleotemas de Iporanga-SP (Cruz et al., 2006a), 5 - espeleotemas de Botuverá (Wang et al. 2006; Cruz et al. 2005a); 6 Paleolagos do Salar de Uyuni (Baker et al., 2001a); 7 -Testemunho de gelo de Sajama, Bolivia (Thompson et al., 1998); 8 - Registros lacustres do Titicaca (Baker et al., 2001b; Baker et al., 2005); 9 -Espeleotemas do norte do Peru (van Breukelen, 2008); 10 - sedimentos marinhos de Cariaco, Venezuela (Haug et al. 2001); 11 Sedimentos marinhos do Atlântico equatorial oeste (testemunho M35003-4) (Rühlemann et al., 1990); 12 Registros lacustres do Lago Caçó, Maranhão (Sifeddine et al. 2003); 13 -Testemunho GeoB 3910-2 (Arz et al., 2001) e 14 - Testemunhos GeoB 3911-3 e GeoB 3104 da costa do nordeste brasileiro (Arz et al. 1998); 15 Espeleotemas do Rio Grande do Norte (Cruz et al. 2009a). As linhas tracejadas indicam a posição média do eixo das principais zonas de convergência de umidade: a zona de convergência do Atlântico sul (ZCAS) e a zona de convergência intertropical. (ZCIT).

Figura 2.9 - Modo de variabilidade interanual de TSM e das precipitações de chuvas anuais da América do Sul durante os eventos de El-Niño. A figura de cima mostra as variações sazonais das anomalias de TSM $\left({ }^{\circ} \mathrm{C}\right)$ do Pacífico durante os meses de DJF (a) e MAM (b). A figura de baixo mostra as variações sazonais de precipitação em \% na América do Sul durante os meses de DJF (c) e MAM (d). A baixa variabilidade interanual no norte do estado de Minas Gerais sugere um fraco impacto de eventos climáticos como ENSO na região de estudo. Retirado de Ambrizzi et al. (2004).

Figura 2.10 - O mesmo que para a Figura 2.9 porém para os eventos de La-Niña (Ambrizzi et al., 2004).--------------15

Figura 2.11 - (a) correlação entre o acumulado mensal de chuvas $(\mathrm{mm})$ e a média ponderada de $\delta^{18} \mathrm{O}$ em relação ao acumulado mensal de chuva; (b) Relação entre a média pluviométrica trimestral e os valores de $\delta^{18} \mathrm{O}$ da chuva nas estações do IAEA em Brasília.

Figura 2.12 - Comparação entre os valores mensais de precipitação com os seus respectivos valores de $\delta^{18} \mathrm{O}$ das mesmas a partir da correlação espacial dos dados das estações IAEA-GNIP pelo modelo geral de circulação atmosférica ECHAM-4. a) Curvas de precipitação de chuva em mm/dia para os meses de dezembro, janeiro e fevereiro (DJF) e b) idem para os meses de junho julho e agosto (JJA). Os contornos marcam os intervalos de 2 , 4, 8 e $12 \mathrm{~mm} / \mathrm{dia}$, valores $>4 \mathrm{~mm} /$ dia são sombreados em cinza claro e valores maiores que $8 \mathrm{~mm} / \mathrm{dia}$ em cinza escuro. c) correlação entre o volume mensal de chuvas e o $\delta^{18} \mathrm{O}$ da mesma. d) diferença entre os valores de $\delta^{18} \mathrm{O}$ das precipitações medidas nas estações IAEA-GNIP durante o verão austral (DJF) como os dados medidos durante os meses de inverno austral (JJA). Valores mais (menos) negativos indicam que o volume de chuva durante o verão austral (boreal) é mais significativo do que durante o inverno. As linhas tracejadas em amarelo marcam a posição média da Zona de Convergência Intertropical (ITCZ) e em vermelho a Zona de Convergência 
do Atlântico Sul (ZCAS). Modificado de Vuille et al. (2003).

Figura 2.13 - Comparação entre as variações pluviométricas no Norte de Minas e Brasília: (a) série história do acumulado anual de chuvas entre 1970 e 2010 de Montalvânia (círculos pretos); Brasília de Minas, região próxima a Luislândia (quadrados cinzas) e Brasília (quadrados verdes); (b) comparação entre as distribuições pluviométricas mensais entre Montalvânia (azul), Brasília de Minas (laranja) e Brasília (verde). ----- 19

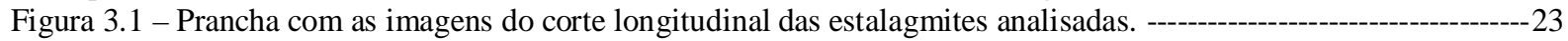

Figura 3.2 - Foto do microamostrador Sherline 5400, equipamento utilizado para coleta de carbonato de cálcio em

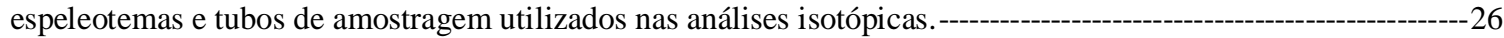

Figura 4.1 - Fracionamento isotópico da água da chuva em função do percentual de umidade relativa da atmosfera. O coeficiente angular da linha de água meteórica se aproxima de 8 em regiões de clima úmido. Modificado de Clark e Fritz (1997).

Figura $4.2-\delta^{18} \mathrm{O}$ e $\delta^{2} \mathrm{D}$ do GNIP da estação de Brasília-DF que formam a "local meoteoric water line" (LMWL) em comparação com a "global meteoric water line" (GMWL). A boa correlação entre a composição isotópica da chuva com a média das precipitações globais indica que, de modo geral, o fracionamento isotópico ocorre em condições de equilíbrio isotópico na região central do Brasil.

Figura 6.1 - Intervalos de deposição das estalagmites estudadas com base nas análises isotópicas de oxigênio e carbono.

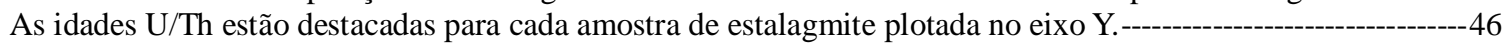

Figura 6.2 - Intervalos de deposição de todas as estalagmites coletadas nas cavernas Lapa Grande (a) e Lapa Sem Fim (b). As idades U/Th estão destacadas para cada amostra de estalagmite plotada no eixo Y. ------------48

Figura 6.3 - Distribuição de idades U/Th versus profundidade (mm) das estalagmites LG3 (a); LSF17 (b); LG11 (c); LG12 (d); LSF15 (e); LSF16 (f) e LSF3 (g). - -

Figura 6.4 - Taxas de crescimento das estalagmites LG3 (a); LSF17 (b); LG11 (c); LG12 (d); LSF15 (e); LSF16 (f) e LSF3(g) em comparação o sinal isotópico de $\delta^{18} \mathrm{O}$ (azul) e $\delta^{13} \mathrm{C}$ (preto). Notar que o eixo $\delta^{18} \mathrm{O}$ e do $\delta^{13} \mathrm{C}$ foram invertidos para facilitar a comparação com a TC.

Figura 6.5 - Comparação entre as razões isotópicas de $\delta^{18} \mathrm{O}$ e $\delta^{13} \mathrm{C}$ das estalagmites LG3 (preto), LSF17 (verde), LG11 (vinho), LG12 (roxo), LSF15 (ciano), LSF16 (azul), LSF3 (laranja). As barras de cor cinza representam eventos climáticos frios registrados nas regiões de altas latitudes do Hemisfério Norte: Heinrich 2 (H2), Último Máximo Glacial (UMG), Heinrich 1 (H1), Young Dryas (YD), eventos Bond (6, 5, 4 e 3) e os eventos 8.2 e 2.7. A linha em vermelho representa a curva de variação de insolação descrita pelo ciclo de precessão de Milankovitch para a latitude de $10^{\circ} \mathrm{S}$.

Figura 6.6 - Comparação entre as razões isotópicas de a) oxigênio $\left(\delta^{18} \mathrm{O}\right)$ e b) carbono $\left(\delta^{13} \mathrm{C}\right)$ da estalagmite LSF16. Em c) é detalhado a estrutura do evento Heinrich 1 com base nos valores de $\delta^{18} \mathrm{O}$ e $\delta^{13} \mathrm{C}$. ---------

Figura 6.7 - Comparação entra as razões isotópicas de $\delta^{18} \mathrm{O}$ e $\delta^{13} \mathrm{C}$ da estalagmite LG12.-----------------------------58

Figura 6.8 - Diagrama de distribuição de $\delta^{13} \mathrm{C}$ vs $\delta^{18} \mathrm{O}$ para as estalagmites LG3(quadrados pretos); LG11 (triângulos vermelhos); LG12 (estrelas roxas); LSF17 (círculos verdes); LSF15 (círculos cianos) LSF16 (quadrados azuis) e LSF3 (triângulos laranjas). Note que os eventos Bølling-Allerød e Young Dryas, registrados pela estalagmite, definem dois campos distintos, com o evento Young Dryas apresentando valores empobrecidos de $\delta^{18} \mathrm{O}$ e valores mais enriquecidos de $\delta^{13} \mathrm{C}$ ao passo que durante o evento $\mathrm{B} \varnothing$ lling-Allerød apresenta valores mais enriquecidos de $\delta^{18} \mathrm{O}$ e mais empobrecidos em $\delta^{13} \mathrm{C}$.

Figura 6.9 - Comparação entre os registros isotópico de $\delta^{18} \mathrm{O}$ das cavernas Lapa Grande e Lapa Sem Fim. Em (a) o registro é apresentado na forma de uma curva normalizada, em (b) é apresentado o registro com correção dos valores de $\delta^{18} \mathrm{O}$ das estalagmites da caverna Lapa Sem Fim pela subtração de 1\%o dos resultados analíticos. -----60

Figura 6.10 - Variação de $\delta^{18} \mathrm{O}$ durante o glacial tardio e o deglacial das cavernas Lapa Grande e Lapa Sem Fim. Os resultados analíticos de $\delta^{18} \mathrm{O}$ das estalagmites da caverna Lapa Sem Fim estão corrigidos para facilitar a comparação com o registro da estalgmite LG12, proveniente da caverna Lapa Grande. A curva em verde representa a variação de insolação para latitude de $10^{\circ} \mathrm{S}$ durante o mês de fevereiro de acordo com o ciclo de precessão de Milankovitch. As barras cinza marcam os intervalos com aumentos abruptos precipitação durante os eventos Heinrich 2 (H2); Heinrich 1 (H1) e Young Dryas (YD). Os eventos quentes são representados pelas siglas B-A para Bølling-Allerød e DA para Dansgaard-Oescheger. Os quadrados pretos com barras de erros horizontais representam a localização das datações.

Figura 6. 11 - Variação de $\delta^{18} \mathrm{O}$ durante o Holoceno das cavernas Lapa Grande e Lapa Sem Fim. A linha tracejada em azul representa a curva média das razões de $\delta^{18} \mathrm{O}$ durante o Holoceno. A curva em vermelho representa a variação de insolação para latitude de $10^{\circ} \mathrm{S}$ durante o mês de fevereiro de acordo com o ciclo de precessão de Milankovitch. Note que diferentemente do registro do Glacial Tardio e Deglacial, existe uma relação em fase com a curva isotópica. Os pontos pretos com barras laterais de erro representam as datações. ------------------------65

Figura 6.12 - Comparação entre: a) taxa de crescimento das estalagmites LG3 e LG11; b) variação da razão de Sr/Ca dada em anomalia (média móvel de 51 pontos para a estalagmite LG3 e interpolação de 111 pontos para a estalagmite LG11); c) variação da razão de $\mathrm{Mg} / \mathrm{Ca}$ dada em anomalia (média móvel de 51 pontos para a estalagmite LG3 e interpolação de 111 pontos para a estalagmite LG11); d) série isotópica de $\delta^{18} \mathrm{O}$; e) $\delta^{13} \mathrm{C}$. ----67

Figura 6.13. - Comparação entre: a) variação da razão de $\mathrm{Mg} / \mathrm{Ca}$ normalizada (a curva em preto representa a média móvel com interpolação de 101 pontos); b) o mesmo que em (a) porem para a razão de $\mathrm{Sr} / \mathrm{Ca}$; c) o mesmo que em 
(a) porém para a razão de $\mathrm{u} / \mathrm{Ca}$; d) o mesmo que em (a) porém para a razão de $\mathrm{P} / \mathrm{Ca}$; e) série isotópica de $\delta^{13} \mathrm{C} ; \mathrm{f}$ ) série isotópica de $\delta^{18} \mathrm{O}$. As barras em azul marcam os eventos de aumento de precipitação--------- 68

Figura 6.14 - Comparação entre: a) curva de média móvel de variação da razão de $\mathrm{Sr} / \mathrm{Ca}$ dada em anomalia (interpolação de 51 pontos); b) curva de média móvel da variação da razão de $\mathrm{Mg} / \mathrm{Ca}$ dada em anomalia (interpolação de 51 pontos ); c) série isotópica de $\delta^{13} \mathrm{C}$; d) $\delta^{18} \mathrm{O}$. As linhas em vermelho e verde representam as médias móveis com interpolação de 12 pontos das razões isotópicas.

Figura 6.15 - comparação entre os registros isotópicos de $\delta^{18} \mathrm{O}$ (a) e $\delta^{13} \mathrm{C}$ (b) da estalagmite LG12 com os registros de elementos traços baseadas nas razões de $\mathrm{Ba} / \mathrm{Ca}$ (c) $\mathrm{Sr} / \mathrm{Ca}$ (d) e $\mathrm{Mg} / \mathrm{Ca}$ (e). As linhas em vermelho nos dados de $\mathrm{Ba} / \mathrm{Ca}$ e $\mathrm{Sr} / \mathrm{Ca}$ representam as curvas de médias móveis calculadas com interpolação de 101 pontos. ---------70

Figura 6.16 - comparação entre o registro isotópicos de $\delta^{13} \mathrm{C}$ (a) da estalagmite LG12 com os registros de elementos traços baseados nas razões de $\mathrm{U} / \mathrm{Ca}(\mathrm{b}), \mathrm{P} / \mathrm{Ca}$ (c), $\mathrm{Sr} / \mathrm{Ca}(\mathrm{d})$ e $\mathrm{Mg} / \mathrm{Ca}(\mathrm{e})$. As linhas em vermelho representam as curvas de médias móveis calculadas com interpolação de 23 pontos para a razão de U/Ca e 101 pontos para as razões de $\mathrm{P} / \mathrm{Ca}$ e $\mathrm{Sr} / \mathrm{Ca}$. Os resultados estão normalizados.

Figura 6.17 - Comparação entre a razão $\mathrm{Mg} / \mathrm{Ca}$ (abaixo) com os dados de $\delta^{18} \mathrm{O}$ para a estalagmite LG12. Os dados de $\mathrm{Mg} / \mathrm{Ca}$ são apresentados em cinza claro e em preto a curva de média móvel calculada para uma interpolação de 31 pontos.

Figura 8.1 - Comparação entre as curvas isotópicas de $\delta^{18} \mathrm{O}$ do norte de Minas Gerais com o registro de variação de temperatura da Groenlândia baseado nas medições de $\delta^{18} \mathrm{O}$ de testemunho de gelo do programa North Greenland Ice Core Project (NGRIP) (North Greenland Ice Core Project members, 2004). Em preto estão apresentados os registros isotópicos da caverna Lapa Grande e em cinza os registros referentes a caverna Lapa Sem Fim. Os resultados analíticos de $\delta^{18} \mathrm{O}$ das estalagmites da caverna Lapa Sem Fim estão corrigidos de 1 \%o para facilitar comparação entre registros das estalagmites da caverna Lapa Grande.

Figura 8.2 - Comparação entre a curva isotópicas do norte de Minas e de espeleotemas das regiões nordeste e sudeste do Brasil. (a) Rio Grande do Norte $\sim 5^{\circ} \mathrm{S}$ (Cruz et al., 2009a); (b) curva isotópica da a estalagmite BT2 de Santa Catarina $\sim 27^{\circ} \mathrm{S}$ (Cruz et al., 2005a); (c) curva isotópica da Chapada Diamantina, Bahia, $12^{\circ} \mathrm{S}$; (d) curva isotópica do norte de Minas dos registros das cavernas Lapa Grande e Lapa Sem Fim localizadas entre 14 e $16^{\circ} \mathrm{S}$ (e) curva de insolação de verão $10^{\circ} \mathrm{S}$ (Berger e Loutre, 1991).

Figura 8.3 - Diagrama esquemático que ilustra relação entre os padrões de precipitação do verão na América do Sul (DJF) e as mudanças relacionadas na célula de Walker e de Hadley para os períodos correspondentes à fases alta insolação de verão no Hemisfério Sul durante os últimos 4 mil anos (imagem a esquerda) e ao período de baixa insolação no Hemisfério Sul entre 9.0 e 6.0 mil anos A.P. (imagem da direita). Os pontos 1 e 2 indicam a localização das cavernas Lapa Grande e Lapa Sem Fim respectivamente. O ponto 3 indica a localização dos registros isotópicos da Chapada Diamantina e o ponto 4 a localização do registro do Rio Grande do Norte. Modificado de Cruz et al. (2009a).

$-82$

Figura 8.4 - Comparação entre a curva isotópica de $\delta^{13} \mathrm{C}$ do norte de Minas com registros de paleopluviosidade dos trópicos: (a) concentração de Ti da Bacia de Cariaco, Venezuela (Haug et al., 2001); (b) registro isotópico do norte de Minas formado pelas estalagmites da caverna Lapa Grande e Lapa Sem Fim localizadas entre 14 e $16^{\circ} \mathrm{S}$; (c) curva de insolação de verão $10^{\circ} \mathrm{S}$ (Berger e Loutre, 1991); (d) registro isotópico de estalagmites de Omã, península Arábica, $17^{\circ} \mathrm{N}$ (Fleitmann et al., 2003); (e) registro isotópico das estalagmites DA e D4 da caverna Dongge, leste da China (Wang et al., 2005; Yuan et al., 2004).

Figura 8.5 - Esquema mostrando o desenvolvimento do padrão de circulação zonal estabelecido entre o nordeste brasileiro e o sudeste durante período de fraca atividade do sistema de monção sul-americana. (a) diferença de precipitação (mm/dia) entre o verão e o outono austral (DJF-MAM) entre 6 mil anos A.P e o presente baseado na simulação do ECHAM-4; (b) como em "a" porém para a velocidade potencial à $850 \mathrm{hPa}$ (as linhas de isovalores são de $2.0 \times 10^{5} \mathrm{~m}^{2} / \mathrm{s}$; os valores negativos são representados pelos contornos tracejados), apresentando convergência (divergência) em baixos níveis na região nordeste (Bacia Amazônica).

Figura 8.6 - Comparação entre registros de paleopluviosidade nas regiões tropicais da América do Sul. (a) $\delta^{18} \mathrm{O}$ do testemunhos de gelo de Huascarán, Peru, Thompson et al. 1995); (b) $\delta^{18} \mathrm{O}$ do testemunho de gelo do monte Sajama, Bolívia (Thompson et al., 1998); (c) variações do nível de água dos paleolagos do Salar de Uyuni, Bolivia baseado nas variações de radiação $\gamma$ (Baker et al., 2001b); (d) registro de paleopluviosidade do norte de Minas; (e) curva de insolação $10^{\circ} \mathrm{S}$.

Figura 8.7 - Comparação do registro de paleopluviosidade do norte de Minas com os registros de paleoprecipitação do SMSA de Cariaco, da Bahia e da Bacia do rio de La Plata: a) $\delta^{18} \mathrm{O}$ de testemunho de gelo do programa (NGRIP); b) concentração de Ti testemunhos sedimentares da Bacia do Rio La Plata, costa do Uruguai, 34 ${ }^{\circ} \mathrm{S}$ (Chiessi et al., 2009); c) curva isotópica da Chapada Diamantina, Bahia, $12^{\circ}$ (Barreto, 2010); curva isotópica do norte de Minas (estalagmite LSF16).

Figura 8.8 - Comparação do registro do norte de Minas com outros registros das regiões tropicais do Hemisfério Norte: (a) composição do registro isotópico de leste da China da caverna Dongge (Yuan et al., 2004; Wang et al., 2005) e Hulu (Wang et al., 2001); (b) registro de variação da concentração de matéria orgânica baseado na \% de reflectância dos sedimentos da bacia costeira de Cariaco, Venezuela (Peterson et al., 2000); (c) registro de paleopluviosidade de $\delta^{18} \mathrm{O}$ do norte de Minas; (d) curva de insolação a $10^{\circ} \mathrm{S}$.

Figura 8.9 - Comparação entre o registro de paleopluviosidade do norte de Minas com os registros de TSM do Atlântico 
tropical: (a) registro de temperatura da atmosfera da Antartica com base nos dados de $\delta^{18} \mathrm{O}$ do testemunho de gelo Byrd (Blunier e Brook, 2001); (b) registro de TSM da região costeira do Rio Grande do Norte com base em variações do índice de insaturação de alquenonas (Jaeschke et al., 2007), testemunho GeoB3910-2; (c) registro de TSM da região costeira do Rio Grande do Norte com base em variações das razões de $\mathrm{Mg} / \mathrm{Ca}$ em foraminífero (Weldeab et al., 2006), testemunho GeoB3129-1 ; (b) registro de TSM da bacia de Cariaco com base na variação das razões de $\mathrm{Mg} / \mathrm{Ca}$ em foraminífero (Lea et al., 2003), testemunho PL07-39PC; (e) registro de espeleotemas do norte de Minas. A linha pontilhada marca o MIS 2.

Figura 8.10 - Análise de decomposição espectral da série temporal do $\delta^{18} \mathrm{O}$ entre 11.7 e 13 mil anos A.P da estalagmite LG12. As linhas coloridas marcam os intervalos de confiança calculados para $99 \%$ (azul), $90 \%$ (verde) e $95 \%$ (vermelho). A linha tracejada em cor vinho indica a curva de "red noise" calculada a partir do modelo AR1 (Shulz e Mudelsee, 2002; Thompson, 1990). (b) o mesmo que em (a) porém com detalhe das frequências mais altas. ---94

Figura 8.11 - Análise de decomposição espectral da série temporal do $\delta^{18} \mathrm{O}$ entre 14.05 e 18.6 mil anos A.P da estalagmite LSF16. As linhas coloridas marcam os intervalos de confiança calculados para $99 \%$ (azul), $90 \%$ (verde) e $95 \%$ (vermelho). A linha tracejada em cor vinho indica a curva de "red noise" calculada a partir do modelo AR1 (Shulz e Mudelsee, 2002; Thompson, 1990).

Figura 8.12 (a) Análise de wavelets da série temporal do $\delta^{18} \mathrm{O}$ das estalagmites LSF16 e LSF3 entre 14.05 e 18.6 mil anos A.P. As regiões contornadas em preto são estatisticamente significantes a $90 \%$ através da análise de "red noise". Os valores com a periodicidade dos eventos estão apresentados no eixo vertical, enquanto a sua intensidade espectral ao longo do tempo é indicada pelo índice de cor (Torrence e Campo, 1998). ---------95

Figura 8.13 - Comparação entre: (a) variação do índice de HSG do testemunho marinho VM29-191 (Bond et al., 1997); (b) registro de $\delta 180$ das estalagmites LG3 e LG11 da caverna Lapa Grande; (c) curva do $\delta 180$ das estalagmites DA e D4 da caverna Dongge, leste da China (Wang et al., 2005; Yuan et al., 2004). A curva em roxo presenta a média móvel de 20 anos da estalagmite DA. As Barras em cinza marcam os eventos Bond 2, 3, 4, 5 e 6 e o evento $8.2 \mathrm{k} Y$.

Figura 8.14 - Comparação entre os registros de paleopluviosidade de Minas e Cariaco e os registros de expansão de gelo do Atlântico norte. (a) Variação na cobertura de gelo do Atlântico norte com base no índice de HSG do testemunho marinho VM29-191 (Bond et al., 1997); (b) registro isotópico de $\delta^{18} \mathrm{O}$ do norte de Minas das estalagmites LG3 e LG11 da caverna Lapa Grande; (c) variação do conteúdo de Ti em \% dos sedimentos da Bacia de Cariaco, testemunho ODP-1002 (Haug et al., 2001). As Barras em cinza marcam os eventos Bond 2, 4 e 6 e o evento 8.2.

Figura 8.15 - Comparação entre os registros $\delta^{18} \mathrm{O}$ das estalagmites LG3 (vermelho) e LG11 (preto) com o registro de variação de $\mathrm{N}-\mathrm{A}$ do lago Titica baseado nos valores normalizados de $\delta^{13} \mathrm{C}$ (verde) (Baker et al. 2005).-------- 100

Figura 8.16 - Comparação dos registros paleoclimáticos de TSM do Atlântico Norte de Bond et al. (1997; 2001) e de paleopluviosidade do norte de Minas e da variação de atividade solar: (a) variação do conteúdo de IRD com base na porcentagem de HSG (hematite stained grain) em azul (Bond et al. 2001), com a curva de variação de irradiação solar baseada no registro destendenciado de $\Delta^{14} \mathrm{C}$ em atmos $/ \mathrm{cm}^{2} / \mathrm{secg}$ (vermelho claro) (Bond et al., 2001); (b) registro de $\delta^{18} \mathrm{O}$ das estalagmites LG3 e LG11, norte de Minas. 102

Figura 8.17 - Comparação entre (a) curva de $\delta^{18} \mathrm{O}$ da estalagmite DV2, Bahia; (b) curva de irradiação solar reconstituida a partir dos registros de $\Delta^{4} \mathrm{C}$ de anéis de crescimento de árvore (Bond et al., 2001) e (c) Curva de $\delta^{18} \mathrm{O}$ da estalagmite LG3

Figura 8.18 - (a) Análise de decomposição espectral de frequências dos dados de $\delta^{18} \mathrm{O}$ da estalagmite LG11. As linhas em vermelho e azul marcam os intervalos de confiança calculados para 90 e $95 \%$ respectivamente e a linha tracejada em cor vinho indica a curva de "red noise" calculada a partir do modelo AR1 (Shulz e Mudelsee, 2002; Thompson, 1990); (b) o mesmo que em "a" porém para a estalagmite LG3; c): Análise de wavelets das série temporal do $\delta^{18} \mathrm{O}$ da estalagmite LG11. As regiões contornadas em preto representam eventos estatisticamente significativos na faixa de $90 \%$ através da análise de "red noise". Os valores com a periodicidade dos eventos estão apresentados no eixo vertical, enquanto a sua intensidade espectral ao longo do tempo é indicada pelo índice de cor (Torrence e Campo, 1998); (d) o mesmo que em "c" porém para a estalagmite LG3.----- 104

Figura 8.19 - (a) Análise de decomposição espectral dos dados de $\delta^{18} \mathrm{O}$ das estalagmites LG11, LSF17 e LG3. As linhas em vermelho e azul marcam os intervalos de confiança calculados para 90 e $95 \%$ respectivamente e a linha tracejada em cor vinho indica a curva de "red noise" calculada a partir do modelo AR1 (Shulz e Mudelsee, 2002; Thompson, 1990); (b) o mesmo que em (a) porém para análise wavelets. As regiões que apresentam contorno em preto representam eventos estatisticamente significativos na faixa de $90 \%$ através de "red noise". $-105$

Figura 8.20 - Comparação das séries de $\delta^{18} \mathrm{O}$ das estalagmites LG11 (preto) e LG3 (verde) com uma função senoidal cuja periodicidade é de 820 anos (vermelho). $-106$ 


\section{LISTA DE ABREVIATURAS}

$\delta^{18} \mathrm{O}$ - Razão dos isótopos de Oxigênio

$\delta^{13} \mathrm{C}$ - Razão dos isótopos de Carbono

GCM's - general circulation models

ENOS - El-Niño oscilação sul

MAM - Março, Abril e Maio

DJF - Dezembro, Janeiro e Fevereiro

JJA - Junho, Julho e Agosto

SMSA - Sistema de Monção Sul-americana

ZCAS- Zona de Convergência do Atlântico Sul

ZCIT - Zona de Convergência Intertropical

ZCA - Zona de Convergência dos Alísios

TSM - Temperatura da Superfície Marinha

GMWL- Global Meteoric Water Line

LMWL - Local Meteoric Water Line

LG - Estalagmite da caverna Lapa Grande

LSF - Estalagmite da caverna Lapa Sem Fim

RN - Estalagmite da caverna Rainha

DA - Estalagmite da caverna Dongge

Bt2 - Estalagmite da caverna Botuverá

$\mathrm{R}^{2}$ - Coeficiente de correlação

CO - Carbono orgânico

DIC - Carbono orgânico dissolvido

CTD - Carbono total dissolvido

ICP-MS - Inductively coupled plasma mass spectrometry

U/Th - Urânio-Tório

$\mathrm{Sr} / \mathrm{Ca}$ - Razões entre Estrôncio e Cálcio

$\mathrm{Mg} / \mathrm{Ca}$ - Razões entre Magnésio e Cálcio

Ti/Ca - Razões entre Titânio e Cálcio

$\mathrm{Fe} / \mathrm{Ca}$ - Razões entre Ferro e Cálcio

[Ti] - Concentração de Titânio

$\mathrm{CO}_{2}$ - Dióxido de carbono

ky - Thousands of years

A.P. - Antes do Presente 
UMG - Último Máximo Glacial

MIS- Marine Isotope Stage

$\mathrm{H}$ - Heinrich event

YD - Younger Dryas

B-A-Bølling-Allerød

D-O - Dansgaard-Oeschger

IRD - Ice-rafted debris

NGRIP- North Greenland Ice Core Project

GRIP - Greenland Ice Core Project

THC - Thermohaline Circulation

NADW- North Atlantic Deep Water

AMOC- Atlantic Meridional Overturning Circulation

ANA - Agência Nacional de Águas

IAEA- GNIP - International Agency Energy Agency - Global Network of Isotopes in

Precipitation 


\section{SUMÁRIO}

1 Introdução ___________________________________________________ 1

1.1 Objetivos da Pesquisa_________________________________________ 3

2 Área de Estudo e Climatologia Moderna _________________________ 3

2.1 Localização e caracterização geológica _____________________________ 3

2.2 Climatologia Moderna ______________________________________ 8

2.3 Monitoramento Pluviométrico do IAEA-GNIP: Análises da composição isotópica da chuva e controles isotópicos______________________ 15

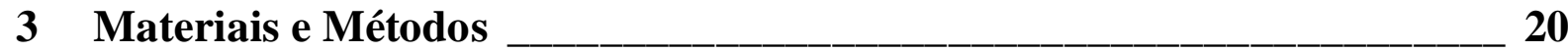

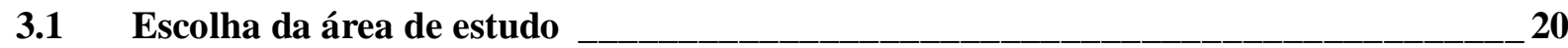

3.2 Coleta de estalagmites ________________________________ 20

3.3 Preparação das amostras para estudo paleoclimático e amostragem para datação radiométrica_______________________________________________ 21

3.4 Datação geocronológica pelo método $\mathrm{U}-\mathrm{Th}$

3.4.1 Procedimentos analíticos para abertura de amostra e concentração de íons de U e Th __ 24

3.5 Amostragem de calcita para isótopos estáveis

3.6 Análise estatística de séries temporais___________________________

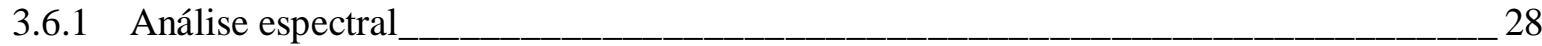

3.6.2 Análises de ondeletas (wavelets)_____________________________ 29

3.7 Análises de elementos traços __________________ 30

4 Conceitos sobre a aplicação das razões isotópicas de oxigênio e carbono em estalagmites na reconstituição da paleopluviosidade _______________ 32

4.1 Fracionamento isotópico do oxigênio no ciclo hidrológico ____________________________

4.2 O $\delta^{18} \mathrm{O}$ e $\mathrm{o} \delta^{13} \mathrm{C}$ no sistema cárstico - fatores que afetam a composição isotópica da água de gotejamento. ____________________________________________ 36

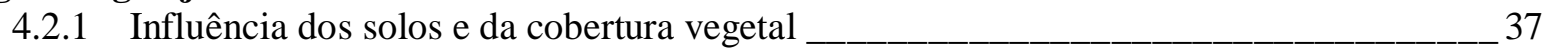

4.2.2 Aquífero cárstico - efeito reservatório _________________________________ 39

4.2.3 Precipitação do $\mathrm{CaCO}_{3}$

5 Conceitos sobre a variação de elementos traços em espeleotemas _____ 43

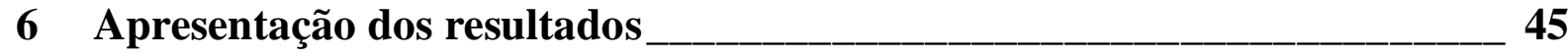




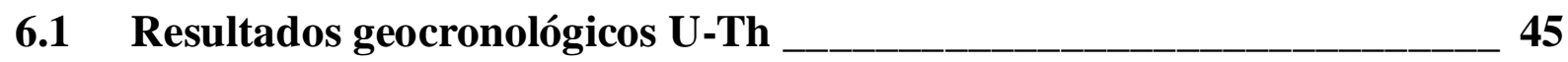

6.2 Registros isotópicos de $\delta^{18} \mathrm{O}$ e $\delta^{13} \mathrm{C}$ em estalagmites____________ 54

6.2.1 Período glacial tardio e deglacial (MIS 2): entre 27 e 10 mil anos A.P. _____________ 61

6.2.2 Período Holoceno: a partir dos últimos 10 mil anos _______________________ 63

6.3 Análises das razões de elementos traços sobre o cálcio ______________ 65

7 Significado paleoclimático das variações de elementos traços e dos isótopos de carbono

8 Reconstituição paleoclimática________________________________ 73

8.1 Variações de escala orbital e ciclos milenares ____________

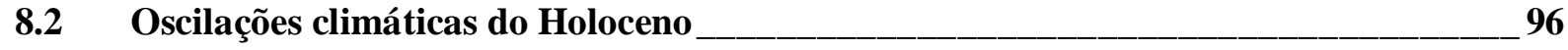

9 Considerações Finais________________________________ 108

10 Referências __________________________________ 111

ANEXOS 


\section{Introdução}

Espeleotemas são depósitos minerais secundários precipitados no interior das cavernas, sendo os carbonatos o grupo mais comum deles. A utilização dos mesmos tem sido amplamente empregada na reconstituição paleoclimática por vários motivos, dentre eles cabe ressaltar a possibilidade de obtenção de longos registros de alta resolução dos últimos 600 mil anos, precisamente datados pelo método U-Th (Fairchild et al., 2006). Outro aspecto importante, é que as variações na composição química ou assinatura isotópica dos espeleotemas, de um modo geral, são bastante sensíveis às oscilações de parâmetros climáticos e ambientais, como temperatura média anual ou pluviosidade, a depender da região geográfica onde a caverna está situada.

A utilização das razões de isótopos de oxigênio em espeleotemas nos estudos paleoclimáticos surgiu no final dos anos 60 a partir dos trabalhos de Hendy e Wilson (1968). Sabese que em regiões subtropicais e tropicais as interpretações baseadas nos valores de $\delta^{18} \mathrm{O}$ em espeleotemas são fortemente direcionadas às reconstituições de paleopluviosidade, devido forte relação entre a composição isotópica da chuva e as variações pluviométricas. Os fatores isotópicos condicionantes das variações de chuva são por sua vez definidos como amount effect e/ou moisture source area effect, cuja importância relativa varia de acordo com o tipo de regime de chuva prevalecente numa determinada região (Clark e Fritz, 1997; Lachniet, 2009). A região sudeste do Brasil é bom exemplo onde variações sazonais da fonte de umidade geram variações significativas da assinatura isotópica das precipitações (Vuille et al., 2003; Cruz et al., 2005 a,b). Durante o verão e parte do outono, a atividade do sistema de monções sul-americana (SMSA) promove a formação de chuvas na região associada ao transporte de umidade da Amazônia através dos jatos de baixos níveis, de modo a gerar precipitações com composição isotópicas mais empobrecidas em oxigênio, $\approx-5 \%$. Já as precipitações que ocorrem durante o inverno e parte da primavera estão associadas à formação de ciclones extratropicais, as quais utilizam umidade proveniente do Atlântico sul, cujos valores de $\delta^{18} \mathrm{O}$ são em média mais altos $\approx-3 \%$. ( Cruz et al., 2005; Cruz et al., 2009a).

Trabalhos prévios de reconstituição da paleopluviosidade, realizados em cavernas do sul e sudeste do Brasil constataram, a partir de valores mais (menos) negativos de $\delta^{18} \mathrm{O}$ dos espeleotemas, que períodos de maior (menor) intensidade da atividade do sistema de monção sul-americana (SMAS) correspondem a fases de insolação mais alta (baixa) (Cruz et al., 2005a; Wang et al., 2006; Cruz et al., 2006a; Cruz et al., 2007; Wang et al., 2007a; Cruz et al. 2009a; Wang et al., 2008). A combinação de registros de $\delta^{18} \mathrm{O}$ com razões de $\mathrm{Mg} / \mathrm{Ca}$ a $\mathrm{Sr} / \mathrm{Ca}$ de espeleotemas, sugerem que essa intensificação da SMAS, caracterizada pelo aumento das chuvas de verão, é a principal causa do aumento da paleopluviometria média anual na faixa subtropical brasileira (Cruz et al., 2007; 
Karmann et al., 2007).

Fortes mudanças na paleopluviosidade do Brasil podem ser também relacionadas com a variação na temperatura atmosférica e da superfície oceânica, registradas durante os eventos milenares do tipo Dansgaard-Oeschger e Heinrich no Hemisfério norte, a partir de testemunhos em sedimentos marinhos e no gelo (Dansgaard et al., 1993; Grootes and Stuiver, 1997; NGRIP members, 2004, Peterson et al., 2000, Haug et al., 2001, Arz et al., 1998; Jennerjahn et al., 2004). Os eventos Heinrich, por exemplo, são caracterizados por aumento relativo de chuva no Hemisfério sul durante o período glacial, coincidente com eventos frios no Hemisfério norte, cuja periodicidade é de 1.5 a 3.0 mil anos (Cruz et al., 2005a; Wang et al., 2006; Wang et al., 2007a). Esses eventos promovem drásticas mudanças climáticas no Oceano Atlântico, influenciando positivamente a pluviosidade pelo Brasil, uma vez que deslocam a Zona de Convergência Intertropical (ZCIT) mais para sul, relativamente à sua posição atual (Chiang et al, 2003). Eles são interpretados a partir de valores mais negativos de $\delta^{18} \mathrm{O}$ nos registros isotópicos de espeleotemas de cavernas da região sudeste e nordeste do Brasil, que interrompem abruptamente a tendência geral da curva isotópica, dominada pela variação de insolação de acordo com o ciclo de precessão.

Espeleotemas, juntamente com outros registros climáticos, precisamente datados e de alta resolução podem ser utilizadas como teste crucial de experimentos realizados a partir de modelos climáticos (GCM`s). Esses testes são imprescindíveis para melhor entendimento de como eventos paleoclimáticos de regiões de altas-latitudes impactam áreas continentais, especialmente aquelas localizadas em regiões tropicais. Nesse contexto, novos registros de espeleotemas são essenciais para investigar a importância geográfica de forçantes climáticas como insolação de verão e eventos milenares tipo Dansgaard-Oescheger e Heinrich no transporte de umidade e na distribuição de precipitação na área abrangida pela SMAS. Os espeleotemas das regiões tropicais possuem grande potencial para reconstrução da paleopluviosidade visto que o seu $\delta^{18} \mathrm{O}$ reflete principalmente variação no volume e/ou origem de chuvas (Vuille et al., 2003).

Trabalhos prévios em espeleotemas mostram que as chuvas associadas com as monções de verão possuem relação antifásica entre regiões situadas nos hemisférios sul e norte, tanto em escala orbital quanto na milenar, devido a mudanças associadas à circulação atmosférica de norte-sul, conhecida como circulação tipo Hadley (Cruz et al., 2005a, Wang et al., 2007a). No entanto, novos registros provenientes da região nordeste, demonstram que as variações de insolação podem também produzir padrões antifásicos das chuvas de verão entre a região nordeste e o restante da América do Sul no mesmo hemisfério, devido a anomalias na circulação E-W em altos níveis ou circulação tipo Walker (Cruz et al, 2009a e Barreto, 2010). Estas últimas também estão associadas à atividade das monções de verão na região central do sistema, na Bacia Amazônica. Em resumo, os registros isotópicos de espeleotemas têm indicado variações substanciais nos padrões de circulação 
atmosférica e na distribuição das chuvas de verão do Pleistoceno Tardio ao Holoceno que precisam ser mais bem entendidas através de dados paleoclimáticos de regiões diretamente afetadas pela monção sul-americana.

Nesse contexto, a reconstituição da paleopluviosidade do norte de Minas Gerais é fundamental para a compreensão dos impactos regionais causado pelas forçantes climáticas de escala orbital e milenar no SMSA, tendo a vista que a região estudada localiza-se próximo ao eixo da Zona de Convergência do Atlântico Sul (ZCAS), onde as chuvas são estritamente devido a atividade do regime de monções Sul-americanas durante o verão (Rao et al., 1996; Garreaud et al., 2009; Vera et al., 2006).

\subsection{Objetivos da Pesquisa}

- Realizar levantamento paleoclimático e paleoambiental, com base em perfis isotópicos de $\delta^{18} \mathrm{O}$ e $\delta^{13} \mathrm{C}$ e das razões elementares em estalagmites depositadas em cavernas da região do norte de Minas durante o Pleistoceno Tardio e o Holoceno.

- Identificar e descrever padrões das variações de paleopluviosidade da região do norte de Minas em diferentes escalas de tempo, de acordo com o ciclo de precessão (periodicidade de aproximadamente 23 mil anos), durante a ocorrência de eventos milenares tipo Heinrich, Young Dryas, Dansgaard-Oeschger e dos eventos Bond (de aproximadamente 1.5 a 3.0 mil anos) e de acordo com variações em escalas multidecadais e centeniais, possivelmente relacionadas a ciclos de variação da atividade solar.

- Discutir os mecanismos responsáveis por mudanças da intensidade e posicionamento geográfico dos sistemas climáticos que afetaram a paleopluviosidade da região centro-leste do Brasil, atualmente situada numa faixa de clima tropical semi-úmido e coberta por uma vegetação do tipo cerrado sensu stricto, com manchas de vegetação estacional decidual nas regiões de ocorrência de rochas carbonáticas. Nesse tópico, atenção especial será dada aos mecanismos associados às monções Sul-americanas, o qual consiste no único sistema climático atuante na região do norte de Minas.

\section{2 Área de Estudo e Climatologia Moderna}

\subsection{Localização e caracterização geológica}

A área de estudo compreende a região entre os municípios de Luislândia e Montalvânia, 
norte do estado de Minas Gerais, onde estão situadas as cavernas Lapa Grande (Montalvânia) e Lapa Sem Fim (Luislândia). Os municípios distam cerca de 200 km um do outro (em linha reta), estando Montalvânia mais a norte, na fronteira entre os estados de Minas Gerais e Bahia (Fig. 2.1).

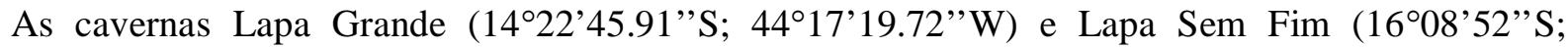
44³6’38”W) foram formadas em unidades carbonáticas neoproterozóicas do Grupo Bambuí (Iglesias e Uhlein, 2009). A caverna Lapa Grande desenvolveu-se nas porções carbonáticas da Formação Sete Lagoas, ao passo que, a caverna Lapa Grande desenvolveu-se nas porções carbonáticas da Formação Lagoa do Jacaré.
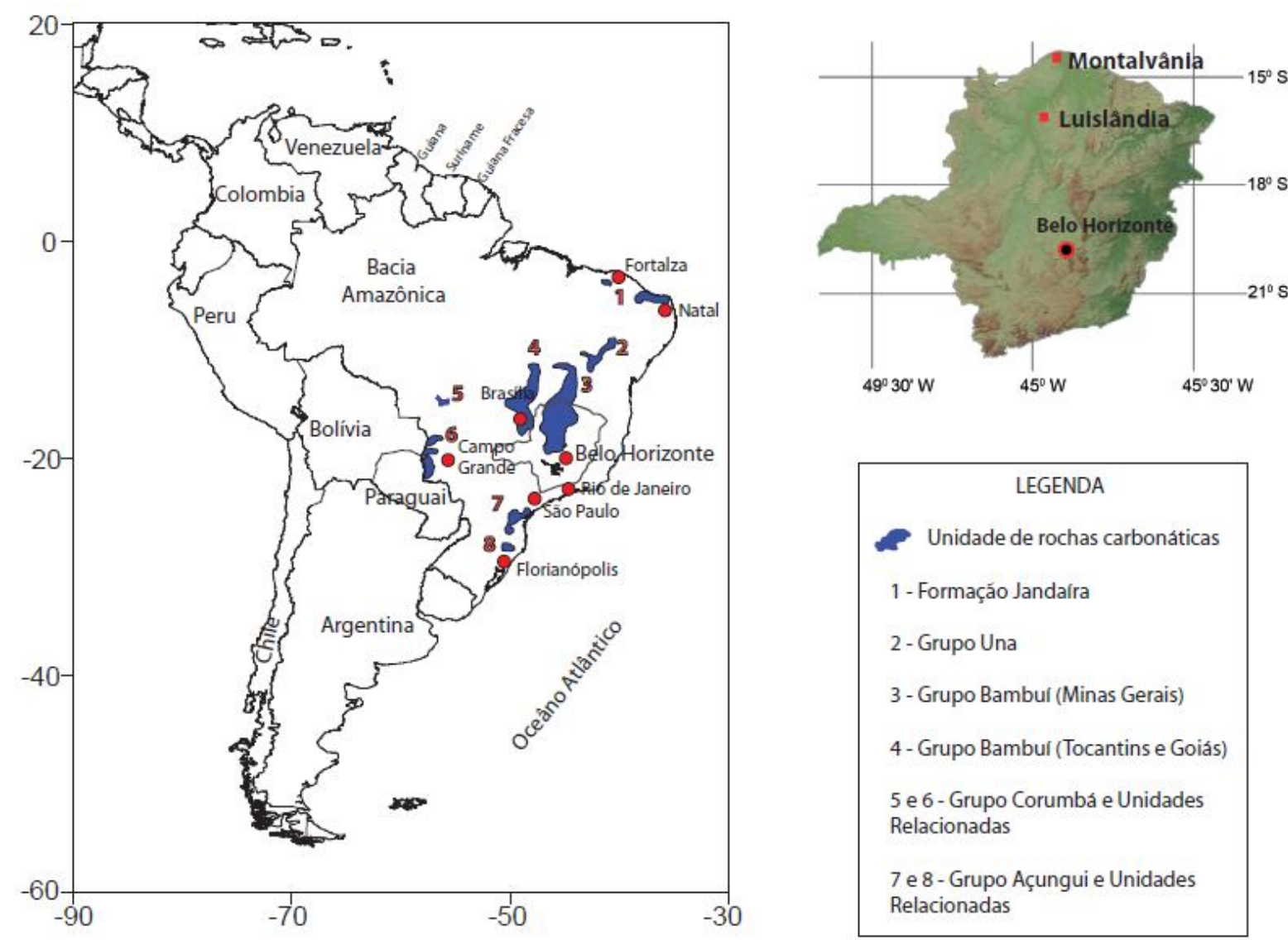

Figura 2. 1 - Localização da área de estudo bem como o contexto das unidades carbonáticas e províncias cársticas do território brasileiro.

A caverna Lapa Sem Fim é a maior cavidade conhecida do Estado de Minas com cerca de 21 $\mathrm{km}$ de desenvolvimento horizontal em planta baixa. O mapa da caverna foi efetuado pelos grupos União Paulista de Espeleologia (UPE, São Paulo-SP) e Espeleogrupo Peter Lund (EPL, Montes Claros-MG) no final dos anos 90 (ANEXO I). Nota-se no mapa o predomínio de padrão morfológico tipicamente labiríntico, com desenvolvimento de condutos controlado por um sistema 
de fraturas de cisalhamento conjugados e por um dobramento aberto das camadas Silva et al. (2003). Karmann (comunicação verbal) atribui a gênese da caverna a um sistema de recarga difuso a partir de unidades areníticas sobrepostas a unidade carbonática, hoje praticamente residuais, e que deve, portanto, ter conferido o padrão morfológico à caverna. Medições de parâmetros atmosféricos realizados durante a atividade de coleta indicam alta umidade relativa do ar (100\%) ao longo de toda a caverna, com temperatura média de $29^{\circ} \mathrm{C}$ e concentração de $\mathrm{CO}_{2}$ variando de níveis entre 600 700 ppm (salões Sharlene e Kássia) para níveis ao redor de 1500 ppm no salão Cristiane, chegando a 4000 ppm nos condutos localizados no final da caverna, próximo ao salão Cristiane.

Análises isotópicas realizadas nos carbonatos da caverna Lapa Sem Fim, amostradas no conduto e em um perfil vertical na entrada da caverna, indicam valores de $\delta^{13} \mathrm{C}$ em torno de $+13.2 \%$ (Fig. 2.2). A assinautara isotópica de $\delta^{13} \mathrm{C}$ da Formação Lagoa do Jacaré por ser vista como anomalamente alta se comparadas com as demais sucessões carbonáticas neoproterozóicas do mundo, cujos valores tipicamente residem entre termos negativos $(<-3 \%$ ) até valores da ordem de + $8 \%$ (Kaufman et al., 1991; Derry et al., 1992; Babinky, 1993). Os resultados são concordantes com os valores de $\delta^{13} \mathrm{C}$ analisados para a mesma unidade carbonática por Babinsky (1993), descritos entre 10 e 12\% PDB. Esse é um aspecto importante a ser considerado nesse trabalho, uma vez que valores elevados de $\delta^{13} \mathrm{C}$, como os observados para a Formação Lagoa do Jacaré, devem influenciar na assinatura isotópica do carbonato das estalagmites analisadas, principalmente em casos onde a cobertura de solos é pequena e o tempo de residência da água de infiltração é curto, de modo que não haja tempo para que a solução entre em equilíbrio com o $\mathrm{CO}_{2}$ gasoso presente no solo (Baker et al., 2001a).

Diferentemente da caverna Lapa Sem Fim, a caverna Lapa Grande apresenta dimensões muito mais modestas, com desenvolvimento horizontal de apenas $2.2 \mathrm{~km}$ e morfologia bem mais simplificada, estruturada por dois longos e largos condutos que formam um piso inferior de aproximadamente $800 \mathrm{~m}$ de comprimento e um nível superior de aproximada $500 \mathrm{~m}$ de comprimento, com desnível máximo de 40m e salões de desmoronamento de aproximadamente 50 $\mathrm{m}$ de largura em ambos os condutos. A caverna se desenvolve ao longo das unidades carbonáticas da Formação Sete Lagoas que afloram na charneira do horst-anticlinal da Serra do Parrela, a norte do Município de Montalvânia (Martinez, 2007; Iglesias e Uhlein, 2009). O mapa da caverna Lapa Grande foi confeccionado pelo Grupo Bambuí de Pesquisas Espeleológicas em 1992 e é apresentado juntamente como o mapa da Lapa Sem Fim no ANEXO I. 


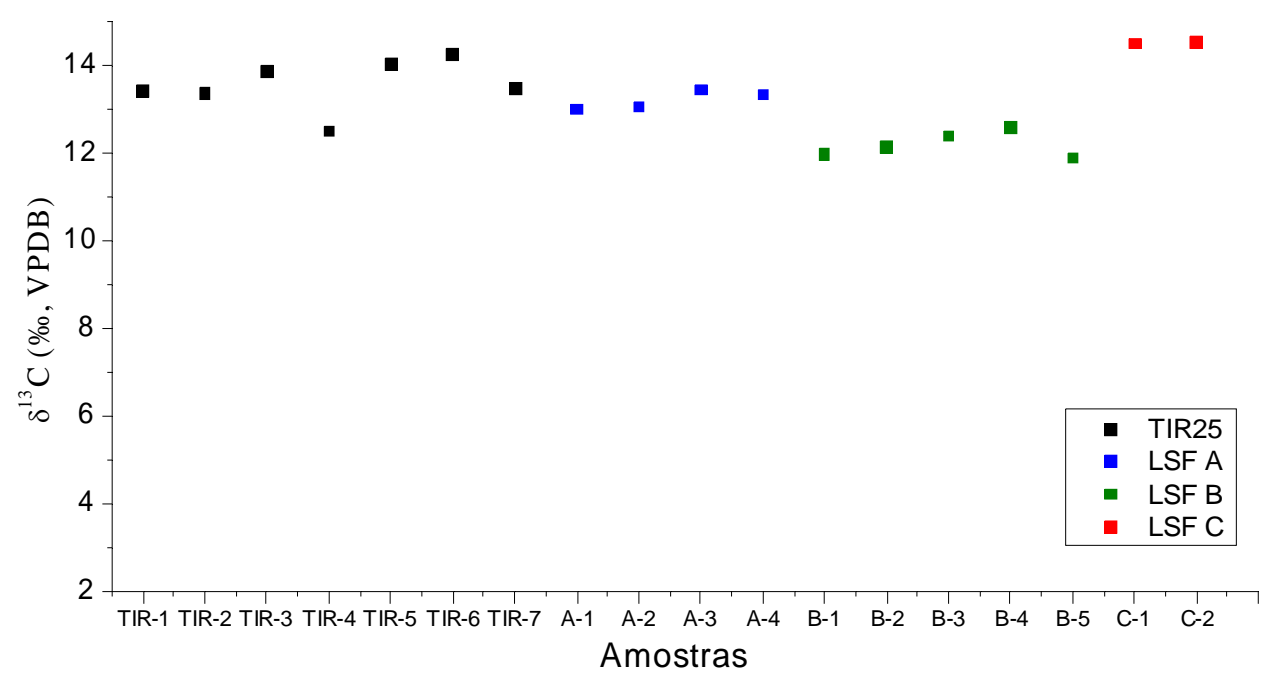

Figura 2.2 - Valores de $\delta^{13} \mathrm{C}$ dos carbonatos da Formação Sete Lagoa do Jacaré, rocha encaixante da caverna Lapa Sem Fim. As amostras TIR25 representam rocha do conduto e as demais (LSF A, B e C) amostras de rochas coletadas em um perfil vertical na entrada da caverna e apresentam valores muito enriquecidos em ${ }^{13} \mathrm{C}$.

A espessura do reservatório varia entre as cavernas, sendo o da Lapa Sem Fim o mais curto. $\mathrm{Na}$ caverna Lapa Grande, estimativas feitas com base na espessura da camada carbonática encaixante da caverna, com base na projeção longitudinal dos condutos sob o perfil topográfico do relevo, sugere que a espessura do reservatório não deve ultrapassar 100m (Fig. 2.3). Em termos de espessura do horizonte de solos, o afloramento expressivo do epicarste na região da caverna Lapa Grande denuncia um fraco recobrimento superficial, possivelmente associado a processos erosivos relacionados ao escoamento superficial de água pluvial. Já, na caverna Lapa Sem Fim, essa relação é evidenciada pelo afloramento rochoso na entreda principal da caverna, que somada a topografia do relevo e ao plano de desenvolvimento dos condutos sugere um reservatório muito raso, como pode ser observado na Figura 2.4. A espessura máxima do reservatório estimada para a Lapa Sem Fim gira em torno de $25 \mathrm{~m}$, tomando por base a variação vertical dos condutos (desnível máximo de $19 \mathrm{~m})$ e a pequena variação topográfica do relevo. 


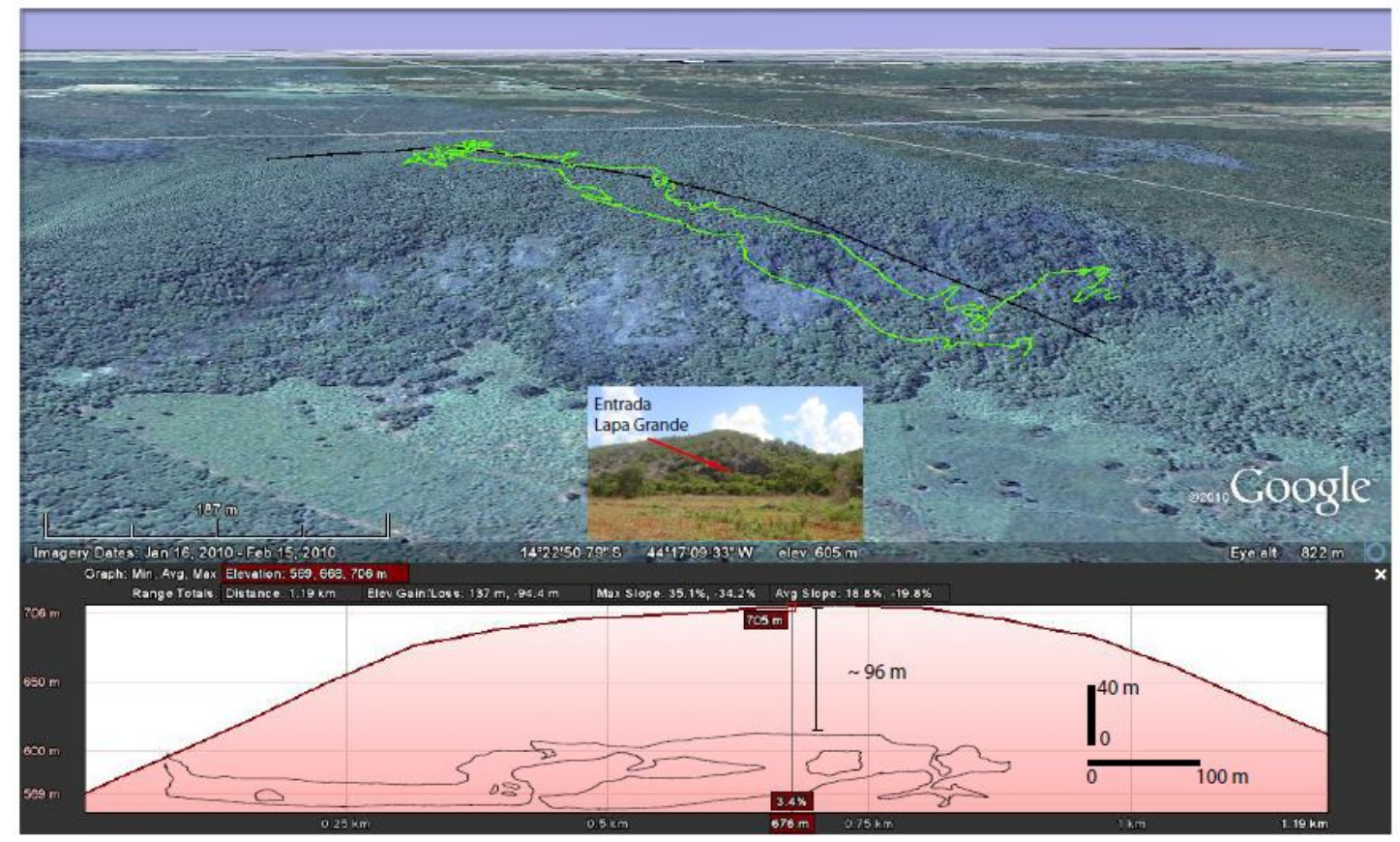

Figura 2.3 - Estimativa de espessura do reservatório da zona vadosa sobre a caverna Lapa Grande. O contorno em verde representa a projeção da planta baixa sobre o relevo. Fonte Google Earth março/2011.

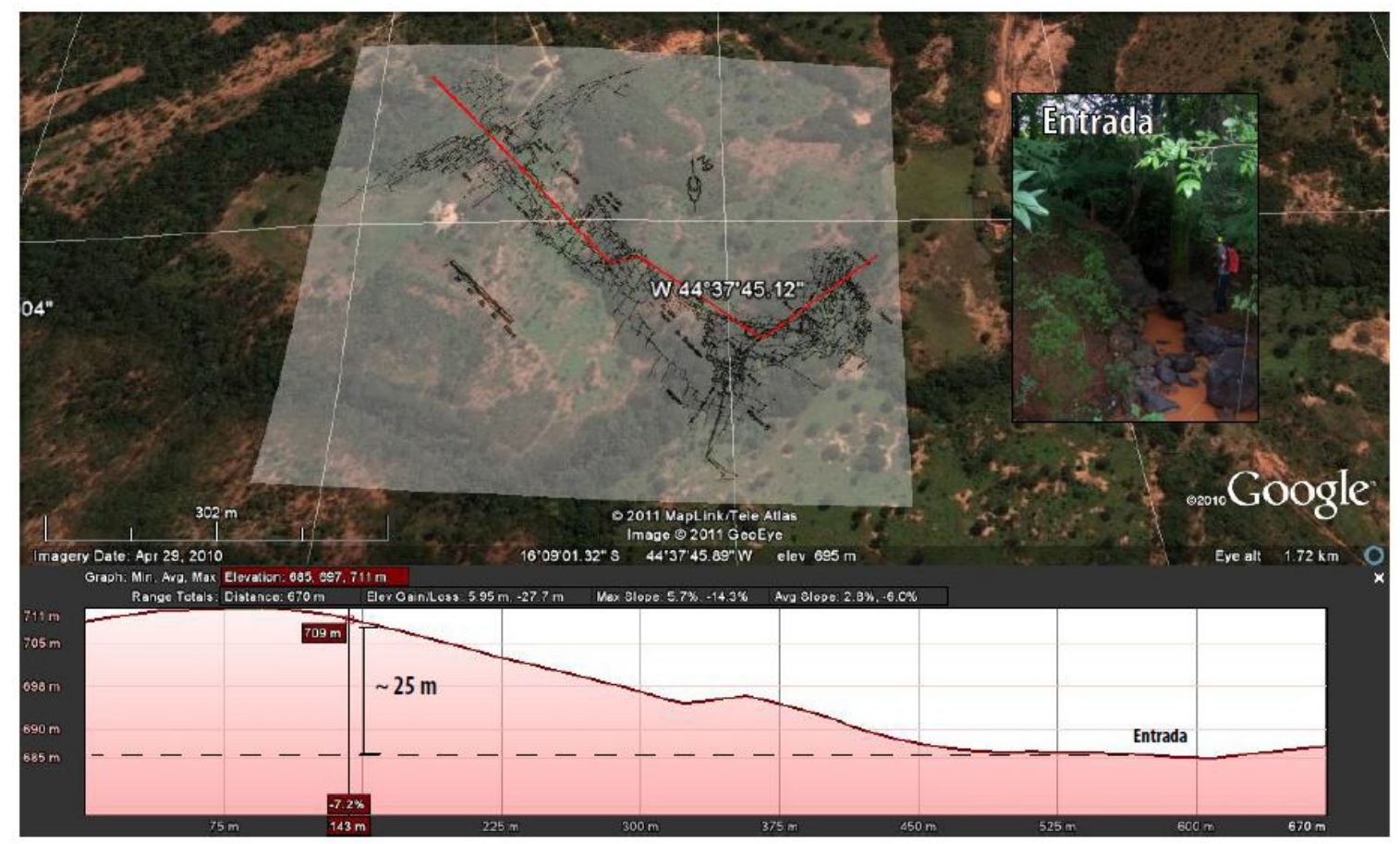

Figura 2.4 - Perfil longitudinal do desnível terreno sobre a caverna Lapa Sem Fim. A linha tracejada ilustra a projeção horizontal do perfil da caverna considerando o pequeno desnível vertical observado. A espessura de aproximadamente 25m corresponde à área do Salão Cristiane, próximo ao final da caverna. Fonte Google Earth março/2011. 


\subsection{Climatologia Moderna}

O clima na região central e norte de Minas é classificado como tropical semi-úmido de acordo com a classificação de Köppen-Geiger, com índices pluviométricos anuais entre 900 a 1500 mm (Fonte:INMET). A climatologia de precipitação no estado é caracterizada pela atuação de sistemas tropicais, associados com a monção sul-americana de verão, cuja convecção é alimentada principalmente pela umidade proveniente da Bacia Amazônica (Rao et al., 1996). As chuvas ocorrem durante os meses de outubro a abril com máximos de atividade convectiva de dezembro a fevereiro (Fig. 2.5), período considerado pico da atividade do SMSA devido ao estabelecimento da Zona de Convergência do Atlântico Sul (ZCAS). A ZCAS é um fenômeno climático que consiste na formação de uma banda de nebulosidade de direção NW-SE que possui características semiestacionárias por dias seguidos, nos quais são registrados os maiores índices médios precipitação acumulada durante o verão (Rao et al., 1996; Melo et al., 2009). O desenvolvimento dessa zona de convergência é considerado como a feição mais importante das monções Sul-americanas, justamente por ser a responsável pela distribuição da umidade da Amazônia para o sul e sudeste do continente através de jatos de baixos níveis (Garreaud et al., 2009; Vera et al., 2006).

A partir do tratamento dos dados das séries históricas de precipitação medidas entre 1953 e 2005, disponibilizados pela Agência Nacional de Águas (ANA), foi possível determinar que os índices pluviométricos anuais são praticamente idênticos em Montalvânia e Brasília de Minas (município vizinho, $20 \mathrm{~km}$ a sudeste de Luislândia), em torno de $940 \mathrm{~mm}$ (Fig. 2.5). Nota-se que a quantidade de chuva que cai sobre a região pode variar consideravelmente de ano para ano, como foi registrado entre os anos de 1993 e 1992 quando o total acumulado de chuva oscilou de 1500 para $500 \mathrm{~mm}$. A boa reprodutibilidade entre as séries históricas de pluviometria indica que ambas as regiões estão fortemente relacionadas ao mesmo sistema climático e que as interpretações paleoclimáticas tanto da Lapa Grande como da Lapa Sem Fim podem ser realizadas conjuntamente e de maneira a se complementarem. 


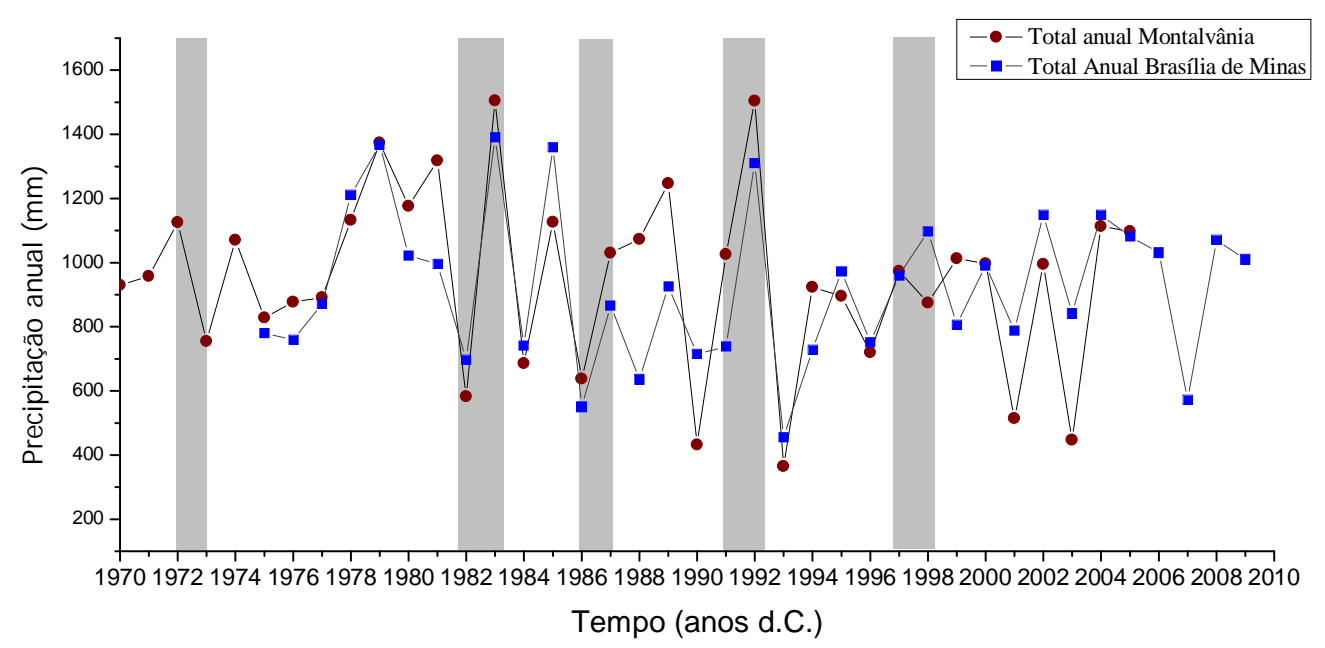

Figura 2.5 - Comparação das séries históricas dos valores dos acumulados anuais de Montalvânia (caverna Lapa Grande) e de Brasília de Minas (município próximo da caverna Lapa Sem Fim) entre os anos de 1974 e 2010 . As séries temporais foram construídas com base nos dados de estações meteorológicas disponibilizados pela agência nacional de águas (ANA). Em ambas as regiões, as médias dos totais acumulados anuais giram em torno de $940 \mathrm{~mm}$. As barras cinza representam anos de forte El-Niño.

De modo geral, o início da circulação monçônica da América do Sul está relacionado ao aumento da convergência de umidade do Atlântico equatorial para região amazônica, favorecida pelo maior aquecimento do continente em relação à temperatura da superfície marinha (TSM) da região oceânica adjacente (Vera et al. 2006). Nesse aspecto, a variação do gradiente de TSM do Atlântico equatorial exerce um papel muito importante na intensidade do SMSA, com expressivos aumentos de chuvas relacionados com aumento relativo da TSM na porção mais a sul do oceano, como pode ser observado na Figura 2.6. A circulação atmosférica é tipicamente anticiclônica, divergente em altos níveis e convergente em baixos níveis, com células ascendentes no interior do continente e descendente nos oceanos (Mechoso et al. 2005; Vera et al. 2006).
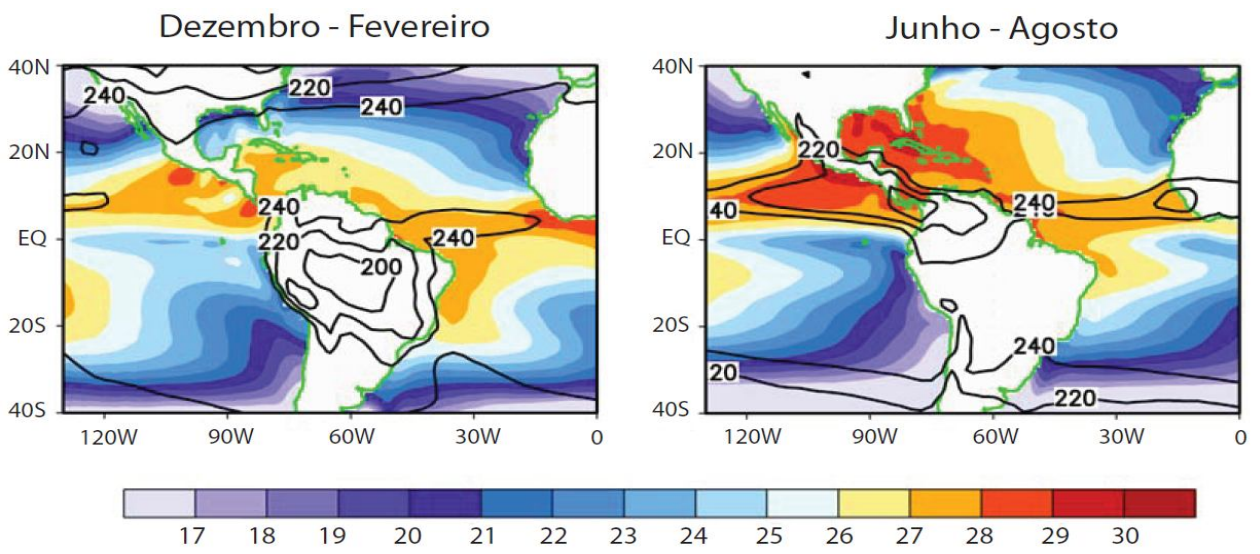

Figura 2.6 - Distribuição de TSM em ${ }^{\circ} \mathrm{C}$ baseado em medições de radiação de ondas longas $\left(\mathrm{W} / \mathrm{m}^{2}\right)$ para os meses de Dezembro a Fevereiro (quadro a esquerda) e de Junho a Agosto (quadro a direita). Notar aumento da TSM do Atlântico equatorial oeste durante o período de pico das monções Sul-americanas. Modificado de Mechoso et al. (2004). 
O início dessa circulação ocorre durante a primavera austral (de setembro a dezembro) com níveis máximos de precipitação no sul da Amazônia associados ao ciclo de variação sazonal de insolação (Vera et al. 2006) (Fig. 2.7 e 2.8). A fase madura das monções ocorre nos meses de dezembro, janeiro e fevereiro (DJF), quando uma zona de baixa pressão próxima à superfície e um anticiclone em altos níveis se estabelecem entre a Bolívia e o Peru, região conhecida climatologicamente como Alto da Bolívia. De acordo com Zhou e Lau (1998) os ventos alísios de nordeste, responsáveis por transportar umidade a baixos níveis do Atlântico Sul para o interior do continente, estão fortalecidos durante a maturidade monçônica e prolongam-se até o leste da região tropical andina, onde são desviados para a costa sudeste do Brasil.

a)

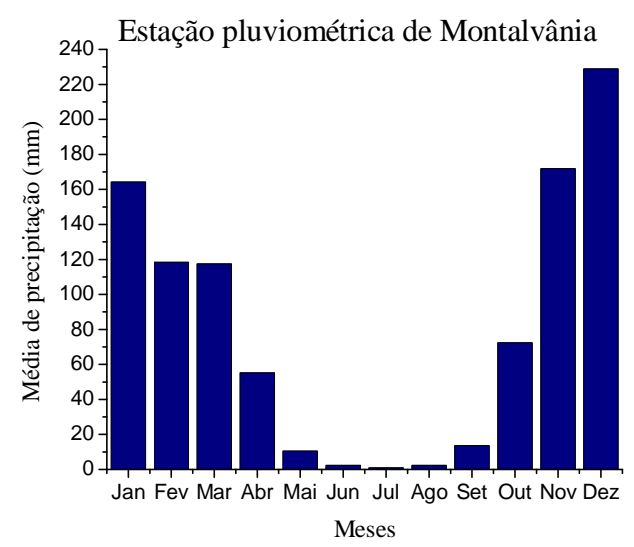

b)

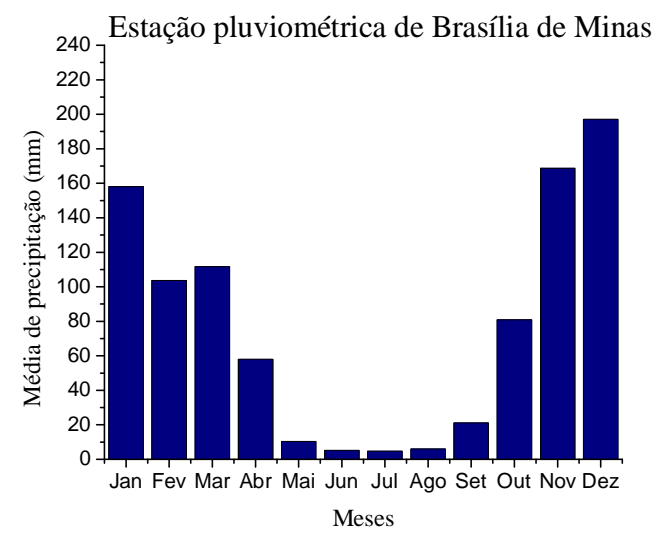

c)

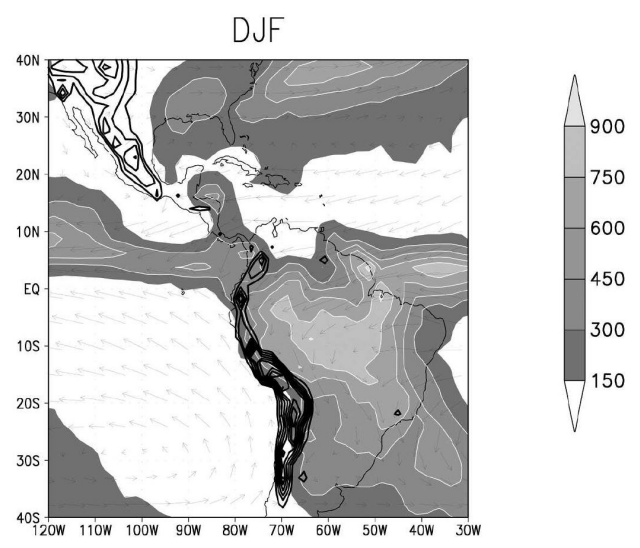

d)

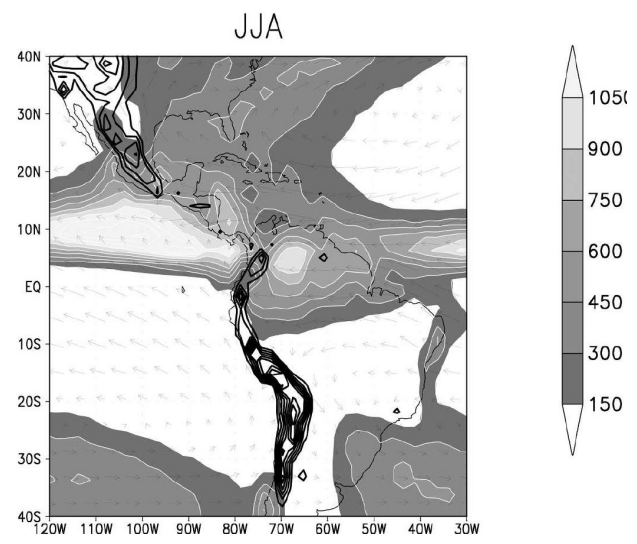

Figura 2.7 - Distribuições pluviométricas mensais nas estações meteorológicas nos municípios de Montalvânia (a) e Brasília de Minas (b), o último localizado a $20 \mathrm{~km}$ de Luislândia. Dados pluviométricos obtidos pela ANA (www2.ana.gov.br). (c) mapas com as médias do total acumulado anual de precipitação média vertical climatológica dos fluxos médios de umidade (proveniente das reanálises do NCEP-NCAR) para os meses de DJA (figura superior) e JJA (figura inferior). Adaptado de Vera et al. (2006). 
Na região das cavernas Lapa Grande e Lapa Sem Fim mais de 90\% da precipitação ocorre durante os meses de setembro a março, período de atividade das monções Sul-americanas (Rao et al., 1996; Vera et al., 2006) (Fig. 2.5 e 2.6). Durante a fase madura das monções, entre novembro e fevereiro, o total acumulado pelas precipitações chega a $70 \%$ do total anual nos sítios de amostragem, sendo que uma parte significativa das chuvas, por volta de $12 \%$, ocorre ainda no mês de março, período que dá início a fase de desintensificação das monções Sul-americanas (Gan et al., 2004; Vera et al., 2006). A partir do mês de maio, as precipitações tornam-se praticamente inexpressivas, somando algo ao redor de $10 \mathrm{~mm}(\approx 1 \%$ do total acumulado no ano). As precipitações são raras nos meses de junho, julho e agosto (JJA), durante o inverno austral, não excedendo 15 mm durante todo o trimestre (Fig. 2.5).

O desenvolvimento da circulação monçônica na América do sul esta relacionada com a migração da Zona de Convergência Intertropical (ZCIT) para sul durante o verão austral em resposta a variações do gradiente de TSM inter hemisférica dos oceanos ao longo das zonas equatoriais. $\mathrm{O}$ aumento da convergência de umidade do Atlântico equatorial para o continente é favorecido pelo deslocamento meridional da ZCIT (Carvalho et al., 2009; Melo et al., 2009). A ZCIT é a conjunção de variáveis meteorológicas que atuam na faixa equatorial dos oceanos, sendo elas: a Zona de Confluência dos Alísios (ZCA), as áreas de máxima TSM e de máxima convergência de massa, e a banda de máxima cobertura de nuvens convectivas (Melo et al., 2009). De modo geral, essas condições caracterizam a ZCIT como um sistema meteorológico formado por uma grande zona de baixa pressão convergente a baixos níveis (divergente em altos níveis) ao longo da faixa equatorial e, cuja posição média flutua de maneira cíclica de acordo com variação de TSM, entre as bacias oceânicas dos hemisférios Norte e Sul, indo ao redor de $14^{\circ} \mathrm{N}$ entre os meses de agosto-setembro e em torno de $2^{\circ} \mathrm{S}$, (chegando a $5^{\circ} \mathrm{S}$ nos anos mais chuvosos) entre os meses março-abril (Melo et al., 2009).

Dentre as variações climáticas interanuais que afetam a América do Sul, os eventos relacionados ao El-Niño Oscilação Sul (ENOS) são considerados com os mais importantes (Grimm e Ambrizzi, 2009). O ENOS está relacionado a um forte e complexo acoplamento dos sistemas oceano-atmosfera sobre a bacia do Pacífico tropical que, por sua vez, leva a fortes oscilações de TSM do Pacífico equatorial, onde as fases de aquecimento são denominadas de El-Niño e as fases de esfriamento de La-Niña (Ambrizzi, et al., 2004). Os eventos ENOS são basicamente relacionados a períodos de enfraquecimento e intensificação dos ventos alísios que condicionam a variação de TSM do Pacífico equatorial leste (Ambrizzi et al., 2004). Uma vez que estes interferem na ressurgência das águas profundas sobre a região, suas alterações acabam por impactar o padrão de circulação zonal (E-W) ou das células de Walker. 

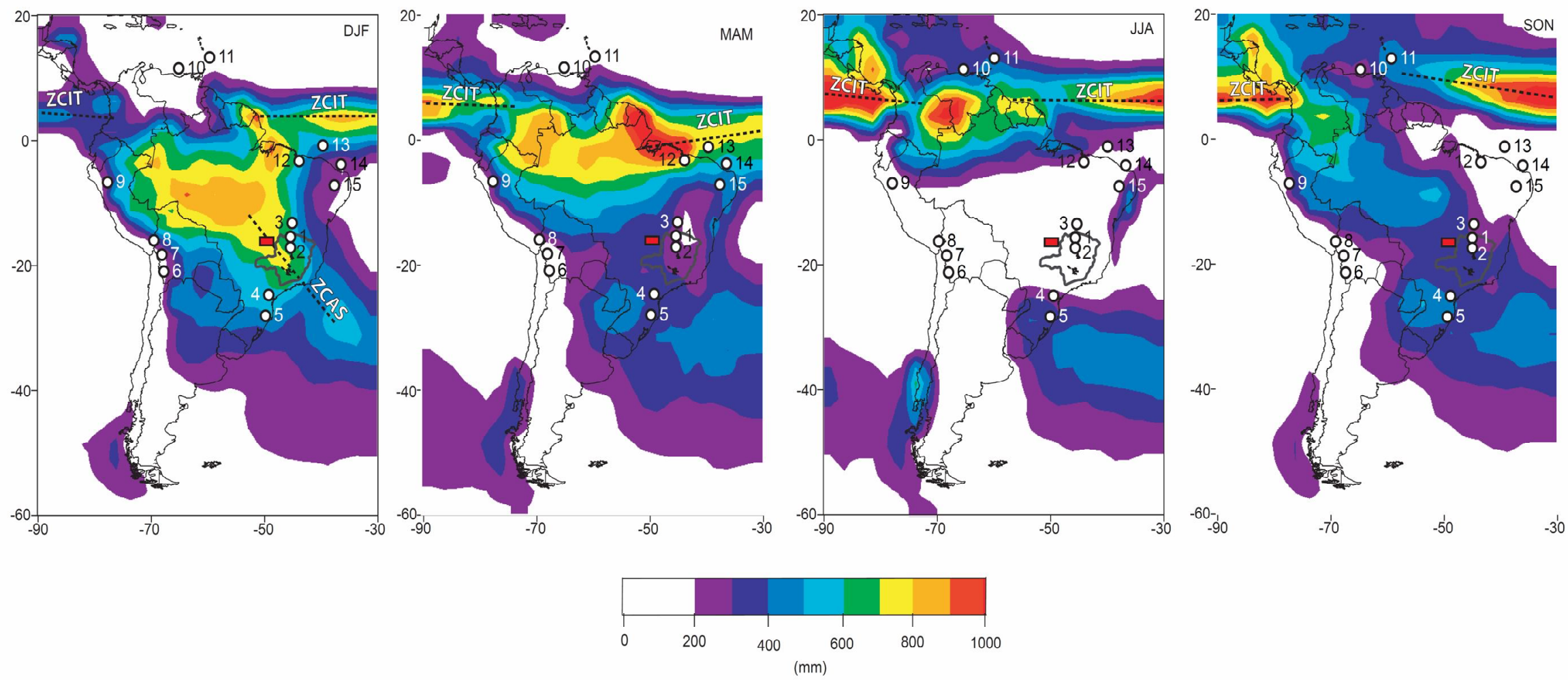

Figura 2.8 - Mapa climático da precipitação da América do Sul entre 1979-2000 (Xie e Ankin, 1997). Para a região do norte de Minas Gerais, as maiores médias de precipitação ocorrem em DJF (verão austral), devido atuação das monções Sul-americanas. Os números indicados no mapa correspondem às seguintes localidades estudadas: 1 - Caverna Lapa Grande, Montalvânia-MG; 2 - Caverna Lapa Sem Fim, Luislândia-MG e outras regiões estudadas paleoclimaticamente; 3 -Espeleotemas do oeste da Bahia (Wang et al. 2007; 2009), 4 - Espeleotemas de Iporanga-SP (Cruz et al., 2006a), 5 - espeleotemas de Botuverá (Wang et al. 2006; Cruz et al. 2005a); 6 -Paleolagos do Salar de Uyuni (Baker et al., 2001a); 7 -Testemunho de gelo de Sajama, Bolivia (Thompson et al., 1998); 8 - Registros lacustres do Titicaca (Baker et al., 2001b; Baker et al., 2005); 9 -Espeleotemas do norte do Peru (van Breukelen, 2008); 10 - sedimentos marinhos de Cariaco, Venezuela (Haug et al. 2001); 11 - Sedimentos marinhos do Atlântico equatorial oeste (testemunho M350034) (Rühlemann et al., 1990); 12 - Registros lacustres do Lago Caçó, Maranhão (Sifeddine et al. 2003); 13 -Testemunho GeoB 3910-2 (Arz et al., 2001) e 14 - Testemunhos GeoB 3911-3 e GeoB 3104 da costa do nordeste brasileiro (Arz et al. 1998); 15 - Espeleotemas do Rio Grande do Norte (Cruz et al. 2009a). As linhas tracejadas indicam a posição média do eixo das principais zonas de convergência de umidade: a zona de convergência do Atlântico sul (ZCAS) e a zona de convergência intertropical. (ZCIT). 
O modo de variabilidade interanual de precipitação relacionada ao ENOS na América do Sul mostra uma clara relação antifásica entre as regiões Nordeste e Sudeste tanto na sua fase positiva (aumento dos valores de anomalias de TSM no Oceano Pacífico Tropical) quanto na fase negativa (diminuição desses valores de TSM), as quais caracterizam os eventos El-Niño e La-Nina respectivamente. Durante os eventos El-Niño a região nordeste sofre com um déficit de precipitações relacionado ao desenvolvimento de uma zona de convergência anômala em altos níveis (divergente em baixos níveis) que inibe a formação de nuvens (Fig. 2.9). A instalação de uma zona de alta pressão próxima à superfície sobre a costa do nordeste ocorre em função de uma perturbação na célula de Walker gerada pelo aquecimento das águas do Pacífico equatorial leste, fazendo com que o braço de subsidência de ar na costa do Peru se desloque para a região nordeste (Grimm e Ambrizzi, 2009; Ambrizzi et al., 2004).

Já na região sudeste do continente, os eventos de ENOS repercutem climatologicamente de maneira contrária, gerando fortes precipitações na época das monções. Entretanto, nessa região os sinais climáticos dos ENOS não ocorrem sempre da mesma maneira, em parte devido à sazonalidade das ondas Rossby, responsáveis pela teleconexão das anomalias de TSM do Pacífico para dentro do continente (Grimm e Ambrizzi, 2009). Diferentemente das regiões nordeste e sudeste do continente Sul-americano, a região centro-leste do Brasil, na qual enquadramos o norte de Minas Gerais, não apresenta um sinal climático claro frente aos eventos de ENOS, como pode ser observado nas Figuras 2.9 e 2.10. O baixo impacto do ENOS nessa região pode ser averiguado nas anomalias de precipitação das séries históricas de monitorados realizados pela ANA. Se nos basearmos nos dados das estações de monitoramento expostos na Figura 2.5 veremos que, para as regiões de Montalvânia e Luislândia, durante anos de forte El-Niño, entre 1972 e 1973; 1982 e 1983; 1991 e 1992 e entre 1997 e 1998 as variações do acumulado anual mostram pouca consistência com anomalias de chuva. Durante os fortes eventos de El-Niño registrados nos anos 1982/83 e de 1992/93, tanto na região de Montalvânia com em Luislândia, observou-se considerável aumento das precipitações (1500 mm), ao passo que nos eventos de 1972/73, 1086/97 e 1997/98 os totais acumulados anuais residiram dentro da média histórica ( $\approx 950 \mathrm{~mm}$ ). 

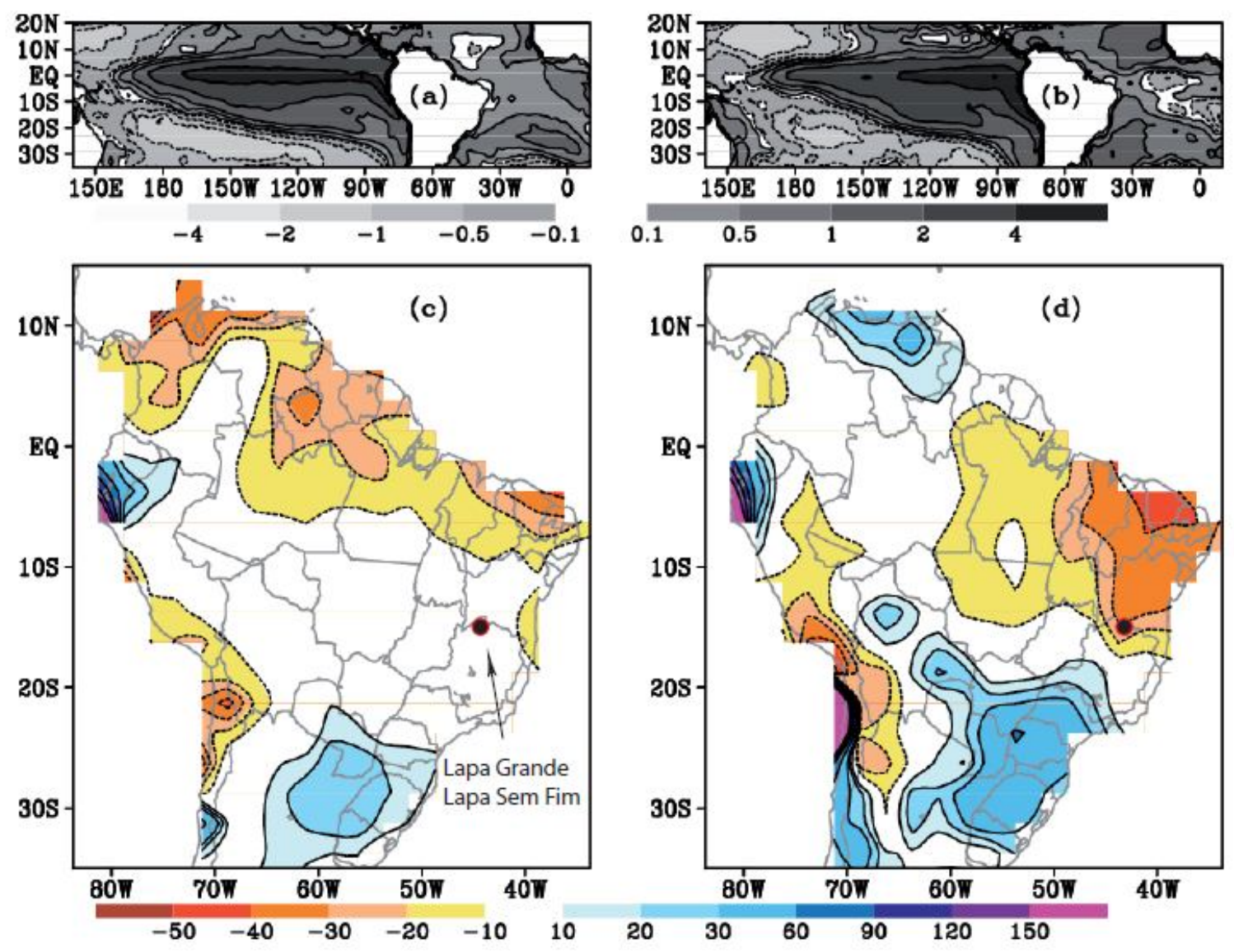

Figura 2.9 - Modo de variabilidade interanual de TSM e das precipitações de chuvas anuais da América do Sul durante os eventos de El-Niño. A figura de cima mostra as variações sazonais das anomalias de TSM $\left({ }^{\circ} \mathrm{C}\right)$ do Pacífico durante os meses de DJF (a) e MAM (b). A figura de baixo mostra as variações sazonais de precipitação em \% na América do Sul durante os meses de DJF (c) e MAM (d). A baixa variabilidade interanual no norte do estado de Minas Gerais sugere um fraco impacto de eventos climáticos como ENSO na região de estudo. Retirado de Ambrizzi et al. (2004).

Oscilações climáticas de escala multidecadal do gradiente de temperatura do Atlântico tropical, conhecida como AMO, do inglês Atlantic Multidecadal Oscillation, tem sido frequentemente relacionada a anomalias positivas de precipitação nas áreas afetadas pelo SMSA, sobretudo no Nordeste do Brasil (Knight et al., 2005,2006; Timmerman et al., 2007). O AMO atualmente é tido como uma oscilação natural da temperatura da superfície do Atlântico com periodicidade média de 65 anos. Essas oscilações exercem um papel importante na modulação da variabilidade das precipitações na América do Sul, visto que esta regula o gradiente de TSM estabelecido entre o Atlântico tropical a norte e a sul da linha do equador. Basicamente, na fase de AMO negativa, o Atlântico tropical sul apresenta anomalias positivas de TSM, em oposição ao Atlântico tropical norte, que apresenta anomalias negativas e vice-versa. Assim, o gradiente de TSM estabelecido na fase de AMO negativa condiciona o deslocamento da ZCIT para sul, aumentando a convergência de umidade do oceano para o interior da bacia Amazônica de modo a ampliar o escoamento de umidade pela ZCAS e, conseqüentemente, intensificando o SMSA. O 
oposto ocorre na fase de positiva de AMO (Knight et al., 2006; Timmerman et al., 2007; Chiessi et al., 2009). Simulações computacionais de TSM do Atlântico para os últimos 1400 anos atribuem oscilações multidecadais entre 70 e 120 anos ao AMO, as quais são associadas a circulação termohalina no oceano Atlântico (Knight et al., 2005).

Em resumo, a princípio, a influência do ENOS em Minas Gerais, sobre tudo no norte do estado, não é robusta, apresentando uma forte variabilidade entre os eventos possivelmente modulado por variações de TSM do Atlântico. Desse modo, oscilações do gradiente de TSM do Atlântico tropical em escala multidecadal estão entre os potenciais parâmetros de variabilidade climática capazes de modular as precipitações do SMSA com um todo.
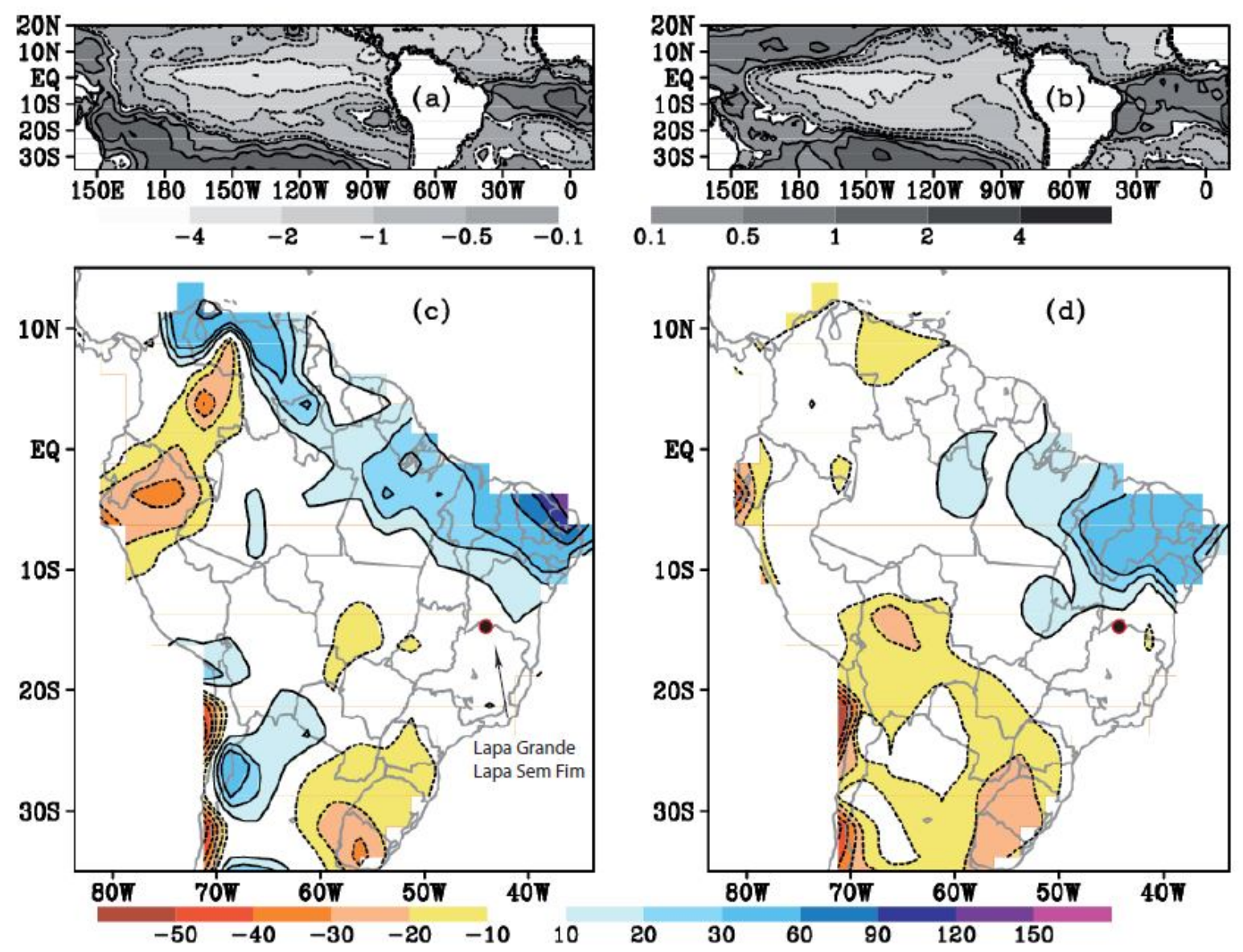

Figura 2.10 - O mesmo que para a Figura 2.9 porém para os eventos de La-Niña (Ambrizzi et al., 2004).

\subsection{Monitoramento Pluviométrico do IAEA-GNIP: Análises da composição isotópica da chuva e controles isotópicos}

Para avaliarmos como a composição isotópica das chuvas está relacionada a mudanças na pluviosidade, foram analisados dados de estações de monitoramento pluviométrico localizadas na 
região próxima do norte do estado de Minas Gerais em conjunto com medições das razões isotópicas de oxigênio e hidrogênio proveniente de estações de monitoramento da Agência Internacional de Energia Atômica em Brasília (IAEA International Atomic Energy Agency). Os dados de monitoramento isotópico e meteorológico disponibilizados pela IAEA foram produzidos durante o programa GNIP (sigla em inglês para Global Network Isotope on Precipitaion) iniciado no começo da década de 60 e que, em algumas regiões, perdurou até meados da década de 90 (www-naweb.iaea.org/napc/ih/IHS_resources_gnip.html).

Dentre as regiões de monitoramento do GNIP, a região de Brasília-DF é a mais próxima e a que apresenta maior semelhança em termos de regime de chuvas com o norte de Minas. A série histórica de monitoramento do GNIP em Brasília teve início em 1965 e encerrou em 1987. Infelizmente, vários são os anos no qual o monitoramento apresenta falhas nas coletas dos dados, com interrupções de ordem mensal e até mesmo hiatos de coletas que perduraram por anos inteiros. Por exemplo, entre os anos de 1976 e 1983 não há registros de precipitação monitorada pelo GNIP; da mesma forma, alguns meses apresentam escassez na coleta de dados, como os meses de junho, julho e agosto, monitorados apenas durante 4, 5 e 6 anos respectivamente ao longo da série toda. Os dados fornecidos pela IAEA são apresentados na Tabela 1, no ANEXO II.

Apesar das interrupções presentes na série histórica de monitoramento do GNIP para a região de Brasília, ainda assim é possível utiliza os dados para avaliar a relação entre a variação do sinal isotópico de oxigênio e o volume de chuvas. Com base na comparação entre a variação do acumulado mensal de chuva e os valores das médias $\delta^{18} \mathrm{O}$ (ponderados em função do volume de chuva mensal na Eq. 1), foi possível obter uma significante correlação negativa entre esses dados $\left(\mathrm{R}^{2}=0.65\right)$ que indica influência da pluviometria na composição isotópica da chuva (Fig 2.11a). Assim, conclui-se que quanto maior o volume de chuva, menor o valor do $\delta^{18} \mathrm{O}$ da mesma dentro do sistema climático estudado.

$$
\overline{\delta^{18} O}=\frac{\sum_{i=1}^{n} P_{i} \delta_{i}^{18} O}{\sum_{i=1}^{n} P_{i}}
$$

Onde:

$\overline{\delta^{18} O}=$ média ponderada em função do acumulado mensal de chuva em mm;

$\mathrm{P}=$ valor de precipitação de chuva em ( $\mathrm{mm} / \mathrm{mês})$;

$\delta^{18} \mathrm{O}=$ valor medido das razões isotópicas de ${ }^{16} \mathrm{O}$ e ${ }^{18} \mathrm{O}$ da chuva. 
A correlação negativa entre o $\delta^{18} \mathrm{O}$ da chuva e a quantidade de precipitação é mais conhecido pelo termo em inglês amount effect, tido como o principal mecanismo controlador da composição isotópica de oxigênio das precipitações nas regiões tropicais. O amount effect é comumente observado onde a formação de chuvas é frequentemente associada ao desenvolvimento de grandes complexos convectivos, como é o caso de Minas Gerais, que levam ao empobrecimento em ${ }^{18} \mathrm{O}$ da água da chuva conforme aumento do volume precipitado (Lachniet, 2009; Vuille et al., 2003). Na comparação entre o sinal isotópico da chuva e o volume acumulado trimestral, nota-se uma boa relação da assinatura isotópica frente à variação sazonal de precipitação, caracterizado por valores muito negativos em DJF, por volta de $-5 \%$ (Fig. 2.11b). A relação estabelecida na Figura 2.11 b evidencia o SMSA como o sistema climático mais preponderante na variação do $\delta^{18} \mathrm{O}$ das chuvas na região central do Brasil.
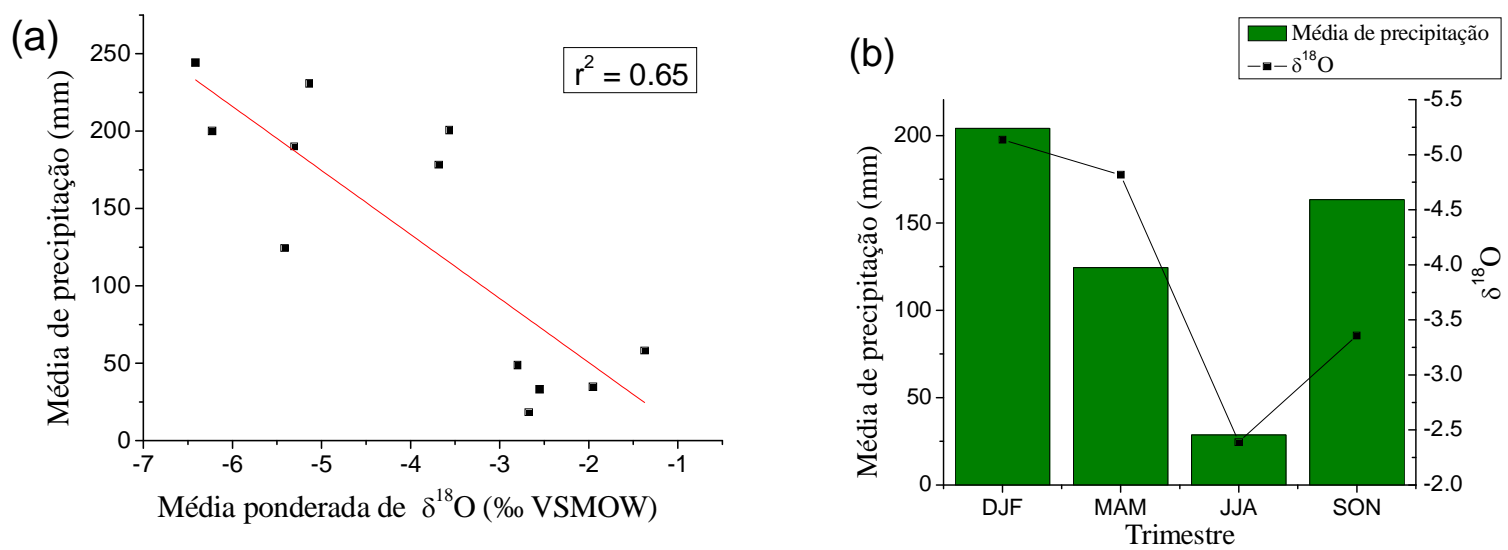

Figura 2.11 - (a) correlação entre o acumulado mensal de chuvas $(\mathrm{mm})$ e a média ponderada de $\delta^{18} \mathrm{O}$ em relação ao acumulado mensal de chuva; (b) Relação entre a média pluviométrica trimestral e os valores de $\delta^{18} \mathrm{O}$ da chuva nas estações do IAEA em Brasília.

A relação entre a variação do volume da precipitação e a composição isotópica de oxigênio da água da chuva é claramente evidenciada nas simulações com a aplicação do modelo geral de circulação atmosférica ECHAM-4 realizado por Vuille et al. (2003) (Fig. 2.12). De acordo com a simulação, em boa parte da faixa tropical da América do Sul, a variação $\delta^{18} \mathrm{O}$ é associada com a atividade da monção sul-americana, de forma que o empobrecimento do $\delta^{18} \mathrm{O}$ das chuvas de verão é concordante com as zonas de maior precipitação de chuvas (Vuille e Werner, 2005). Dessa forma, o padrão de distribuição dos valores isotópicos de $\delta^{18} \mathrm{O}$ das precipitações reflete a atuação das zonas de convecção profunda nas regiões tropicais, sendo caracterizada por correlação negativa entre o $\delta^{18} \mathrm{O}$ das precipitações com o volume de chuvas (Fig. 2. 12a). Os valores negativos obtidos na diferença entre o $\delta^{18} \mathrm{O}$ das chuvas de verão com o $\delta^{18} \mathrm{O}$ das chuvas de inverno indicam que a 
variação isotópica composicional das chuvas é coerente com o que se observa em termos de variação sazonal e espacial do volume de chuva, maior durante o verão para a maioria das regiões do continente Sul-americano (Fig. 2.12 e 13).
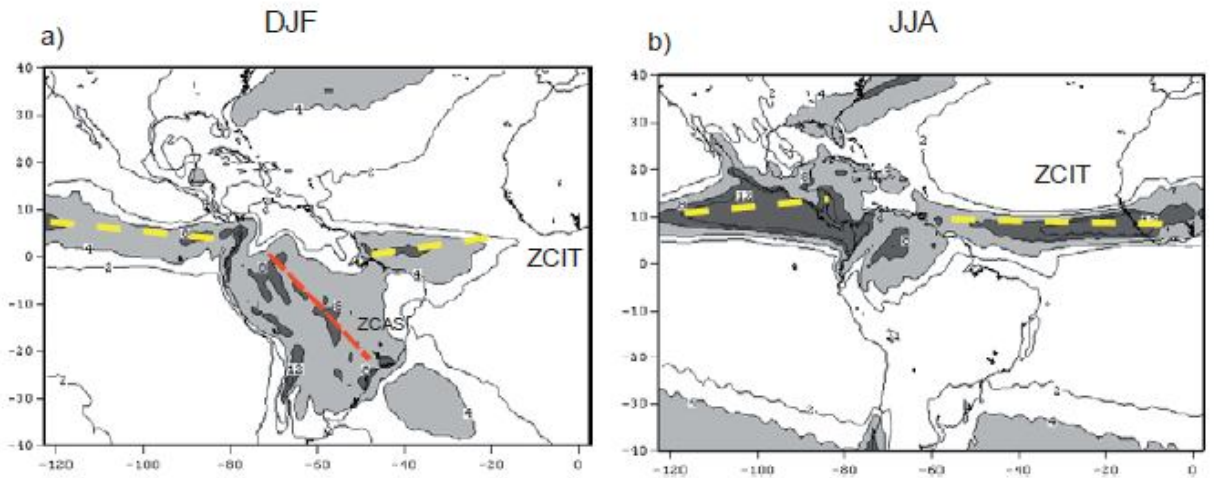

c)
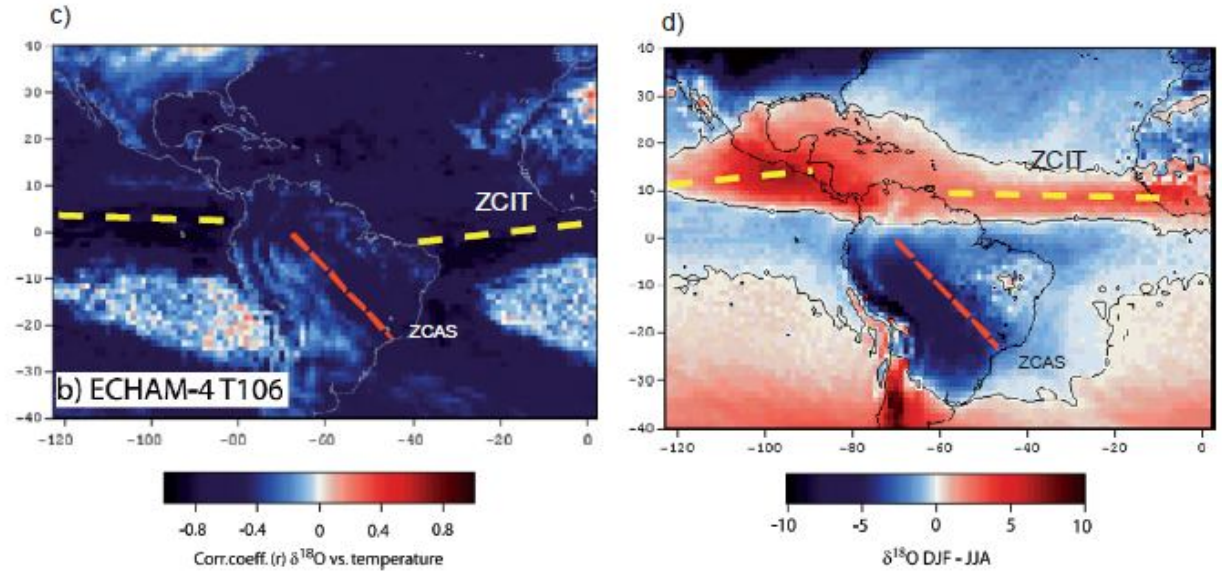

Figura 2.12 - Comparação entre os valores mensais de precipitação com os seus respectivos valores de $\delta^{18} \mathrm{O}$ das mesmas a partir da correlação espacial dos dados das estações IAEA-GNIP pelo modelo geral de circulação atmosférica ECHAM-4. a) Curvas de precipitação de chuva em mm/dia para os meses de dezembro, janeiro e fevereiro (DJF) e b) idem para os meses de junho julho e agosto (JJA). Os contornos marcam os intervalos de 2, 4, 8 e $12 \mathrm{~mm} / \mathrm{dia}$, valores > $4 \mathrm{~mm} /$ dia são sombreados em cinza claro e valores maiores que $8 \mathrm{~mm} /$ dia em cinza escuro. c) correlação entre o volume mensal de chuvas e o $\delta^{18} \mathrm{O}$ da mesma. d) diferença entre os valores de $\delta^{18} \mathrm{O}$ das precipitações medidas nas estações IAEA-GNIP durante o verão austral (DJF) como os dados medidos durante os meses de inverno austral (JJA). Valores mais (menos) negativos indicam que o volume de chuva durante o verão austral (boreal) é mais significativo do que durante o inverno. As linhas tracejadas em amarelo marcam a posição média da Zona de Convergência Intertropical (ITCZ) e em vermelho a Zona de Convergência do Atlântico Sul (ZCAS). Modificado de Vuille et al. (2003).

Outra forma de se estimar se esse mecanismo é o preponderante no norte de Minas é realizar uma comparação entre as séries pluviométricas das referidas regiões com base nos dados das estações de monitoramento da ANA (Fig. 2.13). Como é possível observar na comparação entre os dados pluviométricos apresentados na Figura 2.13a e b, a região norte do estado de Minas e a região de Brasília apresentam uma variabilidade interanual muito semelhante. A diferença crucial reside no valor do acumulado anual médio de chuvas que em Brasília é em torno de 35\% maior: ao passo que no norte de Minas o acumulado anual médio é de $950 \mathrm{~mm}$ em Brasília esse valore chega a $1500 \mathrm{~mm}$ 
(Fig 2.13a). De maneira semelhante ao norte de Minas, em Brasília 90\% da precipitação anual ocorre no período das monções, entre setembro a março, com aproximadamente $50 \%$ vindo a ocorrer entre os meses de dezembro a fevereiro, pico da monções Sul-americanas, e aproximadamente $20 \%$ durante o outono. Em concordância, durante o inverno as chuvas praticamente cessam não excedendo $2 \%$ do total acumulado anual em ambas as regiões. A semelhança na variabilidade em que o SMSA atua sobre a distribuição de chuvas em toda a região central do Brasil é um dos pontos favoráveis para que o "amount effect" seja tido como principal mecanismo controlador da variação de chuva no Norte de Minas.

a)

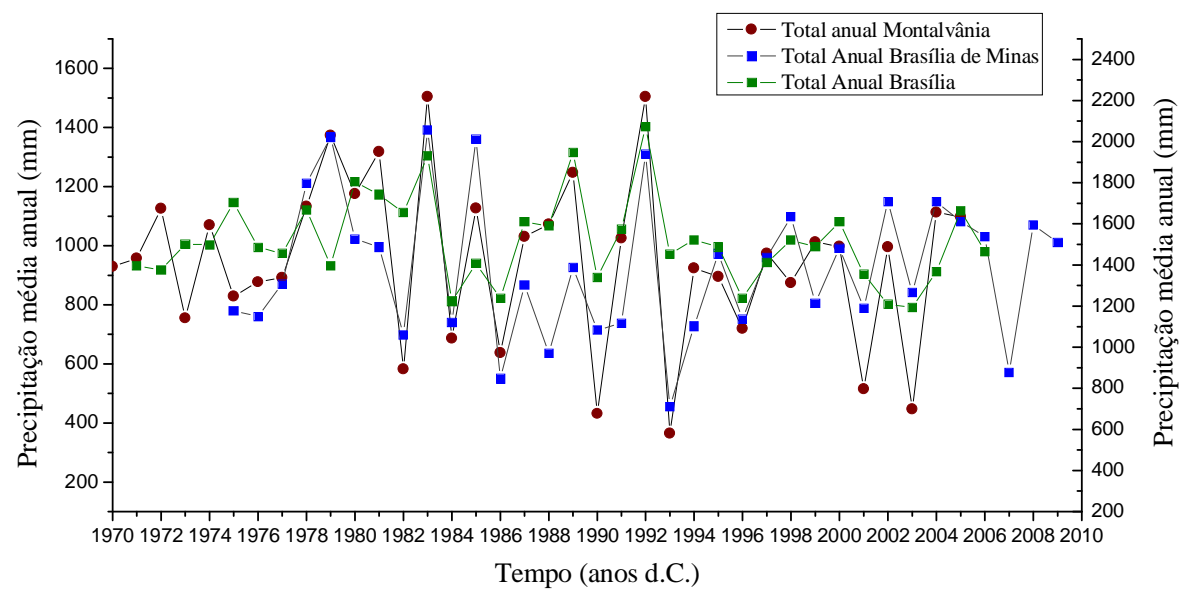

b)

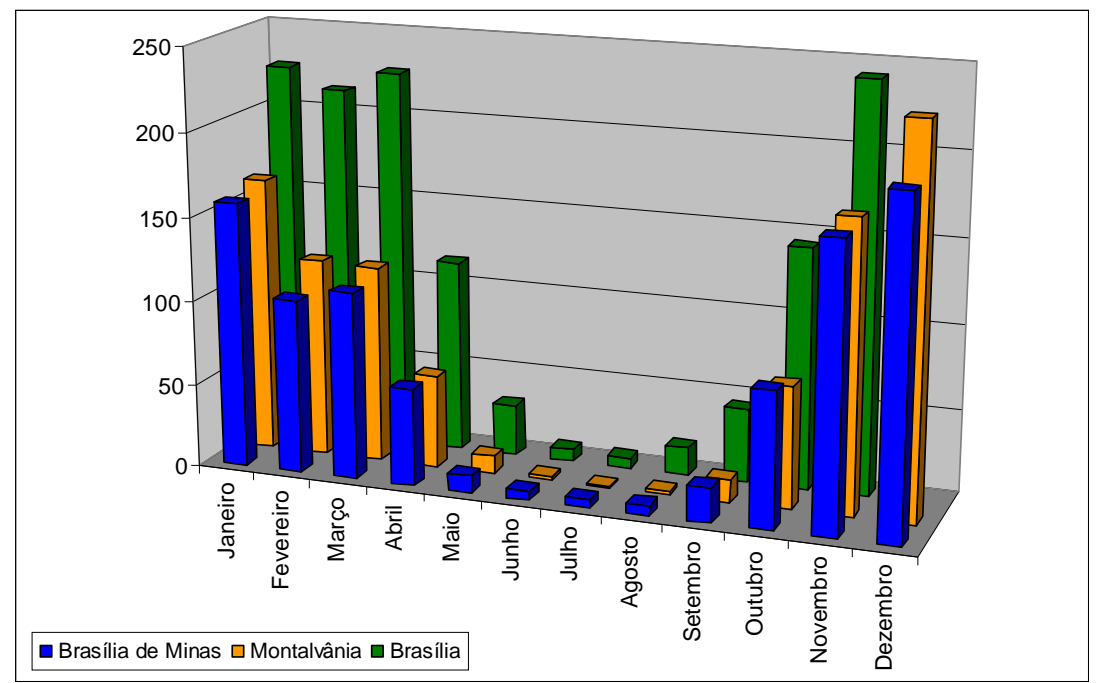

Figura 2.13 - Comparação entre as variações pluviométricas no Norte de Minas e Brasília: (a) série história do acumulado anual de chuvas entre 1970 e 2010 de Montalvânia (círculos pretos); Brasília de Minas, região próxima a Luislândia (quadrados cinza) e Brasília (quadrados verdes); (b) comparação entre as distribuições pluviométricas mensais entre Montalvânia (azul), Brasília de Minas (laranja) e Brasília (verde). 
A magnitude com que o "amount effect" atua numa mesma região não é constante, justamente porque depende do volume inicial de vapor de água da massa de ar e da dinâmica microclimática das nuvens (Clark e Fritz, 1997). Outro fator importante é a fonte de chuva que dever ser levado em consideração para o caso de regiões em que há mais de uma área fonte de umidade para as precipitações. Variações na contribuição relativa entre cada fonte de umidade para o volume total de precipitação podem gerar interpretações errôneas. Nesse caso, pelo fato de praticamente toda a precipitação que se abate sobre a região estudada ocorrer durante as monções Sul-americanas, a partir do escoamento para sudeste da umidade acumulada na Amazônia, o efeito área fonte pode ser descartado como fator capaz de influenciar na assinatura isotópica da chuva.

\section{Materiais e Métodos}

\subsection{Escolha da área de estudo}

As cavernas Lapa Sem Fim e Lapa Grande estão situadas em áreas ideais para o estudo da variação de paleopluviosidade relacionada ao regime de monções por meio de análises isotópicas em espeleotemas. Isso porque elas estão localizadas próximo ao eixo NW-SE da Zona de convergência do Atlântico Sul (ZCAS), somado ao fato de que mais de $90 \%$ das precipitações na região estudada ocorrem durante os meses de outubro a março, período de atividade das monções (Vera et al., 2006). Por esse motivo, o sinal climático obtido com os registros isotópicos de espeleotemas deve refletir variações de um único sistema climático, no caso a SMSA.

\subsection{Coleta de estalagmites}

Para estudos das variações climáticas ocorridas no Holoceno Tardio foi dada preferência as estalagmites com feições de deposição recentes ou que estivessem assoaciadas a gotejamento ativo no momento da coleta. As melhores amostras são aquelas que demontram ausência de indicações de alterações secundárias como cavidades indicativas de dissolução e que sejam formadas por carbonato de coloração clara ou sem presença de lama rica em argilominerais. As estalagmites com formato cilíndrico possuem uma ordenação estratigráfica mais simples, devido eixo de crescimento melhor definido. Variações na posição do eixo de crescimento, além de representarem possíveis hiatos deposicionais, aumentam a necessidade de maior número de datações geocronológicas, fatores estes que além de reduzir a qualidade do registro, consomem mais tempo e recursos laboratoriais. 
Para que as variações das razões isotópicas dos espeleotemas possam refletir mudanças do ciclo hidrológico é necessário que o fracionamento do oxigênio ocorra em condições de equilíbrio isotópico durante a precipitação da calcita. Por isso, a coleta das estalagmites se deu em galerias e salões isolados, ambientalmente caracterizados pela mínima circulação e alta umidade relativa de ar, de forma obter amostras cuja deposição ocorreu em condições de equilíbrio isotópico entre a água e a calcita (Clark e Fritz, 1997; Lachniet et al., 2009). Na caverna Lapa Grande, as amostras foram coletadas em uma galeria superior a $560 \mathrm{~m}$ da entrada da caverna, como pode ser observado no ANEXO I. Na caverna Lapa Sem Fim, as amostras foram coletadas nas galerias e salões distribuídos ao longo da caverna como um todo, em porções onde a concentração média de $\mathrm{CO}_{2}$ reside entre 600 e 800 ppm, de acordo com medições pontuais realizadas na etapa de coleta. Assim, foram evitadas as amostras depositadas próximas às entradas das cavernas, onde fatores ambientais externos, como por exemplo, a atuação de correntes de ar e a baixa umidade relativa da atmosfera da caverna possam induzir a precipitação de $\mathrm{CaCO}_{3}$ sob condições evaporativas ou de rápida degaseificação em locais com baixa $\mathrm{pCO}_{2}$ da atmosfera. Esse é um importante critério para evitar amostras depositadas sob processos de fracionamento cinético, quando as condições de deposição do $\mathrm{CaCO}_{3}$ ocorrem distantes das condições de equilíbrio termodinâmico, em outras palavras, quando o intercâmbio isotópico entre a água dos gotejamentos e o $\mathrm{CaCO}_{3}$ das estalagmites não segue o fator de fracionamento $(\alpha)$ estimado sob uma temperatura aproximadamente constante (Lachniet et al., 2009). Desse modo, o rigor no procedimento de coleta é condição básica para que os valores de $\delta^{18} \mathrm{O}$ e $\delta^{13} \mathrm{C}$ do $\mathrm{CaCO}_{3}$ dos espeleotemas possam ser associados à composição da água meteórica e do carbono orgânico do solo e dessa forma às variações paleoclimáticas.

\subsection{Preparação das amostras para estudo paleoclimático e amostragem para datação radiométrica}

As estalagmites coletadas foram cortadas longitudinalmente ao longo do eixo de crescimento e, em seguida, foi realizada uma triagem de amostras potencialmente mais propícias para o estudo isotópico de acordo com as feições internas dos espeleotemas. Para o corte das estalagmites foram utilizados discos de corte com bordas diamantadas de espessura entre 1 e $2 \mathrm{~mm}$. Durante a triagem das amostras são levados em consideração os aspectos mineralógicos, texturas e estruturais do espeleotema. Foram selecionadas amostras monominerálicas, sem feições de alterações secundárias e que apresentassem a maior continuidade deposicional possível, em outras palavras, com menor número de hiatos e/ou variações da posição do eixo de crescimento. Para facilitar a visualização das feições texturais e estruturais do espeleotema, as amostras foram previamente polidas com a 
utilização de uma politriz Bosch modelo GPO 12 com prato de velcro e lixas de grano 220, 320 e por último, grano 600 para acabamento final.

As estalagmites foram amostradas para datação geocronológica do topo para a base, com detalhamento de trechos localizados entre possíveis hiatos deposicionais e com mudança do eixo de crescimento. Na seleção dos níveis amostrados para datação tenta-se evitar trechos com indicações de processos de dissolução e recristalização, como também camadas amarronzadas a avermelhadas indicativas de maior concentração de materiais terrígenos, fontes de ${ }^{230} \mathrm{Th}$ detrítico, causa dos maiores erros nas datações pelo método U/Th. Esses procedimentos tiveram como objetivo tornar a amostragem geocronológica mais confiável, para conferir maior a exatidão e precisão das idades.

A extração de $\mathrm{CaCO}_{3}$ da estalagmite para datação radiométrica é realizada com auxílio de uma micro retífica de eixo flexível do fabricante Dremel modelo 225. Para cada camada amostrada extraiu-se cerca de 0.4 a 0.2 g de $\mathrm{CaCO}_{3}$ de calcita e 0.1 a $0.15 \mathrm{~g}$ de aragonita, a depender da concentração média de urânio de cada amostra. A Figura 3.1 apresenta a imagem do corte longitudinal das estalagmites analisadas com a locação das amostras datadas.

\subsection{Datação geocronológica pelo método U-Th}

As datações foram realizadas no laboratório de geocronologia do Departamento de Geologia e Geofísica da Universidade de Minnesota, nos Estados Unidos, através do espectrômetro de massa do tipo ICP-MS (Inductively Coupled Plasma Mass Spectrometry), modelos Finnigan Elements e Finnigan Neptune de acordo com os procedimentos estabelecidos por Shen et al. (2002). Os

procedimentos laboratoriais para abertura de amostra e concentração de U e Th são detalhados a seguir: 


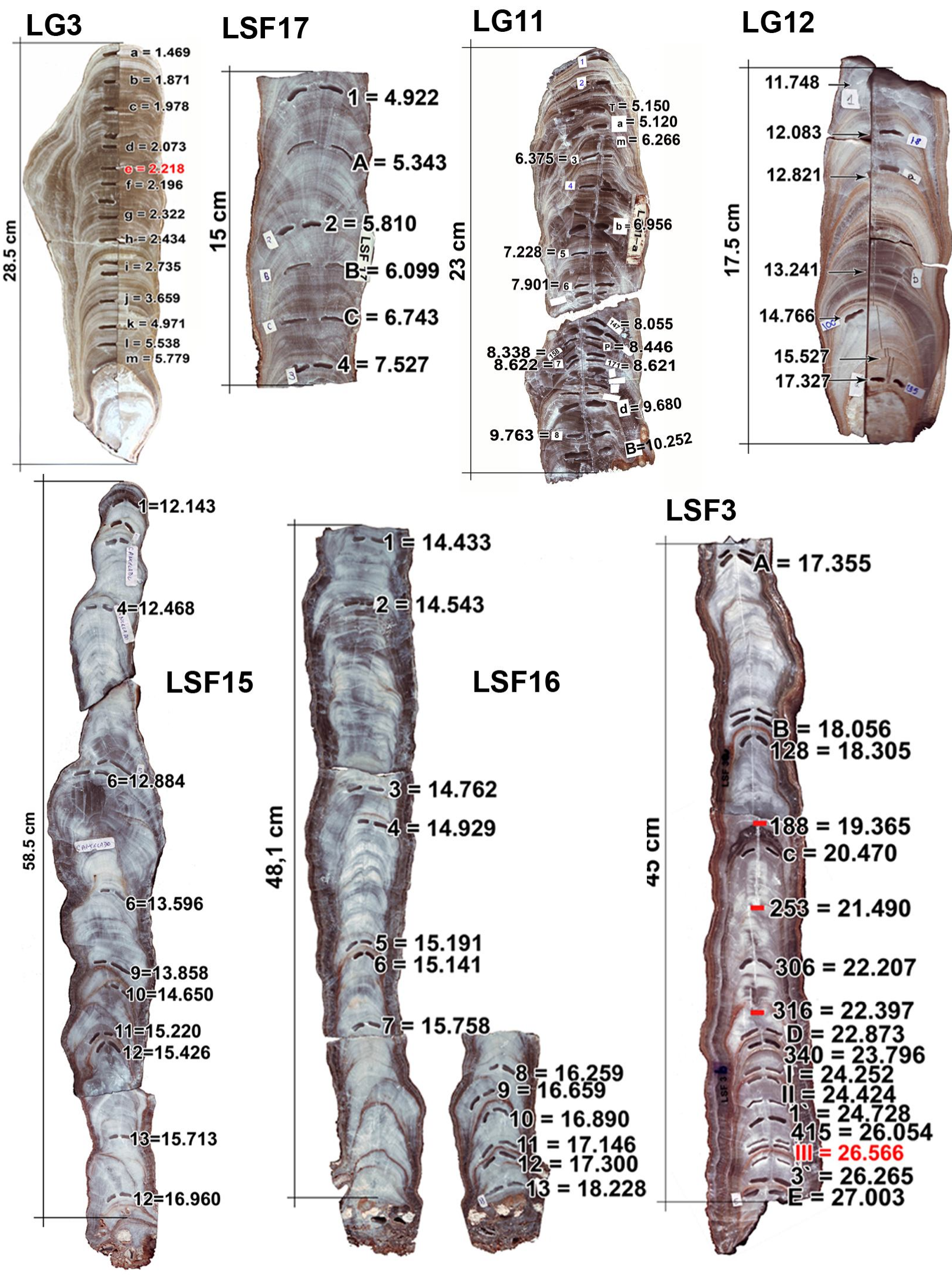

Figura 3.1 - Prancha com as imagens do corte longitudinal das estalagmites analisadas. 


\subsubsection{Procedimentos analíticos para abertura de amostra e concentração de íons de $U$ e Th}

A massa de $\mathrm{CaCO}_{3}$ analisada varia de acordo com a concentração de $\mathrm{U}$ estimada para cada estalagmite. Normalmente utiliza-se $0.2 \mathrm{~g}$ de amostra, mas em casos de amostras contendo altas concentrações de $U$ (> $1 \mathrm{ppm})$, utiliza-se por volta de $0.1 \mathrm{~g}$. A amostra é posta em um béquer de teflon e em seguida dissolvida com adição de $\mathrm{HNO}_{3}$ 7N. Constatada a completa dissolução da amostra, é adicionado à solução o spike contendo ${ }^{236} \mathrm{U}_{-}^{233} \mathrm{U}^{229} \mathrm{Th}$ e depois 4 gotas de $\mathrm{HClO}_{4}$. O número de gotas de $\mathrm{HClO}_{4}$ varia de acordo com a relativa quantidade de matéria orgânica presente na amostra. Em algumas amostras as impurezas associadas à matéria orgânica são muito visíveis logo após a dissolução; nesses casos deve ser adicionado por volta de 7 gotas de $\mathrm{HClO}_{4}$. A fim de garantir a completa homogenização entre a amostra e o spike, o béquer de teflon contendo a amostra é tampado e então posto para aquecer por 20 minutos em uma chapa quente. Em seguida a tampa do béquer é removida e a amostra é posta para secar por completo. Ao final, um precipitado de cor branca é formado no fundo do béquer.

Tendo finalizado o processo de abertura e adição de spike, é feita a precipitação de Fe para concentração dos íons pesados e eliminação do Ca da amostra. O precipitado formado é dissolvido com $\mathrm{HCl} 2 \mathrm{~N}$ e então a solução é transferia para um tubo de ensaio onde é previamente adicionado cerca de 2 a 3 gotas de solução rica em ferro. Em seguida é feito o procedimento para precipitação de óxidos de Fe pela adição gradativa de gotas de $\mathrm{NH}_{4} \mathrm{OH}$ até que a solução atinja o ponto de saturação. Na seqüência, os tubos são cobertos com parafilme e postos para centrifugar. Após a centrifugação todo o sobrenadante é dispensado e, ao tubo de ensaio, é adicionada água deionizada e então a amostra é posta novamente para centrifugar. Esse procedimento é realizado 3 vezes. Ao término da última centrifugação o precipitado é redissolvido com $\mathrm{HNO}_{3} 7 \mathrm{~N}$ e então é retornado ao béquer de teflon.

Finalizada essa etapa, a amostra é posta para secar por completo em uma chapa quente e ao final do processo um pequeno precipitado com dimensões milimétrica a submilimétrica é depositado no fundo do béquer. O precipitado é então dissolvido com aproximadamente 3 gotas de $\mathrm{HClO}_{4}$ e em seguida posto para secar por completo. A mesma amostra é dissolvida com aproximadamente 2 gotas de $\mathrm{HNO}_{3} 14 \mathrm{~N}$, retorna à chapa quente até a solução evaporar por completo. Após repetir procedimento com a utilização de algumas gotas de $\mathrm{HNO}_{3} 7 \mathrm{~N}$ ela estará pronta para ser introduzida às colunas de troca aniônica.

Para a separação de U e Th são utilizada colunas pequenas, com aproximadamente $7 \mathrm{~cm}$ de comprimento. As colunas são montadas com a resina SPECTRA/GEL® ION EXCHANGE Ix8. Antes de receber as amostras as colunas são condicionadas de acordo com os seguintes procedimentos: 
- Adiciona-se água deionizada de modo a preencher todo o volume do reservatório superior por duas vezes. Na segunda vez é adicionada uma gota de $\mathrm{HNO}_{3} 14 \mathrm{~N}$;

- Em seguida adiciona-se $\mathrm{HNO}_{3} 7 \mathrm{~N}$ em duas etapas. Cada uma delas com a adição de cerca de $2 / 3$ do volume do reservatório da coluna.

Finalizada essa etapa, a coluna está pronta para receber a amostra. A amostra é então despejada com cuidado dentro da coluna e a eluição dos reagentes é realizada de acordo com os seguintes passos:

- Após toda a amostra ser adsorvida pela coluna, é adicionado 2/3 do volume do reservatório com $\mathrm{HNO}_{3} 7 \mathrm{~N}$.

- Em seguida adiciona-se $1 / 3$ do volume do reservatório com $\mathrm{HNO}_{3} 7 \mathrm{~N}$.

- Após a última adição de $\mathrm{HNO}_{3} 7 \mathrm{~N}$ atravessar toda a coluna, troca-se o béquer usado para a coleta das soluções despejadas por um béquer de teflon devidamente limpo para dar início à coleta de coleta de Th.

- Para a coleta de Th adiciona-se $2 / 3$ do volume reservatório com $\mathrm{HCl} 6 \mathrm{~N}$ e em seguida repete-se o procedimento.

- Após todo $\mathrm{HCl} 6 \mathrm{~N}$ ter atravessado a coluna inicia-se a coleta de $\mathrm{U}$.

- Troca-se os béqueres de teflon usado na coleta de Th por aqueles utilizados anteriormente na manipulação da amostra.

- Para a coleta de U adiciona-se água deionizada por quase todo o reservatório da coluna. Em seguida repete-se o procedimento mais uma vez e a coleta de U esta finalizada.

Finalizada a coleta de $\mathrm{U}$ e Th, são adicionadas 2 gotas de $\mathrm{HClO}_{4}$ ao concentrado que segue para chapa quente para evaporar por completo. Após isso, nota-se a formação de um pequeno precipitado escuro submilimétrico que é dissolvido com 1 a 2 gotas de $\mathrm{HClO}_{4}$ e posto para evaporar por completo. Em duas etapas semelhantes adiciona-se mais 1 a 2 gotas de $\mathrm{HNO}_{3}$ 14N para nova evaporação por completo. Por fim, são adicionadas algumas gotas de solução padrão para análise em ICP-MS (solução preparada em uma garrafa de 1 L formada por uma mistura de água deionizada com $1 \% \mathrm{HNO}_{3} 14 \mathrm{~N}$ e algumas gotas de $\mathrm{HF}$ ). A partir desse ponto os concentrados de $\mathrm{U}$ e Th estão prontos para as análises espectrométricas em ICP-MS.

Os cálculos das idades foram, de modo geral, realizados com base nas razões isotópicos medidas e fatores de correção para eliminar efeitos de contaminação de Th detrítico (Edwards et al. 1986; Richards e Dorale, 2003). As precisões obtidas, na maior parte das datações, foi de 1\% ou 
inferior, segundo estimativa $2 \sigma$.

\subsection{Amostragem de calcita para isótopos estáveis}

Após obtenção dos dados geocronológicos foi realizada a seleção das estalagmites a serem submetidas a análises isotópicas em função do intervalo temporal preenchido por cada amostra, de modo que pudesse ser obtido um registro paleoclimático que fosse o mais contínuo possível. As distâncias entre camadas datadas foram medidas digitalmente sobre a imagem das estalagmites, com a utilização do programa Corel Draw, segundo o eixo de crescimento das estalagmites. Esses dados foram utilizados nos cálculos das taxas de crescimento e para a estimativa da resolução temporal de cada trecho analisado para isótopos estáveis de $\mathrm{O}$ e $\mathrm{C}$.

A amostragem de $\mathrm{CaCO}_{3}$ das estalagmites para análises isotópicas foi realizada com o uso de um microamostrador modelo 5400 da Sherline, acoplado a um medidor digital da distância entre os pontos amostrados, que permite uma resolução máxima de $0.4 \mathrm{~mm}$ entre amostras (Fig. 3.1). São extraídas aproximadamente $200 \mu \mathrm{g}$ de amostra em pó com a utilização de uma broca de aço carbono de $0.2 \mathrm{~mm}$ de diâmetro que é depositado no fundo de um tubo de ensaio com tampa rosqueada. Os tubos de ensaio contendo as amostras são então levados para as análises de isótopos de oxigênio e carbono.

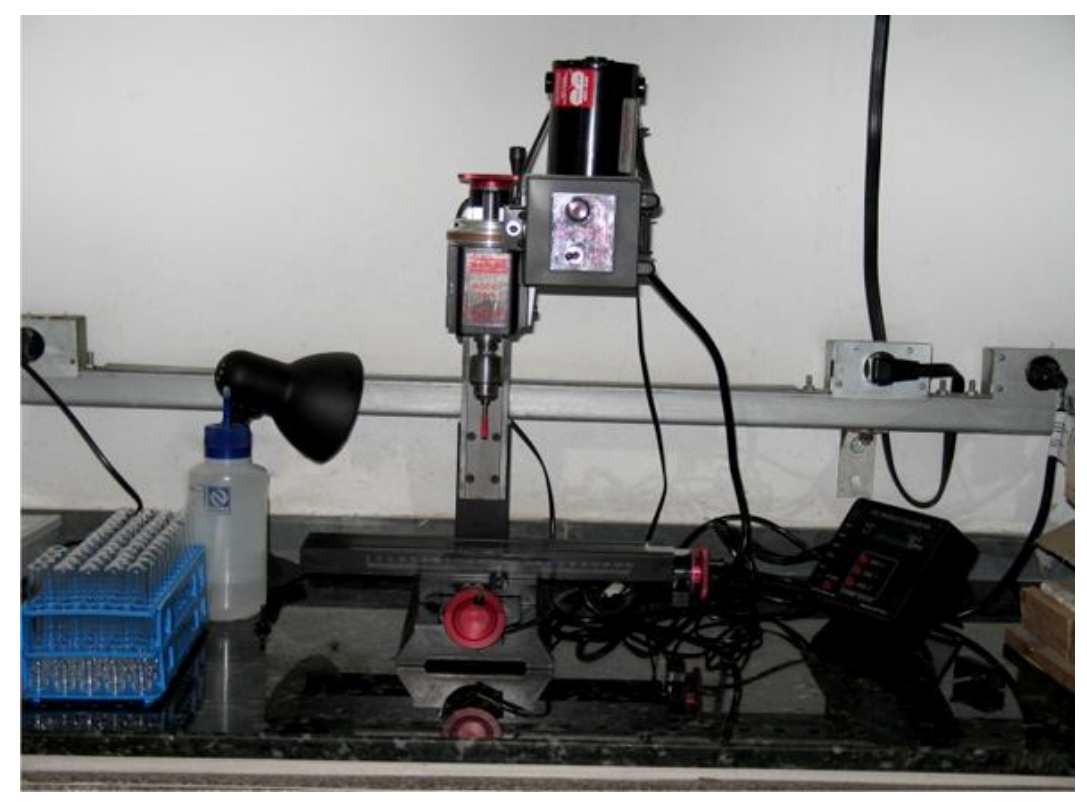

Figura 3.2 - Foto do microamostrador Sherline 5400, equipamento utilizado para coleta de carbonato de cálcio em espeleotemas e tubos de amostragem utilizados nas análises isotópicas. 
As amostras carbonáticas foram analisadas no laboratório de isótopos estáveis do Centro de Pesquisas Geocronológicas (LIE-CPGEO) do IGc/USP, com a utilização de um espectrômetro de massa de fonte gasosa, modelo DeltaPlus Advantage (Thermo Finningan). O princípio básico do procedimento para análíse das razões dos isótopos de $\mathrm{O}$ e $\mathrm{C}$ consiste na extração do dióxido de carbono $\left(\mathrm{CO}_{2}\right)$ liberado a partir da hidrólise ácida do $\mathrm{CaCO}_{3}$ com $\mathrm{H}_{3} \mathrm{PO}_{4}$ a $100 \%$, num reator sob temperatura controlada a $72^{\circ} \mathrm{C}$. $\mathrm{O} \mathrm{CO}_{2}$ é arrastado dos tubos de ensaio através de um fluxo de Hélio para o acessório tipo Finnigan Gas Bench, de onde é separado do vapor d'água dentre outros gases, por um sistema de cromatografia gasosa. Esse sistema opera de forma automatizada.

Já dentro do espectrômetro propriamente dito, um sistema composto por triplo coletor de $\mathrm{O} / \mathrm{C}$ realiza a determinação das razões isotópicas do $\mathrm{CO}_{2}$ através de uma fonte iônica. Os resultados analíticos são baseados na análise de nove alíquotas sequenciais de cada amostra. A precisão analítica é aproximadamente $0.08 \%$ para os valores das razões isotópicas de ${ }^{13} \mathrm{C} /{ }^{12} \mathrm{C}$ e $\pm 0.1 \%$ o para os valores de ${ }^{18} \mathrm{O} /{ }^{16} \mathrm{O}$ para as amostras contendo no mínimo $100 \mu \mathrm{g}$ de carbonato de cálcio.

As razões isotópicas são expressas através da notação delta $(\delta)$ de acordo com as equações 2 e 3. As razões isotópicas são expressas como a diferença entra a razão medida da amostra e o padrão de referência. No caso, foi utilizado padrão CM1 produzido pelo LIE-CPGeo calibrado cuja composição foi calibrada em relação ao padrão internacional VPDB (Vienna Pee Dee Belemnite), utilizado para rochas carbonáticas.

$$
\delta^{18} O=\frac{\left({ }^{18} O /{ }^{16} O\right) \text { amostra }-\left({ }^{18} O /{ }^{16} O\right) \text { padrão }}{\left({ }^{18} O /{ }^{16} O\right) \text { padrão }}
$$

Eq. 2

que pode ser escrito como:

$$
\delta^{18} O=\frac{\left({ }^{18} O /{ }^{16} O\right) \text { amostra }}{\left({ }^{18} O /{ }^{16} O\right) \text { padrão }}-1
$$

Eq. 3

Ao todo são analisados sequencialmente 65 amostras de $\mathrm{CaCO}_{3}$ por vez. A razão entre o número de amostras e padrão foi em geral de 1 para 6 amostras. Os valores de $\delta^{18} \mathrm{O}$ são expressos em \%o (parte por mil) em relação ao padrão de referência, o que torna muito mais fácil a leitura e a interpretação das razões entre isótopos estáveis. Assim a expressão da notação $\delta$ para os isótopos de C e O fica: 


$$
\begin{aligned}
& { }^{18} \mathrm{O}(\% o)=\left[\left({ }^{18} \mathrm{O} /{ }^{16} \mathrm{O}\right)\right)_{\text {amostra }}\left(\left({ }^{18} \mathrm{O} /{ }^{16} \mathrm{O}\right) \text { padrão }-1\right] \times 1000 \\
& { }^{13} \mathrm{C}(\% o)=\left[\left({ }^{13} \mathrm{C} /{ }^{12} \mathrm{C}\right)_{\text {amostra }} /\left({ }^{13} \mathrm{C} /{ }^{12} \mathrm{C}\right) \text { padrão }-1\right] \times 1000
\end{aligned}
$$

\subsection{Análise estatística de séries temporais}

Os dados paleoclimáticos do Holoceno foram tratados com base em duas séries: (i) formada pela integração dos registros da caverna Lapa Grande e Lapa Sem Fim formado a partir dos dados normalizados, tendo à vista eliminar a diferença entre os valores médios absolutos de $\delta^{18} \mathrm{O}$ entre as estalagmites das duas cavernas, como será visto adiante; e (ii) formada pelas séries temporais somente com dados das estalagmites da caverna Lapa Grande.

Para os dados do deglacial, a análise de séries temporais foi empregada nos trechos referentes aos eventos milenares Heinrich 1 e Young Dryas, a fim de se averiguar a correspondência da variabilidade climática de alta frequência do SMSA frente as mudanças da circulação oceânica atribuíveis a esses eventos. Nessas análises foram utilizadas as estalagmites LSF 16 e L12

Os métodos estatísticos utilizados têm os seguintes objetivos: 1) Separar os componentes estruturais dos componentes aleatórios; 2) Caracterizar a dinâmica das séries e 3) Detectar variações periódicas semelhantes entre os parâmetros analisados com fenômenos climáticos e forçantes climáticas conhecidas.

A seguir serão descritas brevemente algumas das análises que foram utilizadas na pesquisa:

\subsubsection{Análise espectral}

A análise espectral, ou função de densidade espectral, trata da decomposição em frequências da série temporal através de uma transformada. Esta transformada pode permitir melhor entendimento dos componentes da série temporal uma vez que eles são bem separados. Segundo Mangin (1984) foi demonstrado que a transformada da série temporal para o domínio das frequências corresponde à decomposição da variância dos componentes oscilatório da série expressos em frequência. A decomposição da variância pode ser obtida pela transformada de Fourier expressa pela equação 6 proposta por Jenkins e Watts (1968). 


$$
S(f)=2\left[1+2 \sum_{k=1}^{m} D(k) r(k) \cos (2 \pi f k)\right]
$$

Eq. 6

Onde:

$\mathrm{S}_{f}$ é a densidade espectral

$k$ é o tempo de deslocamento;

f é a frequiência, $f=j / 2 m \quad(\mathrm{j}=1 \ldots \mathrm{m})$;

$D(k)$ é uma função de ponderação necessária para assegurar que os valores de $\mathrm{S} f$ estimados não sejam tendenciosos.

Após o cálculo de $S_{f}$, é gerado um gráfico de frequência versus densidade espectral. Cada pico observado no gráfico indica a presença de um fenômeno periódico. Esta análise é uma maneira útil de avaliar a presença de componentes cíclicos em uma série temporal.

As análises de séries espectrais foram realizadas pelo software PAST v.2.7 (Hammer et al., 2001) através da análise de REDFIT desenvolvida por Shulz e Mudelsee (2002) e que utilizada o modelo autoregressivo AR1 para a determinação do "red noise" (ruído aleatório do sinal). O sistema de análise espectral empregada pelo REDFIT é versão aprimorada do periodograma de Lomb. Para estimar a probabilidade teórica de um frequência ser ou não atribuída a um componente aleatório, o espectro de "red noise" teórico (definido pelo modelo AR1) é graduado em uma escala de porcentagem composta pela distribuição dos valores de qui-quadrado. Dessa forma é possível estimar a probabilidade de uma frequência de natureza aparentemente não estocástica ocorrer na série temporal (Schulz e Mudelsee, 2002). As curvas de confiança marcam a amplitude espectral esperada se a série temporal fosse gerada por um processo AR1, em outras palavras, se tivesse uma natureza aleatória (Shulz e Mudelsee, 2002; Thompson, 1990). Dessa forma, os picos do espectro que excedem as curvas de confiança indicam frequências estatisticamente significativas.

\subsubsection{Análises de ondeletas (wavelets)}

A análise espectral tipo Fourier opera globalmente na série, e com ela não é possivel determinar em que ponto determinado evento periodico ocorre no registro, e nem o seu comportamento em diferentes escalas de resolução. Esta limitação pode ser superada com a análise 
de ondeletas (wavelets). Esta ferramenta fornece informação sobre a variabilidade dos processos em diferentes escalas de resolução de forma compacta e concisa (Labat et al., 2000). O objetivo básico do uso de ondeletas é alcançar uma representação completa de fenômenos localizados e transientes que ocorrem em diferentes escalas de tempo, através do ajuste de uma função "ondeleta" em diferentes escalas na série temporal, e com isso é possivel gerar uma representação gráfica da atuação de determinadas frequencias ao longo do tempo abragido pelo registro, sendo a intencidade do sinal registrada por um indice de cor. Vários tipos de funções de ondeletas podem ser aplicadas nesse método; o seu uso depende dos objetivos a serem atingidos na representação. Em estudos de registro paleoclimáticos, a ondeleta mais utilizada é a Morlet, que é uma função não ortogonal de uma onda plana modulada por uma Gaussiana:

$$
\psi_{0}(\eta)=\pi^{-1 / 4} e^{i \omega_{0} \eta} e^{-\eta^{2} / 2}
$$

onde $\omega_{0}$ é uma frequência não dimensional e $\eta$ é o tempo não dimensional. A transformada de ondeleta contínua de uma série discreta $X n$ é definida como a convolução de $X n$ com uma versão escalada e transladada de $\psi 0(\eta)$ :

$$
W_{n}(s)=\sum_{n^{\prime}=0}^{N-1} x_{n} \psi^{*}\left[\frac{\left(n^{\prime}-n\right) \delta t}{s}\right]
$$

Eq. 8

onde o (*) indica o complexo conjugado. Variando a escala (s) da ondeleta e com a translação ao longo do tempo (n), é possível construir uma figura mostrando a amplitude versus a escala de qualquer feição e como esta amplitude varia no tempo (Torrence e Compo, 1998).

\subsection{Análises de elementos traços}

As análises de elementos traços foram aplicadas às estalagmites LG12, LG11 e LG3, que juntas compreendem o final do deglacial e quase todo o Holoceno, até 1.4 mil anos A.P. As análises 
de elementos traços da estalagmite LG3 foram realizadas na Australian National University, e as estalagmites LG11 e LG12 foram realizadas no Centro de Geociencias de la Universidad Nacional Autonoma de Mexico. Ambos laboratórios utilizam um Excimer Laser Ablation Inductively Couplet Plasma Mass Spectrometry (ELA-ICP-MS) modelo Thermo X-Series II ICP-MS, produzido pela Resonetics LLC. A técnica de análise consiste no emprego de um laser de ablação de $193 \mathrm{~nm}$ de comprimento, com onda e fluência de 5-6 J/cm ${ }^{2}$ que percorre o material a ser analisado com uma frequência de amostragem de $5 \mathrm{~Hz}$ e velocidade de $0.8 \mathrm{~mm} / \mathrm{min}$. O material da amostra é ablacionado pelo laser e em seguida expulso da câmara de análise através de um fluxo de hélio, utilizado como gás de arraste, sendo o material produzido então analisado na forma de plasma por um espectrômetro de massa (ICP-MS). Os procedimentos analíticos adotados nas análises de elementos traços seguiram a metodologia estabelecida por Treble et al. (2003).

O equipamento de ICP-MS foi programado para quantificar os seguintes elementos/isótopos: ${ }^{7} \mathrm{Li},{ }^{23} \mathrm{Na},{ }^{24} \mathrm{Mg},{ }^{26} \mathrm{Mg},{ }^{29} \mathrm{Si},{ }^{30} \mathrm{Si},{ }^{31} \mathrm{P},{ }^{44} \mathrm{Ca},{ }^{46} \mathrm{Ca},{ }^{47} \mathrm{Ti},{ }^{48} \mathrm{Ca},{ }^{51} \mathrm{~V},{ }^{52} \mathrm{Cr},{ }^{53} \mathrm{Cr},{ }^{57} \mathrm{Fe}$ ${ }^{66} \mathrm{Zn},{ }^{88} \mathrm{Sr},{ }^{89} \mathrm{Y},{ }^{137} \mathrm{Ba},{ }^{138} \mathrm{Ba}{ }^{139} \mathrm{La},{ }^{140} \mathrm{Ce},{ }^{141} \mathrm{Pr},{ }^{206} \mathrm{~Pb},{ }^{208} \mathrm{~Pb},{ }^{232} \mathrm{Th}$ e ${ }^{238} \mathrm{U}$. Utilizando os dados de dois padrões (NIST610 e NIST612) com os valores obtidos, foram calculados as relações de $\mathrm{Mg} /{ }^{46} \mathrm{Ca}, \mathrm{Sr} /{ }^{46} \mathrm{Ca}, \mathrm{Ba} /{ }^{46} \mathrm{Ca} \mathrm{P} /{ }^{46} \mathrm{Ca}$ e $\mathrm{U} /{ }^{46} \mathrm{Ca}$. Os valores dos elementos magnésio, estrôncio e bário foram normalizados utilizando dados do padrão NIST610.

As estalagmites selecionadas foram cortadas em tabletes (de dimensão máxima $5 \mathrm{~cm}$ x 2.8 $\mathrm{cm}$ x $0.8 \mathrm{~cm}$ ) amostrados ao longo de eixo de crescimento de cada um dos espeleotemas e sempre da sua base para o topo, tanto do espécime quanto do tablete. Antes de cada análise foi feita a préablação das "trilhas" a serem analisadas para eliminar eventuais resquícios de materiais contaminantes. Nesta etapa o equipamento percorria os padrões e a amostra a uma velocidade de $8 \mathrm{~mm} / \mathrm{min}$ com o feixe de laser ativado a $50 \mathrm{~Hz}$.

Com intuito de facilitar a comparação entre as curvas relativas às taxas de Elemento/Ca e destas com as de isótopos estáveis, os dados de elementos traços foram normalizados segundo à fórmula:

$$
n=(y-\bar{y}) / \sigma
$$

onde:

$\mathrm{n}=$ dado normalizado;

$\mathrm{y}=$ dado de elemento/Ca (ex: Sr/Ca);

$\overline{\mathrm{y}}=$ média dos dados;

$\sigma=$ desvio padrão da série. 
No período entre 1.4 e 5.7 mil anos A.P. registrado na estalagmite LG3, foram realizadas ao todo 9711 análises para $\mathrm{Mg}, \mathrm{Ca}, \mathrm{Sr}, \mathrm{Ba}, \mathrm{U}$ e P. Os dados foram plotados em função da idade interpolada para cada ponto e foi ajustada uma curva de média móvel de 51 pontos para suavização do sinal. Para a estalagmite LG11 (5.2 a 10.25 mil anos A.P.) foram realizadas 31722 análises de $\mathrm{Ca}, \mathrm{Mg}, \mathrm{Sr}, \mathrm{Ba}$ e U. Os dados foram integrados aos da estalagmite LG3 em gráficos de Mg/Ca, $\mathrm{Sr} / \mathrm{Ca}, \delta^{18} \mathrm{O}$ e $\delta^{13} \mathrm{C}$ versus idade apresentados na Figura 6.12. Para melhor visualização das curvas de Elemento/Ca da amostra LG11 foi utilizada uma média móvel de 111 pontos.

Para a estalagmite LG12 foram realizadas ao todo 28940 análises de $\mathrm{Ca}, \mathrm{Sr}, \mathrm{Mg}, \mathrm{Ba}, \mathrm{P}, \mathrm{U}$. Da mesma forma como para as demais amostras, os dados são apresentados na forma de razões do elemento/Ca e comparados com os resultados de $\delta^{18} \mathrm{O}$ (Fig. 6.13 e 6.14). Para facilitar a visualização das flutuações das razões elementares, foi ajustada uma curva de média móvel de 31 pontos para as razões de $\mathrm{Mg} / \mathrm{Ca}$ (Fig. 6.13) e de 100 pontos para as razões de $\mathrm{Sr} / \mathrm{Ca}$ (Fig. 6.13).

\section{Conceitos sobre a aplicação das razões isotópicas de oxigênio e carbono em estalagmites na reconstituição da paleopluviosidade}

\subsection{Fracionamento isotópico do oxigênio no ciclo hidrológico}

O fracionamento isotópico ocorre devido a diferenças no fluxo entre isótopos, que por definição possuem massas distintas, gerando intercâmbio isotópico durante mudanças de estado físico em processos de evaporação, condensação, convecção e sublimação. O resultado disso é uma concentração desproporcional de isótopos leves e pesados entre diferentes fases de um mesmo composto. O fracionamento isotópico pode ser expresso por uma constante $\alpha$, que representa a razão entre intercâmbio isotópico de um reagente e um produto de mesma composição química:

$$
\alpha=\frac{R_{\text {reagente }}}{R_{\text {produto }}}
$$

Eq. 10

$$
\text { ex.: } \quad \alpha{ }^{18} O_{\text {agua-vapor }}=\frac{\left({ }^{18} O /{ }^{16} O\right)_{\text {água }}}{\left({ }^{18} O /{ }^{16} O\right)_{\text {vapor }}}
$$


A base físico-química para o fracionamento isotópico está na diferença da energia de ligação química entre os isótopos leves e pesados de um determinado composto. As diferenças na força das ligações para isótopos se refletem na reatividade química desses isótopos. Quanto mais pesado é um isótopo, maior será a energia potencial necessária para promover a quebra da ligação. A partir daí, conclui-se então que, a energia necessária para romper uma ligação química (condição necessária para que haja intercâmbio isotópico) difere entre moléculas com massas distintas (Clark e Fritz, 1997). A própria força da gravidade pode atuar na segregação entre isótopos de modo a restringr a mobilidade dos isótopos mais pesados.

Em reações que ocorrem em equilíbrio termodinâmico as ligações químicas e intermoleculares são continuamente quebradas e reorganizadas. Do ponto de vista estatístico, é muito mais provável que as ligação químicas mais fortes perdurem por mais tempo em relação as mais fracas, de modo que os isótopos mais pesados serão mais frequentente incorporados a fase líquida durante condensação. Portanto, nas fases sólidas das reações de precipitação de minerais ou na fase aquosa das reações de mudança de fase vapor-líquido, a razão de isótopos pesados sobre os leves será maior. Esse é o princípio que rege o fracionamento dos isótopos de oxigênio no ciclo hidrológico (Clark e Fritz, 1997).

Sob condições de equilíbrio isotópico, a razão entre os isótopos de oxigênio do $\mathrm{CaCO}_{3}$ dos espeleotemas, medida pelos valores de $\delta^{18} \mathrm{O}$, é controlado basicamente por duas variáveis: variação do $\delta^{18} \mathrm{O}$ da água de gotejamento e a temperatura da caverna. A magnitude das variações de $\delta^{18} \mathrm{O}$ no ciclo hidrológico, associada ao efeito de intercâmbio isotópico entre as fases vapor e chuva, são comumente maiores que aquelas associadas ao fracionamento por temperatura entre a calcita e a solução gotejante (Fairchild, 2006; Lachniet, 2009). Desse modo, variações na composição isotópica das águas de precipitação geram mudanças mais significativas nacomposição isotópica dos espeleotemas do que a variação anual de temperatura, sobretudo nas regiões tropicais.

Em termos gerais, a formação de precipitação sob a forma de chuva ou de neve ocorre em equilíbrio termodinâmico quando a umidade relativa do ar está próxima de 100\%. Já partindo de um sistema com temperatura constante e ausência de umidade relativa do ar, o equilíbrio isotópico é alcançado ao final do processo de evaporação, quando a umidade relativa do ar alcança os $100 \%$. Nessas condições de equilíbrio termodinâmico o intercâmbio isotópico passa a ocorrer na mesma taxa em ambos os sentidos das fases vapor-líquido (Clark e Fritz, 1997).

Em virtude do equilíbrio isotópico presente na condensação, a variação entre os isótopos de ${ }^{18} \mathrm{O}$ e ${ }^{2} \mathrm{H}$ (D) das precipitações segue uma relação linear de proporcionalidade, coerente com o modelo previsto estabelecido pela equação 12. Uma vez que a temperatura influencia diretamente o gradiente de energia necessário para romper essas ligações, o aumento da temperatura diminui o $\alpha$ : 
$1000 \ln \alpha_{\text {liquido-vapor }}=1.137\left(10^{6} / T_{k}^{2}\right)-0.4156\left(10^{3} / T_{k}\right)-2.0667$

Eq. 12

onde:

$\mathrm{T}=$ temperatura em Kelvin (refere-se à temperatura de mudança de fase).

Note que o fator de fracionamento é representado em termos de 1000ln $\alpha$ ao invés de ser simplesmente o valor absoluto de uma razão. Essa notação de $\alpha$ facilita muito a leitura do resultado, pois o valor torna-se mais próximo da notação \%o, por exemplo: durante a evaporação de água do mar a $25^{\circ} \mathrm{C}(298 \mathrm{~K})$, o fracionamento isotópico em equilíbrio dessa água será de $9.34 \%$ (Lachniet, 2009).

Tomando por base a molécula de $\mathrm{H}_{2} \mathrm{O}$, a diferença na pressão de vapor entre $\mathrm{H}_{2}{ }^{18} \mathrm{O}$ e ${ }^{2} \mathrm{HHO}$ proporciona um empobrecimento desproporcional dos isótopos pesados ${ }^{2} \mathrm{H}$ (deutério) e ${ }^{18} \mathrm{O}$ em relação ao leves ${ }^{1} \mathrm{H}$ e ${ }^{16} \mathrm{O}$, na fase liquida e consequente enriquecimento da fase vapor durante a evaporação. Segundo Clark e Fritz (1997), em condições de equilíbrio a relação entre H e O se estabelece numa taxa 8 vezes maior de $\delta \mathrm{D}$ em relação a $\delta^{18} \mathrm{O}$ na fase vapor. Pelo fato da precipitação ocorrer em condições de equilíbrio termodinâmico, essa relação também é expressa nas precipitações de chuva. A correlação linear entre $\delta^{18} \mathrm{O}$ e $\delta \mathrm{D}$ das precipitações que ocorrem no planeta define a linha meteórica global, representada pela sigla GMWL do inglês "global meteoric water line” (Fig. 4.1). A razão pela qual o coeficiente angular é $\approx 8$ se deve ao fato do fracionamento ocorrer em condições de equilíbrio. Nesse caso, relação entre os fatores de fracionamento de $\mathrm{H}$ e $\mathrm{O}$ da fase líquido-vapor é:

$$
s \approx \frac{10^{3} \ln \alpha^{2} H_{l-v}}{10^{3} \ln \alpha^{18} O_{l-v}}=8.2 \text { a } 25^{\circ} \mathrm{C}
$$

Eq. 13

note que o fator de fracionamento ( $\alpha$ ) é dado em termos de $10^{3} \ln \alpha$, que é uma notação que torna o $\alpha$ mais próximo da notação \%o. A equação mais detalhada da GMWL estabelece a seguinte relação: $\delta \mathrm{D}=(8.2 \pm 0.07) \times \delta^{18} \mathrm{O}+(11.27 \pm 0.065)($ Clark e Fritz, 1997) 


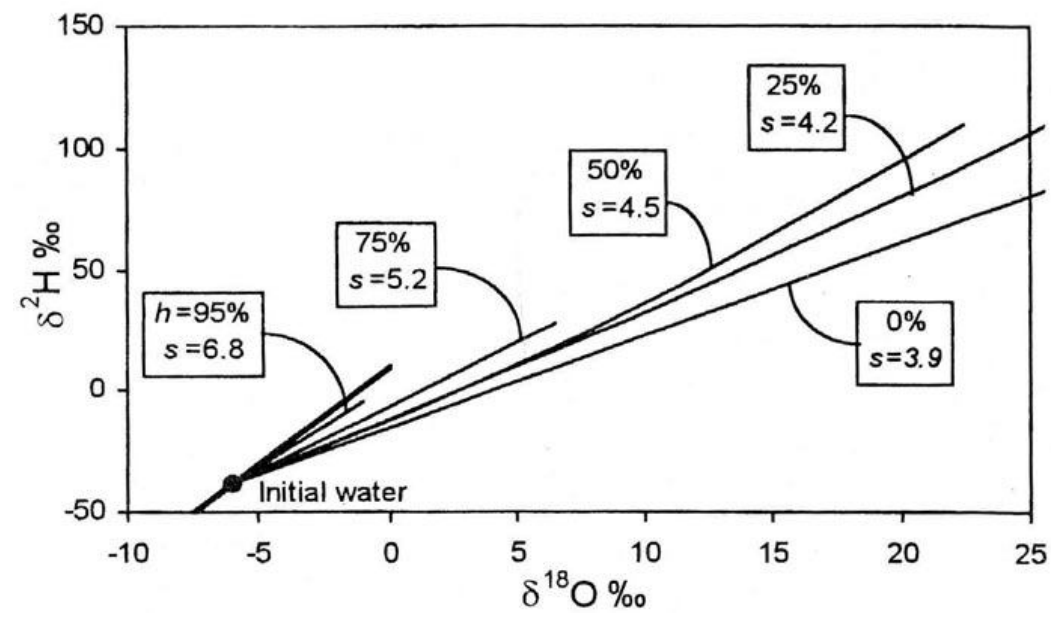

Figura 4.1 - Fracionamento isotópico da água da chuva em função do percentual de umidade relativa da atmosfera. O coeficiente angular da linha de água meteórica se aproxima de 8 em regiões de clima úmido. Modificado de Clark e Fritz (1997).

Em contraste com as condições de equilíbrio, quando a evaporação ocorre em ambientes onde a umidade relativa é inferior a 100\%, o fracionamento cinético ganha maior participação e consequentemente ambos $\delta^{18} \mathrm{O}$ e $\delta \mathrm{D}$ são lançados abaixo da GMWL, descrevendo uma reta com coeficiente angular <8 (Fig. 4.1). No caso onde as fontes de umidade são caracterizadas por pequenos reservatórios a exemplo de lagos, rios ou mesmo solos encharcados, mesmo que não haja fracionamento cinético, o progressivo empobrecimento da fonte em isótopos leves faz com que a composição isotópica do vapor acompanhe a do reservatório.

Para os estudos paleoclimáticos em espeleotemas, a linha de água meteórica local ou "local meteoric water line" (LMWL) deve ser estabelecida previamente, a partir de medições da composição isotópica da chuva no entorno da região estudada. É possível que a LMWL varie em relação à GMWL associada a ambientes muito evaporativos ou mesmo à participação de outras fontes de umidade, a exemplo de lagos e rios. Estabelecer a LMWL é crucial para os estudos paleoclimático, pois permite avaliar o efeito da evaporação da umidade do solo e/ou da água de gotejamento em relação à precipitação, de modo a estabelecer mais apropriadamente o sinal isotópico da água de gotejamento com as variações sazonais das precipitações e assim estimar a reciclagem da umidade. A LMWL pode ser obtida para diversas localidades do planeta a partir do banco de dados fornecido pela Agência Internacional de Energia Atômica (IAEA) que disponibiliza os dados coletados nas estações meteorológicas da "Global Network for Isotopes in Precipitation" (GNIP). A Figura 4.2 apresenta a composição isotópica da chuva monitorada pelo GNIP para a estação de Brasília-DF em comparação com a GMWL. 


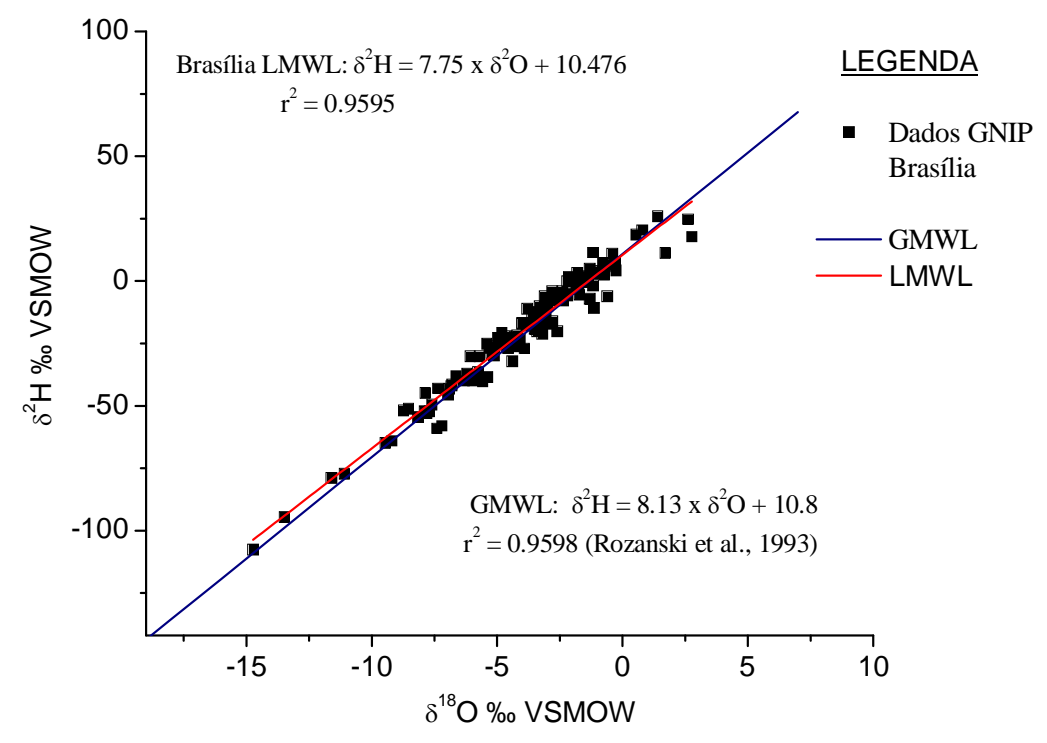

Figura $4.2-\delta^{18} \mathrm{O}$ e $\delta^{2} \mathrm{D}$ do GNIP da estação de Brasília-DF que formam a "local meoteoric water line" (LMWL) em comparação com a "global meteoric water line" (GMWL). A boa correlação entre a composição isotópica da chuva com a média das precipitações globais indica que, de modo geral, o fracionamento isotópico ocorre em condições de equilíbrio isotópico na região central do Brasil.

$\mathrm{O}$ valor do coeficiente angular $=7.75$, estabelecido pela reta que passa pelos pontos lançados no gráfico de $\delta^{18} \mathrm{O}$ por $\delta \mathrm{D}$ para a precipitação na estação de Brasília, indica que outros fatores como: diferenças na área fonte de umidade, evaporação da água dos solos, pouco contribuem no sinal isotópico das chuvas.

\subsection{O $\delta^{18} \mathrm{O}$ e $\mathrm{o} \delta^{13} \mathrm{C}$ no sistema cárstico - fatores que afetam a composição isotópica da água de gotejamento.}

Uma vez que os processos climáticos associados à dinâmica atmosférica geram variabilidade na composição isotópica das precipitações, a exemplo do "amount effect", compreender como esse sinal isotópico pode ser impresso no registro geológico é fundamental para a paleoclimatologia. Os fatores que podem influenciar na composição isotópica de $\mathrm{O}$ e $\mathrm{C}$ da calcita vão além da variabilidade climática regional. Há basicamente três outros fatores de importância local que podem influenciar o sinal isotópico da água de gotejamento e consequentemente da geoquímica dos espeleotemas, como: cobertura de vegetação/solo, aquífero cárstico (efeito reservatório) e as taxas de precipitação da calcita. Todos esses fatores são independentemente importantes e são atuantes desde o princípio da infiltração da água até a formação do espeleotema (Fairchild et al., 2006). 


\subsubsection{Influência dos solos e da cobertura vegetal}

Durante a percolação no solo, pode haver aumento dos valores de $\delta^{18} \mathrm{O}$ da água meteórica logo nos primeiros metros que ela atravessa o epicarste devido à evaporação. Parte significativa dessa água pode ser evaporada ou mesma consumida durante a evapotranspiração das plantas. A magnitude da alteração dos valores de $\delta^{18} \mathrm{O}$, gerada por esses processos, será relacionada com a umidade relativa dos poros do solo e o volume de água evaporada (Lachniet, 2009).

A evaporação irá resultar em aumento do $\delta^{18} \mathrm{O}$ da água do solo, ao passo que evapotranspiração, por não gerar fracionamento isotópico da água, não altera significativamente o sinal isotópico da mesma. Entretanto, pelo fato da cobertura vegetal aumentar a área sombreada, o desenvolvimento de florestas pode reduzir a evaporação de água do solo, conservando o sinal isotópico original da água das precipitações. Portanto, regiões de clima árido e de vegetação esparsa, onde a evaporação é intensa, estão mais sujeitas ao aumento do valor de $\delta^{18} \mathrm{O}$ da água do solo (Lachniet, 2009). É possível ainda que, em virtude da intensa evaporação dessas regiões, praticamente toda a água evapore antes mesmo de atingir o conduto cárstico (Lachniet, 2009). Consequentemente o desenvolvimento de espeleotemas pode ter uma componente sazonal muito importante, crescendo apenas nos períodos de chuvas mais frequentes ou somente durante eventos climáticos caracterizados por precipitações anomalamente mais altas. Por exemplo, Wang et al. (2004) demonstraram que o crescimento de estalagmites da caverna Toca da Boa Vista, localizada na região semi-árida do norte da Bahia, ocorreu apenas durante os eventos Heinrich. Esses eventos climáticos são caracterizados por períodos de frio extremos no Hemisfério Norte, originalmente observados em registros de paleotemperatura da superfície do Mar do Atlântico Norte e estão diretamente associados com o deslocamento para sul da ZCIT (Cruz et al., 2009b).

O impacto da evaporação de água do solo na composição isotópica do oxigênio e do hidrogênio pode ser avaliado através de estudos de monitoramento da água do solo no transcorrer de um ano. No caso dos valores de $\delta \mathrm{D}$ e $\delta^{18} \mathrm{O}$ caírem em cima ou mesmo muito próximos da GMWL significa que a evaporação não foi significativa na modificação da assinatura isotópicas da água meteórica (Cruz et al., 2009b).

Em se tratando da composição isotópica da água de infiltração, o solo e o tipo de vegetação exercem influência principalmente sobre os isótopos de carbono. Em solos ricos em matéria orgânica, a acidificação da água pela formação de $\mathrm{H}_{2} \mathrm{CO}_{3}$ é maior em função da elevada concentração de $\mathrm{CO}_{2}$ produzido pela respiração celular das raízes das plantas e pela decomposição da matéria orgânica (Clark e Fritz, 1997; Amundson et al., 1998; Dorale et al., 1998; Kaufmann e Dreybrodt, 2004; Oster et al., 2010).

A origem do carbono orgânico $(\mathrm{CO})$ incorporado aos espeleotemas vem do $\mathrm{CO}_{2}$ dissolvido 
na água durante sua percolação pelo solo. A pressão parcial de $\mathrm{CO}_{2}\left(P_{\mathrm{CO} 2}\right)$ é muito maior no solo do que na atmosfera e é assim proporcional a produção biogênica relacionada aos processos de decomposição da matéria orgânica e da respiração celuluar que ocorre nas raízes das plantas (Ford e Williams, 2007). $\mathrm{O} \mathrm{CO}_{2}$ incorporado forma quatro espécies: $\mathrm{CO}_{2(\mathrm{aq})}, \mathrm{H}_{2} \mathrm{CO}_{3}$ (ácido carbônico), $\mathrm{HCO}_{3}{ }^{-}$(íon bicarbonato) e $\mathrm{CO}_{3}$ (íon carbonato), que juntas formam carbono total dissolvido (CTD), sendo o carbono inorgânico dissolvido (CID) sua fração inorgânica. A ocorrência desses compostos é controlada pelo ph, pela temperatura e pela $P_{\mathrm{CO}_{2}}$ do solo e taxa de dissolução das rocha carbonática encaixante (Clark e Fritz, 1997; Amundson et al., 1998; Kaufmann e Dreybrodt, 2004). A sequência de reações abaixo ilustra o processo de dissolução do carbonato e a formação dos demais compostos que juntos compõem CTD da água de infiltração:

$$
\mathrm{CO}_{2 \text { (gás) }}+\mathrm{H}_{2} \mathrm{O} \leftrightarrow \mathrm{H}_{2} \mathrm{CO}_{3} \leftrightarrow \mathrm{H}^{+}+\mathrm{HCO}_{3}^{-} \leftrightarrow 2 \mathrm{H}^{+}+\mathrm{CO}_{3}^{-}
$$

A composição isotópica do carbono orgânico dos solos pode ser função do tipo de vegetação dominante, uma vez que os valores de $\delta^{13} \mathrm{C}$ dos vegetais com metabolismo do tipo $\mathrm{C} 3$ e $\mathrm{C} 4$ variam em intervalos específicos. Os vegetais $\mathrm{C} 4$, de modo geral, são representados pelas gramíneas características de clima seco e apresentam valores de $\delta^{13} \mathrm{C}$ que oscilam entre -10 a $-16 \%$, com valor médio de $-13 \%$. Os vegetais C3 são representados pelas plantas de porte arbóreo em geral e são, portanto, associadas a um clima mais úmido e apresentam valores de $\delta^{13} \mathrm{C}$ que variam entre 24 a -30\%o, com valor médio de $-23 \%$ (Boutton, 1996; Pessenda et al., 1996). Por exemplo, na região do município de Salitre de Minas, localizado a $300 \mathrm{~km}$ a oeste de Belo Horizonte e a $\approx 400$ km a sudoeste da caverna Lapa Sem Fim, a vegetação de porte arbóreo, atualmente classificada como mata estacional semidecídua, apresenta valores de $\delta^{13} \mathrm{C}$ da matéria orgânica ao redor de -24 a $-27 \%$ (Pessenda et al., 1996).

A maneira pela qual a atividade biológica modifica o $\delta^{13} \mathrm{C}$ do CTD da água de infiltração inicia-se com a liberação de $\mathrm{CO}_{2}$ durante a decomposição da matéria orgânica e pela respiração celular que ocorre nas raízes das plantas. A decomposição da matéria orgânica vegetal gerada pelas bactérias libera $\mathrm{CO}_{2} \operatorname{com} \delta^{13} \mathrm{C}$ muito próximo do $\delta^{13} \mathrm{C}$ da matéria orgânica, que por sua vez, reflete a composição isotópica das plantas dominantes, no caso plantas C3 ou C4. Tomando como exemplo um solo com $\delta^{13} \mathrm{C}=-27 \%$ (vegetação predominantemente $\mathrm{C} 3$ ) o $\delta^{13} \mathrm{C}$ do $\mathrm{CO}_{2 \text { (gás) }}$ do solo será de $\approx$ - 22\%o. Nesse caso um fracionamento da ordem de $4 \%$ pode vir a ocorre por difusão gerada pela perda preferencial de ${ }^{12} \mathrm{CO}_{2}$ para a atmosférica em virtude do gradiente de $P_{\mathrm{CO} 2}$ entre o solo e a atmosfera (Boutton, 1996; Clark e Fritz, 1997; Amundson et al., 1998).

As reações que se processam durante a formação do CTD, desde a dissolução do $\mathrm{CO}_{2}$ na 
água $\left(\mathrm{CO}_{2 \text { (gás) }} \leftrightarrow \mathrm{CO}_{2(\mathrm{aq})}\right)$ até a formação dos demais compostos, fracionam o $\mathrm{C}$ isotopicamente. $\mathrm{O}$ fracionamento mais significativo, da ordem de $10 \%$, ocorre durante a hidratação do $\mathrm{CO}_{2 \text { (aq) }}$ para a formação do íon $\mathrm{HCO}_{3}{ }^{-}$. A partir desse ponto pouca coisa ocorre em termos de fracionamento isotópico do $\mathrm{C}$ até a precipitação da calcita, exceto nos casos em que a precipitação da calcita não ocorra em equilíbrio isotópico ou associado a processos de destilação Rayleigh durante a precipitação de calcita nos condutos (Clark e Fritz, 1997; Fairchild, 2006).

$\mathrm{O}$ valor de $\delta^{13} \mathrm{C}$ nos espeleotemas é geralmente da ordem de $-16 \%$ a $+2 \%$ e depende da proporção entre $\mathrm{CO}$ e CID do carbono total dissolvido na água de percolação, assim como da variação na composição isotópica da matéria orgânica, por exemplo, do percentual relativo entre plantas C3 e C4 ao longo do tempo (Fairchild, 2006). Entretanto os valores do $\delta^{13} \mathrm{C}$ da calcita são também gerados por fracionamento isotópico em condições de desequilíbrio no momento da deposição do espeleotema. Apesar da composição isotópica do carbono ser comumente relacionada a variações no tipo de vegetação (Dorale et al., 1998), outros fatores como a produtividade de $\mathrm{CO}_{2}$ biogênico no solo ou mesmo a erosão do solo podem modular o $\delta^{13} \mathrm{C}$ dos espeleotemas (Cruz et al., 2006b). O melhor exemplo disso é observado nos estudos paleoclimáticos de regiões onde não ocorrem plantas C4, como na Austrália (Desmarchelier et al., 2000) e na Nova Zelândia (Williams et al., 2005; Hellstrom e McCulloch, 2000). Nesse contexto, fatores climáticos relacionados a variações da disponibilidade hídrica ou mesmo variações de temperatura podem afetar a produtividade do $\mathrm{CO}_{2}$ biogênico no solo e consequentemente a composição isotópica das águas de infiltração (Cruz et al., 2006b).

\subsubsection{Aquífero cárstico - efeito reservatório}

As mudanças na composição isotópica da água de gotejamento devido a ocorrência de eventos de chuva podem ser atenuadas ou mesmo se tornarem pouco distintas em virtude da mistura com águas mais antigas na zona vadosa. Isso, em tese, poderia resultar em variações espaciais do $\delta^{18} \mathrm{O}$ entre espeleotemas de uma mesma caverna alimentados por gotejamentos com características hidrológicas distintas, como diferentes razões de mistura entre águas de infiltração mais antigas e mais novas. Em cavernas rasas, nas quais a espessura da zona vadosa é pequena, esse problema é minimizado, justamente porque os reservatórios de água do aquífero suspenso são pequenos e o tempo de percolação da água desde o solo até caverna é mais curto (Cruz et al., 2009b).

De modo geral, a água de infiltração em direção a cavernas mais rasas apresenta período de residência mais curto o que as tornam ideais para estudos paleoclimáticos de alta resolução, ao passo que as cavernas mais profundas são indicadas para estudos paleoclimáticos em mais longa 
escala temporal. Nessas últimas, os gotejamentos são mais constantes ao longo do tempo, o que pode proporcionar a formação de espeleotemas com crescimento mais contínuo e que abrangem um intervalo maior de tempo (Cruz et al., 2009b). Nesse contexto, o efeito reservatório parece não ser tão significante na interpretação do sinal climático dos registros isotópicos das cavernas Lapa Grande e Lapa Sem Fim visto que a camada de rocha carbonática que compõem o reservatório vadoso não ultrapassa mais que 100 e $30 \mathrm{~m}$ de espessura, respectivamente.

Em regiões tropicais de clima úmido, estudos de monitoramento isotópico e geoquímico das águas de gotejamento sugerem curtos períodos de residência da água meteórica nos condutos cársticos; em geral menores que 6 meses (Lachniet, 2009; Karmann et al., 2007). Em alguns casos, estudos de monitoramento da água de gotejamento indicam que o fluxo de água subterrânea dentro da zona vadosa ocorre segundo o efeito pistão, exercida pela coluna d’água após intenso período de chuva. Um exemplo clássico do efeito pistão é a variação sazonal da composição isotópica da água de gotejamento de forma semelhante em pontos distintos da caverna Santana (sudeste do estado de São Paulo) que apresentam espessuras de cobertura carbonática variande entre e 100 e 350m. Isso indica que variações de espessura do reservatório podem não obliterar o sinal isotópico produzido pela variação mensal de chuvas devido ao efeito pistão sobre a hidrologia dos gotejamentos (Cruz et al., 2005b).

\subsubsection{Precipitação do $\mathrm{CaCO}_{3}$}

Para que os valores de $\delta^{18} \mathrm{O}$ reflitam as variações do ciclo hidrológico é necessário que, durante a precipitação da calcita, o fracionamento do oxigênio ocorra em condições de equilíbrio isotópico. A precipitação da calcita pode ser descrita pela seguinte relação:

$$
\mathrm{Ca}^{2+}+2 \mathrm{HCO}_{3}^{-} \leftrightarrow \mathrm{CaCO}_{3}+\mathrm{CO}_{2}+\mathrm{H}_{2} \mathrm{O}
$$

A precipitação do $\mathrm{CaCO}_{3}$ pode tanto ocorrer sob condições de equilíbrio isotópico, como em condições de desequilíbrio, associados a processos de fracionamento cinético. $\mathrm{O}$ fracionamento em equilíbrio isotópico ocorre quando a solução atinge o ponto de equilíbrio termodinâmico, possibilitando o intercâmbio isotópico entre o oxigênio do $\mathrm{CaCO}_{3}$ com o da molécula de $\mathrm{H}_{2} \mathrm{O}$ no gotejamento. Nessas condições o $\delta^{18} \mathrm{O}$ do $\mathrm{CaCO}_{3}$ será estabelecido de acordo com o fator de fracionamento $\alpha$ que varia de modo inversamente proporcional com a temperatura, como pode ser observado pela equação 14 . 


$$
1000 \ln \alpha_{\text {calcita-ägua }}=18.03\left(10^{3} / T\right)-32.42
$$

O fracionamento em equilíbrio também depende da mineralogia do carbonato, por exemplo, no caso dos polimorfos calcita e aragonita (normalmente formada em soluções com maior teor de $\mathrm{Mg}$ ). Como a aragonita apresenta um fator de fracionamento ligeiramente maior do que o da calcita seu valor de $\delta^{18} \mathrm{O}$ será $\approx 0.8 \%$ maior que o da calcita em condições de equilíbrio a $25{ }^{\circ} \mathrm{C}$ (Lachniet, 2009).

Em casos em que a formação da calcita é induzida por processos que aceleram a reação de precipitação do $\mathrm{CaCO}_{3}$, as condições de equilíbrio químico deixam de existir, pois o intercâmbio isotópico entre o $\mathrm{CaCO}_{3}$ e a água não segue a constante de fracionamento definida. Nessas condições operam os processos de fracionamento cinético, caracterizado pelo deslocamento do equilíbrio químico para o lado dos produtos, que no caso da evaporação resulta em valores mais altos de $\delta^{18} \mathrm{O}$ da calcita pelo enriquecimento de ${ }^{18} \mathrm{O}$ no gotejamento. Os dois principais processos que podem induzir a precipitação de $\mathrm{CaCO}_{3}$ são: a desidratação e a degaseificação rápida. A desidratação ocorre pela retomada das condições de equilíbrio termodinâmico através da formação $\mathrm{H}_{2} \mathrm{O}$ em função da baixa pressão de vapor na atmosfera da caverna. A degaseificação atua através da liberação de $\mathrm{CO}_{2}$ da solução de gotejamento de forma gradual, em condições de equilíbrio isotópico. No entanto, ela pode ser acelerada em virtude do baixo $P_{\mathrm{CO} 2}$ da atmosfera da caverna, o que também induz ao fracionamento cinético. Portanto, os processos de fracionamento cinético associados à desidratação e a degaseificação ocorrem principalmente em cavernas que apresentam baixa umidade relativa do ar ou baixa $P_{\mathrm{CO} 2}$, as quais dificultam as interpretações paleoclimáticas nos estudos com espeleotemas. Nessas cavernas, a relação do clima com a composição isotópica dessas formações é obliterada no momento que a composição isotópica do gotejamento passa a não depender simplesmente da variação do $\delta^{18} \mathrm{O}$ da chuva, mas de outros fatores relacionados a fatores ambientais da caverna (Fairchild et al., 2006; McDermott, 2004).

Nesse contexto, variações da concentração isotópicas de C podem decorrer também de alterações sazonais da circulação atmosférica no interior da caverna associada às variações de temperatura, que podem ocorrer de forma independente do fracionamento dos isótopos de oxigênio (Spötl et al., 2005, Boch et al., 2011). Tendo a vista que a composição do ar no interior da caverna modula a degaseificação, por perda de $\mathrm{CO}_{2}$ entre a água de gotejamento e a atmosfera, alterações da concentração de $\mathrm{CO}_{2}$ induzida por mudanças do gradiente térmico entre a caverna e o ambiente externo podem afetar a composição isotópica do espeleotemas (Spötl et al., 2005; Boch et al., 2011). Entretanto, no norte de Minas Gerais a pequena variação sazonal de temperatura entre as 
cavernas e o exterior tende a invalidar esse mecanismo como um fator preponderante na assinatura isotópica do $\delta^{13} \mathrm{C}$ dos espeleotemas.

De acordo com Dreybrodt (2008) e Mickler et al. (2004) o efeito do fracionamento cinético na composição isotópica do oxigênio é mais brando quando comparado com o carbono em função do contínuo processo de hidratação do $\mathrm{H}_{2} \mathrm{CO}_{3}$, como pode ser visto nas reações abaixo, o que consequentemente, leva a um tamponamento do processo de enriquecimento isotópico de oxigênio. Assim, ao passo que o $\delta^{13} \mathrm{C}_{\text {do } \mathrm{HCO}_{3}}{ }^{-}$experimenta considerável enriquecimento isotópico associado a um processo de destilação Rayleigh gerado pelo escape de $\mathrm{CO}_{2}$, o $\delta^{18} \mathrm{O}$ sofre pouca ou nenhuma alteração em função da hidratação do $\mathrm{H}_{2} \mathrm{CO}_{3}$ (Dreybrodt, 2008; Lachniet, 2009). Nesse momento, é importante levarmos em consideração que a concentração de moléculas de $\mathrm{H}_{2} \mathrm{O}$ em relação às moléculas de $\mathrm{H}_{2} \mathrm{CO}_{3}$ e $\mathrm{HCO}_{3}{ }^{-}$na solução em questão é pelo menos 10 mil vezes maior, criando um efeito reservatório que oblitera o efeito da destilação Rayleight sobre os isótopos de oxigênio (Dorale e Liu, 2009; Dreybrodt, 2008; Lachniet, 2009; Mickler et al., 2004).

$$
\begin{aligned}
& \mathrm{H}_{2} \mathrm{CO} 3 \leftrightarrow \mathrm{H}_{2} \mathrm{O}+\mathrm{CO}_{2} \\
& \mathrm{HCO}_{3}{ }^{-} \leftrightarrow \mathrm{OH}-+\mathrm{CO}_{2}
\end{aligned}
$$

Em casos aonde a deposição de calcita venha a ocorrer lentamente, haverá também maior intercâmbio isotópico de oxigênio do $\mathrm{H}_{2} \mathrm{CO}_{3}{ }^{-}$com o $\mathrm{H}_{2} \mathrm{O}$ da solução, possibilitando que o $\mathrm{HCO}_{3}{ }^{-}$ atinja o equilíbrio isotópico com as moléculas de $\mathrm{H}_{2} \mathrm{O}$ (Dreybrodt, 2008; Lachniet, 2009;).

Uma maneira de avaliar o efeito do fracionamento cinético nas razões isotópicas de oxigênio e carbono, sobretudo nas razões de oxigênio, é o teste de Hendy. Amplamente citado na literatura, o teste de Hendy consiste na comparação dos valores de $\delta^{13} \mathrm{C}$ e $\delta^{18} \mathrm{O}$ da calcita ao longo do eixo de crescimento do espeleotema e ao longo de uma mesma camada (Hendy, 1971). Condições de fracionamento cinético podem ser indicadas quando a correlação estatística positiva entre $\delta^{13} \mathrm{C}$ e $\delta^{18} \mathrm{O}$ de amostras tomadas ao longo do eixo for alta ou mesmo quando há variação dos valores de $\delta^{18} \mathrm{O}$ ao longo de uma mesma camada. Quando a deposição de calcita ocorre em condições desequilíbrio, o processo cinético atua tanto no fracionamento dos isótopos de $\mathrm{O}$ como nos de $\mathrm{C}$, apesar de que de ser geralmente mais intenso nos isótopos de carbono (Dreybrodt 2008; Dorale e Liu, 2009). Segundo Lachniet (2009) apesar do teste de Hendy ser amplamente utilizado para averiguar as condições de equilíbrio isotópico, há condições em que o teste pode falhar como caso em que os isótopos de $\mathrm{C}$ e $\mathrm{O}$ co-variam em função de aspectos climáticos relacionados ao ciclo hidrológico. 


\section{Conceitos sobre a variação de elementos traços em espeleotemas}

Em geral, as variações dos teores de elementos traços nos espeleotemas são relacionadas a parâmetros ambientais e climáticos, comumente associados a variações do ciclo hidrológico (Fairchild e Treble, 2008). Dentre os fatores que mais influenciam variações na concentração dos elementos traços nas soluções de percolação que formam as estalagmites estão: mudanças da temperatura da caverna, alterações da taxa de crescimento dos espeleotemas, deposição de calcita na rede de condutos vadosos (PCP) ou na ponta das estalactites, variações da taxa de dissolução da rocha carbonática e variações da produtividade orgânica dos solos (Fairchild e Treble, 2008; Karmann et al., 2007, Johnson et al., 2006). Os elementos traços podem ser incorporados da solução para os espeleotemas por diferentes mecanismos. A incorporação ocorre mais usualmente entre cátions bivalentes na solução, a exemplo do $\mathrm{Sr}^{2+}, \mathrm{Mg}^{2+}$ e $\mathrm{Ba}^{2+}$ (juntamente com $\mathrm{Mn}^{2+}$ e $\mathrm{Fe}^{2+}$ nas soluções mais reduzidas), que substituem o $\mathrm{Ca}^{2+}$ do retículo cristalino dos carbonatos. Outros elementos, a exemplo do U, que apresenta um raio iônico muito maior, podem ser incorporados no retículo cristalinos dos minerais calcíticos sob a forma de materiais detrítico finos, bem como colóides microscópicos (Fairchild e Treble 2008).

Dentre as análises de elementos traços recentemente aplicadas em estalagmites para reconstituição da variação do regime hidrológico, as variações de $\mathrm{Mg} / \mathrm{Ca}$ e $\mathrm{Sr} / \mathrm{Ca}$ estão entre as que apresentam os sinais mais robustos quando comparadas com os índices isotópicos de $\delta^{18} \mathrm{O}$ e $\delta^{13} \mathrm{C}$ (Karmann et al., 2007; Fairchild et al., 2000; Fairchild e Treble, 2008; Huang e Fairchild, 2001, Cruz et al., 2007). No ambiente cárstico, há quatro fatores que basicamente controlam os processos responsáveis por gerar variações nas razões elementares de $\mathrm{Mg} / \mathrm{Ca}$ e $\mathrm{Sr} / \mathrm{Ca}:$ 1) dissolução preferencial de calcita em relação à dolomita, de modo a possibilitar o aumento da concentração de $\mathrm{Mg}$ da solução percolante. Porém para que haja uma dissolução preferencial de $\mathrm{Mg}$ em relação a Ca nos dolomitos é necessário um longo período de interação entre a água de infiltração e a rocha encaixante. 2) o mecanismo do "prior calcite precipitation" (PCP) que consiste na precipitação de

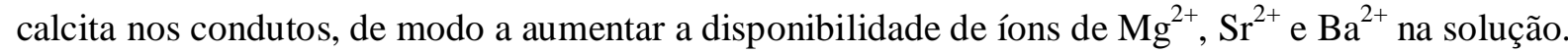
3) dissolução incongruente de dolomita que, de acordo com Fairchild et al. (2000), é pouco significante na concentração $\mathrm{Mg}$ e $\mathrm{Sr}$ da solução. 4) lixiviamento seletivo de $\mathrm{Mg}^{2+}$ e $\mathrm{Sr}^{2+}$ em relação ao Ca gerado pela dissolução incongruente da calcita (Sinclair, 2010). Esse fenômeno pode vir a ocorrer, por exemplo, quando o Ca é sequestrado sob a forma de precipitados durante um processo de congelamento ou quando a precipitação é induzida por condições muito secas.

Normalmente, os mecanismo que regem as variações das razões elementos/Ca nos espeleotemas levam em conta diferenças no coeficiente de partição (D) dos cátions envolvidos, a exemplo dos íons de $\mathrm{Sr}\left(\mathrm{D}_{\mathrm{Sr}}=(\mathrm{Sr} / \mathrm{Ca})_{\text {calcita }} /(\mathrm{Sr} / \mathrm{Ca})_{\text {solução }}\right)$ e $\mathrm{Mg}\left(\mathrm{D}_{\mathrm{Mg}}=(\mathrm{Mg} / \mathrm{Ca})_{\text {calcita }} /(\mathrm{Mg} / \mathrm{Ca})_{\text {solução }}\right)$, 
cujo os valores de D são menores que 1. Nesse contexto temos o fenômeno do PCP, que é fortemente controlado pela variação do nível d'água (N-A) no aqüífero vadoso sobre a caverna. Em períodos mais secos o aumento da espessura da zona vadosa, gerada por rebaixamento do N-A, aumenta a aeração nos condutos induzindo a deposição de calcita por degaseificação ainda durante a fase de percolação da solução no perfil solo-caverna (Fairchild et al., 2000; Huang e Fairchild, 2001). Uma vez que o Ca é preferencialmente incorporado no retículo cristalino da calcita em relação a outros elementos da família dos alcalinos terrosos, ocorre aumento das razões de $\mathrm{Mg} / \mathrm{Ca}$ e $\mathrm{Sr} / \mathrm{Ca}$ da solução de infiltração e consequentemente dos carbonatos depositados nos espeleotemas induzido pelo PCP (Cruz et al., 2009b; Fairchild, 2008; Huang e Fairchild, 2001; Karmann et al., 2007). Mesmo em regiões de clima tropical úmido, as variações sazonais de precipitação podem ser suficientes para gerar alterações significativas das razões elementares de $\mathrm{Mg} / \mathrm{Ca}$ e $\mathrm{Sr} / \mathrm{Ca}$ na água de gotejamento, como foi demonstrado por Karmann et al. (2007), no estudo de monitoramento realizado na área da caverna Santana, sul do estado de São Paulo.

A exemplo do que ocorre durante a PCP nas fases secas, a variação da concentração de $\mathrm{Mg}$ pode ocorrer associada a processos de evaporação, como observado por Railsback et al. (1994) em estudos de elementos traços em estalagmites coletadas na caverna Drotsky, no noroeste de Botsuana, África. Como constatado pelos autores, o aumento da razão $\mathrm{Mg} / \mathrm{Ca}$ gerado durante esse processo permitiu inclusive alterações mineralógicas do espeleotema, com alternâncias de níveis de aragonita e calcita depositada durante as fases mais secas e úmidas, respectivamente.

Num processo reverso ao observado durante o PCP, a incorporação preferencial de $\mathrm{Sr}$ e $\mathrm{Mg}$ nas soluções de percolação podem estar relacionadas a uma maior taxa de dissolução do carbonato encaixante ou mesmo aumento da mobilidade de íons associado ao aumento da acidificação da água de infiltração (Fairchild et al., 2000; van Beynen, 2008).

O principal fator condicionante da remoção preferencial de íons de $\mathrm{Mg}^{2+} \mathrm{e} \mathrm{Sr}^{2+}$, entre outros, durante a dissolução incongruente da calcita ainda é controverso, sobre tudo em cavernas localizadas em regiões tropicais, onde trabalhos sobre o tema são ainda escassos. De acordo com McGillen e Fairchild (2005) a razão fluido/rocha é o principal fator que age na dissolução incongruente da calcita. Entretanto, segundo Fairchild (2000) o aumento das razões de Sr/Ca e $\mathrm{Mg} / \mathrm{Ca}$ nas águas de infiltração, associadas a processos de dissolução incongruente da calcita, pode ser relacionado com a mobilização preferencial de espécies solúveis de $\mathrm{Mg}$ e $\mathrm{Sr}$ produzidas durante o intemperismo do epicarste. Van Beynen et al. (2008) relaciona tanto o aumento das concentrações de $\mathrm{Sr}$ em espeleotemas da caverna Briars, Flórida quanto à diminuição das razões de $\delta^{13} \mathrm{C}$ ao aumento da produtividade dos solos. O aumento da produtividade dos solos aumenta a concentração de ácido carbônico que, por sua vez, promove tanto o aumento das taxas de dissolução da rocha carbonática encaixante como também a solubilidade de cátions como o $\mathrm{Sr}^{2+}$, por exemplo. 
A decomposição da matéria orgânica no solo também pode aumentar a incorporação de outros elementos aos espeleotemas, dentre ele o $\mathrm{P}$ e o U que normalmente se alojam nos defeitos do retículo cristalino da calcita (Treble et al., 2003; Baldini et al., 2002). O $\mathrm{HPO}_{4}{ }^{2-}$ hidrolisado, produzido durante a decomposição da matéria orgânica de origem vegetal, é facilmente solubilizado pelas águas de infiltração em condições de ph neutro, como normalmente ocorre nos ambientes em questão. Variações do conteúdo de $\mathrm{P}$ em espeleotemas frequentemente exibem variações sazonais relacionadas à mudanças da produtividade dos solos em resposta às variações do volume de precipitação (Fairchild et al., 2001). Variações das concentrações de U por sua vez podem ser relacionadas às variações do conteúdo de $\mathrm{P}$, uma vez que o radical uranila $\left(\mathrm{UO}_{2}\right)$ é susceptível a formação de complexos fosfatados (Treble et al., 2003). A própria mobilização do radical uranila sob a forma de colóides orgânicos pode gerar co-variações positivas entre as concentrações de U e P nos espeleotemas, tendo a vista que o aumento da produtividade orgânica leva ao aumento de $\mathrm{HPO}_{4}{ }^{2-}$ nos solos.

Variações das razões de elementos traços podem também ser relacionadas a fatores que controlam a extensão do coeficiente de partição. Por exemplo, ao passo que o coeficiente de partição do $\mathrm{Mg}$ é sensível a variações de temperatura $\left(\mathrm{DMg}=0.031\right.$ a $25^{\circ} \mathrm{C}$ e cai para 0.019 a $15^{\circ} \mathrm{C}$ ) o coeficiente de partição do $\mathrm{Sr}$ e mesmo do Ba são influenciados por mudanças na taxa de crescimento (Huang e Fairchild, 2001; Roberts et al., 1998). Um aumento da taxa de crescimento ao redor de uma ordem de magnitude pode levar a mudanças no coeficiente de partição do $\mathrm{Sr}$ em torno de $15 \%$. No entanto, para que ocorram variações significativas de $\mathrm{Sr} / \mathrm{Ca}$ e $\mathrm{Mg} / \mathrm{Ca}$ devido a mudanças de temperatura são necessárias variações muito expressivas desse parâmetro. Por isso, é pouco provável que variações da razão de $\mathrm{Mg} / \mathrm{Ca}$ venham a ocorrer por mudanças de temperatura em cavernas do norte de Minas, uma vez que a variação desse parâmetro é muito pequena no interior de cavernas em regiões tropicais.

\section{Apresentação dos resultados}

\subsection{Resultados geocronológicos U-Th}

Nesse trabalho serão apresentados todos os resultados geocronológicos obtidos pelas datações das estalagmites das cavernas Lapa Grande e Lapa Sem Fim executados durante o programa de mestrado do autor e pelo orientador previamente ao início do mestrado. De todo o conjunto de coletado foram datadas 29 estalagmites que perfazem um registro de aproximadamente 85 mil anos do norte mineiro. Dessas, foram escolhidas 7 amostras para realização de análises 
isotópicas de oxigênio e carbono para fins de obtenção de um registro paleoclimático dos últimos $\approx 30$ mil anos, tema do presente trabalho de mestrado. As demais amostras serão estudadas posteriormente juntamente com outras amostras coletadas em Minas Gerais.

Ao todo foram produzidas 212 datações U-Th para as estalagmites das cavernas Lapa Grande e Lapa Sem Fim, o que abrange um intervalo temporal que vai de 85 a 1.4 mil anos A.P. Para as estalagmites selecionadas no presente estudo paleoclimático foram obtidas 77 datações UTh, em sua maioria apresentando erro inferior a $1 \%$ (estimativa $2 \sigma$ ).

As estalagmites foram selecionadas com o objetivo de cobrir o intervalo temporal que abrange desde o glacial tardio ( 30 mil anos A.P.), passando por todo o deglacial (20 a 10 mil anos A.P.), até o Holoceno superior. As idades das estalagmites estão distribuídas em uma sequência cronoestratigráfica normal, por vezes interrompidas por hiatos, como pode ser observado no gráfico de distribuição de idades das amostras (Fig. 6.1). O detalhamento geocronológico realizado variou de acordo com o período geológico de interesse e a taxa de crescimento de cada estalagmite. Foi realizado maior refinamento geocronológico nas estalagmites depositadas no período Holoceno (LG3 e LG11) (Fig. 6.1), uma vez que os eventos climáticos desse período ocorrem em escala temporal menor, geralmente em ciclo seculares. O registro geocronológico completo, obtido pela datação de todas as estalagmites das cavernas Lapa Grande e Lapa Sem Fim é apresentado na Figura 6.2. As Figuras 6.1 e 6.3 apresentam a distribuição das datações das estalagmites utilizadas na análise paleoclimática do norte Minas. Os resultados geocronológicos são apresentados no ANEXO III.

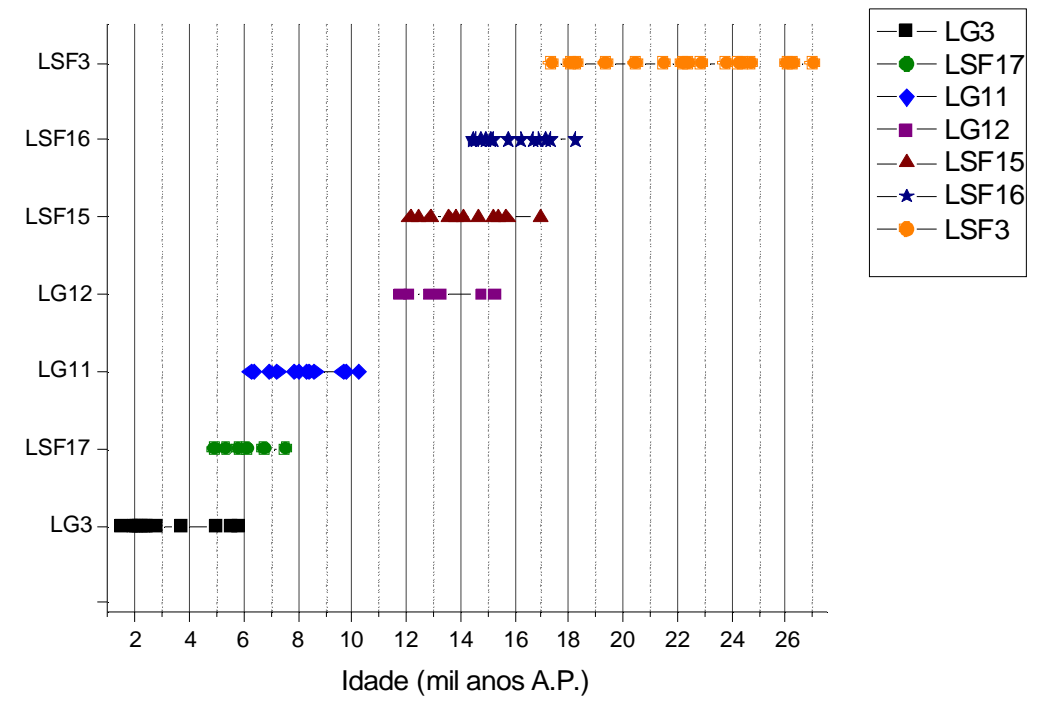

Figura 6.1 - Intervalos de deposição das estalagmites estudadas com base nas análises isotópicas de oxigênio e carbono. As idades U/Th estão destacadas para cada amostra de estalagmite plotada no eixo Y. 
Para efeito de descrição paleoclimatológica, o registro do norte de Minas Gerais foi subdividido em duas fases: (1) do glacial tardio ao final do período deglacial. (2) Holoceno, indo de 10 mil anos A.P. até o limite superior do registro que termina em 1.4 mil anos A.P. O período glacial tardio é considerado aqui como o intervalo temporal que varia entre $\sim 27$ e 20 mil anos A.P. e marca o início do MIS 2. A designação MIS, vem do termo em inglês Marine Isotope Stage e foi dada por Emiliani (1955), a partir da separação da série temporal de $\delta^{18} \mathrm{O}$ (indicador de TSM) de testas de foraminíferos planctônicos em estágios, onde os números ímpares referem-se a períodos quentes, que passam a contar a partir do Holoceno, e os números pares a períodos frios. Desse modo, o MIS 2 tem início em 27 mil A.P. e vai até 14.8 mil anos A.P. quando ocorrem o eventos quentes e frios a exemplo do Bølling-Allerød e Younger Dryas, respectivamente. O glacial tardio foi estudado através da estalagmite LSF3, que possui 12 datações U/Th apenas para esse trecho do registro de Minas (Fig. 63f). Nesse período, o intervalo de tempo entre as datações variou entre 170 anos e 1.32 mil anos, sendo sua cronologia robusta o suficiente para permitir precisa delimitação de eventos milenares do tipo Heinrich e Dansgaard-Oeschger. O hiato temporal mais evidente durante o glacial tardio ocorre entre 23.8 e 22.86 mil anos A.P., período que coincide com o evento climático quente do Dansgaard-Oescheger 2 ocorrido a 23.5 mil anos A.P. registrado nos testemunhos de gelo da Groenlândia (Fig. 6.3f).

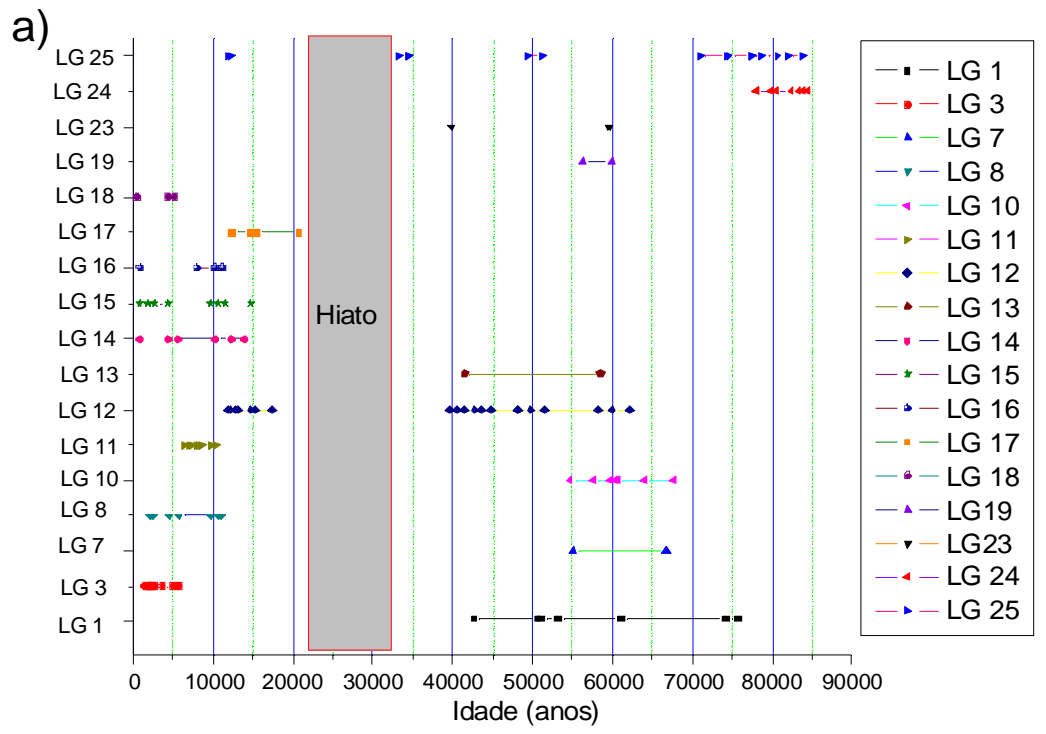




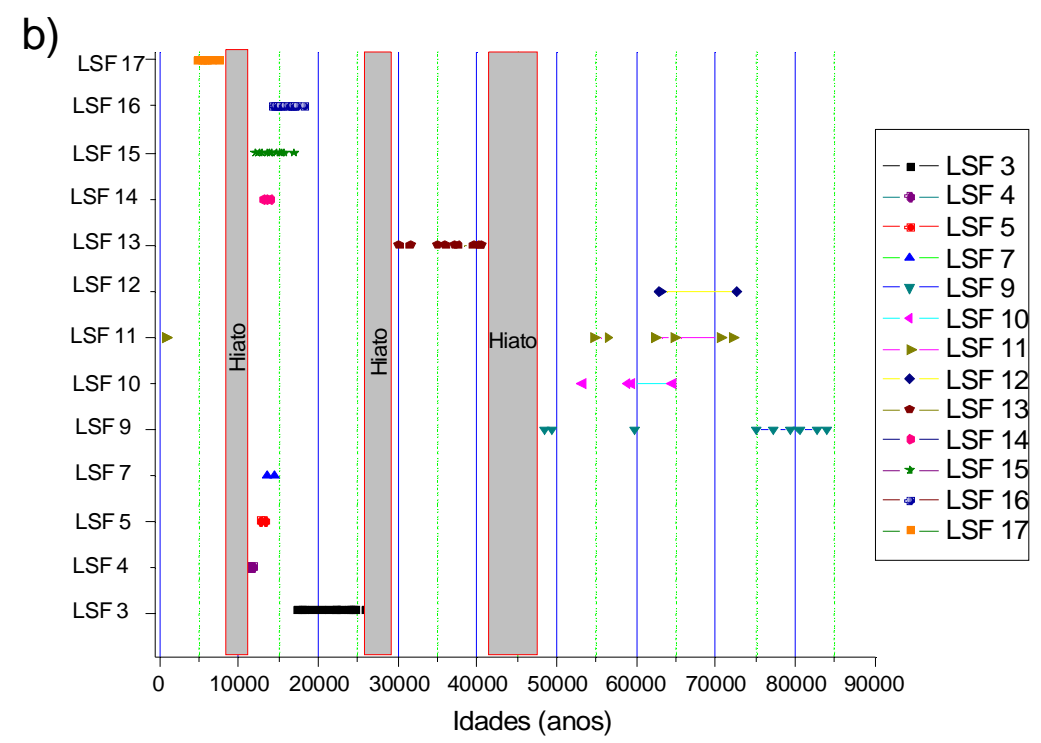

Figura 6.2 - Intervalos de deposição de todas as estalagmites coletadas nas cavernas Lapa Grande (a) e Lapa Sem Fim (b). As idades U/Th estão destacadas para cada amostra de estalagmite plotada no eixo Y.

O período deglacial se iniciou com a finalização do Último Máximo Glacial (UMG) por volta de 19 mil anos A.P. e terminou com aumento da temperatura global que define o início do Holoceno, a cerca de 10 mil A.P. Esse período foi estudado através da estalagmite LG12 da caverna Lapa Grande (Fig. 6.3d) e das estalagmites LSF3, LSF16 e LSF15 da caverna Lapa Sem Fim (Fig. 6.3e;f;g). Ao todo são somadas 34 datações para estalagmites depositadas durante o deglacial, cujo intervalo temporal entre as datações varia entre $\approx 110$ anos e 2.415 anos.

Por fim, temos o Holoceno, período que se inicia por volta de 10 mil anos A. P. e está representado no registro por estalagmites depositadas entre 10 mil anos e 1.4 mil anos A.P. com cronologia estabelecida através de 30 datações U/Th. Esse período foi estudado através das estalagmites LG3 e LG11, da caverna Lapa Grande (Fig. 6. 3a;c) e da estalagmite LSF17, da caverna Lapa Sem Fim (Fig. 6.3b). A resolução média dos dados isotópicos é de 10 anos, variando entre 1 a 40 anos. De maneira semelhante ao trecho do deglacial, não foi observado nítidos hiatos temporais nos intervalos datados durante esse período, como pode ser observado na Figura 6.1. No entanto, não foram encontradas amostras depositadas nos últimos 1400 anos.

A partir dos trechos datados foi possível estimar a taxa de crescimento (TC) das estalagmites e suas variações ao longo do tempo. A observação dos valores da TC é importante para se estabelecer possíveis relações da velocidade de deposição de cada espeleotema com períodos mais úmidos ou secos. Embora seja parcimonioso estimar que a TC varie de modo concordante a disponibilidade hídrica dentro do sistema cárstico, nem sempre o aumento da pluviosidade implica diretamente em aumento da TC de um espeleotema. Variações da TC de espeleotemas podem ser controladas por diversas variáveis ambientais tais como: quantidade de água infiltrada, temperatura 
regional, $\mathrm{P}_{\mathrm{CO} 2}$ da atmosfera do solo, e concentração de Ca na solução de infiltração. Trabalhos realizados por Cruz et al. (2006b) na caverna Botuverá em Santa Catarina, por Plagnes et al. (2002) no sul da França e por Drysdale et al. (2004) no noroeste da Itália associam as variações da TC em estalagmites a períodos de maior produtividade biológica do solo com base na co-variação entre a TC e o $\delta^{13} \mathrm{C}$ das estalagmites. A diminuição (aumento) das TC concordante com os períodos de aumento (diminuição) do $\delta^{13} \mathrm{C}$ sugere que a variação da atividade biológica do solo, relacionada a variações da disponibilidade hídrica ou mesmo variações da espessura da camada de solo, atuaria diretamente na concentração de $\mathrm{HCO}^{-}$da solução de infiltração. Consequentemente, o aumento de $\mathrm{CO}_{2(\mathrm{~g})}$ no solo aumenta a dissolução da rocha encaixante e, por conseguinte a concentração de íons $\mathrm{Ca}^{+2}$ na solução de percolante de modo aumentar a TC dos espeleotemas. 

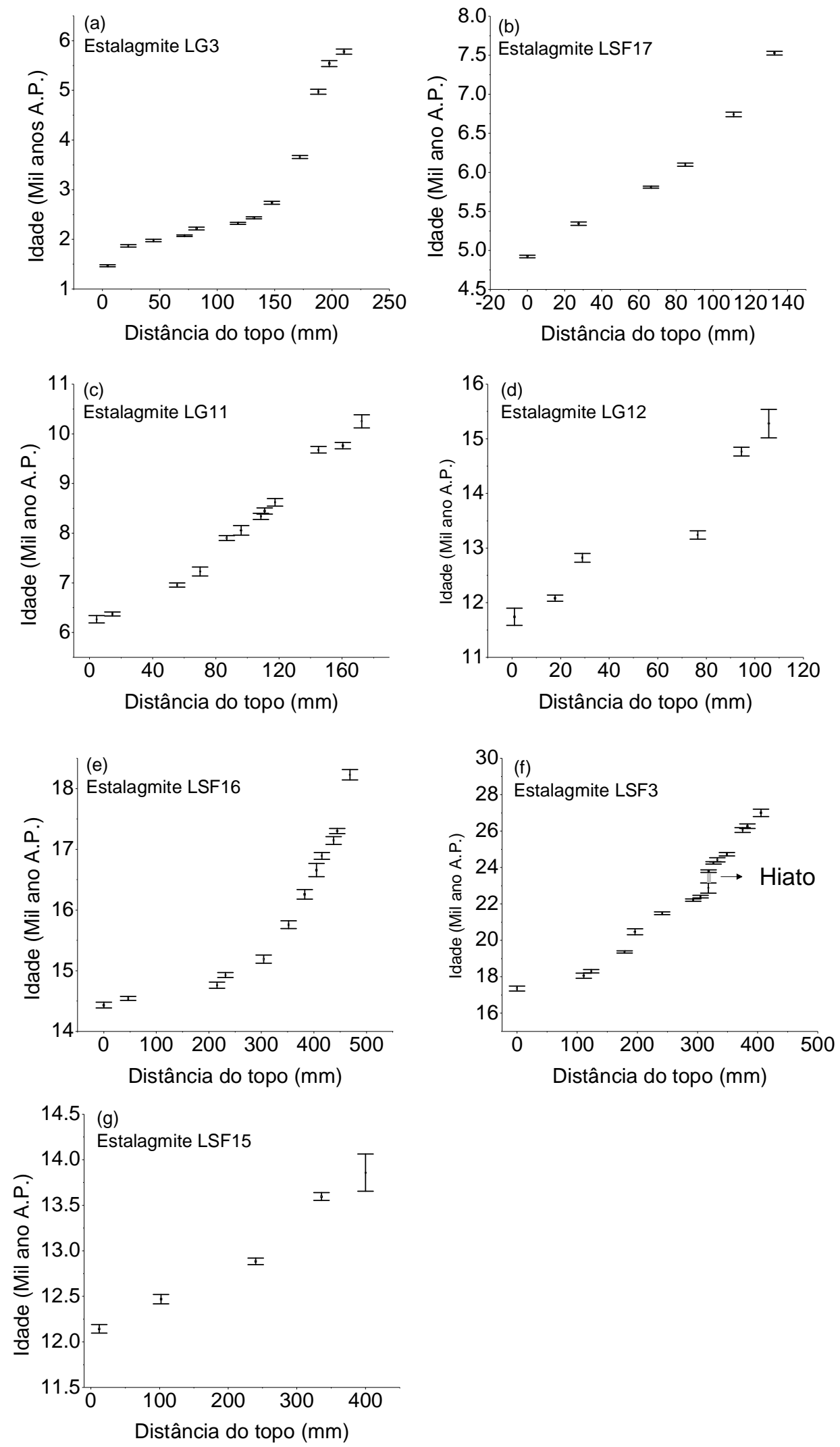

Figura 6.3 - Distribuição de idades U/Th versus profundidade (mm) das estalagmites LG3 (a); LSF17 (b); LG11 (c); LG12 (d); LSF16 (e); LSF3 (f), LSF15 (g). 
Na Figura 6.4 são apresentadas as relações entre as variações das TC em comparação com os valores de $\delta^{18} \mathrm{O}$ e $\delta^{13} \mathrm{C}$ para as estalagmites utilizadas na reconstituição da paleopluviosidade das cavernas Lapa Grande e Lapa Sem Fim.

$\mathrm{Na}$ comparação entre os valores de TC e as curvas isotópicas das mesmas estalagmites, é possível notar que a relação entre esses parâmetros pode mudar de acordo com o período abrangido pela amostra. De modo geral, quando a séries de $\delta^{18} \mathrm{O}$ e $\delta^{13} \mathrm{C}$ são concordantes em uma mesma estalagmite a taxa de crescimento parece acoplar-se ao sinal isotópico de $\delta^{18} \mathrm{O}$, como é possível observar para as amostras LG3, LSF15 e LSF3 (Fig 6.4a;e;g). Nessas estalagmites o aumento da TC é concordante com valores mais negativos de $\delta^{18} \mathrm{O}$ e $\delta^{13} \mathrm{C}$, o que seria a princípio, uma boa indicação de que o aumento da produtividade de $\mathrm{CO}_{2}$ biogênico do solo foi favorecido por aumento de chuvas. Durante o Holoceno, abruptas variações de $\delta^{18} \mathrm{O}$ associadas ao aumento da paleopluviosidade entre 2.0 e 2.5 mil anos A.P. (estalagmite LG3) apresentam boa correspondência com aumentos abruptos da TC. Da mesma forma, na estalagmite LSF3, onde há variações sincrônicas de $\delta^{18} \mathrm{O}, \delta^{13} \mathrm{C}$ e TC, o aumento da TC entre 24.5 e 24.0 mil anos A.P. é coincidente temporalmente com o evento climático frio Heinrich 2 (24.3 mil anos A.P.), assim o hiato deposicional seguido da redução da TC são feições concordantes com o evento climático quente Dansgaard-Oescheger 2, ocorrido por volta de 23.5 mil anos A.P (Fig 6.4g). Ainda na estalagmite LSF3, o aumento da TC após final do UMG em 19 mil anos A.P. é concordante, sobretudo, com o sinal isotópico de $\delta^{18} \mathrm{O}$, indicando que a TC é influenciada pelo aumento da pluviosidade (Cruz et al. 2009b).

Entretanto, como é possível observara para as estalagmites LSF17 e LSF16, em casos que o sinal isotópico de $\delta^{18} \mathrm{O}$ e $\delta^{13} \mathrm{C}$ descreve padrão discordante, ou mesmo antifásico, as TC de crescimento se acoplam muito mais às variações de $\delta^{13} \mathrm{C}$ que as de $\delta^{18} \mathrm{O}$ propriamente ditas (Fig 6.4f). Na estalagmite LSF17 a tendência de aumento gradativo dos valores de $\delta^{13} \mathrm{C}$ entre 7.5 e 5 mil anos A.P. acompanha perfeitamente os aumentos dos valores de TC, o que sugere um aumento da saturação dos gotejamento em carbonato de cálcio associado a maior dissolução da rocha carbonática no epicarste (Fig 6.4b), possivelmente favorecido por um aumento da disponibilidade de $\mathrm{CO}_{2}$ do solo e conseqüentemente de $\mathrm{HCO}_{3}$ na solução como descrito em outras áreas cársticas (Drysdale et al., 2004; Cruz el al., 2006b). Na estalagmite LSF16, entre 17.5 e 15.8, período de ocorrência do evento climáticos Heinrich 1, a TC apresenta valores muito pequenos, em torno de $0.01 \mathrm{~mm} / \mathrm{ano}$, contrastando com a excursão negativa de $\delta^{18} \mathrm{O}$ atribuída a um aumento da paleopluviosidade durante o evento. Ao final do evento Heinrich 1 ao redor de 15.5 mil anos, ao passo que os valores de $\delta^{18} \mathrm{O}$ caminham para valores progressivamente mais enriquecidos, de 
maneira sincrônica, os valores de $\delta^{13} \mathrm{C}$ do espeleotema experimentam uma forte redução concomitante com aumentos expressivos da TC.

A única exceção em que a TC não segue a curva de $\delta^{13} \mathrm{C}$ foi observado na amostra LG12, no momento em que o aumento da TC ocorre durante a transição de uma fase mais seca (caracterizado por valores mais altos de $\delta^{18} \mathrm{O}$ ) para uma fase mais úmida (valores mais baixos de $\delta^{18} \mathrm{O}$ ) entre 13.2 e 12.8 mil anos A.P., na transição do Bølling-Allerød para o Young Dryas (Fig 6.4d). Durante essa transição, ao passo que os valores de $\delta^{18} \mathrm{O}$ descrevem uma forte queda coerente com o aumento da TC, os valores de $\delta^{13} \mathrm{C}$ sofrem forte aumento, estabelecendo assim um padrão antifásico nesse período. A própria estrutura do Young Dryas registrado pelo sinal isotópico de $\delta^{18} \mathrm{O}$ da estalagmite LG12 se assemelha a TC do espeleotema, que apresenta dois picos associados ao aumento de umidade perto de 12.8 e 11.8 mil anos A.P., cortados por um período relativamente mais seco entre 12.4 e 12 mil anos aproximadamente. 

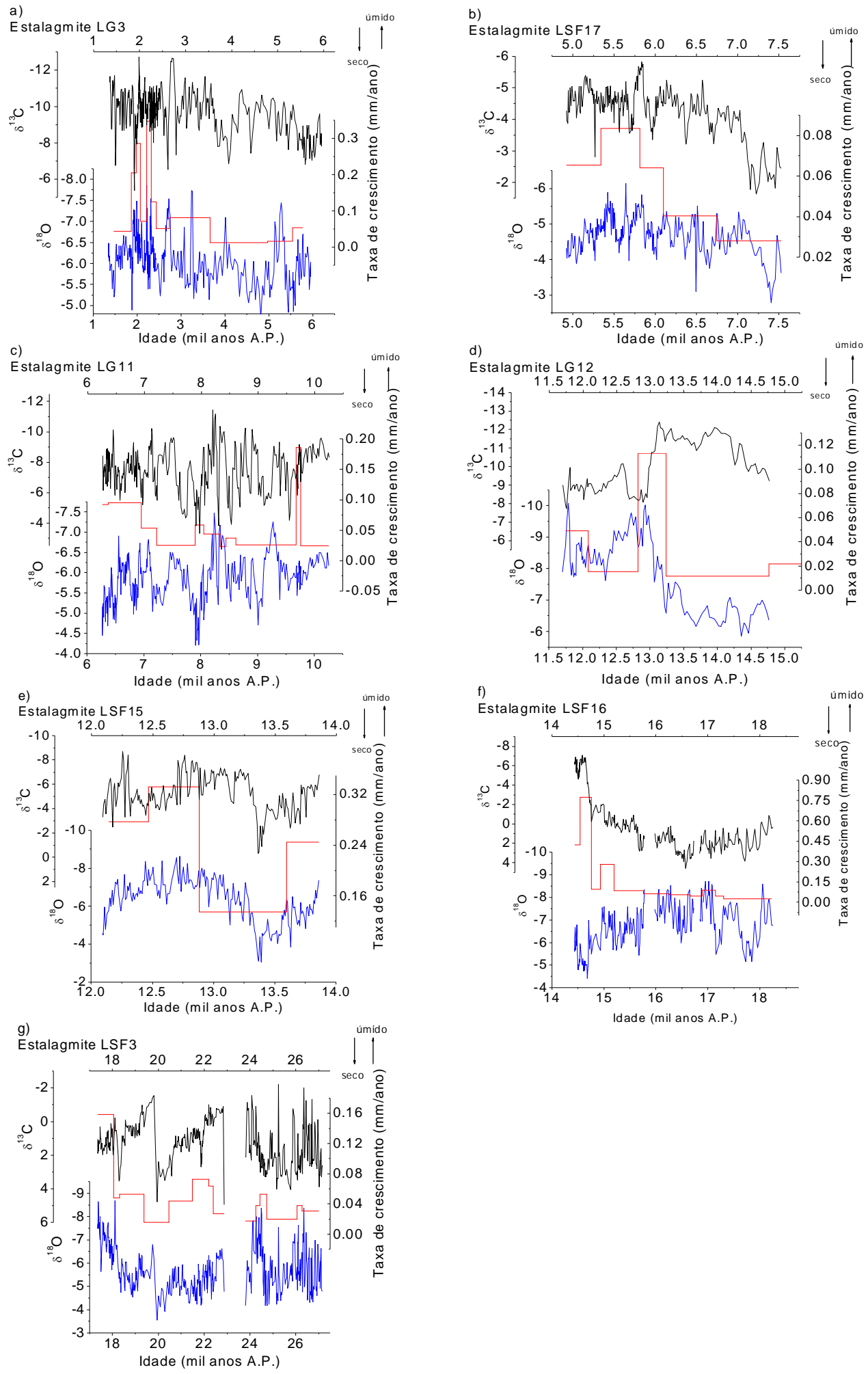

Figura 6.4 - Taxas de crescimento das estalagmites LG3 (a); LSF17 (b); LG11 (c); LG12 (d); LSF15 (e); LSF16 (f) e LSF3(g) em comparação o sinal isotópico de $\delta^{18} \mathrm{O}$ (azul) e $\delta^{13} \mathrm{C}$ (preto). Notar que o eixo $\delta^{18} \mathrm{O}$ e do $\delta^{13} \mathrm{C}$ foram invertidos para facilitar a comparação com a TC. 


\subsection{Registros isotópicos de $\delta^{18} \mathrm{O}$ e $\delta^{13} \mathrm{C}$ em estalagmites}

Com base no que foi discutido na fundamentação teórica do presente trabalho, os dados de $\delta^{18} \mathrm{O}$ estão diretamente associados a variações da quantidade de chuva, de forma que os valores mais negativos são indicativos de aumento de pluviosidade e vice-versa. Já as variações de $\delta^{13} \mathrm{C}$ estão associados principalmente a mudanças da disponibilidade de $\mathrm{CO}_{2}$ biogênico no solo, em última análise, atribuídas a variação da produtividade orgânica relacionada a mudanças na disponibilidade hídrica. Para a reconstrução da paleopluviosidade a partir dos registros isotópicos de espeleotemas do norte de Minas Gerais foram realizadas ao todo 4.647 análises das razões isotópicas de oxigênio $\left(\delta^{18} \mathrm{O}\right)$ e carbono $\left(\delta^{13} \mathrm{C}\right)$ em um conjunto de sete estalagmites coletadas nas cavernas Lapa Grande e Lapa Sem Fim. A partir dessas análises foram obtidos perfis isotópicos de alta resolução para os últimos $\approx 27$ mil anos A.P. Assim como nos dados geocronológicos, a resolução temporal aplicada às amostras variou de acordo com o período paleoclimático. A resolução de amostragem foi escolhida com base na frequência das oscilações climáticas de interesse para o período climático a que este se insere e de acordo com os valores de TC da estalagmite. Para as amostras do Holoceno a resolução média de amostragem foi de $\approx 10$ anos na maior parte do registro, variando localmente entre 40 e 2 anos a depender da TC. Por exemplo, o trecho entre 2.2 e 2.3 mil anos A.P. na estalagmite LG3 possibilitou uma resolução de amostragem de 2 anos, em virtude da alta TC nesse ponto, em torno de $0.3 \mathrm{~mm} / \mathrm{ano}$. Para as estalagmites do deglacial e glacial tardio, a resolução média da amostragem na maior parte do registro foi de 20 anos, variando localmente entre 40 e 10 anos. Os trechos com maior resolução ocorreram entre 15.2 e 16.66 mil anos A.P na estalagmite LSF16 e entre 17.36 e 18 mil anos AP e 24.42 e 24.73 mil anos A.P na estalagmite LSF3.

Os perfis isotópicos de $\mathrm{O}$ e $\mathrm{C}$ de todas as estalagmites estão apresentadas na Figura 6.5. A partir destes, foi possível observar variações paleoclimáticas de escalas orbitais (periodicidade de $\approx 23$ mil anos), milenares $(\approx 1.5$ a 3 mil anos), seculares $(\approx 800$ anos) e de escala multidecadal ( $\approx 60$ anos).

Para comparação dos dados das razões isotópicas de oxigênio com a curva de insolação de verão (Fig. 6.6) foram utilizados os dados referentes ao mês de fevereiro para a latitude $10^{\circ} \mathrm{S}$ (Berger e Loutre, 1991), os quais melhor representam a atividade das monções no Hemisfério Sul (Cruz et al. 2005a; Ruddiman, 2006). Já a discussão da influência dos eventos de escala milenar, do tipo Heinrich (H) e Dansgaard-Oeschger (D-O) no clima do norte de Minas Gerais foi baseada na comparação com trabalhos clássicos da literatura, a exemplo dos trabalhos de Bond et al. (1993), Bond e Lotti (1995), Dansgaard et al. (1993) e O’Brien et al. (1995). Também foram utilizados trabalhos mais recentes que discutem e comparam o impacto desses eventos nas regiões tropicais, 
com base em registros paleoclimáticos continentais e oceânicos. A correspondência entre os eventos de escala orbital e milenar pôde ser observada da mesma forma a partir dos registros isotópicos de carbono, exceto em alguns trechos do registro em que $\delta^{13} \mathrm{C}$ não segue os valores de $\delta^{18} \mathrm{O}$.

Comparativamente ao registro isotópico da caverna Lapa Grande, os valores de $\delta^{18} \mathrm{O}$ da caverna Lapa Sem Fim são média em 1\%o mais enriquecidos. Essa diferença pode ser bem observada nos pontos onde há sobreposição das séries temporais, como no trecho compreendido pela estalagmite LSF3 entre 4.8 e 7.4 mil anos A.P em comparação com as estalagmites LG3 e LG11 e, na porção inicial da LSF16 entre 14.9 e 14.48 mil anos A.P, que se sobrepõe com o trecho final da estalagmite LG12. Essa mesma tendência de enriquecimento isotópico também ocorre para os isótopos de carbono (Fig. 6.5). Nos pontos onde há sobreposição dos registros isotópicos da caverna Lapa Grande com os da caverna Lapa Sem, os valores de $\delta^{13} \mathrm{C}$ da caverna Lapa Sem Fim apresentam-se em média 3\%o mais enriquecidos (Fig. 6.5).

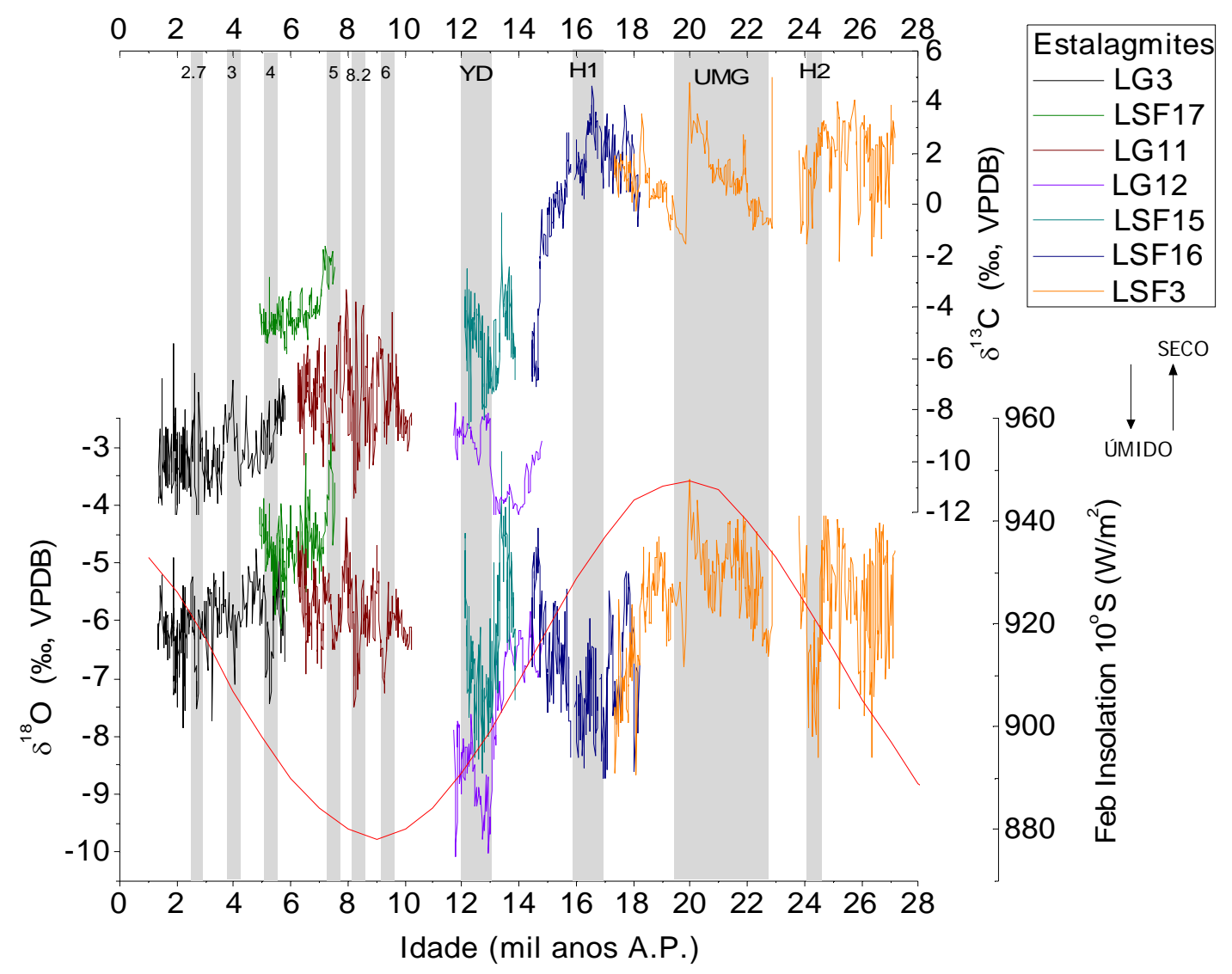

Figura 6.5 - Comparação entre as razões isotópicas de $\delta^{18} \mathrm{O}$ e $\delta^{13} \mathrm{C}$ das estalagmites LG3 (preto), LSF17 (verde), LG11 (vinho), LG12 (roxo), LSF15 (ciano), LSF16 (azul), LSF3 (laranja). As barras de cor cinza representam eventos climáticos frios registrados nas regiões de altas latitudes do Hemisfério Norte: Heinrich 2 (H2), Último Máximo Glacial (UMG), Heinrich 1 (H1), Young Dryas (YD), eventos Bond (6, 5, 4 e 3) e os eventos 8.2 e 2.7. A linha em vermelho representa a curva de variação de insolação descrita pelo ciclo de precessão de Milankovitch para a latitude de $10^{\circ} S$. 
Se tomarmos por base o registro isotópico da caverna Lapa Grande, que abrange quase que continuamente os últimos 15 mil anos, veremos consideráveis oscilações climáticas no norte de Minas, com amplitude de variação do $\delta^{18} \mathrm{O}$ por volta de $5.5 \%$, relativamente alta para registros de espeleotemas. Os valores mais negativos ocorrem entre 13 e 11.6 mil anos A.P., período referente ao evento climático Young Dryas, quando o $\delta^{18} \mathrm{O}$ atingiu $\approx-10 \%$. Os valores mais positivos observados na série temporal da caverna Lapa Grande ocorrem durante o Holoceno Tardio e Médio na forma de rápidas oscilações de escala centeniais centradas em 9.0, 8.05 e 6.3 mil anos, cujos valores de $\delta^{18} \mathrm{O}$ giram em torno de $-4.5 \%$.

Considerando apenas o registro da caverna Lapa Sem Fim, que abrange o glacial tardio e quase todo o deglacial, indo de 27.5 a 14.4 mil anos, a amplitude da variação de $\delta^{18} \mathrm{O}$ chega a $5.2 \%$. A mesma é considerada muito alta, comparada aos espeleotemas de regiões como a China e Israel que apresentam variações máximas em torno de 3\%o. O valor mais positivo registrado na série temporal ocorre à 20.3 mil anos A.P., período logo antes de uma forte excursão negativa de $\delta^{18} \mathrm{O}$ associado a um evento abrupto dentro UMG, $\operatorname{com} \delta^{18} \mathrm{O}=-3.57 \%$ o. Já o valor mais negativo ocorre entre 17 e 16 mil anos A.P. durante o evento $\mathrm{H} 1$ com valor de $\delta^{18} \mathrm{O}=-8.75 \%$.

Na comparação dos registros isotópicos de oxigênio e carbono, chama a atenção os valores extremamente enriquecidos em ${ }^{13} \mathrm{C}$ obtidos nas análises isotópicas das estalagmites da caverna Lapa Sem Fim, especialmente durante todo o glacial tardio e parte do deglacial, até 15 mil anos A.P., quando os valores de $\delta^{13} \mathrm{C}$ sofrem forte queda no período que marca o início do evento climático Bølling-Allerød. Durante o glacial tardio e início do deglacial, o $\delta^{13} \mathrm{C}$ assume valores positivos em geral, em torno de $+1.5 \%$, chegando até $+4.2 \%$ o durante eventos de natureza abrupta, os quais são concordantes com variações de $\delta^{18} \mathrm{O}$. A exceção se faz para os dados das estalagmites LSF16 e LG12 durante os eventos Heinrich 1 e Young Dryas, em que as variações de $\delta^{13} \mathrm{C}$ mostram-se concordantes com os baixos valores de $\delta^{18} \mathrm{O}$. Essa relação é mais bem marcada durante o deglacial tardio, pela estalagmite LSF3, onde flutuações abruptas de $\delta^{18} \mathrm{O}$ são absolutamente sincrônicas com as variações de $\delta^{13} \mathrm{C}$, como pode ser observado durante os eventos $\mathrm{H} 2$ e UMG na Figura 6.5. Em ambos os eventos, fortes quedas dos valores de $\delta^{18} \mathrm{O}$ da ordem de $3 \%$ em um espaço de tempo menor que 100 anos são acompanhados por quedas de $\delta^{13} \mathrm{C}$ da ordem de 3.5\% (Figura 6.5). Durante o Holoceno, variações entre $\delta^{18} \mathrm{O}$ e $\delta^{13} \mathrm{C}$ são em geral concordantes e por isso refletem variações no ciclo hidrológico associadas ao aumento de chuvas. 


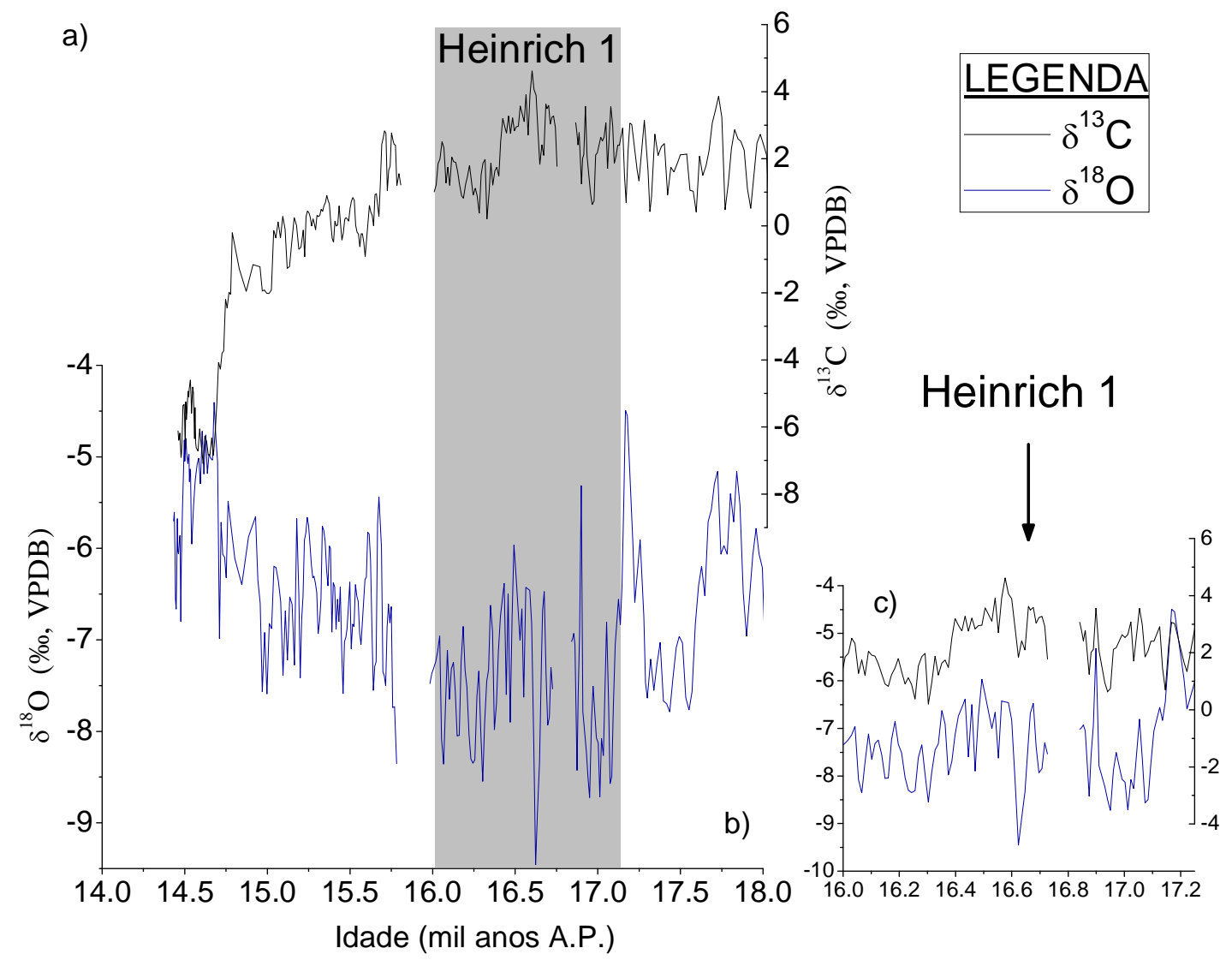

Figura 6.6 - Comparação entre as razões isotópicas de a) oxigênio $\left(\delta^{18} \mathrm{O}\right)$ e b) carbono $\left(\delta^{13} \mathrm{C}\right)$ da estalagmite LSF16. Em c) é detalhado a estrutura do evento Heinrich 1 com base nos valores de $\delta^{18} \mathrm{O}$ e $\delta^{13} \mathrm{C}$.

Entretanto, diferentemente da relação estabelecida pelas estalagmites LSF3 e LG11 a relação entre os sinais isotópicos de $\delta^{18} \mathrm{O}$ e $\delta^{13} \mathrm{C}$ é exatamente oposta nas estalagmites LSF16 e LG12, entre 17 a 11.5 mil anos A.P durante o período deglacial. Esse trecho recoberto pelas estalagmites LSF16 e LG12 é considerado período chave, pois engloba uma série de eventos climáticos importantes para as regiões tropicais, como os eventos Heinrich1, Bølling-Allerød e Young Dryas. Como pode ser observado nas Figuras 6.6 e 6.7, ao final do evento Heinrich 1, a 15.5 mil anos A.P., existe um aumento forte e abrupto dos valores de $\delta^{18} \mathrm{O}$, acompanhado por acentuada redução dos valores de $\delta^{13} \mathrm{C}$. Da mesma forma, variações antifásicas entre $\delta^{18} \mathrm{O}$ e $\delta^{13} \mathrm{C}$ são observadas na estalagmite LG12 na transição entre dois eventos abruptos, o Bølling-Allerød e Young Dryas (Fig. 6.7). É importante notar que nesse período as variações entre as razões isotópicas de carbono e oxigênio nas estalagmites LSF16 e LG12 ainda são sincrônicas, mesmo com a mudança na relação. De fato a estrutura interna dos eventos Heinrich 1, e Young Dryas, definidos aqui como úmidos devido a valores muito negativos das curvas de $\delta^{18} \mathrm{O}$, possuem em comum essa relação antifásica com as curvas de $\delta^{13} \mathrm{C}$ (Figs 6.6c e 6.7). Outro aspecto interessante nos dados da estalagmite LSF16 é que os valores de TC são sempre consistente com a variação de 
$\delta^{13} \mathrm{C}$, mesmo que esse último seja discordante do $\delta^{18} \mathrm{O}$. Isso sugere que a taxa de crescimento das estalagmites é mais dependente dos processos relacionados a produtividade de $\mathrm{CO}_{2}$ no solo, mesmo que sob menor disponibilidade hídrica.

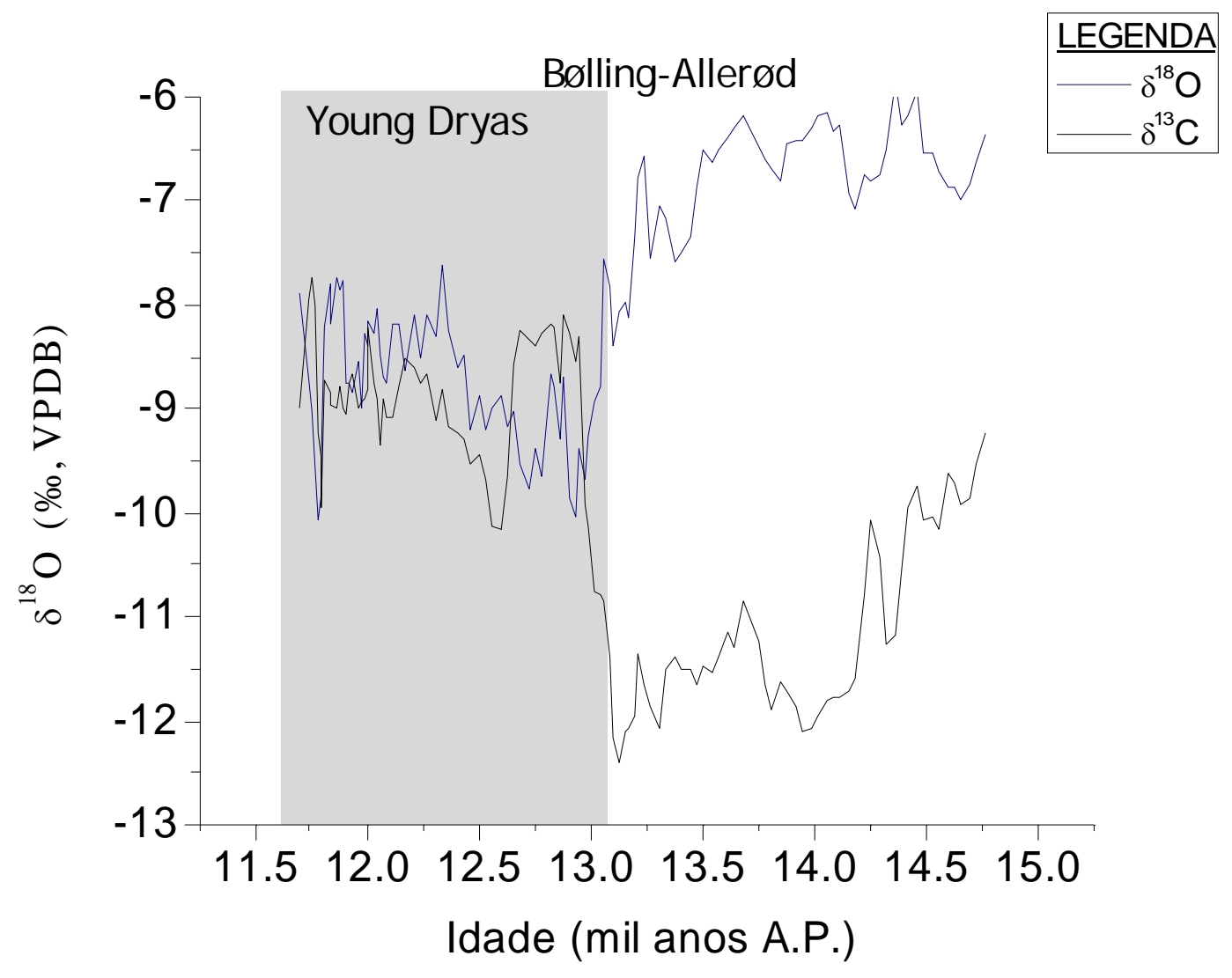

Figura 6.7 - Comparação entra as razões isotópicas de $\delta^{18} \mathrm{O}$ e $\delta^{13} \mathrm{C}$ da estalagmite LG12.

$\mathrm{Na}$ análise de correlação estatística entre os valores $\delta^{18} \mathrm{O}$ e $\delta^{13} \mathrm{C}$ observa-se baixa correlação linear para as amostras da caverna Lapa Grande: LG3 $\left(r^{2}=0.16\right)$, LG11 $\left(r^{2}=0.24\right)$, LG12 $\left(r^{2}=0.42\right)$ e Lapa Sem fim: LSF17 $\left(r^{2}=0.34\right), \operatorname{LSF} 15\left(r^{2}=0.28\right), \operatorname{LSF} 16\left(r^{2}=0.23\right)$ e LSF3 $\left(r^{2}=0.11\right)$ (Fig. 6.8). Isso indica que o sinal isotópico do $\delta^{18} \mathrm{O}$ não sofreu alterações significativas devido a fracionamento cinético (Hendy, 1971). 


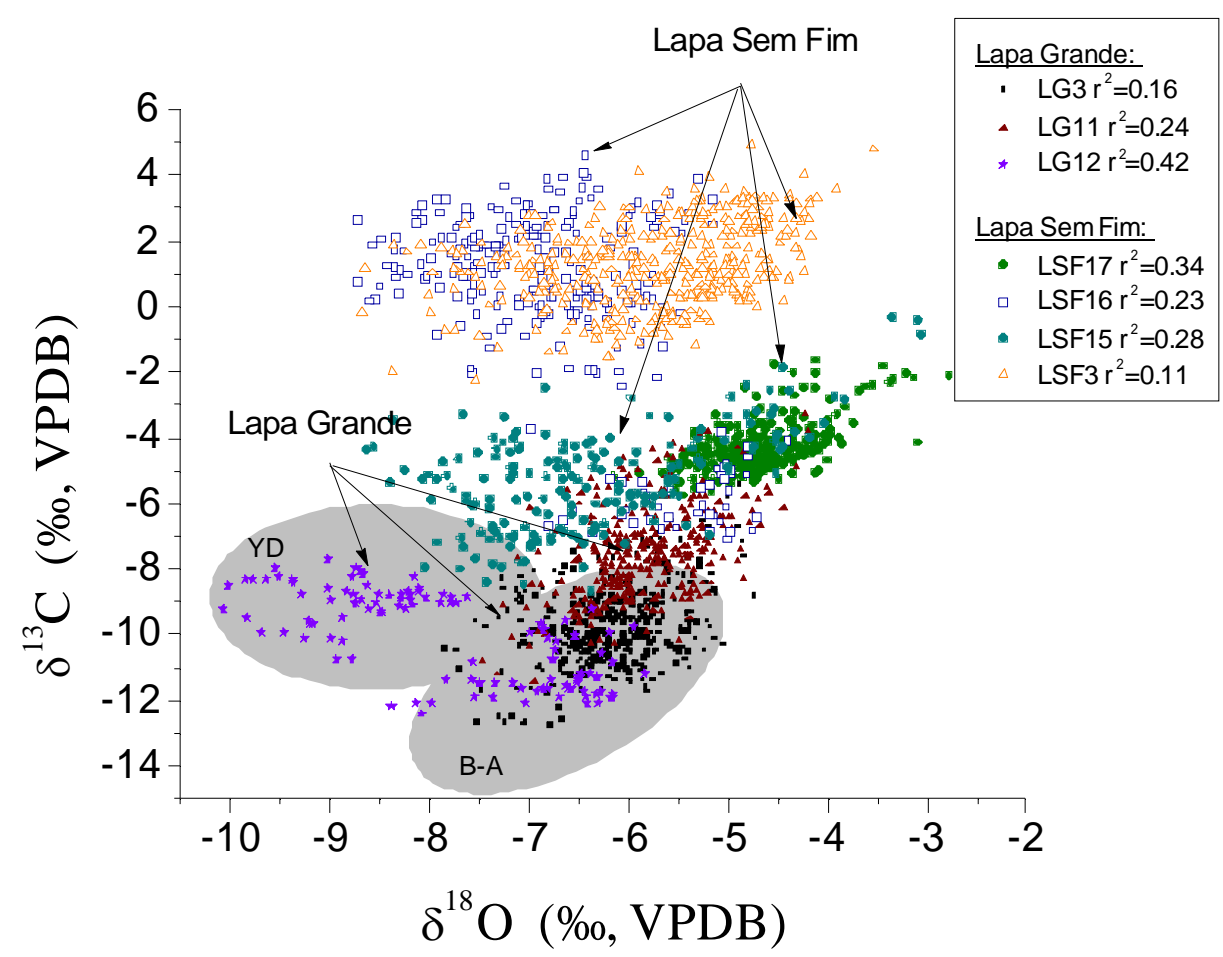

Figura 6.8 - Diagrama de distribuição de $\delta^{13} \mathrm{C}$ vs $\delta^{18} \mathrm{O}$ para as estalagmites LG3(quadrados pretos); LG11 (triângulos vermelhos); LG12 (estrelas roxas); LSF17 (círculos verdes); LSF15 (círculos cianos) LSF16 (quadrados azuis) e LSF3 (triângulos laranjas). Note que os eventos Bølling-Allerød e Young Dryas, registrados pela estalagmite, definem dois campos distintos, com o evento Young Dryas apresentando valores empobrecidos de $\delta^{18} \mathrm{O}$ e valores mais enriquecidos de $\delta^{13} \mathrm{C}$ ao passo que durante o evento Bølling-Allerød apresenta valores mais enriquecidos de $\delta^{18} \mathrm{O}$ e mais empobrecidos em $\delta^{13} \mathrm{C}$.

Somado a isso, o fato dos valores de $\delta^{18} \mathrm{O}$ serem inversamente proporcionais aos de $\delta^{13} \mathrm{C}$ em alguns espeleotemas, indica que a deposição de calcita ocorreu sob condições de equilíbrio isotópico, caso contrário uma correlação positiva seria esperada. Outro critério muito positivo para considerar a variação isotópica de $\delta^{18} \mathrm{O}$ dos espeleotemas como sendo função principalmente da variação de pluviosidade do norte de Minas é a forte correlação observada entre registros de cavernas distintas, como no caso da comparação entre os registros da LSF15/ LSF16 com a LG12/e LSF17 com a LG3/LG11. A própria concordância com os demais registros paleoclimáticos de alta resolução registrados não apenas nas regiões tropicais, mais também com os registros clássicos da paleoclimatologia moderna, a serem discutidos mais a frente, é um indicador da forte reprodutibilidade do sinal paleoclimático registrado nos espeleotemas desse estudo.

O fato dos resultados isotópicos das estalagmites da caverna Lapa Sem Fim serem em média $1 \%$ mais enriquecidos em relação as estalagmites da caverna Lapa Grande, torna mais dificil a comparação entre os registros de diferentes cavernas. Para facilitar a análise comparativa, foram utilizados os dados normalizados em função da média e do desvio padrão dos registros isotópicos do norte de Minas (Fig. 6.9a). Alternativamente, os valores de $\delta^{18} \mathrm{O}$ das estalagmites da caverna 
Lapa Sem Fim foram subtraídos em 1\%o (Fig. 6.9b). O segundo procedimento parece ser visualmente mais satisfatório, pois não distorce a noção de amplitude relativa entre os eventos paleoclimáticos.

a)

a)

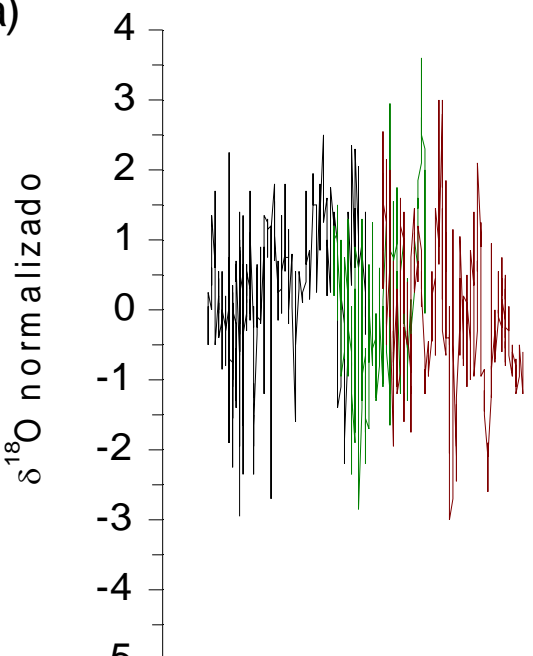

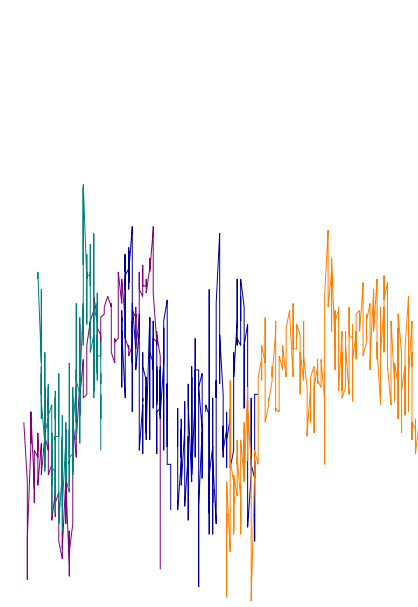

Holoceno

LG 3

LSF17

LG 11

Glacial tardio e

Deglacial

b)

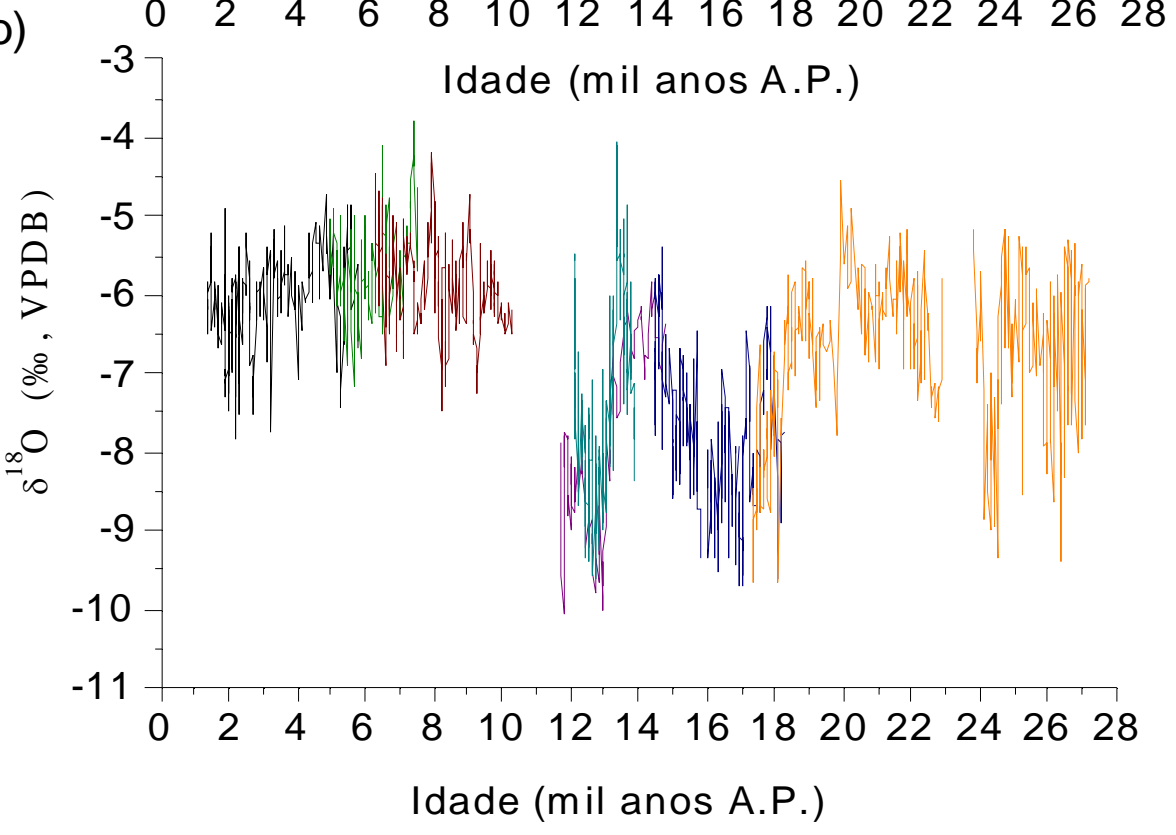

Figura 6.9 - Comparação entre os registros isotópico de $\delta^{18} \mathrm{O}$ das cavernas Lapa Grande e Lapa Sem Fim. Em (a) o registro é apresentado na forma de uma curva normalizada, em (b) é apresentado o registro com correção dos valores de $\delta^{18} \mathrm{O}$ das estalagmites da caverna Lapa Sem Fim pela subtração de 1\%o dos resultados analíticos.

A série temporal de $\delta^{18} \mathrm{O}$ do norte de Minas será discutida paleoclimaticamente a seguir em função do contexto climático no qual se insere. Para isso o registro isotópico do norte de Minas Gerais foi dividido em dois períodos: período glacial tardio/deglacial e Holoceno. 


\subsubsection{Período glacial tardio e deglacial (MIS 2): entre 27 e 10 mil anos A.P.}

O período glacial tardio e o deglacial são apresentados em conjunto com o objetivo de facilitar a intercomparação entre as variações climáticas dentro de um contexto de glaciação com um período de transição climática, conhecido como deglacial. O período em questão refere-se a uma saída de condições significativamente mais frias no último máximo glacial (UMG), a exemplo da diminuição média em até $5^{\circ} \mathrm{C}$ no nordeste brasileiro por volta de $\approx 21$ ka A.P. (Stute et al., 1995) para uma fase a partir do qual a Terra passa por um aquecimento progressivo que é truncado por variações climáticas abruptas de natureza milenar até o Holoceno, quando a variabilidade climática sobre forte redução de amplitude e o clima passa a variar mais linearmente (Dansgaard et al., 1993; O'Brien et al., 1995; Bond et al., 1997; Bond et al., 2001). Como anteriormente descrito, esse período é representado pelas estalagmites LSF3, LSF16 e LG12.

A Figura 6.10 apresenta os resultados isotópicos do glacial tardio e deglacial. As maiores variações de $\delta^{18} \mathrm{O}$ observada nos registros isotópicos da caverna Lapa Grande e Lapa Sem Fim ocorrem durante os eventos abruptos Young Dryas (YD), Heinrich 1 (H1) e Heinrich 2 (H2), com variações médias de - 3.2\%o. O tempo de duração varia bastante entre eventos milenares, sendo os mesmos mais curtos durante o período glacial tardio com duração de $\sim 500$ anos e mais longos durante o período deglacial, com duração entre 1 e 1.3 mil anos. As fases mais secas, relacionadas aos valores mais elevados de $\delta^{18} \mathrm{O}$, ocorre durante o Bølling-Allerød entre 14.7 e 13.4 mil anos A.P. e em evento abrupto de curta duração durante o UMG ocorrido em 20.35 mil anos A.P. Entre 23.8 e 22.9 mil anos um hiato deposicional coincidente com o evento quente Dansgaard-Oeschger 2, registrado nos dados de $\delta^{18} \mathrm{O}$ de testemunhos de gelo da Groenlândia, provavelmente pode ser relacionado a condições mais secas em Minas Gerais. O período de duração do hiato $(\approx 1.0$ mil anos) é circunscrito pelo Dansgaard-Oeschger 2 o que reforça a hipótese do seu significado paleoclimático dentro de um contexto de variação climática de escala global, como poder ser observado na Figura 6.1. De maneira geral, os eventos frios apresentam caráter extremamente abrupto, marcados por variações de clima seco-úmido-seco com um tempo médio de $100+/-15$ anos. A única exceção fica para o Young Dryas com um período de cerca de 300 anos, desde o final do Bølling-Allerød até o seu início de fato. 


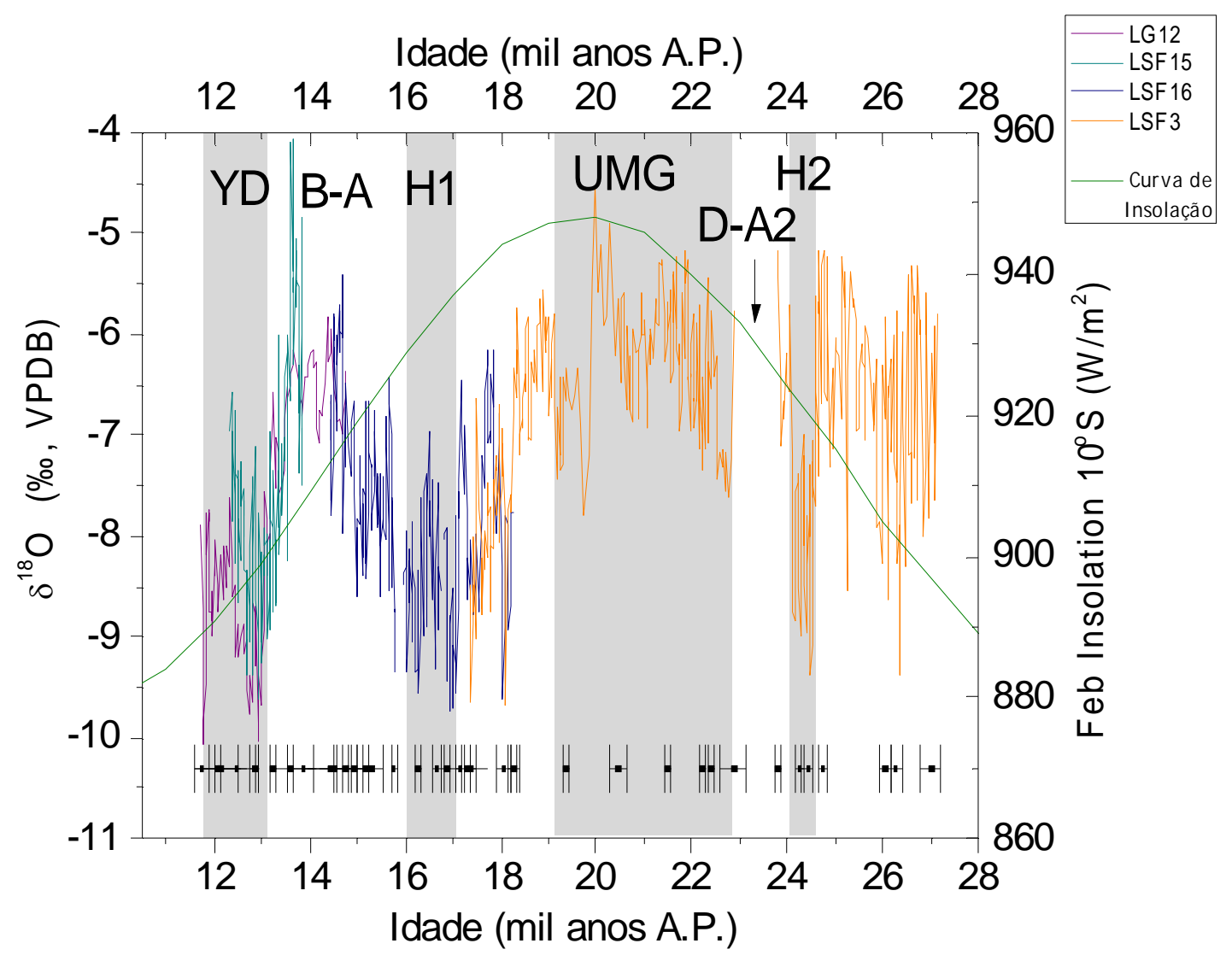

Figura 6.10 - Variação de $\delta^{18} \mathrm{O}$ durante o glacial tardio e o deglacial das cavernas Lapa Grande e Lapa Sem Fim. Os resultados analíticos de $\delta^{18} \mathrm{O}$ das estalagmites da caverna Lapa Sem Fim estão corrigidos para facilitar a comparação com o registro da estalgmite LG12, proveniente da caverna Lapa Grande. A curva em verde representa a variação de insolação para latitude de $10^{\circ} \mathrm{S}$ durante o mês de fevereiro de acordo com o ciclo de precessão de Milankovitch. As barras cinza marcam os intervalos com aumentos abruptos precipitação durante os eventos Heinrich 2 (H2); Heinrich 1 (H1) e Young Dryas (YD). Os eventos quentes são representados pelas siglas B-A para Bølling-Allerød e DA para Dansgaard-Oescheger. Os quadrados pretos com barras de erros horizontais representam a localização das datações.

Chama a atenção nos registros dos eventos milenares de espeleotemas tanto do norte de Minas quanto na porção central da Bahia (Barreto, 2010) a amplitude relativa do Young Dryas, que é comparitvamente maior que a do H1 (Fig. 6.10). Isso difere do que foi observado na maior parte dos registros de paleopluviosidade dos trópicos, a exemplo dos trabalhos do leste da China (Wang et al., 2001), sudeste do Brasil (Cruz et al., 2005a) (Fig. 8.3), altiplanos andinos (Baker et al., 2001a;b) (Fig. 8.6) e mesmo em registros de TSM do Atlântico tropical oeste (Peterson et al., 2000) (Fig. 8.7), onde o Young Dryas apresenta uma amplitude significativamente menor que a do Young Dryas. Entretanto, diferenças semelhantes à observada em Minas podem ser observadas nos registros isotópicos de $\delta^{18} \mathrm{O}$ dos testemunhos de gelo da Groenlândia (North Greenland Ice Core Project members, 2004) (Fig. 7.1) ou mesmo no registros de TSM do Atlântico tropical oeste de Lea et al. (2003) (Fig. 7.7).

Durante o glacial tardio a região do norte de Minas foi relativamente seca nos trechos que 
coincidem com o final do MIS 3 (término a 27.0 mil anos A.P.) e durante o MIS 2 (entre 27 e 14.8 mil anos A.P) (Grootes e Stuiver, 1997; Wrigth, 1999). O estágio MIS 2 é caracterizado por ampla expansão de geleiras para latitudes mais baixas sobre os mares e continentes, o que teria proporcionado o abaixamento das temperaturas oceânicas e queda do nível do mar (Shackleton, 1967; Cutler et al. 2003). O período no qual o nível do mar atingiu seu ponto mais baixo durante toda a última glaciação ocorre durante o MIS 2 a $\approx 21$ mil anos A.P., durante o UMG, quando o nível do mar recuou $\approx 120 \mathrm{~m}$ (Cutler et al., 2003). É nessa fase do MIS 2 que ocorre a máxima insolação no Hemisfério Sul e mínima no Hemisfério Norte de acordo com o ciclo de insolação de Milankovitch. Na integração dos ciclos orbitais, que considera a modulação da insolação pelos ciclos de precessão, obliquidade e excentricidade, o período do MIS 2 representa uma das fases mais agudas de mínima insolação da última glaciação juntamente com o período entre o MIS 4 e 5 a $\approx 70$ mil anos A.P., quando o nível do mar recuou $\approx 80 \mathrm{~m}$ (Imbrie e Imbrie, 1980; Grootes e Stuiver, 1997; Cutler et al., 2003). Durante parte do MIS 3 e 2, até 19.5 mil anos A.P., ambos registros de paleopluviosidade do norte de Minas e centro da Bahia apontam para um período de seca prolongada, com um patamar muito próximo do observado durante o Bølling-Allerød (Barreto, 2010).

Nos períodos glacial tardio e deglacial, o registro isotópico do norte de Minas parece seguir, de maneira antifásica, a curva de variação de insolação descrita pelo o ciclo de precessão de Milankovitch. Desse modo, o aumento da precipitação (diminuição dos valores de $\delta^{18} \mathrm{O}$ ) seria concordante com a diminuição da insolação. Entretanto a interrupção das oscilações paleoclimáticas de escala orbital por eventos milenares abruptos como o Dansgaard-Oescher 2, Heinrich1, BøllingAllerød e Young Dryas dificulta a comparação entre a série de paleopluviosidade do norte de Minas com o ciclo de precessão durante o deglacial.

\subsubsection{Período Holoceno: a partir dos últimos 10 mil anos}

O período Holoceno foi estudado a partir das estalagmites LG11 (6.27 a 10.25 mil anos A.P.), LSF17 (4.92 a 7.53 mil anos A.P.) e LG3 (1.34 a 5.95 mil anos A.P.). De maneira geral, a amplitude das variações de $\delta^{18} \mathrm{O}$ observada no norte Minas durante o Holoceno para os eventos abruptos $(\approx 1.5 \%$ ) ultrapassam as observadas em outros registros isotópicos de espeleotemas nas regiões tropicais do globo. Por exemplo, variações abruptas de escala milenar de $\delta^{18} \mathrm{O}$ observadas no leste da China por Wang et al. (2005) e em Israel (Bar-Matthews e Ayolan, 1997) não ultrapassam 0.5\%o. Já em Botuverá, Santa Catarina, esses eventos abruptos do Holoceno não ultrapassam 1\%o. Em contra partida, os registros isotópicos do norte de Minas se assemelham em 
magnitude às variações observadas nos registros da Chapada Diamantina de Barreto (2010), cujas variações podem atingir até $2 \%$ durante o evento 8.2 e no geral apresentam oscilações da ordem de $1 \%$.

A principal característica da série isotópica de $\delta^{18} \mathrm{O}$ do norte de Minas durante o Holoceno são as flutuações abruptas, com variações na estrutura e no tempo de duração dos eventos observados no Holoceno Inferior em comparação com os eventos do Holoceno Tardio (Fig 6.11). Durante o Holoceno, o registro isotópico do norte de Minas apresenta eventos abruptos de aumento de precipitação centrados em 9.2, 8.2, 7.4, 7.0, 6.4, 5.2, 3.7, 3.1, 2.7, 2.3 e 1.7 mil anos A.P. Durante o Holoceno Tardio a duração desses eventos gira em torno de 300 anos, com amplitudes que variam entre 0.9 a $1.5 \%$, sendo os valores mais negativos observados durante o evento de 8.2 mil anos A.P. (Fig 6.11). A amplitude desses eventos mantém-se similar no Holoceno Superior, entretanto, a duração dos eventos cai consideravelmente, não ultrapassando 100 anos, de modo a acentuar o caráter abrupto, mas pontual dos eventos nesse período. $\mathrm{O}$ eventos mais longo registrado no Holoceno Superior ocorre à 2.7 mil anos A.P., com duração de cerca de 100 anos, seguido pelos eventos a 3.7 e 3.1 mil anos, com duração aproximada de 50 anos, ao passo que os demais eventos ( 3.0, 2.3, 2.2 e 1.7 mil anos A.P.) não duram mais do que 20 anos. Esses resultados, a priori, sugerem diferentes mecanismos climáticos na condução dos eventos climáticos do Holoceno conforme as condições associadas ao contexto climático do glacial são deixadas para traz e nos adentramos num interglacial. De modo diferente do que é comumente observado nos registros paleoclimáticos das regiões tropicais (Fleitmann et al., 2003; Wang et al., 2005; Griffiths et al., 2009), a variabilidade paleoclimática apontada no registro isotópico de $\delta^{18} \mathrm{O}$ do norte de Minas Gerais apresenta-se mais intensa, comparada de certo modo às amplitudes dos eventos milenares observados durante o glacial tardio e o deglacial.

$\mathrm{Na}$ escala de tempo orbital, os registros isotópicos de $\delta^{18} \mathrm{O}$ do norte de Minas seguem em fase a curva de insolação de verão, sendo ligeiramente mais negativos nos últimos quatro mil anos (Fig. 6.11). Entretanto, a trajetória descrita pelas séries isotópicas do norte de Minas é muito truncada por eventos milenares e seculares, quando comparadas com os registros isotópicos de Santa Catarina (Cruz et al., 2005a) e da Chapada Diamantina (Barreto, 2010), o que torna a relação entre a variação da paleopluviosidade com a insolação não tão clara em Minas. 


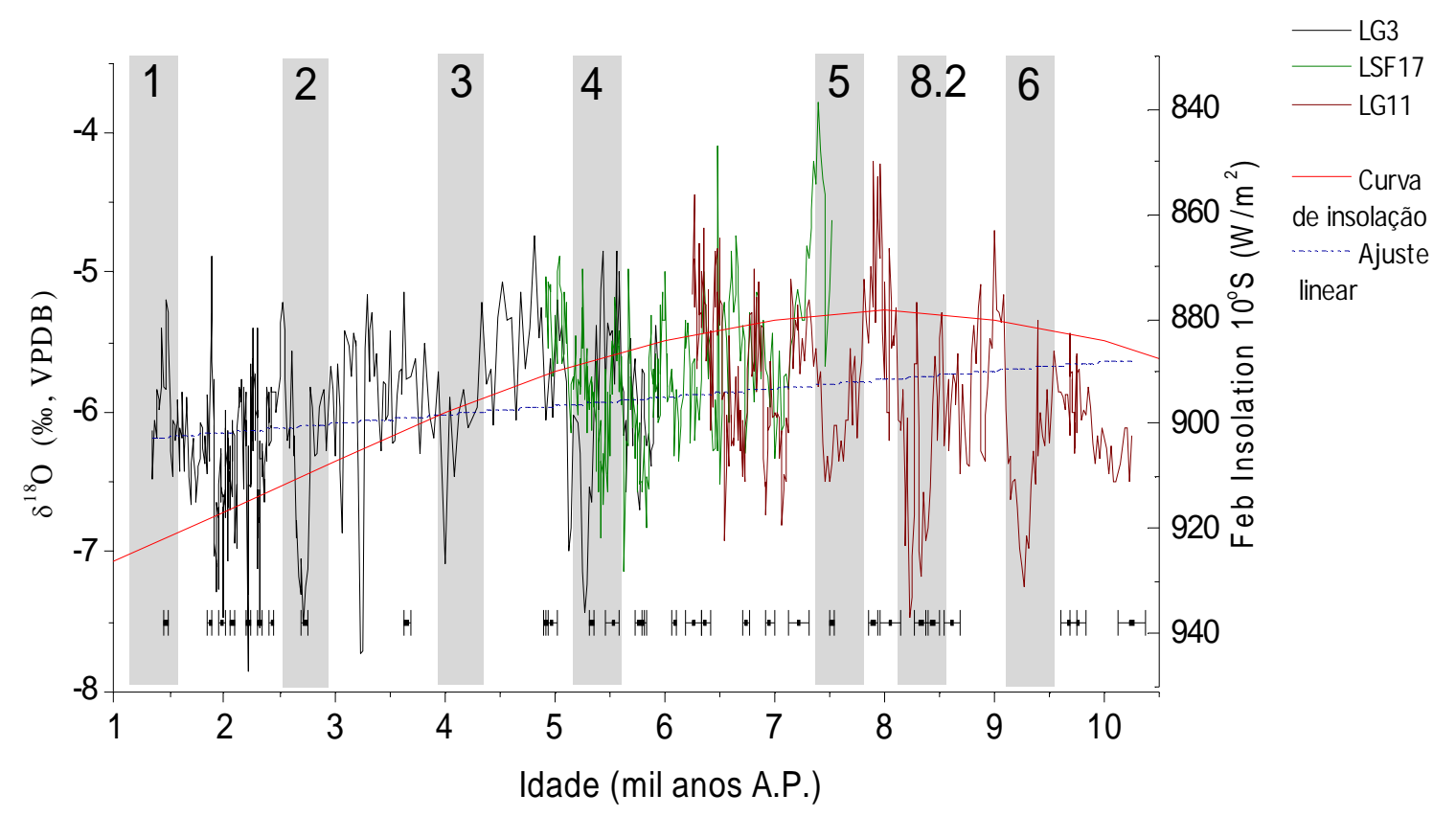

Figura 6. 11 - Variação de $\delta^{18} \mathrm{O}$ durante o Holoceno das cavernas Lapa Grande e Lapa Sem Fim. A linha tracejada em azul representa a curva média das razões de $\delta^{18} \mathrm{O}$ durante o Holoceno. A curva em vermelho representa a variação de insolação para latitude de $10^{\circ} \mathrm{S}$ durante o mês de fevereiro de acordo com o ciclo de precessão de Milankovitch. Note que diferentemente do registro do Glacial Tardio e Deglacial, existe uma relação em fase com a curva isotópica. Os pontos pretos com barras laterais de erro representam as datações.

Em geral os resultados da curva isotópica da estalagmite LSF17 aparentam boa reprodutibilidade com a curva isotópica das estalagmites LG11 e LG3. Na sobreposição dos registros isotópicos é possível observar leves desalinhamentos entre alguns eventos abruptos, como entre um evento seco, centrado em 7.4 mil anos A.P. na estalagmite LSF17 e que vem a ocorrer somente 7.27 mil anos A.P. na estalagmite LG11 e outro evento, dessa vez úmido, centrado a 5.4 mil anos A.P na estalagmite LSF17 e a 5.3 na estalagmite LG3. Essas discrepâncias são passíveis de ocorrer em virtude da sobreposição dos erros analíticos das datações (Fig. 6.11).

\subsection{Análises das razões de elementos traços sobre o cálcio}

Durante o Holoceno, as razões elementares de $\mathrm{Mg} / \mathrm{Ca}$ e $\mathrm{Sr} / \mathrm{Ca}$ das estalagmites LG3 e LG11 apresentam co-variações consistentes ao longo da série como um todo, às vezes com algumas discordâncias localizadas (Fig. 6.12). Variações concordantes de caráter abrupto de $\mathrm{Mg} / \mathrm{Ca}$ e $\mathrm{Sr} / \mathrm{Ca}$ ocorrem ao redor de 9.2 mil anos A.P., caracterizada por uma forte redução das razões elementares, seguido de eventos de diminuições de menor amplitude em: 8.4, 7.6, 7.1, 5.2 mil anos A.P. coerente com os eventos de aumento de precipitação observado ao longo do Holoceno registrados pelas 
flutuações de $\delta^{18}$ O. Da mesma forma, durante o Holoceno Superior, a partir de 2.8 mil anos A.P., observa-se nos registros de elementos traços da estalagmite LG3 uma forte queda das razões de elementos traços evidenciada, sobre tudo, nas razões de $\mathrm{Mg} / \mathrm{Ca}$ e que é, em parte, coincidente com o aumento da TC da estalagmite LG3 e com maiores valores de insolação. Variações das razões de $\mathrm{P} / \mathrm{Ca}$ e U/Ca ocorrem em geral de modo consistente com as variações isotópicas de oxigênio e carbono, registrando aumento abrupto durante eventos correlatos de diminuição das razões isotópicas. A co-variação positiva entre as curvas isotópicas de oxigênio e carbono com as razões de $\mathrm{Mg} / \mathrm{Ca}$ e $\mathrm{Sr} / \mathrm{Ca}$ sugerem a PCP com o principal mecanismo responsável pela concentração de cátions bi-valentes nas soluções de infiltração. Em contrapartida, a relação antifásica entre as razões de U/Ca e P/Ca com as curvas de ${ }^{18} \mathrm{O}$ e $\delta^{13} \mathrm{C}$ sugere mudanças da produtividade biológica do solo, o qual seria fator responsável pela mobilização de tais elementos em solução para os gotejamentos nas cavernas (Treble et al., 2003; Fairchild et al., 2001).

De modo geral, durante o Holoceno, ás variações de $\mathrm{Mg} / \mathrm{Ca}$ e $\mathrm{Sr} / \mathrm{Ca}$ apresentam maior consistência com as variações de $\delta^{13} \mathrm{C}$ principalmente na escala de tempo orbital. Como é possível observar na Figura 6.12c;e as curvas descritas pelas variações das razões de $\mathrm{Mg} / \mathrm{Ca}$ são concordantes com o sinal isotópico de $\delta^{13} \mathrm{C}$, que por sua vez apresenta grande consistência com a curva de insolação característica do ciclo de precessão. Sobretudo no Holoceno Inferior e Médio, , períodos secos caracterizados por valores mais positivos de $\delta^{18} \mathrm{O}$ registrados na estalagmite LG11 são em geral consistentes com valores mais elevados de $\mathrm{Sr} / \mathrm{Ca}$ e $\mathrm{Mg} / \mathrm{Ca}$; e dessa forma são também coerentes com os eventos Bond ao redor de 9.2, 7.5. Por outro lado, eventos secos como o que está centrado em 7.0 mil anos A.P. na curva de $\delta^{18} \mathrm{O}$, são acompanhados de queda das razões elementares. 


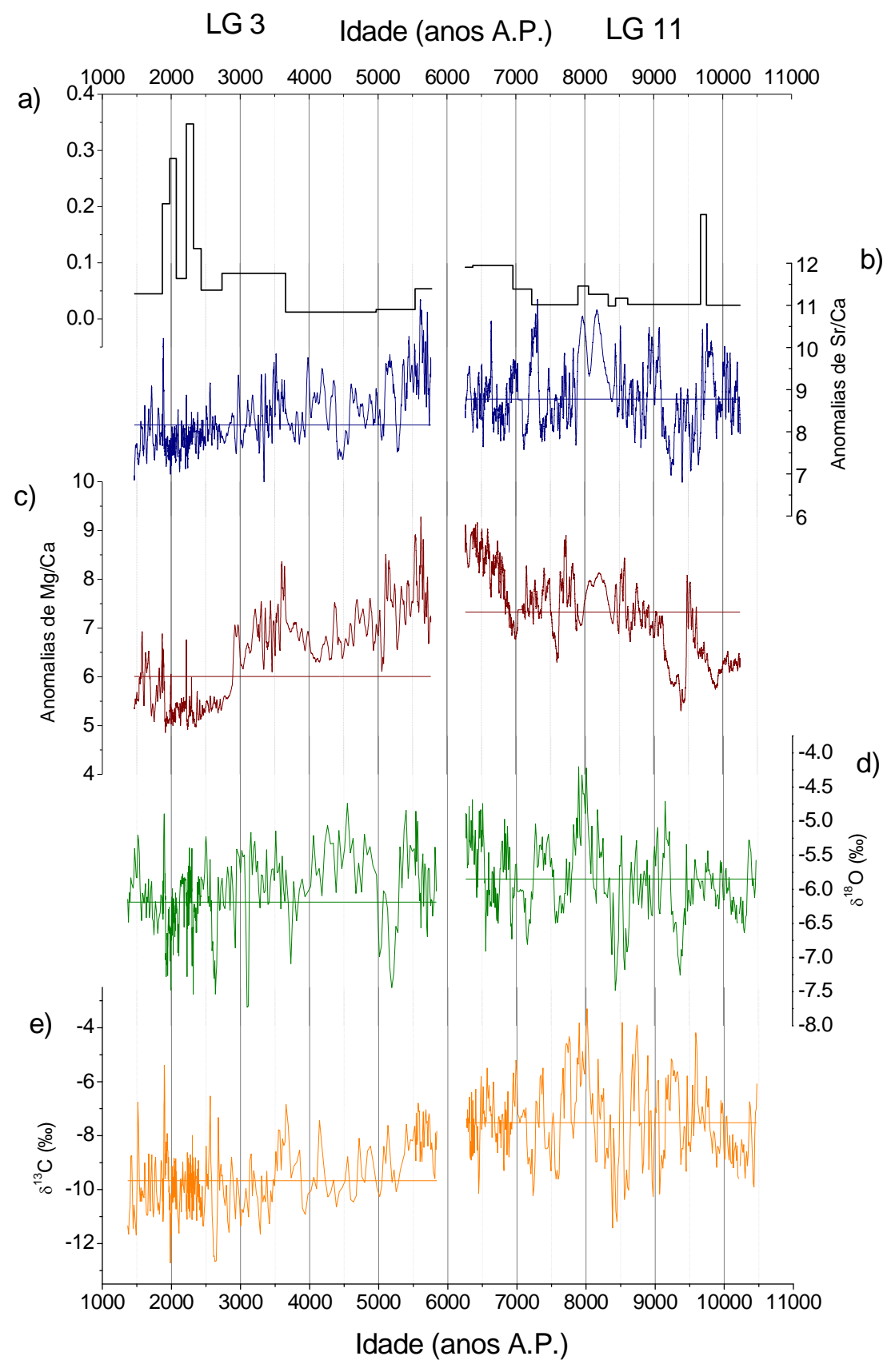

Figura 6.12 - Comparação entre: a) taxa de crescimento das estalagmites LG3 e LG11; b) variação da razão de Sr/Ca dada em anomalia (média móvel de 51 pontos para a estalagmite LG3 e interpolação de 111 pontos para a estalagmite LG11); c) variação da razão de $\mathrm{Mg} / \mathrm{Ca}$ dada em anomalia (média móvel de 51 pontos para a estalagmite LG3 e interpolação de 111 pontos para a estalagmite LG11); d) série isotópica de $\delta^{18} \mathrm{O}$; e) $\delta^{13} \mathrm{C}$.

Durante o Holoceno Médio, entre 5.5 e 3.5, o aumento da razão de $\mathrm{Mg} / \mathrm{Ca}$ ocorre de maneira concordante à variação de $\delta^{13} \mathrm{C}$, com uma excursão mais negativa em antifase com o sinal isotópico de $\delta^{18} \mathrm{O}$. O bom acoplamento entre os valores de $\delta^{13} \mathrm{C}$ e as razões de $\mathrm{Mg} / \mathrm{Ca}$ é observado ao longo de praticamente todo o Holoceno Médio e Superior. Comportamento semelhante ocorre para as razões de $\mathrm{P} / \mathrm{Ca}$ e U/Ca, por sua vez relacionada à queda da produtividade biológica (Fig 6.13). Já, 
as razões de $\mathrm{Sr} / \mathrm{Ca}$ apresentam pouca consistência com as razões de $\mathrm{Mg} / \mathrm{Ca}$. Entretanto, em vários trechos do Holoceno Médio e Superior ocorre bom acoplamento das razões de $\mathrm{Sr} / \mathrm{Ca}$ com as razões de $\mathrm{P} / \mathrm{Ca}$ e U/Ca (Fig 6.13 e 14). Isso sugere que fatores relacionados a produtividade dos solos, como formação de ácido carbono por exempolo, foi suficiente para maior mobilização de $\mathrm{Sr}^{2+} \mathrm{em}$ relação ao $\mathrm{Mg}$, já que esse cátion está mais associado a faixas mais solúveis da rocha carbonática encaixante, caracterizadas por composição mais calcítica (Karmann et al., 2007).

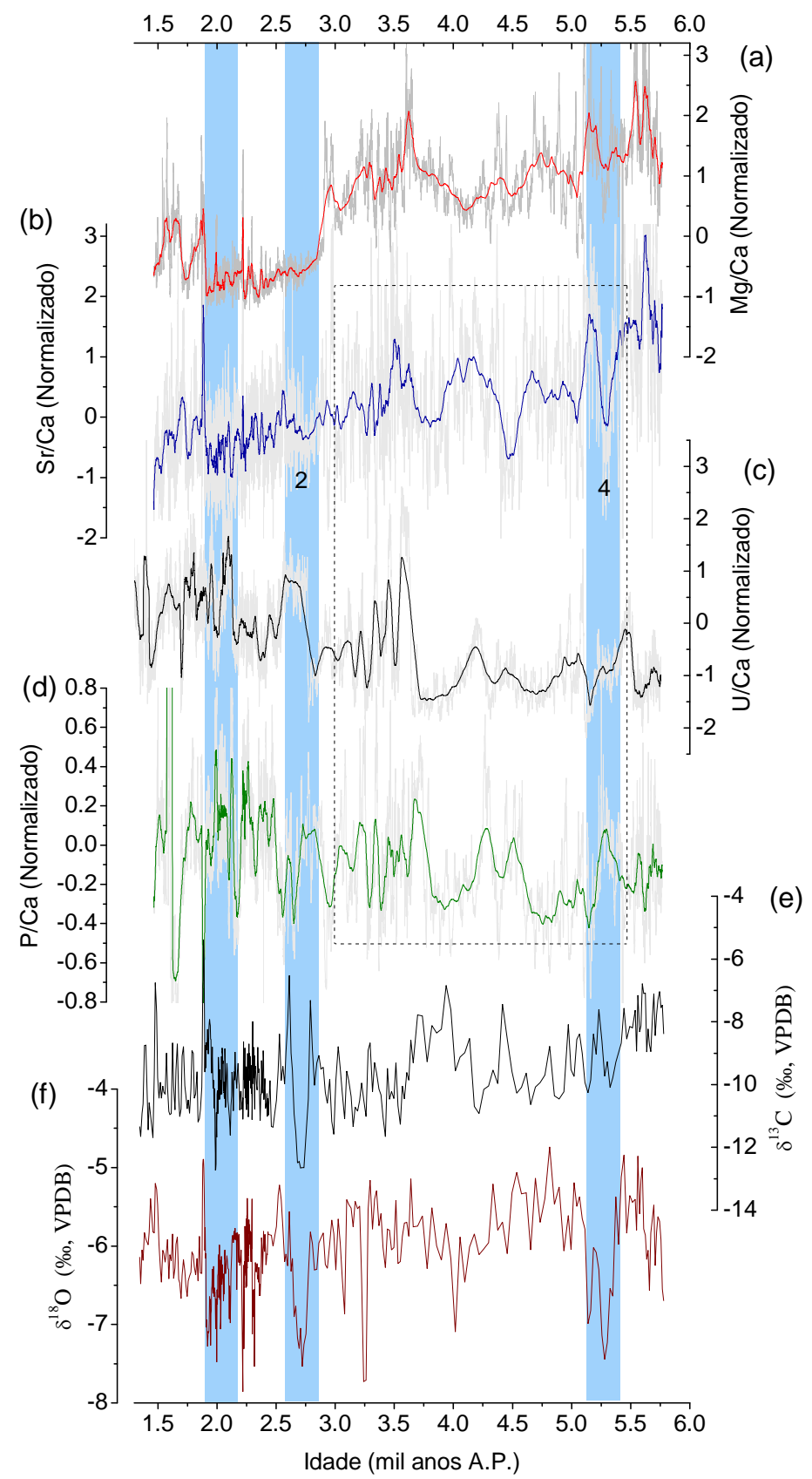

Figura 6.13. - Comparação entre: a) variação da razão de $\mathrm{Mg} / \mathrm{Ca}$ normalizada (a curva em preto representa a média móvel com interpolação de 101 pontos); b) o mesmo que em (a) porem para a razão de $\mathrm{Sr} / \mathrm{Ca}$; c) o mesmo que em (a) porém para a razão de $\mathrm{u} / \mathrm{Ca}$; d) o mesmo que em (a) porém para a razão de $\mathrm{P} / \mathrm{Ca}$; e) série isotópica de $\delta^{13} \mathrm{C}$; f) série isotópica de $\delta^{18} \mathrm{O}$. As barras em azul marcam os eventos de aumento de precipitação. 
Já na estalagmite LG12, existe um forte aumento dos valores de $\mathrm{Mg} / \mathrm{Ca}$ concomitante com um aumento mais brando das razões de $\mathrm{Sr} / \mathrm{Ca}$ e $\mathrm{Ba} / \mathrm{Ca}$ durante o evento Bølling-Allerød entre 14 e 13 mil anos A.P., que sugere aparente instalação de uma fase mais seca relacionada a uma provável queda no nível do aquífero vadoso, de modo a condicionar a formação de PCP (Fig. 6.15). Entretanto, apesar do aumento das razões de elementos traços na estalagmite LG12 coincidir com o aumento dos valores de $\delta^{18} \mathrm{O}$, estas descrevem uma correlação negativa com os valores de $\delta^{13} \mathrm{C}$, como pode ser observado na Figura 6.15.

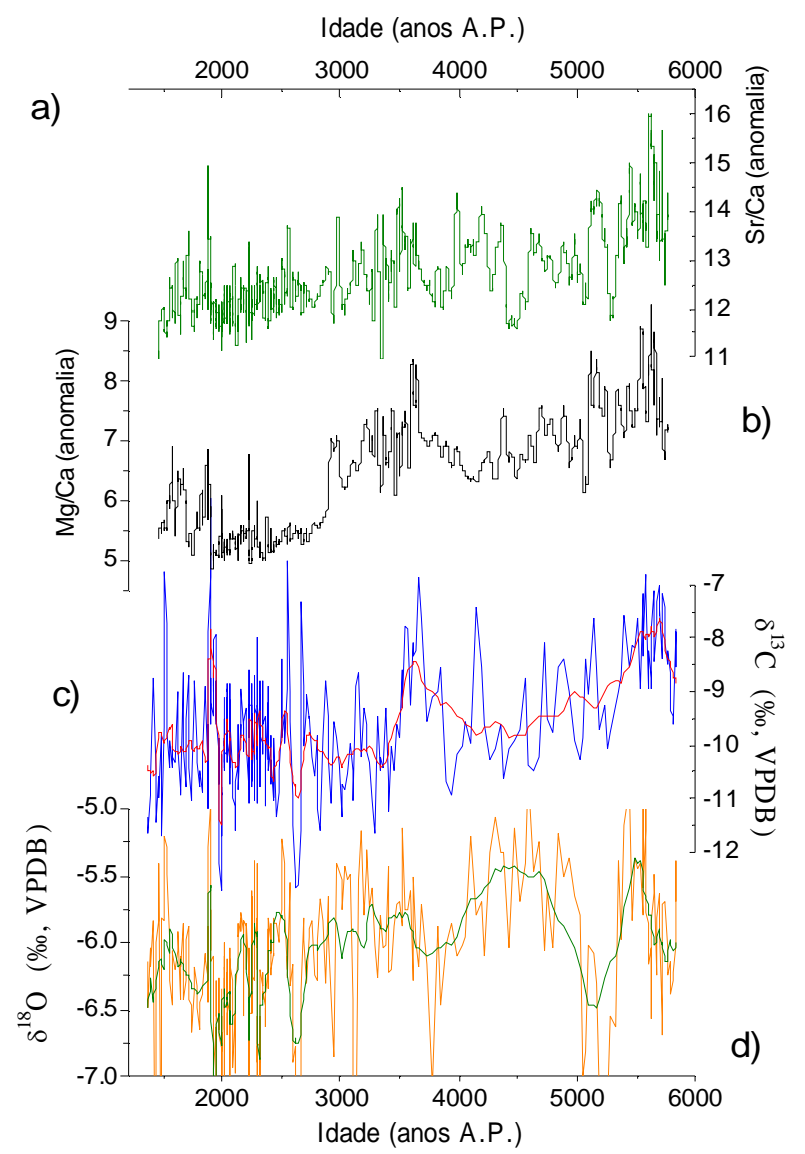

Figura 6.14 - Comparação entre: a) curva de média móvel de variação da razão de $\mathrm{Sr} / \mathrm{Ca}$ dada em anomalia (interpolação de 51 pontos); b) curva de média móvel da variação da razão de $\mathrm{Mg} / \mathrm{Ca}$ dada em anomalia (interpolação de 51 pontos ); c) série isotópica de $\delta^{13} \mathrm{C}$; d) $\delta^{18} \mathrm{O}$. As linhas em vermelho e verde representam as médias móveis com interpolação de 12 pontos das razões isotópicas.

Durante o Bølling-Allerød o aumento das razões de elementos traços não ocorre simultaneamente às variações isotópicas de carbono e oxigênio. Na verdade, a exceção das razões de $\mathrm{Sr} / \mathrm{Ca}$ e $\mathrm{P} / \mathrm{Ca}$, visivelmente mais acopladas aos dados de $\delta^{13} \mathrm{C}$, o aumento das razões de $\mathrm{Mg} / \mathrm{Ca}$ e $\mathrm{Ba} / \mathrm{Ca}$ ocorrem quase mil anos depois do início do evento seco, por volta de 14 mil anos A.P. 
Idade (mil anos A.P.)

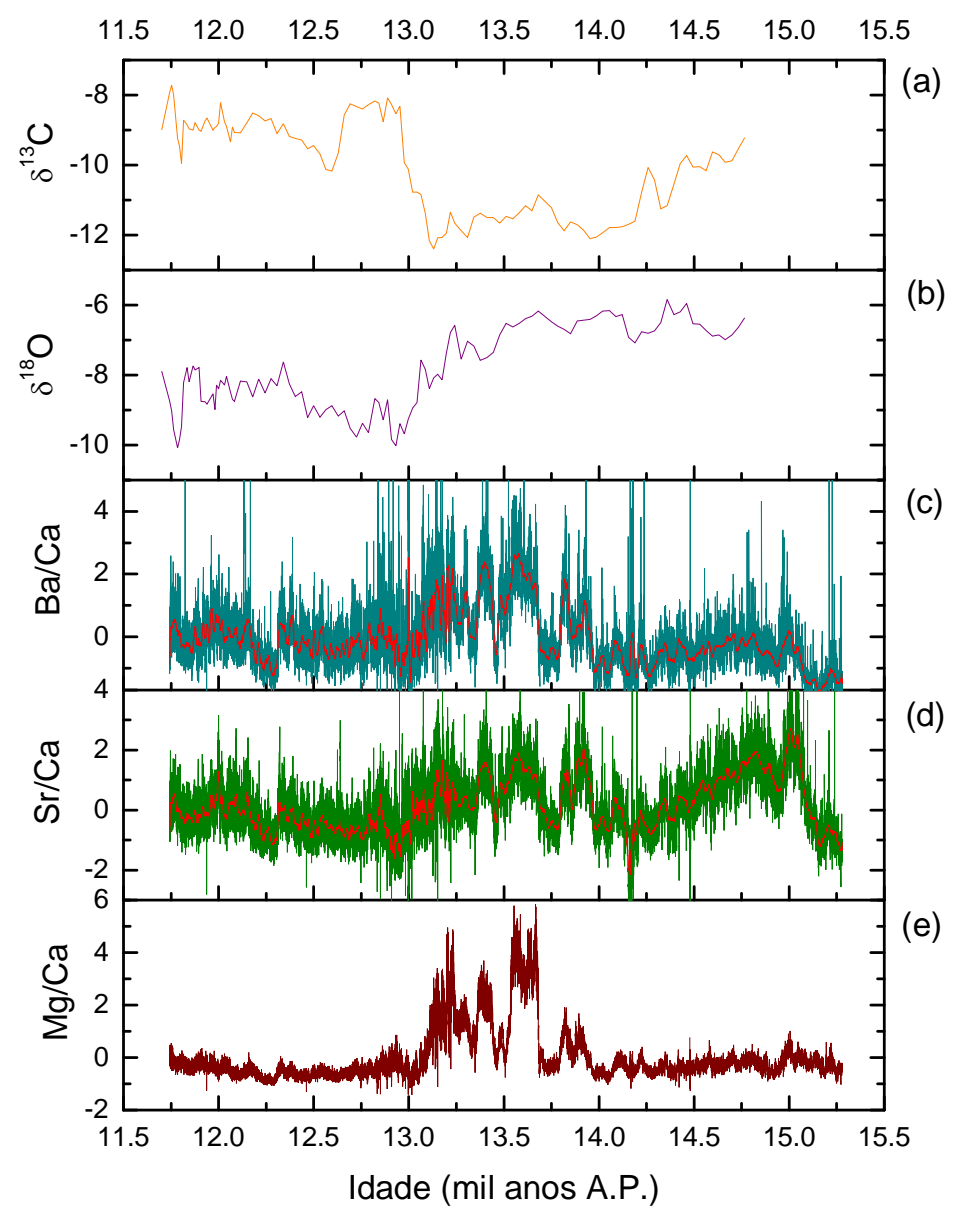

Figura 6.15 - comparação entre os registros isotópicos de $\delta^{18} \mathrm{O}$ (a) e $\delta^{13} \mathrm{C}$ (b) da estalagmite LG12 com os registros de elementos traços baseadas nas razões de $\mathrm{Ba} / \mathrm{Ca}$ (c) $\mathrm{Sr} / \mathrm{Ca}$ (d) e $\mathrm{Mg} / \mathrm{Ca}$ (e). As linhas em vermelho nos dados de $\mathrm{Ba} / \mathrm{Ca}$ e $\mathrm{Sr} / \mathrm{Ca}$ representam as curvas de médias móveis calculadas com interpolação de 101 pontos.

A co-variação positiva entre as razões de $\mathrm{Mg} / \mathrm{Ca}, \mathrm{Sr} / \mathrm{Ca}$ e $\mathrm{Ba} / \mathrm{Ca}$ com a curva isotópica de carbono aponta para a produtividade biológica e seu efeito na produção de ácido carbônico no solo como um dos principais fatores responsáveis pela mobilização de álcalis pela solubilização da rocha encaixante para água subterrânea, muito proeminente no período que compreende o Bølling-Allerød e o Young Dryas. Para testar essa hipótese, as razões de $\mathrm{Mg} / \mathrm{Ca}$ e $\mathrm{Sr} / \mathrm{Ca}$ foram comparadas às variações das razões de $\mathrm{P} / \mathrm{Ca}$ e $\mathrm{U} / \mathrm{Ca}$, tendo a vista que a concentração desses elementos, sobretudo o P, é fortemente relacionada à decomposição da matéria orgânica de origem vegetal (Fairchild et al., 2001; Treble et al., 2003). Como é possível observar na Figura 6.16, as variações de $\mathrm{Sr} / \mathrm{Ca}$ e $\mathrm{Ba} / \mathrm{Ca}$ estabelecem ao longo da série uma correlação positiva com a razão de $\mathrm{P} / \mathrm{Ca}$, com apenas algumas inversões localizadas durante o Bølling-Allerød. Variações sincrônicas de $\mathrm{P} / \mathrm{Ca}, \mathrm{Sr} / \mathrm{Ca}$ e $\mathrm{Mg} / \mathrm{Ca}$, sobretudo na transição entre o Bølling-Allerød e o Young Dryas, apontam para mudanças 
das condições do solo, associadas à eventos de diminuição da produtividade biológica ou mesmo redução da cobertura de solo devido a processos erosivos (Fig. 6.16).

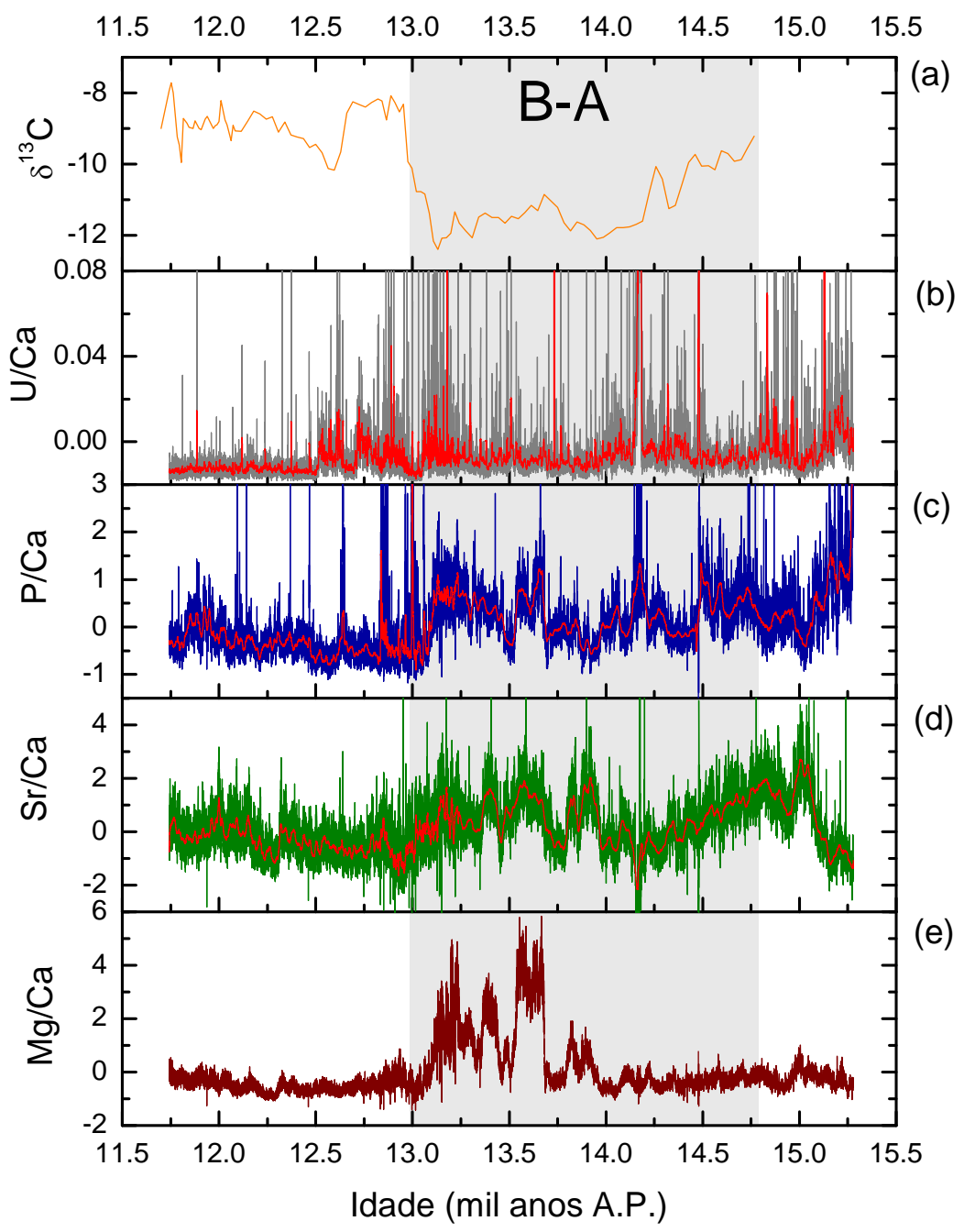

Figura 6.16 - comparação entre o registro isotópicos de $\delta^{13} \mathrm{C}$ (a) da estalagmite LG12 com os registros de elementos traços baseados nas razões de $\mathrm{U} / \mathrm{Ca}(\mathrm{b}), \mathrm{P} / \mathrm{Ca}(\mathrm{c}), \mathrm{Sr} / \mathrm{Ca}(\mathrm{d})$ e $\mathrm{Mg} / \mathrm{Ca}$ (e). As linhas em vermelho representam as curvas de médias móveis calculadas com interpolação de 23 pontos para a razão de $\mathrm{U} / \mathrm{Ca}$ e 101 pontos para as razões de $\mathrm{P} / \mathrm{Ca}$ e $\mathrm{Sr} / \mathrm{Ca}$. Os resultados estão normalizados.

Apesar da variação dos elementos traços ocorrer mais fortemente da metade para o final do Bølling-Allerød, na transição para o Young Dryas, as variações das razões de $\mathrm{Sr} / \mathrm{Ca}, \mathrm{Mg} / \mathrm{Ca}, \mathrm{Ba} / \mathrm{Ca}$ e $\mathrm{P} / \mathrm{Ca}$ ocorrem sincronicamente às variações de $\delta^{18} \mathrm{O}$ e $\delta^{13} \mathrm{C}$. Essa relação sugere que estas razões elementares são sensíveis ao aumento/diminuição de umidade, seja lá qual for o parâmetro climático/ambiental que modulou as concentrações dos elementos traços nas estalagmites em questão (Fig. 6.18). No caso das razões de $\mathrm{Mg} / \mathrm{Ca}$ propriamente dita, o aumento das concentrações durante o Bølling-Allerød dependeu aparentemente da maior taxa de dissolução da rocha 
carbonática, o que reflete maior taxa de deposição das estalagmites nas cavernas, que nesse foi mais modulada pela maior produtividade de $\mathrm{CO}_{2}$ no solo, que ocorreu mesmo sob redução de chuvas como sugere altos valores de $\delta^{18} \mathrm{O}$ nesse período (Fig. 6.18).

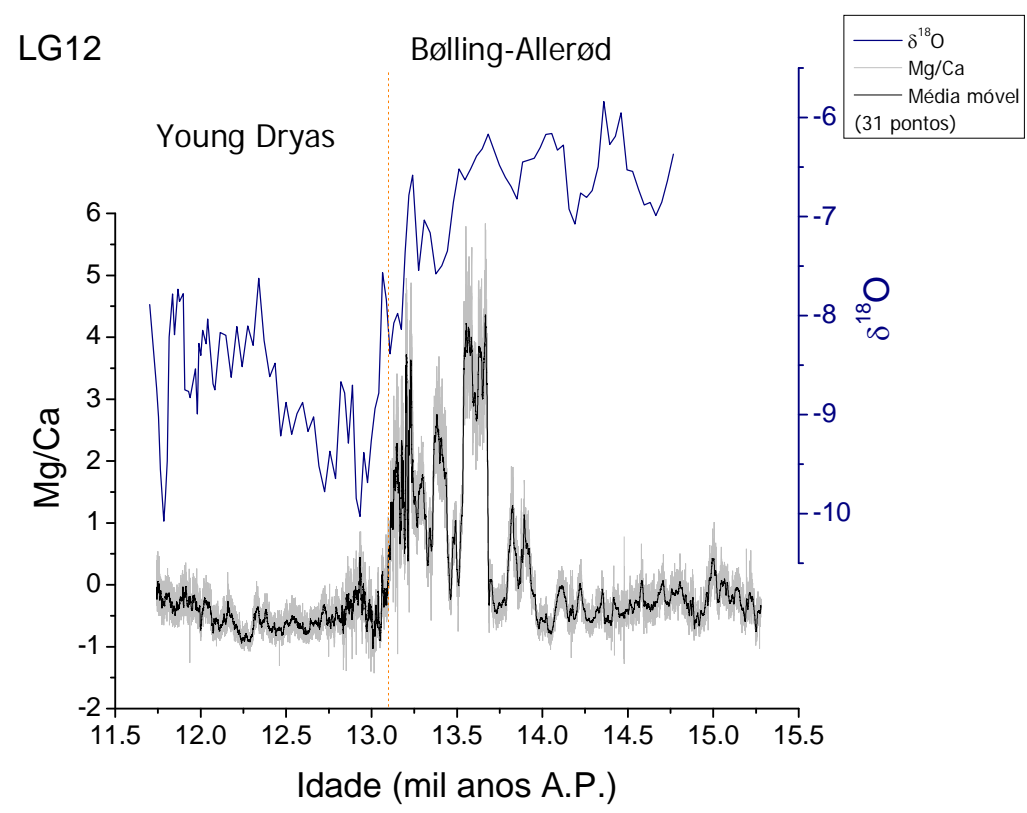

Figura 6.17 - Comparação entre a razão $\mathrm{Mg} / \mathrm{Ca}$ (abaixo) com os dados de $\delta^{18} \mathrm{O}$ para a estalagmite LG12. Os dados de $\mathrm{Mg} / \mathrm{Ca}$ são apresentados em cinza claro e em preto a curva de média móvel calculada para uma interpolação de 31 pontos.

\section{Significado paleoclimático das variações de elementos traços e dos isótopos de carbono}

O bom acoplamento das variações das TC com as curvas isotópicas de $\delta^{13} \mathrm{C}$ observadas sugere que a deposição de calcita na forma de estalagmites foi modulada não somente pela disponibilidade de água no sistema, mas também por variações geoquímicas da água de infiltração associadas aos processos que ocorrem na cobertura de solo sobre a caverna. Assim, as prováveis fases de aumento na produção de $\mathrm{CO}_{2}$ biogênico no solo, registrado pelos valores mais negativos de $\delta^{13} \mathrm{C}$ das estalagmites, correspondem a períodos onde houve maior dissolução de rocha no epicarste devido à maior formação de $\mathrm{H}_{2} \mathrm{CO}_{3} \mathrm{e}$, portanto maior acidez das águas de percolação no epicarste, traduzido pelo aumento dos valores de TC nas estalagmites. Por outro lado, a diminuição do $\delta^{13} \mathrm{C}$ $\mathrm{CO}_{2}$ dissolvido na forma do hidrogeno carbonato $\left(\mathrm{HCO}_{3}{ }^{-}\right)$reflete produção biogênica de $\mathrm{CO}_{2}$ no solo, assim como descrito em outras áreas cásrticas (Drysdale et al., 2004; Cruz et al., 2006b). Essa relação é mais bem observada no caso de espeleotemas onde as variações isotópicas de carbono e oxigênio variam de forma mais independente, como no caso das estalagmites LSF16 e LSF17, em 
que as taxas de crescimento estão mais atreladas aos processos do solo do que a disponibilidade de água. Nos casos onde há co-variação positiva entre o $\delta^{18} \mathrm{O}$ e $\delta^{13} \mathrm{C}$, a exemplo da estalagmite LSF3, LG3 e LG11, o aumento das TC ocorre mais associado ao aumento da disponibilidade hídrica em conjunto com a produtividade dos solos.

A principal questão no caso das amostras LSF16 e LSF17 reside no fato que se esperaria uma diminuição conjunta dos valores de $\delta^{13} \mathrm{C}$ e de $\delta^{18} \mathrm{O}$, ao invés do contrário, devido, por exemplo, ao aumento da produtividade do $\mathrm{CO}_{2}$ no solo ou adensamento de florestas (por maior contribuição de plantas do tipo C3) associada ao aumento de chuvas. O que ocorre na região das cavernas do Norte de Minas no período deglacial está provavelmente relacionado a mudanças nas taxas de erosão e deposição do solo sobre as áreas das cavernas. De fato, a espessura de solos que recobre os afloramentos carbonáticos da região é pouco expressiva sobre as cavernas Lapa Grande e Lapa Sem Fim. Também, a topografia acidentada do relevo na primeira e a distribuição das drenagens no entorno da segunda caverna sugere que a erosão do solo ocorreria com certa facilidade em períodos mais secos e de vegetação mais aberta, durante o período glacial.

O indício mais forte da remoção quase total da cobertura de solos são os valores positivos de $\delta^{13} \mathrm{C}$ observados na estalagmite LSF3, que em média gira em torno $+2 \%$, chegando até $+4 \%$ em alguns eventos durante o MIS2 (Fig. 6.5). No caso, o enriquecimento em ${ }^{13} \mathrm{C}$ seria devido à pouca contribuição de carbono de fontes biogênicas na formação do $\mathrm{CO}_{2}$ dissolvido nas águas de infiltração, relacionadas a perda da cobertura de solos. Desse modo parte expressiva da assinatura isotópica de carbono dos espeleotemas da Lapa Sem Fim reflete a composição isotópica da própria rocha encaixante, cujos resultados são de aproximadamente $+13 \%$ (Fig. 2.2) indicam que altos valores de $\delta^{13} \mathrm{C}$ observados nas estalagmites analisadas não estão relacionados a processos de fracionamento cinético.

A transição do evento úmido Heinrich 1 para o evento seco Bølling-Allerød registrado na estalagmite LSF16 é marcada por forte diminuição do $\delta^{13} \mathrm{C}$ e súbito aumento das TC. Como o aumento de TC implica também em maior dissolução da rocha encaixante, fica evidente que os valores mais baixos de $\delta^{13} \mathrm{C}$ seriam devido a um considerável aumento do $\mathrm{CO}_{2}$ biogênico dissovido nas águas de infiltração, mesmo que os dados de $\delta^{18} \mathrm{O}$ na mesma estalagmite indiquem estabelecimento de uma fase de redução hídrica na região (Fig. 6.5).

Essa relação inversa entre $\delta^{13} \mathrm{C}$ e $\delta^{18} \mathrm{O}$ se mantém na estalagmite LG12 durante o BøllingAllerød e na transição para o Young Dryas (Fig. 6.15a e Fig. 6.15b) e sugere associação com maior permanência da cobertura do solo sobre a caverna nesse período. Por outro, ficaria difícil explicar esse resultado através de maior produção de solos, devido condições climáticas desfavoráveis para isso. Nesse contexto, tais relações observadas principalmente durante a transição abrupta entre 
diferentes eventos de pluviosidade estão mais relacionadas ao fator erosão /ou permanência da cobertura do solo do que da sua deposição. As maiores erosões ocorreram na passagem de períodos secos para úmidos como do LGM para evento Heinrich 1 por volta de 19 ka A.P. e também do Bølling-Allerød para o Young Dryas em 13 ka A.P. , quando houve grandes mudanças climáticas na região (Fig. 6.6 e 6.7 ).

De acordo com Knox (1972) mudanças abruptas de clima seco para úmido relacionadas à incrementos substâncias de precipitação pode levar a fortes processos erosivos de encostas em virtude da maior exposição dos solos durante as fases mais secas. Auler et al. (2009) observam relações similares nos depósitos clásticos da região sul de Minas, onde períodos de condições climáticas intermediárias na transição entre eventos secos e úmidos favoreceram a erosão de sedimentos na área da caverna de Lagoa Santa. A relação apontada pelos autores corrobora as interpretações realizadas para as estalagmites LSF16 e LG12, onde mudanças do $\delta^{13} \mathrm{C}$ na transição entre os eventos Heinrich1 (úmido) - Bølling-Allerød (seco) - Young Dryas (úmido) seriam relacionadas a mudanças da espessura dos solos sobre a caverna associada a mudanças das taxas de erosão/deposição na superfície.

$\mathrm{O}$ aumento relativo da participação de $\mathrm{CO}_{2}$ biogênico durante o $\mathrm{B} \emptyset$ lling-Allerød associada às mudanças das condições do solo é apoiado pelas análises de elementos traços. Como é observado nas Figuras 6.15 e 6.16, o aumento das razões elementos traços pelo Ca ocorrem concomitante ao aumento do $\delta^{18} \mathrm{O}$ e a redução dos valores de $\delta^{13} \mathrm{C}$. Co-variações sincrônicas das razões de elementos traços com o $\delta^{13} \mathrm{C}$, caracterizadas pelo aumento das razões de $\mathrm{Sr} / \mathrm{Ca}, \mathrm{Ba} / \mathrm{Ca}, \mathrm{P} / \mathrm{Ca}$ e U/Ca durante as excursões mais negativas de $\delta^{13} \mathrm{C}$ apontam para a produção biogênica de $\mathrm{CO}_{2}$ como o principal fator responsável pela modulação das concentrações dos elementos traços nas águas de infiltração.

Aumento das razões de $\mathrm{Mg} / \mathrm{Ca}$ e $\mathrm{Sr} / \mathrm{Ca}$ durante períodos de redução de umidade tem sido comumente associada à deposição de carbonato secundário na zona vadosa, pelo mecanismo do Prior Calcite Precipitation (PCP), que é mais efetivo em fases de maior rebaixamento de N.A e ampliação da zona insaturada (Fairchild et al., 2000; Huang e Fairchild, 2001; Karmann et al., 2007; Oster et al., 2010; Lewis et al., 2011). Entretanto, esse parece não ser o caso das variações nas razões elementares registradas na estalagmite LG12 da caverna Lapa Grande, pois esse macanismo é inconsistente com a forte redução do $\delta^{13} \mathrm{C}$ observada durante o Bølling-Allerød. Na hipótese de PCP ser dominante se esperaria o contrário, pois a liberação do $\mathrm{CO}_{2}$ da solução geraria um forte aumento do $\delta^{13} \mathrm{C}$, em virtude da perda preferencial dos isótopos leves de $\mathrm{C}$ para a atmosfera durante a deposição da calcita na zona vadosa ou mesmo na ponta das estalactites.

Em virtude do exposto, sugerimos que períodos em que ocorre aumento relativo da concentração de elementos traços, a exemplo do Sr concomitante com a redução do $\delta^{13} \mathrm{C}$ podem ser relacionados à maior dissolução de rocha carbonática encaixante. Isso seria devido ao aumento da 
acidez das águas de infiltração gerado pelo aumento de $\mathrm{CO}_{2}$ biogênico no solo e consequente formação de $\mathrm{H}_{2} \mathrm{CO}_{3}{ }^{-}$, a exemplo do observado por van Beynen et al. (2008) em espeleotemas da Flórida. Além de possibilitar maior dissolução da rocha carbonática e possivelmente aumento das razões de elementos traços/Ca pela liberação preferencial de álcalis com coeficiente de partição menor que o do $\mathrm{Ca}$, a acidificação da água também facilita o transporte de cátions para os gotejamentos (van Beynen et al., 2008; Hellstrom e McCulloch, 2000). Essa hipótese é apoiada, sobretudo, pela co-variação positiva entre $\mathrm{Sr} / \mathrm{Ca}, \mathrm{Ba} / \mathrm{Ca}$ e $\mathrm{Mg} / \mathrm{Ca}$ com a razão de $\mathrm{P} / \mathrm{Ca}$, tendo a vista que o $\mathrm{P}$ é diretamente relacionado à formação de $\mathrm{PO}_{4}{ }^{2-}$ durante a decomposição da matéria orgânica de origem vegetal. Além do mais, os picos de U/Ca em fase com os períodos de máximo $\mathrm{P} / \mathrm{Ca}$ sugerem maior mobilização do radical uranila sob a forma de complexos fosfatados (Treble et al., 2003). Discordâncias locais entre as variações de Sr e P observadas durante o Bølling-Allerød podem ser relacionadas a variações da TC tendo a vista que a incorporação de Sr no retículo cristalino da calcita pode ter influência das variações da TC (Fairchild e Treble, 2008).

A amplitude da variação das razões $\mathrm{Mg} / \mathrm{Ca}$ durante o Bølling-Allerød está assim mais relacionada ao aumento do tempo de residência da solução de infiltração associada à instalação de uma fase mais seca, o que possibilitou a dissolução incongruente de dolomita na presença de calcita. A princípio calcita e dolomita dissolvem congruentemente, entretanto, após a solução atingir a saturação em relação à calcita a dissolução de dolomita ainda continua de modo a aumentar a concentração de Mg na solução (Fairchild et al., 2000; Roberts et al., 1998). Tendo a vista à ocorrência de níveis dolomíticos na Formação Sete Lagoas, a eventual dissolução incongruente entre calcita e dolomita condicionada pelo aumento do tempo residência da água de infiltração é compatível os picos de $\mathrm{Mg} / \mathrm{Ca}$ observados durante o final do Bølling-Allerød, seguido de forte queda com a instalação de uma fase chuvosa na transição abrupta para o Young Dryas (Fig. 6.17).

Durante o Holoceno os valores absolutos de $\delta^{18} \mathrm{O}$ residem num patamar muito próximo ao estabelecido durante o Bølling-Allerød, tido como um período relativamente seco, o que sugere que o Holoceno também foi seco, comparativamente aos eventos milenares úmidos e abruptos do período deglacial (Fig. 6.5 e 6.9). No Holoceno, diferentemente do que se observa durante o Bølling-Allerød, as variações de $\delta^{18} \mathrm{O}$ e $\delta^{13} \mathrm{C}$ variam de maneira concordante entre si e também com as razões de elementos traços, de maneira geral, principalmente com os dados de $\delta^{13} \mathrm{C}$. Assim, durante períodos mais secos, caracterizados por valores mais positivos de $\delta^{18} \mathrm{O}$, é observado aumento concordante entre os valores de $\delta^{13} \mathrm{C}$ e das razões de elementos traços. Essa relação positiva entre os isótopos de carbono e oxigênio com a curva de elementos traços sugere o PCP como o principal mecanismo atuante sobre a variação das concentrações de $\mathrm{Sr}$ e $\mathrm{Mg}$ nas soluções de infiltração durante o Holoceno como um todo (Fairchild et al., 2000; Huang e Fairchild, 2001). Nesse contexto, talvez a manutenção de uma fase relativamente seca, como foi o Holoceno inferior 
e médio, pode ter condicionado a formação de PCP nos condutos do reservatório cárstico da caverna Lapa Grande a ponto de tornar esse mecanismo ainda mais significativo na modulação da concentração de elementos traços (Fig 6.12).

\section{Reconstituição paleoclimática no norte de Minas Gerais}

Nesse tópico será feita uma reconstituição paleoclimática do norte de Minas Gerais com base nos registros isotópicos e das razões entre elementos traços/Ca. Os mesmos registros paleoclimáticos são discutidos em conjunto com outros obtidos nas regiões tropicais do continente Sul-americano e de outras partes do globo.

Com o objetivo de discutir a origem de certos eventos milenares os dados aqui obtidos serão comparados aos registros paleoclimáticos de altas latitudes mais utilizados na delimitação dos eventos climáticos do Pleistoceno Superior. A partir dessas comparações, é possível avaliar a significância das variações climáticas do norte de Minas frente às grandes mudanças climáticas de escala global.

Primeiramente, será apresentado o registro completo, a fim de permitir a intercomparação entre a variabilidade climática presente dentro de um contexto de período glacial, deglacial (27.5 e 10.0 mil anos A.P.) e interglacial, no caso o Holoceno (últimos 10 mil anos A.P.). Em seguida, será apresentada uma discussão mais detalhada do Holoceno.

\subsection{Variações de escala orbital e ciclos milenares}

Dentre os registros paleoclimáticos do Pleistoceno Superior, os registros de $\delta^{18} \mathrm{O}$ dos testemunhos de gelo de Groenlândia são considerados na literatura como os mais importantes na reconstituição de paleotemperatura da superfície da Terra; sendo o responsável pelas constatações de mudanças paleoclimáticas mais significativas das últimas décadas (Bond et al., 1997; Clement e Peterson, 2008). Em conjunto com testemunhos de gelo da Antártica e com o emprego de diversos indicadores paleoclimáticos, a exemplo das análises de metano, $\mathrm{CO}_{2} \mathrm{e}$ isótopos de hidrogênio $(\delta \mathrm{D})$, foi possível estabelecer a periodicidade e extensão dos ciclos glaciais dos últimos $~ 800$ mil anos, a partir dos quais constatou-se uma frequência média em torno de 125 mil anos (Jouzel et al., 2007; Ruddiman, 2008). Uma das características mais proeminentes dos resultados dos testemunhos de gelo da Groenlândia são as intensas variações climáticas de caráter abrupto, em escala milenar (Clement e Peterson, 2008). Em termos paleoclimáticos, os eventos abruptos milenares podem ser 
considerados com as feições mais marcantes do último glacial e são, basicamente, caracterizadas por elevações bruscas de temperatura da atmosfera da Terra interrompidas por novas quedas associadas à retomadas das condições glaciais (Dansgaard et al., 1993; Bond et al., 1993).

A reconstituição de eventos abruptos milenares no Atlântico norte foi em parte baseada no índice de concentração de clastos transportados por icebergs que evidenciam a expansão de gelo até latitudes muito mais baixas do que o limite alcançado. Esses depósitos são conhecidos como IRD (Ice Rafted Debries) e foram originalmente publicados por Harmut Heinrich em 1988. Desde então, esses eventos de IRD em testemunhos marinhos são intensivamente utilizados para demarcar períodos com quedas abruptas da temperatura da superfície do mar (TSM), as quais são sincrônicas com as registradas nos testemunho de gelo da Groenlândia. A partir dos picos de IRD observados por Dansgaard et al. (1993) e Bond e Lotti (1995) para os últimos 250 mil anos, foi possível estabelecer com clareza que, durante os últimos ciclos glaciais, a Terra foi submetida a fortes variações abruptas do clima em escala milenar relacionada ao acoplamento dos sistemas oceanoatmosfera.

Deste então, os eventos frios, definidos pelas variações sincrônicas entre os picos de IRD no Atlântico norte com os picos mais negativos de $\delta^{18} \mathrm{O}$ dos testemunhos de gelo da Groenlândia se tornaram conhecidos como "Eventos Heinrich". Em suma são períodos de frio extremo com duração média de 1.5 mil anos e com um intervalo médio de 1.47 mil anos entre os eventos (Broecker, 1994; Rahmstorf, 2002). Por outro lado, os períodos quentes, identificados por aumentos abruptos nos valores de $\delta^{18} \mathrm{O}$ dos testemunhos de gelo da Groenlândia, ficaram conhecidos com eventos Dansgaard-Oeschger (D-O) (Dansgaard et al., 1993). Os eventos D-O são também bem visíveis nos registros de TSM do oceano, a exemplo da curva baseada nas razões de insaturação de alquenonas nos sedimentos do Atlântico de Sachs e Lehmann (1999), e são caracterizados por extremas elevações de temperatura que podem gerar elevações das médias anuais de 5 a $10{ }^{\circ} \mathrm{C}$ nas zonas de altas latitudes do Hemisfério Norte no transcorrer de algumas décadas (Rahmstorf, 2002; Clement e Peterson, 2008). É importante ressaltar que, durante o deglacial, variações muito semelhantes e que seguem o padrão estabelecido pelos eventos Heinrich e Dansgaard-Oeschger são ainda mais marcantes, porém recebem nomes diferentes, como Young Dryas, evento equivalente ao que seria o último Heinrich, também referido com H0, e o evento Bølling-Allerød, equivalente aos eventos Dansgaard-Oeschger.

O reconhecimento do evento Young Dryas remonta o início do século XX, primeiramente registrado nos estudos paleoclimáticos de sedimentos lacustres do lago Allerød, na Dinamarca. $\mathrm{O}$ Young Dryas foi determinado pela ocorrência de níveis argilosos contendo restos de uma planta característica de tundra, conhecida como Dryas octopetela, sobrepostos a níveis ricos em matéria 
orgânica contendo restos de plantas da família das Bertulaceae. Essa última é característica de climas temperados do Hemisfério Norte. A partir desse registro bioestratigráfico, foi possível delimitar dois períodos climaticamente distintos conhecidos como Bølling-Allerød e Young Dryas (Anderson, 1997). Na verdade, o termo Young Dryas foi empregado para separar os níveis mais recentes, depositados por volta de 12 ka A.P., de ocorrência de restos de Dryas octopetela de outros níveis mais antigos depositados por volta de 16.5 ka A.P., denominados Oldest Dryas (equivalente ao Heinrich 1) e o Older Dryas que ocorreu entre os eventos Bølling e Allerød (Wohlfarth, 1996). Esses mesmos eventos são muito bem marcados nos registros isotópico dos testemunhos de gelo da Groenlândia, bem como nos registros de TSM das zonas de altas latitudes (Bond e Lotti, 1995; Bond et al., 2001; Isono et al., 2009; Rahmstorf, 2002; Sachs e Lehmann, 1999) e das regiões tropicais (Arz et al., 1999, 2001; Leduc et al., 2010; Marchitto et al., 2010; Weldeab et al., 2006).

Existe uma notável semelhança entre os registros isotópicos de $\delta^{18} \mathrm{O}$ do norte de Minas com os registros de $\delta^{18} \mathrm{O}$ dos testemunhos de gelo da Groenlândia (NGRIP), como pode ser observado na Figura 8.1. Nessa comparação, as variações climáticas de escala milenar registradas na reconstituição de paleotemperatura das zonas de altas latitudes do Hemisfério norte possuem forte correspondência com as variações de paleopluviosidade do norte de Minas. As fortes reduções de temperatura observadas durante os eventos Heinrich e Young Dryas na Groenlândia coincidem com aumentos equivalentes de paleopluviosidade no norte de Minas, associada às fases de intensificação da atividade do sistema de monções sul-americana (SMSA). Na comparação entre os registros notase não apenas a sincronia desses eventos, como também o fato da variação relativa de amplitude entre os eventos serem muito parecidas, a exemplo da amplitude entre o Heinrich e o Young Dryas (Fig. 8.1).

As diferenças mais significativas entre esses registros ocorrem durante o Holoceno. No norte de Minas os registros de $\delta^{18} \mathrm{O}$ apresentam variações de amplitude muito maiores em comparação com os dados de $\delta^{18} \mathrm{O}$ do NGRIP, mesmo que consideradas menos dramáticas que as observadas no período deglacial. A forte redução de amplitude observada no NGRIP entre outros registros de testemunhos de gelo levou a caracterizar o Holoceno como uma época climaticamente muito mais estável em relação ao deglacial e o glacial (Fig 8.1). 


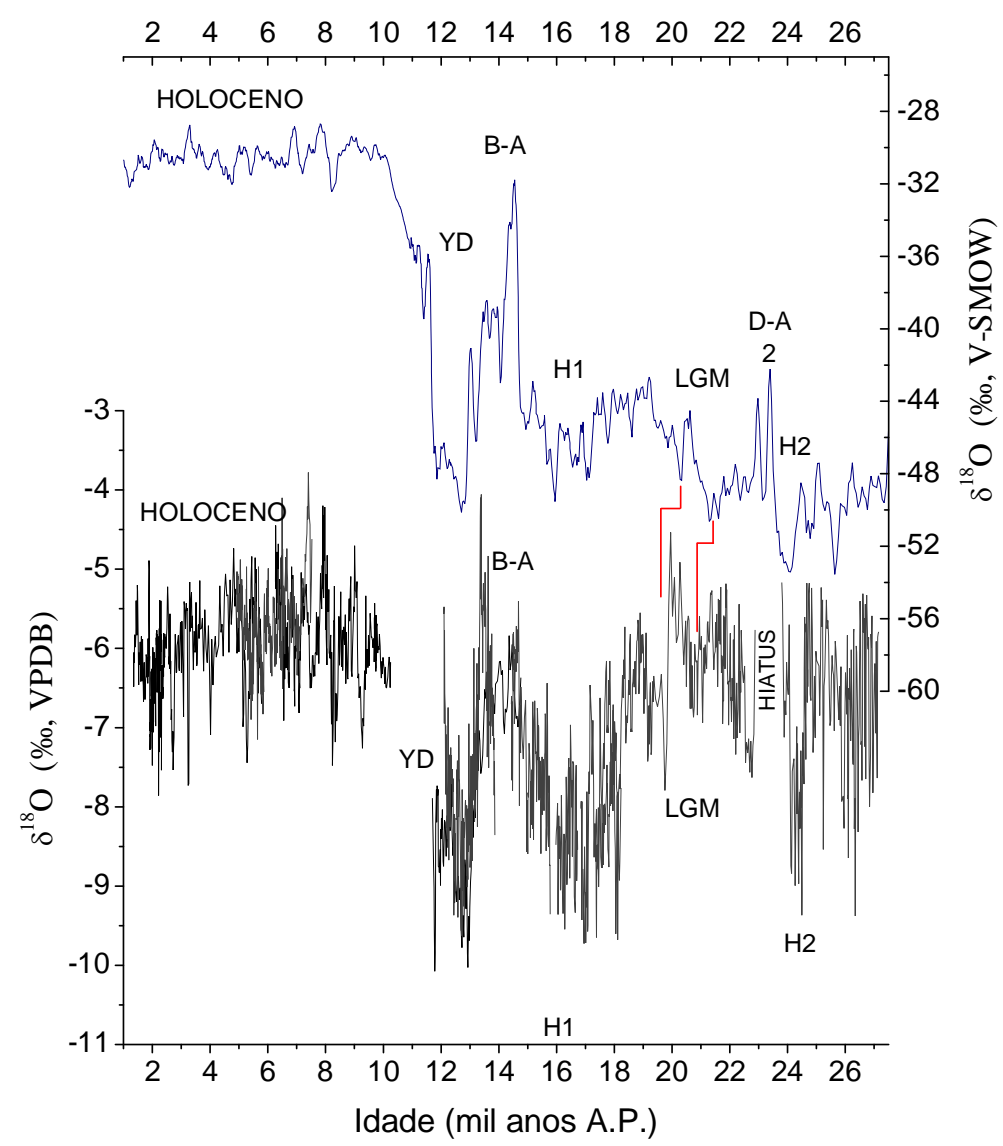

Figura 8.1 - Comparação entre as curvas isotópicas de $\delta^{18} \mathrm{O}$ do norte de Minas Gerais com o registro de variação de temperatura da Groenlândia baseado nas medições de $\delta^{18} \mathrm{O}$ de testemunho de gelo do programa North Greenland Ice Core Project (NGRIP) (North Greenland Ice Core Project members, 2004). Em preto estão apresentados os registros isotópicos da caverna Lapa Grande e em cinza os registros referentes a caverna Lapa Sem Fim. Os resultados analíticos de $\delta^{18} \mathrm{O}$ das estalagmites da caverna Lapa Sem Fim estão corrigidos de $1 \%$ para facilitar comparação entre registros das estalagmites da caverna Lapa Grande.

O Último Máximo Glacial (UMG) é referido como o período no qual as calotas polares e o gelo continental atingiram máxima expansão, concomitante à queda do nível do mar, cujo ápice ocorreu por volta de 21 mil anos atrás (Clark et al., 1999; Singarayer e Valde, 2010). Durante o UMG, o registro isotópico do norte de Minas apresenta estrutura formada por dois pontos de mínimo valor, secionados por um patamar de valores mais elevados de $\delta^{18} \mathrm{O}$ (Figura 8.1). A exceção desses eventos de aumento de precipitação de mais curta duração, o final do período glacial é caracterizado, de um modo geral, por clima tão seco quanto o observado ao longo do Holoceno e do Bølling-Allerød na porção norte de Minas Gerais, como sugere os valores mais altos de $\delta^{18} \mathrm{O}$ entre 27 e 19 mil anos A.P. em relação ao resto do registro.

Comportamento semelhante para o regime de precipitação monçônica pode ser encontrado nos registros de $\delta^{18} \mathrm{O}$ de espeleotemas estudados por Barreto (2010) em cavernas da Chapada Diamantina, região central do estado da Bahia, localizada a apenas $380 \mathrm{~km}$ a nordeste de 
Montalvânia, e também por Cruz et al. (2009a) em registros de espeleotemas do Rio Grande do Norte (Fig. 8.2). Evidencias de condições mais secas durante o UMG no nordeste do Brasil também foram observadas em registros lacustres (Jacob et al., 2007; Sifeddini et al., 2008). No mesmo sentido, modelações computacionais sugerem variações espaciais na distribuição de chuvas durante o UMG com respostas antifásicas entre o Nordeste e o Brasil central com a porção sudeste do continente (Wainer e Caluzet, 2005). Outro aspecto semelhante aos dados do nordeste é a falta de correlação visual entre as curvas de insolação de verão e a curva de $\delta^{18} \mathrm{O}$ durante o período glacial. Já no período deglacial existe uma aparente relação em fase entre insolação e a precipitação monçônica no norte de Minas, assim como observado na Bahia no mesmo período por Barreto (2010).

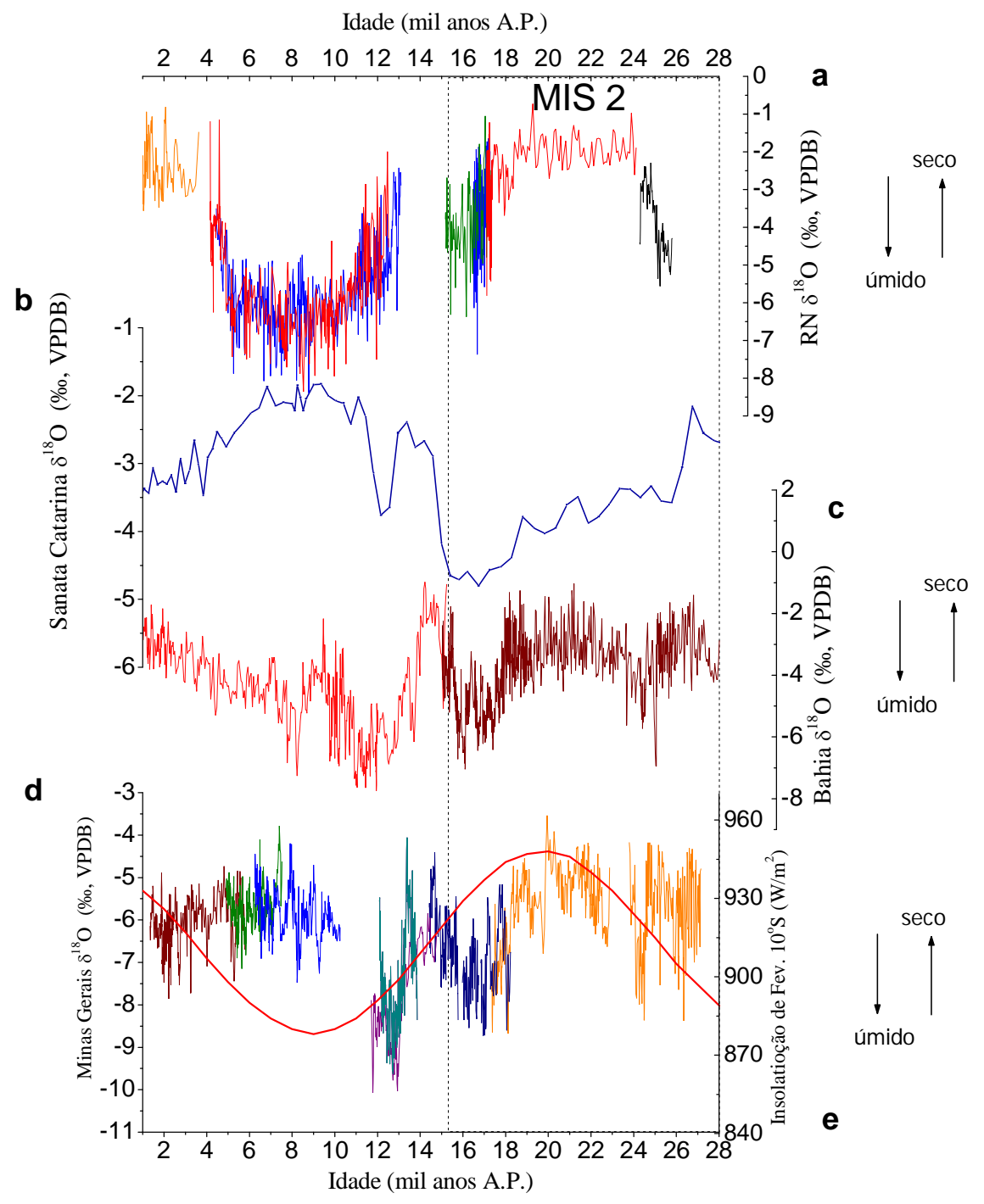

Figura 8.2 - Comparação entre a curva isotópicas do norte de Minas e de espeleotemas das regiões nordeste e sudeste do Brasil. (a) Rio Grande do Norte $\sim 5^{\circ} \mathrm{S}$ (Cruz et al., 2009a); (b) curva isotópica da a estalagmite BT2 de Santa Catarina $\sim 27^{\circ} \mathrm{S}$ (Cruz et al., 2005a); (c) curva isotópica da Chapada Diamantina, Bahia, $12^{\circ} \mathrm{S}$; (d) curva isotópica do norte de Minas dos registros das cavernas Lapa Grande e Lapa Sem Fim localizadas entre 14 e $16^{\circ} \mathrm{S}$ (e) curva de insolação de verão $10^{\circ} \mathrm{S}$ (Berger e Loutre, 1991). 
Em contrapartida, no mesmo período, registros de paleoprecipitação situados nos altiplanos andinos (Baker et al., 2001b; Fritz et al., 2004) e no sudeste do Brasil (Pessenda et al., 2009; Ledru et al., 2005; Cruz et al., 2005a, 2007) em adição a modelos computacionais de circulação atmosférica (Lee et al., 2009) apontam para condições mais úmidas durante o UMG relacionadas à intensificação da atividade do SMSA, por sua vez, atribuída ao deslocamento para sul da ZCIT. O deslocamento meridional da ZCIT é apoiado inclusive pelos registros de paleoprecipitação da China, que indicam clara diminuição das monções asiáticas durante o MIS 2 (Fig. 8.8).

Cruz et al. (2009) atribuiu ao padrão antifásico de precipitação monçônica entre a região nordeste e o restante da América do Sul (citada a sul da linha do equador) à intensificação de uma circulação zonal em altos níveis entre a zona de alta pressão formada na Bolívia, conhecida como alta da Bolívia, com o cavado do Nordeste. A Alta da Bolívia é formada durante a fase madura da monções (DJF), quando o movimento convergente de ar em baixos níveis gera alta pressão em altos níveis. Através do desenvolvimento de uma circulação W-E, é estabelecida sob os trópicos da América do Sul uma célula de Walker que promove o deslocamento dessa massa de ar rumo ao nordeste brasileiro e a subsidência no oceano Atlântico, próximo da região da costa do Nordeste do Brasil. A subsidência da massa de ar fria e seca em altos níveis promove circulação divergente de massas de ar em baixos níveis, fator esse que inibi a convergência de umidade para o continente e a formação de nuvens e por isso provoca clima seco na região (Cruz et al., 2009a). O padrão de movimentação das massas de ar estabelecido pela circulação zonal é bem representado na Figura 8.3.

Entretanto, a fase mais seca observada durante esse período não pode ser explicada apenas pela curva de insolação, tendo a vista que o platô observado nos registros isotópicos não encontra correspondência com o ciclo de precessão. A relação antifásica da pluviosiade do norte de Minas deve-se provavelmente a uma migração para sudoeste da Zona de Convergência do Atlântico Sul (ZCAS), relacionada ao fortalecimento da circulação meridional tipo Hadley e intensificação da alta da Bolívia, como indica os dados de espeleotemas da região sul e sudeste do Brazil (Cruz et al., 2009b). A mesma intensificação da Alta da Bolívia teria levado a um clima mais seco no nordeste, pois induz fortalecimento da circulação zonal tipo Walker que resulta em maior subsidência em altos níveis da troposfera e o estabelecimento do cavado do nordeste. Nesse contexto, a modulação da circulação zonal não pode ser explicada apenas pela variação de insolação descrita pelo ciclo de pressão, como observado por Cruz et al. (2009a), mas pela intensificação da pluviosidade em pelo menos parte da região amazônica. O clima úmido na região de origem da feição denominada de Alto da Bolívia estaria primariamente relacionado à maior convergência de umidade na Amazônia devido às baixas TSM's no Atlântico norte, durante fases de maior expanção do gelo (Chiang et al., 2003; Lee et al., 2009). 


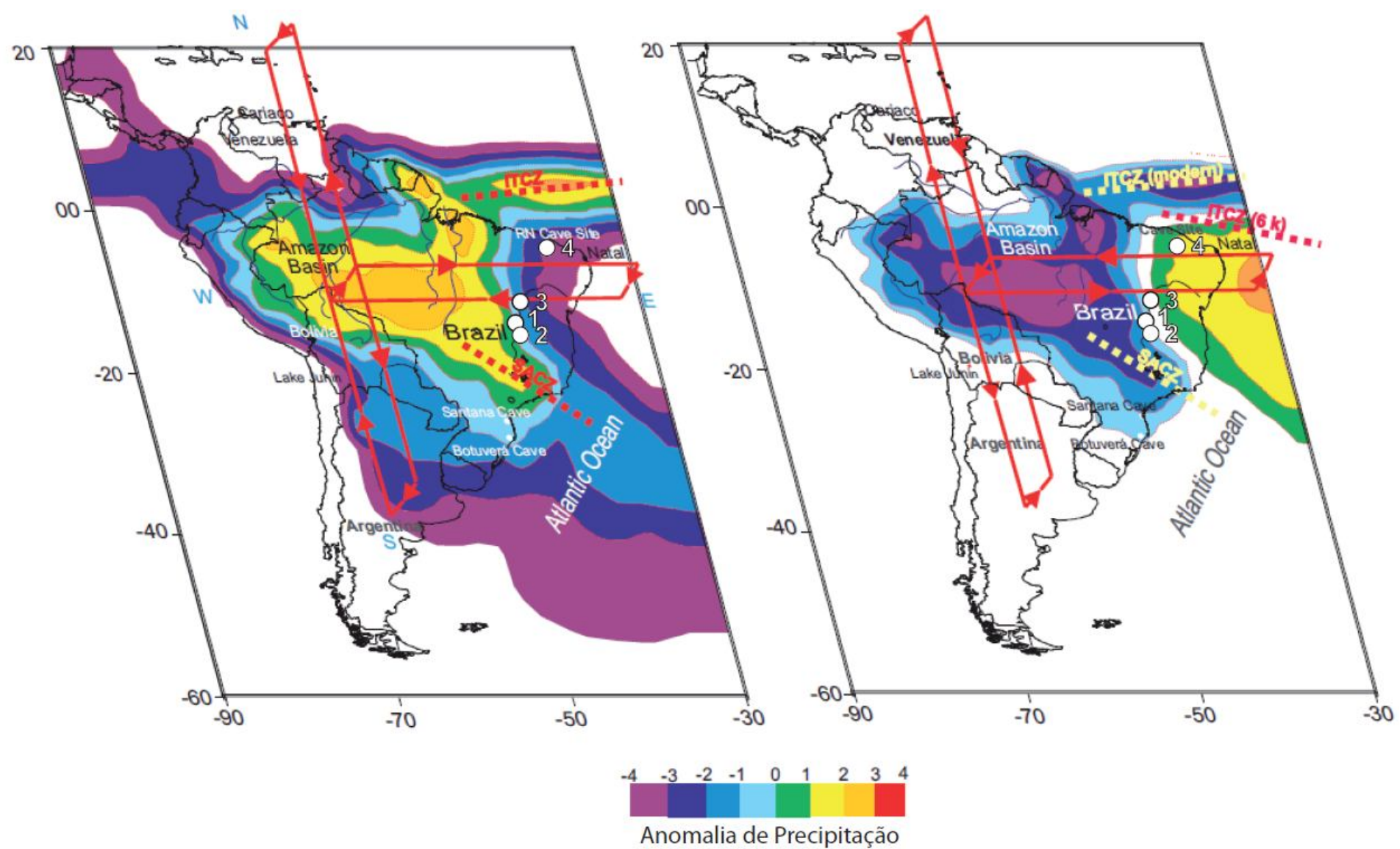

Figura 8.3 - Diagrama esquemático que ilustra relação entre os padrões de precipitação do verão na América do Sul (DJF) e as mudanças relacionadas na célula de Walker e de Hadley para os períodos correspondentes à fases alta insolação de verão no Hemisfério Sul durante os últimos 4 mil anos (imagem a esquerda) e ao período de baixa insolação no Hemisfério Sul entre 9.0 e 6.0 mil anos A.P. (imagem da direita). Os pontos 1 e 2 indicam a localização das cavernas Lapa Grande e Lapa Sem Fim respectivamente. O ponto 3 indica a localização dos registros isotópicos da Chapada Diamantina e o ponto 4 a localização do registro do Rio Grande do Norte. Modificado de Cruz et al. (2009a). 
Já durante o Holoceno as curvas isotópicas exibem um padrão em fase com o ciclo de insolação, em que o aumento de chuva ocorre simultaneamente com o aumento da insolação, de modo semelhante ao que foi observado por Cruz et al. (2005a e 2006a) e Wang et al. (2006) nos registros isotópicos de $\delta^{18} \mathrm{O}$ das cavernas Botuverá e Santana, no sudeste e sul do Brasil. Em oposição, os registros isotópicos do nordeste indicam nítida diminuição de chuva (valores mais altos de $\delta^{18} \mathrm{O}$ ) (Fig. 8.2). A relação em fase durante o Holoceno é realçada pela curva de $\delta^{13} \mathrm{C}$ que aponta para aumento da produtividade dos solos concomitante ao aumento da precipitação (Fig. 8.4). A queda acentuada durante a transição entre o Holoceno Médio e o Superior registrada pelo $\delta^{13} \mathrm{C}$ do norte de Minas é coerente com a tendência descrita pela curva de isolação e muito semelhante ao observado em registros dos trópicos relacionados à variação de paleoprecipitação (Haug et al., 2001; Fleitmann et al., 2003; Cruz et al., 2009a). Nota-se também que as quedas abruptas de $\delta^{13} \mathrm{C}$ também marcam a influência dos eventos abruptos de aumento de precipitação e da disponibilidade de $\mathrm{CO}_{2}$ biogênico no norte de Minas, que por sua vez são coincidentes com os eventos Bond 6, 5, 3 e 2 e com o evento 8.2 ky (Fig. 8.4).

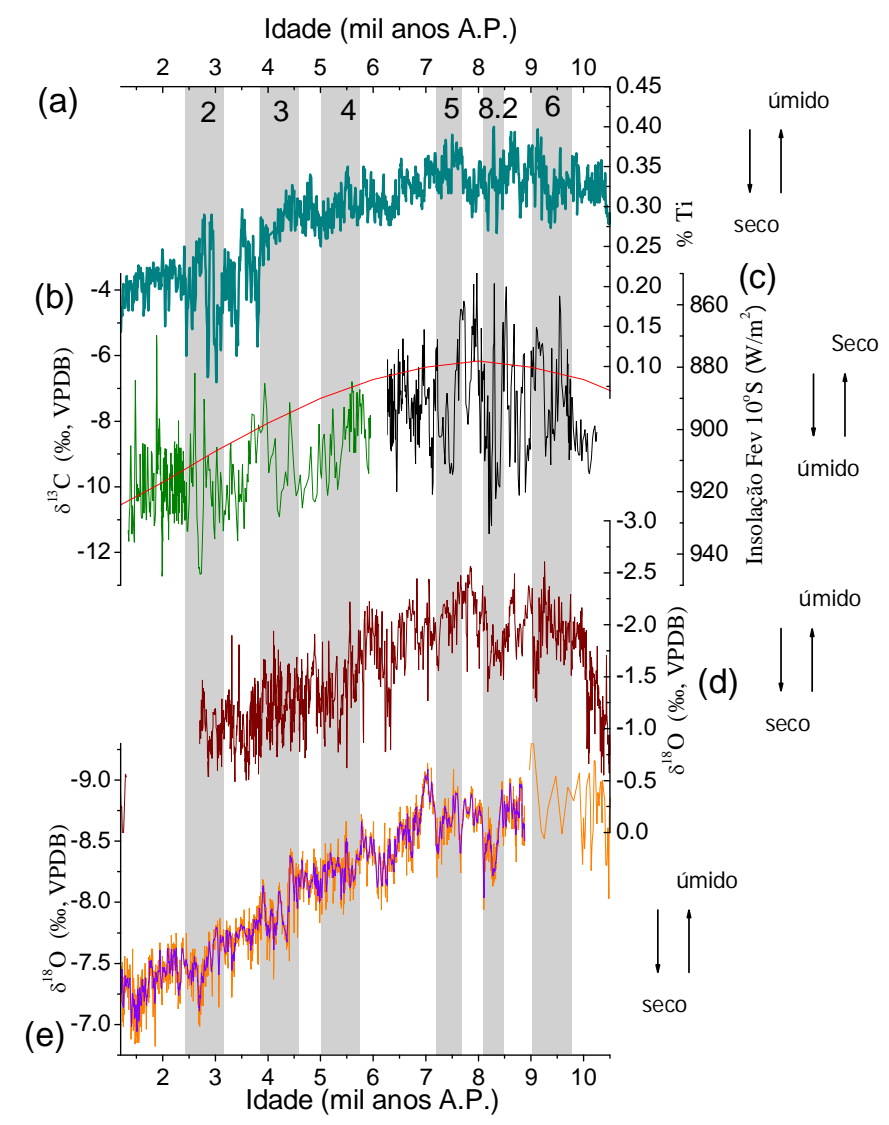

Figura 8.4 - Comparação entre a curva isotópica de $\delta^{13} \mathrm{C}$ do norte de Minas com registros de paleopluviosidade dos trópicos: (a) concentração de Ti da Bacia de Cariaco, Venezuela (Haug et al., 2001); (b) registro isotópico do norte de Minas formado pelas estalagmites da caverna Lapa Grande e Lapa Sem Fim localizadas entre 14 e $16^{\circ} \mathrm{S}$; (c) curva de insolação de verão $10^{\circ} \mathrm{S}$ (Berger e Loutre, 1991); (d) registro isotópico de estalagmites de Omã, península Arábica, $17^{\circ}$ N (Fleitmann et al., 2003); (e) registro isotópico das estalagmites DA e D4 da caverna Dongge, leste da China (Wang et al., 2005; Yuan et al., 2004). 
Portanto, a variação do padrão de pluviosidade modulado pela insolação de verão parece variar entre a região norte de Minas, que abrange as áreas das cavernas Lapa Grande e Lapa Sem Fim e a porção central da Bahia, mesmo que a distância em relação à Chapada Diamantina seja de apenas $380 \mathrm{~km}$. Esse quadro é coerente com o contexto de região limítrofe no qual se insere o norte de Minas em termos de relação entre precipitação e a variação na posição média da ZCAS em escala orbital. No caso do Holoceno a intensificação do regime de monções nos últimos quatro mil anos não foi o suficiente para deslocar a ZCAS para sudoeste a ponto de tornar a região mais seca, ao contrário do que aconteceu durante o período glacial, nas fases iniciais do MIS 2 (entre 28 e 19 mil anos A.P). Já no oeste (Wang, 2004; 2007b) e centro da Bahia (Barreto, 2010) parece haver uma desintensificação das chuvas devido atuação da ZCAS no mesmo período. Por fim, a amplitude de variação do $\delta^{18} \mathrm{O}$ observada nos últimos 4 mil anos do registro baiano é superior a $4 \%$, ou seja aproximadamente o dobro do valor observado no norte de Minas. Isso sugere que existe uma variação muito maior na distribuição das chuvas ao passo que se distancia a ZCAS, região de maior atividade do sistema de monções Sul-americanas, cujo eixo passa hoje por Brasília-DF. Além disso, é provável que o maior desenvolvimento do cavado do Nordeste tenha inibido a propagação das chuvas devido a ZCAS para a Bahia tanto no Holoceno como no período glacial em fases de maior intensidade das monções.

(a)

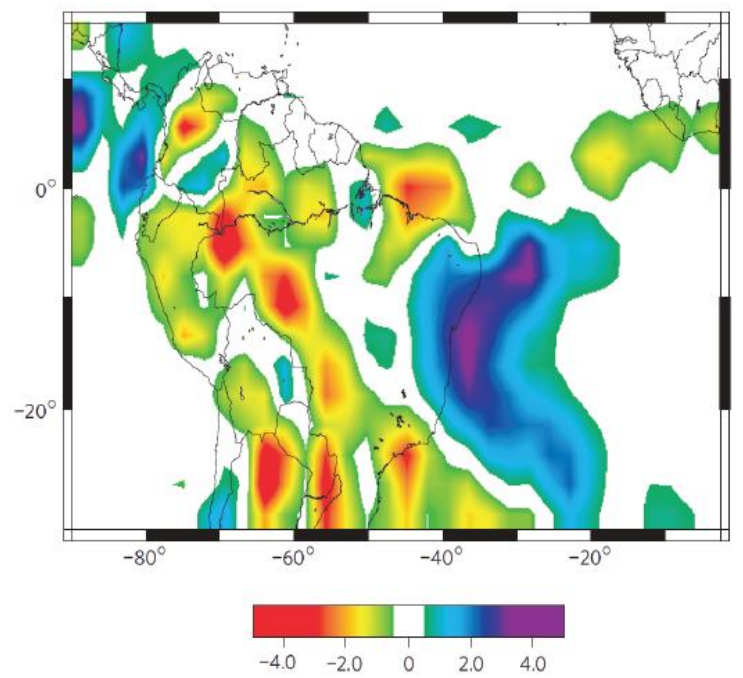

(b)

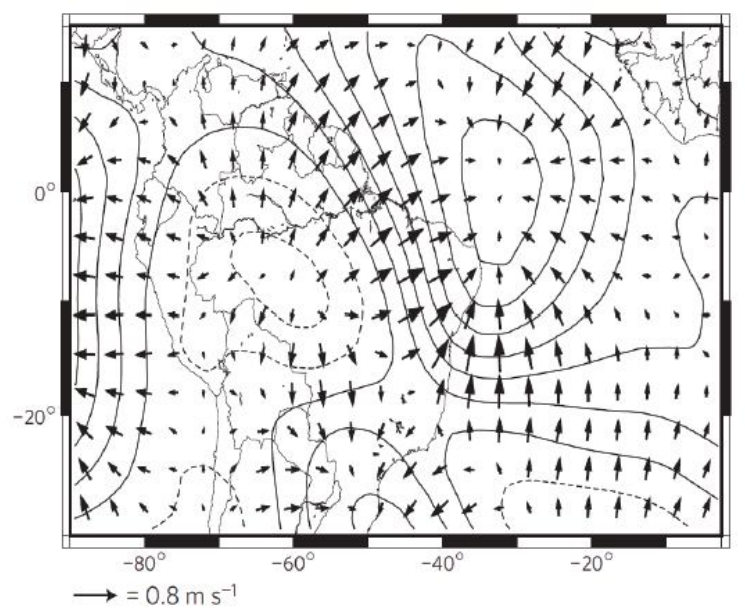

Figura 8.5 - Esquema mostrando o desenvolvimento do padrão de circulação zonal estabelecido entre o nordeste brasileiro e o sudeste durante período de fraca atividade do sistema de monção sul-americana. (a) diferença de precipitação (mm/dia) entre o verão e o outono austral (DJF-MAM) entre 6 mil anos A.P e o presente baseado na simulação do ECHAM-4; (b) como em "a" porém para a velocidade potencial à $850 \mathrm{hPa}$ (as linhas de isovalores são de $2.0 \times 10^{5} \mathrm{~m}^{2} / \mathrm{s}$; os valores negativos são representados pelos contornos tracejados), apresentando convergência (divergência) em baixos níveis na região nordeste (Bacia Amazônica). 
Diferentemente da variação da precipitação monçônica da América do Sul na escala orbital, eventos abruptos de escala milenar, a exemplo dos eventos Heinrich, promoveram forte aumento das chuvas de monções tanto na região nordeste quanto na região sudeste, o que inclui o norte de Minas (Barreto, 2010; Cruz et al., 2005a; Cruz et al., 2009; Wang et al., 2004; Wang et al., 2007). As anomalias positivas de precipitação monçônica registrada nos trópicos do Hemisfério sul são diretamente relacionados com o posicionamento mais a sul da ZCIT durante o verão austral, que condiciona o aumento da convergência de umidade dos oceanos para o continente (Cruz et al., 2005a; Cruz et al., 2009a; Wang et al., 2004; Wang et al., 2007). Durante os eventos milenares abruptos frios, a exemplo dos eventos Heinrich, o aumento das precipitações de monções é pervasivo em todo o território Sul-americano a sul da linha do Equador, enquanto tem-se forte decréscimo de precipitação no hemisfério oposto (Haug et al., 2001; Fleitmann et al., 2003; Wang et al., 2004; Wang et al., 2006; Cruz et al., 2005a). Esse padrão é muito bem definido quando comparado aos dados de espeleotemas da China (Wang et al., 2005; Wang et al., 2004; Wang et al., 2006).

A partir da comparação entre os registros isotópicos do norte de Minas com os demais registros paleoclimáticos relacionados a variações de disponibilidade hídrica nos trópicos da América do Sul, é possível verificar uma forte relação positiva das anomalias de precipitação durante os eventos frios abruptos registrados nas zonas de altas latitudes do Hemisfério Norte (Fig. 8.6). Como pode ser observado na Figura 8.6, variações positivas de precipitação durante os eventos Heinrich e Young Dryas são compatíveis com períodos de aumento do N.A dos paleolagos do Salar de Uyuni, indicados a partir de dados da variação da emissão natural de radiação $\gamma$ da coluna sedimentar (Baker et al., 2001b). Valores altos de radiação $\gamma$ estão diretamente relacionados com a deposição de lamas características de ambiente lacustres, que por sua vez, contrastam com níveis ricos em evaporitos depositados durante as fases de seca e que apresentam baixo índice de emissão de radicação $\gamma$. Concomitante com os períodos de aumento de precipitação registrados no norte de Minas e no Salar de Uyuni, os registros isotópicos de $\delta^{18} \mathrm{O}$ em testemunhos de gelo dos montes andinos de Sajama, Bolívia, e de Huascarán, Peru apresentam valores mais negativos (Fig. 8.6). Originalmente, relacionados com a diminuição de temperatura nos picos das montanhas (Thompson et al., 1995; 1998), atualmente o emprobrecimento isotópico de oxigênio e deutério são considerados evidência de aumento da precipitação na forma de neve (Vimeux et al., 2005), assim como interpretado para o registro do testemunho do monte Illimani na Bolívia (Ramirez et al, 2003). 


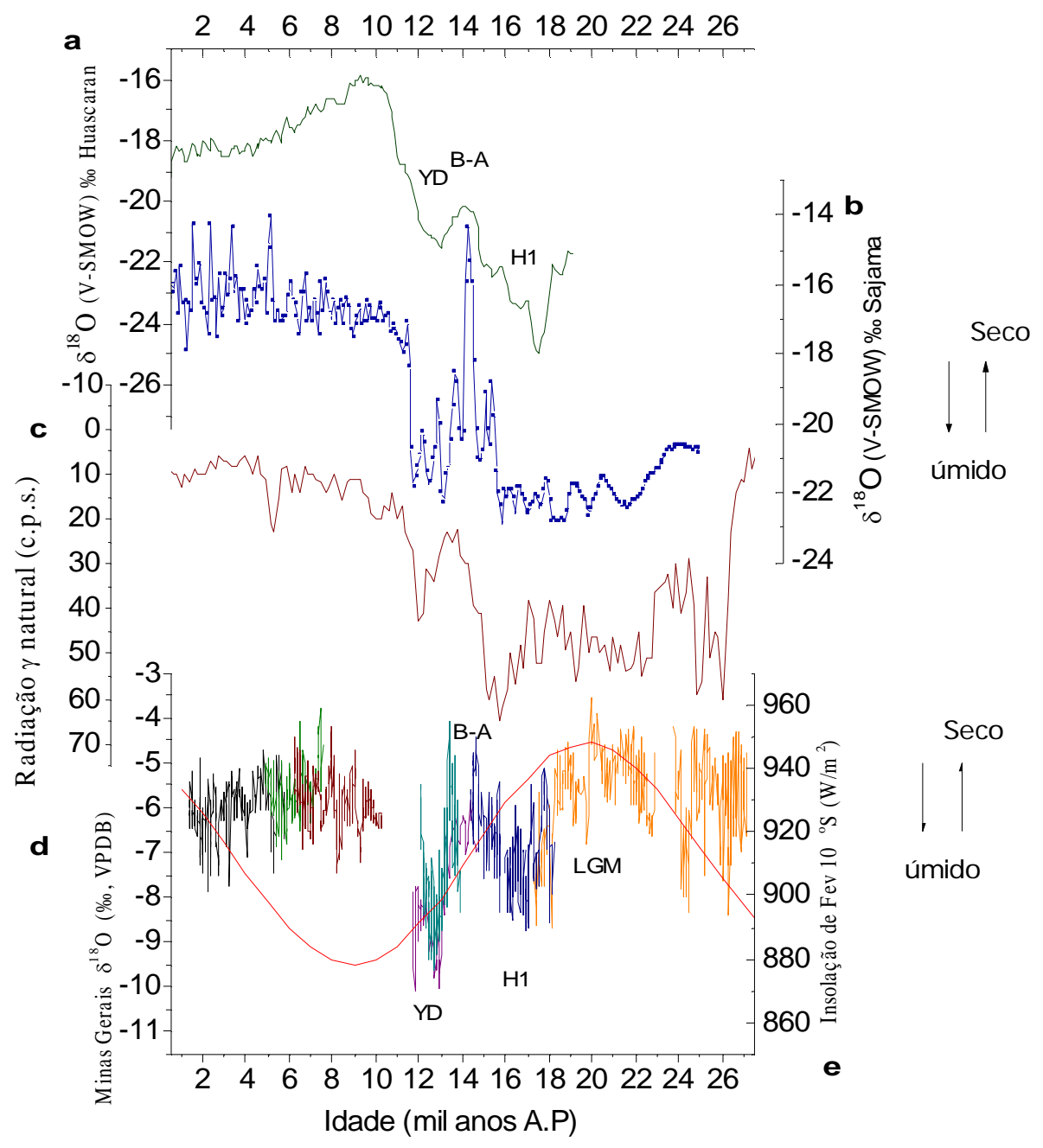

Figura 8.6 - Comparação entre registros de paleopluviosidade nas regiões tropicais da América do Sul. (a) $\delta^{18} \mathrm{O}$ do testemunhos de gelo de Huascarán, Peru, Thompson et al. 1995); (b) $\delta^{18} \mathrm{O}$ do testemunho de gelo do monte Sajama, Bolívia (Thompson et al., 1998); (c) variações do nível de água dos paleolagos do Salar de Uyuni, Bolivia baseado nas variações de radiação $\gamma$ (Baker et al., 2001b); (d) registro de paleopluviosidade do norte de Minas; (e) curva de insolação $10^{\circ} \mathrm{S}$.

Os dados do norte de Minas Gerais confirmam forte coerência na variação de pluviosidade em escala milenar em toda a América do Sul. Existe não apenas um sincronismo nas mudanças de precipitação, mas também uma semelhança geral na estrutura dos eventos registrados no período glacial. O evento Heinrich 1, um dos mais discutidos na literatura, é caracterizado por um intervalo de aumento máximo de precipitação logo no seu início próximo de 17 mil anos A.P. indicado por valores mínimos de $\delta^{18} \mathrm{O}$ e outro ao final do evento em 16.1. Esses resultados são consistentes com a diminuição de temperatura registrada através de valores mais baixos de $\delta^{18} \mathrm{O}$ dos testemunhos de gelo da Groenlândia. Essa relação fica bem evidente em escala continental na comparação do registro do norte de Minas com os registros de paleoprecipitação de alta resolução da Bahia (Barreto, 2010) e dos depósitos da Bacia do Rio de La Plata (Chiessi et al., 2009), como exposta na 
Figura 8.7. A mesma estrutura formada por um pulso duplo ocorre também durante o Young Dryas, com picos de máxima atividade do SMSA centrados em 12.8 e 11.7 mil anos A.P., observado com idades semelhantes nos registros de Cariaco (Peterson e Haug, 2006); Bahia (Barreto, 2010) e na China (Wang et al., 2006). Cheng et al. (2009) atenta para a mesma estrutura durante evento 8.2 ka (com um primeiro pulso em 8.2 e o segundo em 8.06 mil anos A.P.) nos registros de precipitação monçônica da China (Wang et al., 2005), Península Arábica (Fleitmann et al., 2003), Bahia (Wang et al., 2007b) e que também é evidenciado no norte de Minas. Esses duplos pulsos são coerentes com simulações computacionais da circulação termohalina durante $8.2 \mathrm{ka}$, os quais resultam de variações na intensidade da "Meridional Overturning Ocean Circulation (AMOC)" no Atlântico Norte, relacionadas a eventos pontuais de introgressão de água doce (LeGrande et al., 2006). Essas relações sugerem queas estruturas observadas no Young Dryas e no Heinrich estão possivelmente associadas a um padrão de variabilidade estabelecido pelo colapso da AMOC.

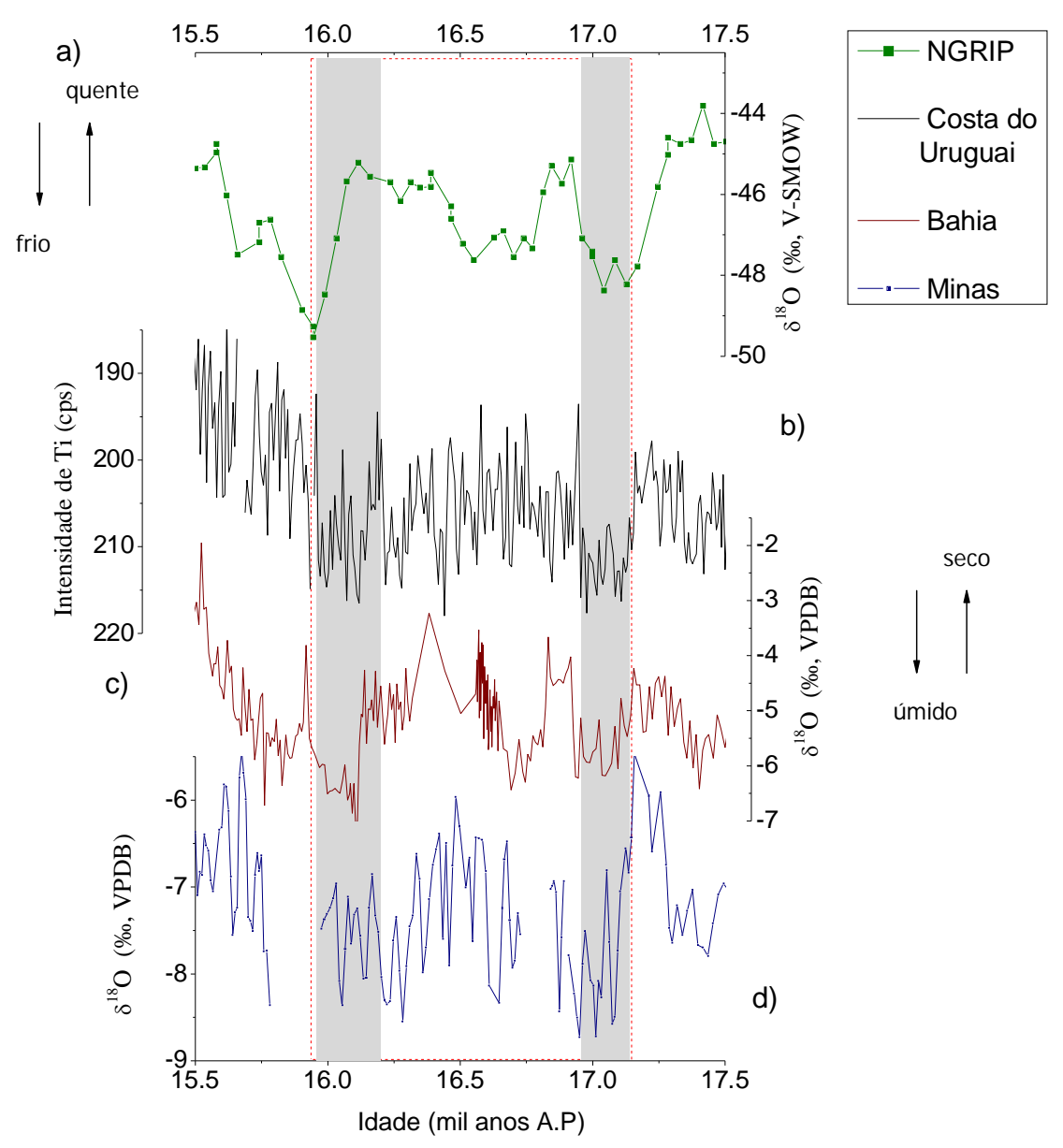

Figura 8.7 - Comparação do registro de paleopluviosidade do norte de Minas com os registros de paleoprecipitação do SMSA de Cariaco, da Bahia e da Bacia do rio de La Plata: a) $\delta^{18} \mathrm{O}$ de testemunho de gelo do programa (NGRIP); b) concentração de Ti testemunhos sedimentares da Bacia do Rio La Plata, costa do Uruguai, $34^{\circ} \mathrm{S}$ (Chiessi et al., 2009); c) curva isotópica da Chapada Diamantina, Bahia, $12^{\circ}$ (Barreto, 2010); curva isotópica do norte de Minas (estalagmite LSF16). 
No nordeste, evidencias de eventos milenares tipo Heinrich foram inicialmente observadas na região do semi-árido baiano através de fases de crescimento de espeleotemas da caverna Toca da Boa Vista, as quais exibem notável sincronismo com os eventos Heinrich 1, 4 e 6 além de indícios de fases úmidas durante o UMG (Wang et al. 2004). Evidencias de fases úmidas no período que abrange o UMG e o eventos Heinrich 1 foram sugeridas em estudos prévios baseados na datação de travertinos no norte da Bahia e na ocorrência associada de macrofósseis de folhas de espécies de plantas comuns a Mata Atlântica e Amazônia (Auler et al., 2001; Cristalli, 2006; Auler et al., 2004). A ocorrência abundante dos macrofósseis vegetais em tufas carbonáticas depositadas as margens de rios sugerem condições de alta umidade, atribuídas à expansão de florestas úmidas para região hoje ocupada pela Caatinga (Cristalli, 2006).

Os registros da lagoa Caçó, localizada próximo a costa do Maranhão, indicam também aumento abrupto de umidade durante o evento Heinrich 1 a partir de um acentuado e pontual aumento na sedimentação de siderita autigênica por volta de 17.0 mil anos A.P., acompanhado de um pico na deposição de poléns de Myrtaceae (Sifeddine et al. 2003; Jacob et al., 2007). Nesse contexto, o aumento da precipitação de chuva na região e a consequente expansão de florestas seria responsável pela mobilização de Fe para o interior da bacia, favorecendo a neoformação de minerais de ferro, a exemplo da siderita. Em concordância com o sugerido por Sifeddine et al. (2003), os registros polínicos da Lagoa Caço apresentados por Ledru et al. (2006) apontam para uma fase úmida durante o Heinrich 1, atribuída a um súbito aumento da concentração de pólen arbóreo (de níveis inferiores a $50 \%$ para 85\%) a partir de 17.5 mil anos A.P., principalmente de Melastomataceae/Combretaceae, Moraceas/Urticaeae, Mysine e Didymopanax (gênero com algumas espécies características de cerrado). Esse aumento de poléns arboriais ocorreu concomitante a um decréscimo de halophytes e Borreria, que são plantas características de terrenos encharcados e gramíneas, respectivamente.

Apesar do registro da lagoa Caço indicar aumento de umidade durante o Heinrich 1, o mesmo não é observado durante o Young Dryas. Da mesma forma, não se observa aumento de umidade nesse período nos registros de $\delta^{18} \mathrm{O}$ das cavernas do Rio Grande do Norte de Cruz et al. (2009a), em oposição aos registros da Chapada Diamantina e norte de Minas, bem como nos registros do sudeste do Brasil (Cruz et al., 2006a; Wang et al, 2006). Esse padrão em fase não poderia ser atribuído às variações das condições do oceano Pacífico devido ao ENOS como postulado por Clement e Cane (1999), pois os eventos La-Niña ou El-Niño produziriam padrão antifásico na pluviosidade das regiões Nordeste e Sudeste do Brasil (Wang et al., 2007a).

No Nordeste do Brasil, durante período que abrange o evento Bølling-Allerød, ocorre uma provável expansão de florestas atribuída à ampla ocorrência de espécies de plantas indicativas de 
clima úmido, no caso Myrtaceae e, mais subordinadamente, Podocarpus entre 17 e 12.8 mil anos A.P. em concordância com os registros polínicos apontados por Ledru et al. (2006). O acentuado aumento dos pólens de Myrtaceae durante o Bølling-Allerød pode indicar que, apesar de aparentemente seco em algumas áreas, como no Rio Grande do Norte (Cruz et al, 2009a), esse período foi ainda capaz de sustentar plantas de clima úmido na porção mais a oeste da região (Ledru et al., 2006). Essa relação é concordante com o observado nos registros de $\delta^{13} \mathrm{C}$ e elementos traços da caverna Lapa Grande que indicam considerável participação de $\mathrm{CO}_{2}$ biogênico nas águas de infiltração, possivelmente relacionados ao aumento da produtividade dos solos.

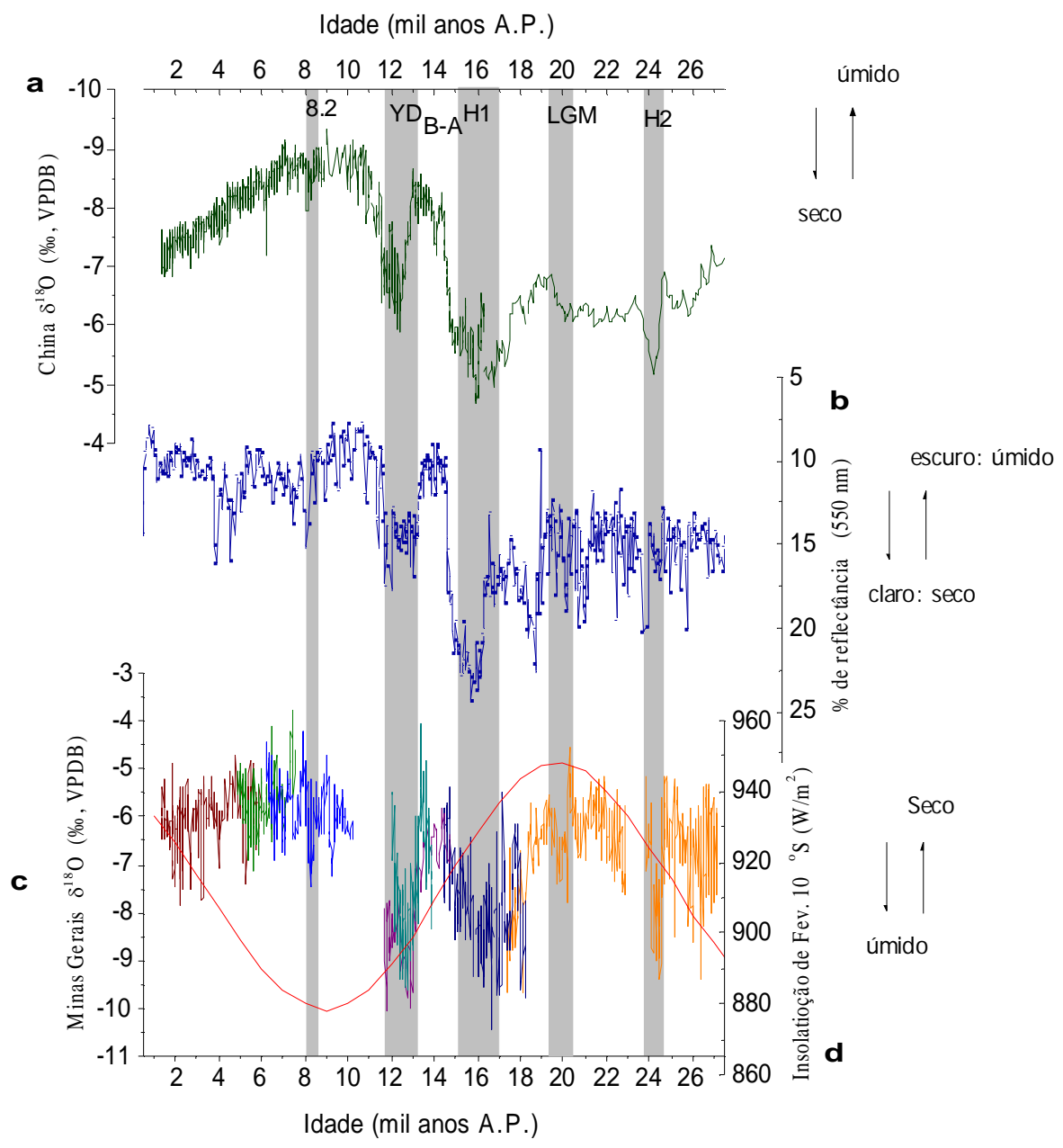

Figura 8.8 - Comparação do registro do norte de Minas com outros registros das regiões tropicais do Hemisfério Norte: (a) composição do registro isotópico de leste da China da caverna Dongge (Yuan et al., 2004; Wang et al., 2005) e Hulu (Wang et al., 2001); (b) registro de variação da concentração de matéria orgânica baseado na \% de reflectância dos sedimentos da bacia costeira de Cariaco, Venezuela (Peterson et al., 2000); (c) registro de paleopluviosidade de $\delta^{18} \mathrm{O}$ do norte de Minas; (d) curva de insolação a $10^{\circ} \mathrm{S}$.

Já, quando comparados com registros de paleopluviosidade das regiões tropicais do Hemisfério Norte, o registro isotópico do norte de Minas exibe uma perfeita relação antifásica nas 
variações de precipitação com os eventos de escala milenar. Como pode ser observado na Figura 8.8, períodos de anomalias positivas de precipitação no norte de Minas durante os eventos frios Heinrich 2, Heinrich 1 e Young Dryas coincidem com períodos de stress hídrico no leste da China (Wang et al., 2001; Wang et al., 2005; Yuan et al., 2004) e na bacia de Cariaco, Venezuela (Peterson et al., 2000). Na comparação entre registros, vê-se claramente que a diminuição dos valores de $\delta^{18} \mathrm{O}$ das estalagmites do norte de Minas é sincrônica com valores mais elevados de $\delta^{18} \mathrm{O}$ dos espeleotemas do sudeste da China e com aumento da reflectância dos sedimentos da bacia de Cariaco. Esses dados são, por sua vez, indicativos de diminuição de aporte de sedimentos terrígenos na área da bacia e aumento de resurgência a leste do mar do Caribe, ao passo que ocorre aumento de chuvas em Minas e secas no sudeste asiático e na costa da Venezuela respectivamente.

É provável que as diferenças nos padrões de precipitação observados durante os eventos abruptos de escala milenar e também durante as variações de insolação de verão, estejam relacionadas à natureza dos eventos e ciclos paleoclimáticos (Cruz et al, 2009b). Na discussão dos mecanismos controladores das chuvas relacionadas aos sistemas de monções, é importante considerar variações no gradiente de temperatura entre continente e oceano. Em escala orbital, a relação entre a convergência de umidade e as variações de precipitação é impulsionada pelo aumento relativo da temperatura do continente em relação à temperatura do mar devido à relativa inércia do oceano em responder ao aumento de insolação de verão (Biasutti et al., 2004). Já o transporte de umidade para o continente durante os eventos milenares dependeria principalmente do gradiente de TSM entre o oceano Atlântico tropical a sul e a norte do equador, assim como acontece em tempos modernos (Vera et al., 2006).

No caso dos eventos abruptos milenares, a exemplo dos eventos Heinrich, a flutuação de TSM estaria relacionada a variações da circulação oceânica associadas ao enfraquecimento da circulação termohalina com consequente aumento do gradiente térmico entre os trópicos e as zonas de altas latitudes, sobretudo do Hemisfério Norte (Hemming, 2004; Rahmstorf, 2002; Rudimann, 2008). Como dito anteriormente, os eventos Heinrich são caracterizados por períodos de frio extremo que promovem fortes reduções da temperatura da atmosfera e da superfície do nível do mar no Atlântico norte (Heinrich, 1988; Dansgaard et al.,1993; Bond e Lotti, 1995 e Rahmstorf, 2002). De maneira geral, os eventos Heinrich são relacionados à redução da circulação termohalina, também referida na literatura como AMOC gerada, possivelmente, pela introgressão de água doce proveniente do derretimento de geleiras no Atlântico norte, ao final dos eventos DansgaardOescheger (Arz et al., 1999; Rahmstorf, 2002; Zhang e Delworth, 2005; Timmermann et al., 2007). A redução da atividade da AMOC, ou mesmo seu completo desativamento, afetaria a distribuição de calor do Atlântico. Isso porque a quebra do gradiente de densidade causado pela libertação de água doce, reduz a formação das águas profundas do Atlântico norte, mais conhecida como NADW, 
do inglês North Atlantic Deep Water, responsável pelo transporte das águas frias superficiais do Atlântico norte para o sul (Hemming, 2004). O inevitável resfriamento das águas do Atlântico norte se propagaria então para atmosfera, intensificando os jatos polares e consequentemente a atividade do anticiclone extratropical do Atlântico norte, na região da alta dos Açores. A expansão dessa alta resulta na intensificação dos ventos alísios de NE, que por sua vez vai esfriar o oceano Atlântico norte e deslocar a ITCZ para sul ou do lado onde o oceano estaria mais quente (Chiang e Koutavas, 2004).

A desativação da AMOC e o consequente resfriamento do Atlântico norte e aquecimento do Atlântico Sul produz um efeito "gangorra" inter-hemisférico de TSM, mais comumente conhecido na literatura pelo termo em inglês "see-saw effect" (Barker et al., 2009; Broecker, 1998; Timmerman et al., 2007; Chiessi et al., 2008; McManus et al., 2004; Vellinga e Wood, 2002). Esse padrão foi observado em diversos registros paleoclimático tanto na comparação entre os testemunhos de gelo da Groenlândia (NGRIP e GRIP) com os da Antártica (Vostok e Byrd), como nas comparações entre as TSM do Atlântico Sul e Norte (Bond et al., 1995; Blunier e Brook, 2001; Jaeschke et al., 2007; Chiessi et al., 2008) e em diversos modelos computacionais de circulação oceânica-atmosférica (Claussen et al. 2003).

A intensificação das precipitações relativas ao SMSA no norte de Minas durante os eventos abruptos frios e sua relação antifásico com os registros de precipitação monçônica do Hemisfério norte indica manutenção do gradiente de TSM entre o Atlântico tropical sul e norte durante tais eventos. Nesse contexto, a exemplo do observado durante as fases de AMO negativo, o deslocamento para sul da ZCIT é condicionado pela diminuição da TSM do Atlântico tropical norte em relação ao Atlântico tropical sul. Condições de TSM favoráveis ao deslocamento da ZCIT para sul são observadas por Weldeab et al. (2006), Arz et al. (1999) e Jaeschke et al. (2007) na região costeira do Nordeste brasileiro desde o Young Dryas ao Heinrich 6. Esse padrão de variação da TSM do Atlântico tropical sul evolui ao mesmo tempo que ocorre aquecimento progressivo da Antártica, como pode ser observado na Figura 8.9. Além disso, modelos computacionais de circulação atmosférica e oceânica a exemplo de Vellinga e Wood (2000) indicam aumento de precipitação e de TSM no Atlântico tropical sudoeste em resposta a redução da formação da NADW.

Um aspecto importante e que chama a atenção na comparação entre as curvas de TSM do Atlântico tropical Norte e Sul, exposta na Figura 8.9, é o sutil aumento da TSM durante o Young Dryas observado na costa do Nordeste do Brasil (Jaeschke et al., 2007; Weldeab et al., 2006), em forte oposição ao observado na costa da Venezuela (Lea et al., 2003). Essa relação pode explicar a diferença de amplitude entre o Young Dryas e o Heinrich 1 nos registros de Minas e na Bahia que, em comparação com outros registros relacionados a precipitação monçônica no Hemisfério sul e 
norte, apresenta um Young Dryas muito mais forte. Nesse contexto, o acentuado aumento gradiente de TSM estabelecido durante o Young Dryas no Atlântico tropical oeste promoveu considerável aumento da convergência de umidade do oceano para o interior da bacia amazônica e consequente intensificação do transporte de umidade pela ZCAS, o que explicaria a amplitude do Young Dryas no registro norte mineiro (Fig. 8.9).

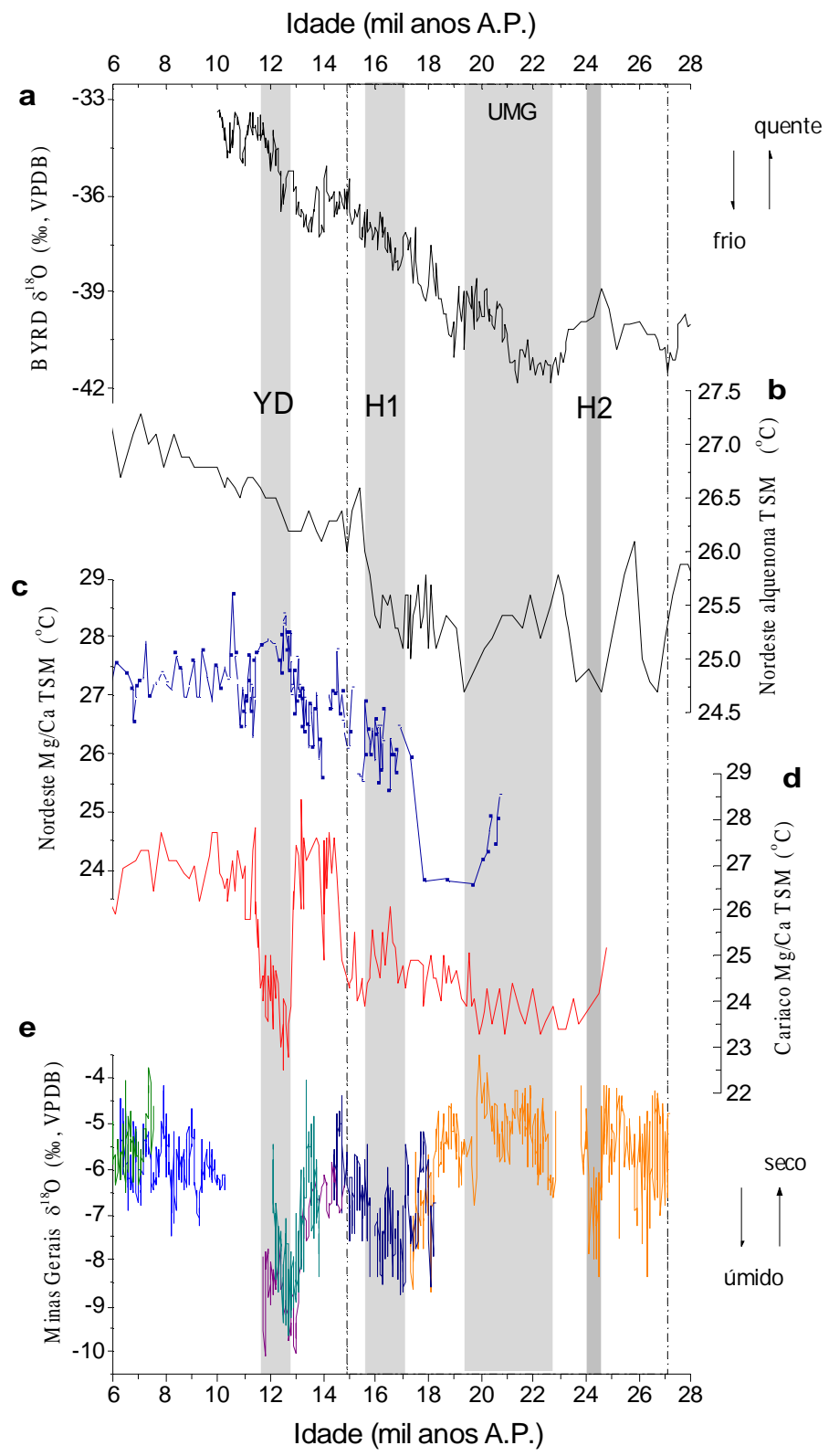

Figura 8.9 - Comparação entre o registro de paleopluviosidade do norte de Minas com os registros de TSM do Atlântico tropical: (a) registro de temperatura da atmosfera da Antartica com base nos dados de $\delta^{18} \mathrm{O}$ do testemunho de gelo Byrd (Blunier e Brook, 2001); (b) registro de TSM da região costeira do Rio Grande do Norte com base em variações do índice de insaturação de alquenonas (Jaeschke et al., 2007), testemunho GeoB3910-2; (c) registro de TSM da região costeira do Rio Grande do Norte com base em variações das razões de $\mathrm{Mg} / \mathrm{Ca}$ em foraminífero (Weldeab et al., 2006), testemunho GeoB3129-1 ; (b) registro de TSM da bacia de Cariaco com base na variação das razões de $\mathrm{Mg} / \mathrm{Ca}$ em foraminífero (Lea et al., 2003), testemunho PL07-39PC; (e) registro de espeleotemas do norte de Minas. A linha pontilhada marca o MIS 2. 
Em resumo, a razão pela qual o aumento das precipitações monçônica é pervasivo durante os eventos Heinrich em todo em todo o território Sul-americano a sul do equador é devido a rápida resposta da atmosfera ao enfraquecimento da AMOC, associado à intensificação dos anticiclones subtropicais do Hemisfério norte que gerou fortalecimento dos alísios de NE. Nesse contexto, é possível que a magnitude do deslocamento meridional da ZCIT durante esses eventos tenha ampliado a convergência de umidade para o interior do continente Sul-americano, a ponto de suplantar a influência da insolação de verão.

Oscilações climáticas de escala multidecadal, a exemplo do AMO, tem sido frequentemente atribuída a variações da atividade de chuvas na América do Sul pela sua influência na geração de anomalias de TSM e consequentemente no deslocamento meridional da ZCIT (Knight et al., 2005, 2006; Timmerman et al., 2007). Como comentado anteriormente, a fase positiva do AMO é caracterizada pelo aumento da TSM do Atlântico tropical norte concomitante a redução da TSM do Atlântico tropical sul, associada à intensificação da AMOC. O oposto ocorre na fase negativa da AMO e redução da AMOC, quando o deslocamento para sul da ZCIT gera anomalias positivas de chuvas no nordeste do Brasil, de modo semelhante ao que se observa durante os eventos Heinrich (Knight et al., 2006; d'Orgeville e Peltier, 2007; Zhang e Delworth, 2005). Chiessi et al. (2009) relaciona o modo de variabilidade estabelecido pela AMO durante o deglacial no Atlântico Sul à variações do SMSA a partir da identificação de frequências decadais próximas a 60 anos nos depósitos sedimentares da Bacia do rio de La Prata, costa do Uruguai. Portanto, modos de variabilidade multidecadais entre 60 e 80 anos observados no norte de Minas durante o Heinrich 1 e no Young Dryas corroboram a hipótese de que variações da AMOC atribuídas às fases de AMO controlam a variabilidade do SMSA (Figs. 8.10 e 8.11). 


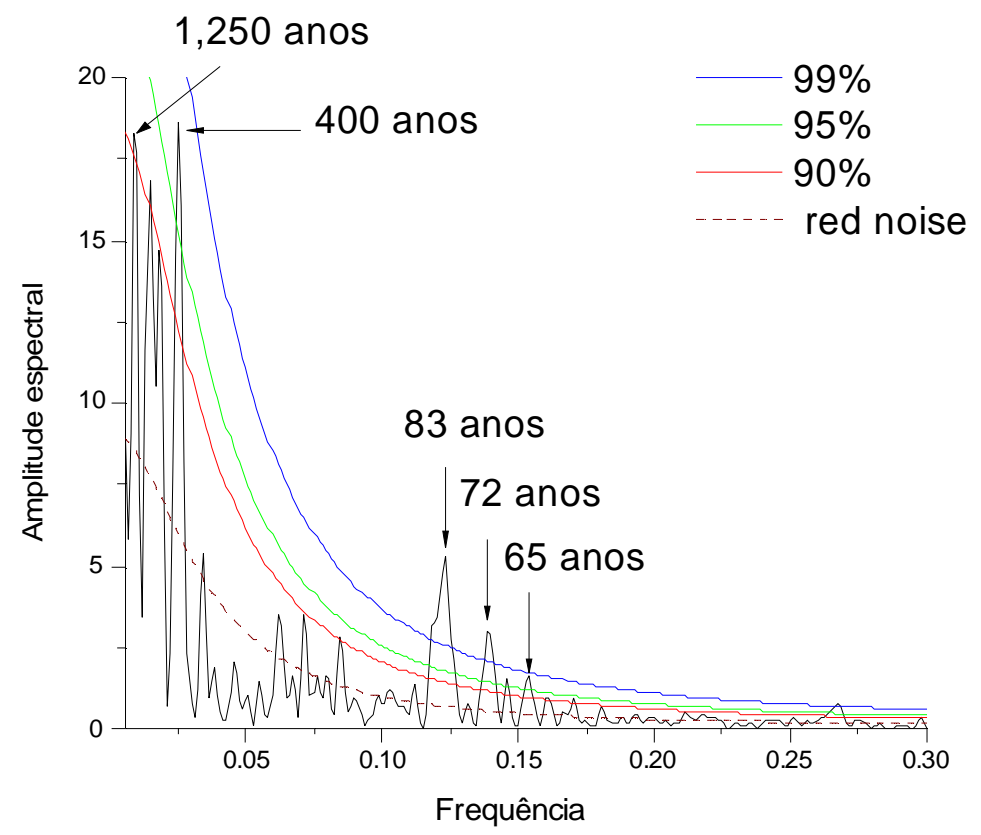

Figura 8.10 - Análise de decomposição espectral da série temporal do $\delta^{18} \mathrm{O}$ entre 11.7 e 13 mil anos A.P da estalagmite LG12. As linhas coloridas marcam os intervalos de confiança calculados para $99 \%$ (azul), $90 \%$ (verde) e $95 \%$ (vermelho). A linha tracejada em cor vinho indica a curva de "red noise" calculada a partir do modelo AR1 (Shulz e Mudelsee, 2002; Thompson, 1990). (b) o mesmo que em (a) porém com detalhe das frequências mais altas.

a)

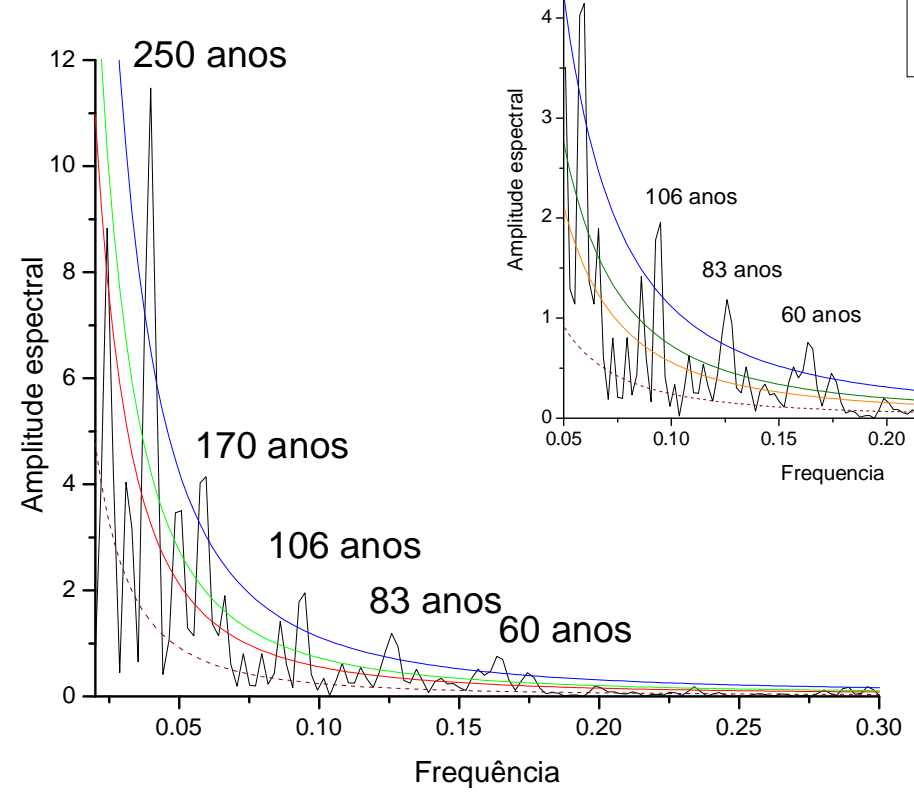

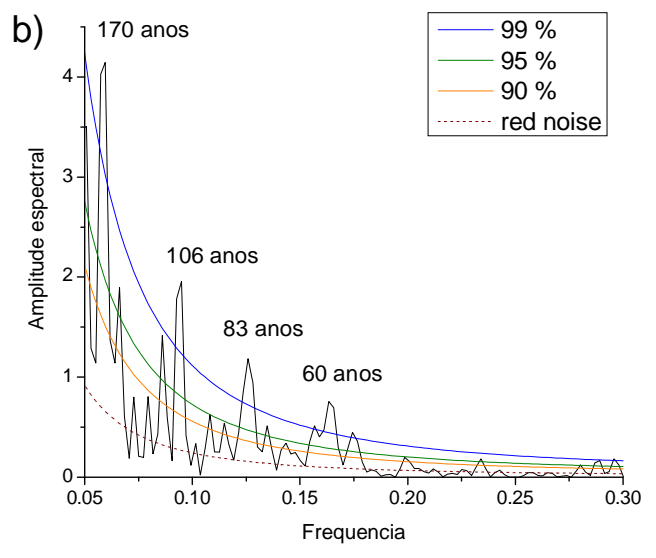

Frequência

Figura 8.11 - Análise de decomposição espectral da série temporal do $\delta^{18} \mathrm{O}$ entre 14.05 e 18.6 mil anos A.P da estalagmite LSF16. As linhas coloridas marcam os intervalos de confiança calculados para $99 \%$ (azul), $90 \%$ (verde) e $95 \%$ (vermelho). A linha tracejada em cor vinho indica a curva de "red noise" calculada a partir do modelo AR1 (Shulz e Mudelsee, 2002; Thompson, 1990). 
Tomando por base o mesmo intervalo temporal analisado por Chiessi et al. (2009), entre 18.6 e 14.05 mil anos, nota-se uma grande consistência entre as oscilações multidecais, com destaque para os períodos de 83 e 60 anos em comparação com o período referente ao Young Dryas entre 13 e 11.5 ka A.P. A ocorrência de variabilidade climática multidecadal relacionada ao AMO durante os eventos abruptos milenares é confirmada nas análises wavelets que apontam para periodicidade de 60 anos como significante estatísticamente acima de $90 \%$ atuante entre 16 e 17 mil anos A.P (Figura 8.12).

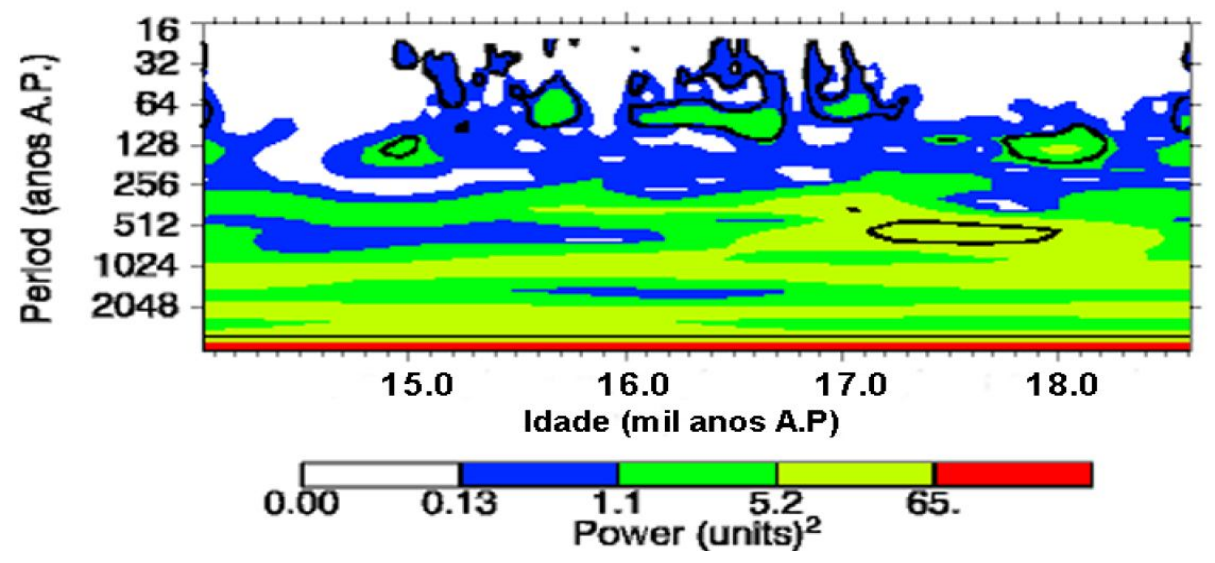

Figura 8.12 (a) Análise de wavelets da série temporal do $\delta^{18} \mathrm{O}$ das estalagmites LSF16 e LSF3 entre 14.05 e 18.6 mil anos A.P. As regiões contornadas em preto são estatisticamente significantes a $90 \%$ através da análise de "red noise". Os valores com a periodicidade dos eventos estão apresentados no eixo vertical, enquanto a sua intensidade espectral ao longo do tempo é indicada pelo índice de cor (Torrence e Campo, 1998).

Essas relações sugerem que, ao menos durante deglacial, oscilações da circulação oceânica relacionadas a variações da circulação termohalina no Atlântico estão entre as principais causas da variabilidade multidecadal dos SMSA e, por conseguinte das anomalias positivas de precipitação no norte de Minas, nas fases de AMO negativo. Em resumo, o aquecimento do Atlântico tropical Sul em relação ao Atlântico tropical Norte e o consequente deslocamento para sul da ZCIT durante o AMO negativo aumenta convergência de umidade do Atlântico tropical para o interior da bacia Amazônica que intensifica as chuvas do SMSA em boa parte do continente Sul-americano. O acoplamento da TSM do Atlântico tropical na costa do nordeste sugere variações da circulação termohalina com um dos fatores responsáveis pela geração da variabilidade climática nos trópicos. Essa constatação é muito evidente no período deglacial, quando a atuação do AMO na modulação da variabilidade climática multidecadal é muito marcante. 


\subsection{Oscilações climáticas do Holoceno}

Os dados inéditos do Holoceno aqui apresentados foram integrados com demais registros paleoclimáticos dos trópicos é também abordado em um artigo científico submetido para publicação no periódico Geology (Stríkis et al., 2011, ANEXO IV).

Desde a publicação dos primeiros registros isotópicos de $\delta^{18} \mathrm{O}$ dos testemunhos de gelo da Groenlândia (Dansgaard et al., 1993) o Holoceno foi caracterizado como um período de grande estabilidade climática, muito inclusive que o último interglacial (Bond et al., 1997; O'Brien et al., 1995; Ruddiman, 2008). A discussão a respeito da ocorrência e da magnitude das flutuações climáticas do Holoceno somente foi retomada em 1995 por O'Brien et al. (1995), a partir da reconstituição paleoclimática da circulação atmosférica das zonas de altas latitudes do Atlântico norte baseada na medição de impurezas solúveis $\left(\mathrm{Na}^{+}, \mathrm{Cl}^{+}\right.$, de fonte marinha, e $\mathrm{Na}^{+}, \mathrm{Cl}^{+}, \mathrm{Mg}^{2+}, \mathrm{K}^{+}$e $\mathrm{Ca}^{2+}$, de fonte continental) em testemunhos de gelo da Groenlândia. Uma vez que a variação do conteúdo de álcalis no gelo é diretamente associada com o aumento da deposição de poeira transportada pelo mesmo, a variação desses índices químicos pode ser diretamente relacionada a mudanças na intensidade dos jatos polares. Apesar das flutuações de $\delta^{18} \mathrm{O}$ nos testemunhos de gelo da Groenlândia não definirem claramente eventos milenares durante o Holoceno (Dansgaard et al., 1993; Bond et al., 1995; Bond et al., 1997), as variações dos teores de álcalis de fonte marinha e continental dos últimos 10 mil anos indicam uma variação "quasi periódica” dos mesmos.

As variações mais significativas marcadas pelo aumento na deposição de álcalis foi observada durante a Pequena Idade do Gelo (PIG) entre 0.4 e 0.15 mil anos A.P. e também entre os intervalos 2.4-3.1; 5.0-6.1 e 7.8-8.8 mil A.P.. Entretanto, mesmo com o trabalho de O'Brien et al. (1995) pouco foi abordado a respeito da amplitude dessas variações, inclusive se elas foram realmente significativas do ponto de vista climático até os trabalhos Bond et al. (1997). A partir de registros de TSM do Atlântico norte baseado em multindicadores paleoambientais, tais como: variações IRD e variações de $\delta^{18} \mathrm{O}$ e $\delta^{13} \mathrm{C}$ em testas de foraminíferos bentônicos e planctônicos, Bond e colaboradores foram capazes de estimar, com razoável precisão, eventos de resfriamento abrupto no Atlântico norte durante o Holoceno, a exemplo dos eventos Heinrich, porém de amplitude e duração menores.

Dentre todos os indicadores paleoclimáticos e paleoambientais utilizados, o que se mostrou mais robusto na determinação e na delimitação dos eventos foi o índice de IRD. A partir dos picos de aumento de concentração de IRD foram determinados os períodos de resfriamento abrupto que mais tarde vieram a ser referidos na literatura como "eventos Bond". Os eventos de maior ocorrência de IRD no Holoceno exibem padrões com ciclicidade variável dentro da escala milenar, 
com picos ao redor de 1.4, 2.8, 4.2, 5.9, 7.4, 8.2 e 9.4 mil anos A.P., concordantes com os períodos de aumento na deposição de álcalis apontados por O'Brien et al. (1995).

Mesmo com intensidade reduzida em relação aos eventos Heinrich, as oscilações de TSM impactaram o regime dos ventos do Hemisfério Norte durante os eventos Bond, os quais estiveram relacionados às variações nos sistemas climáticos dos trópicos, incluindo o Hemisfério Sul. A possível expressão global dos eventos Bond motiva estudos paleoclimáticos de alta resolução baseados em indicadores paleoclimáticos e paleoambientais que estão direta ou indiretamente relacionados às variações da paleopluviosidade nas zonas tropicais e subtropicais.

A repercussão climática dos eventos abruptos observados nas zonas de altas latitudes do Atlântico norte durante o Holoceno foi primeiramente identificada nas regiões tropicais pelo registro paleoclimático de Cariaco publicado por Haug e colaboradores em 2001. A curva de variação de paleopluviosidade publicada por Haug et al. (2001), baseada na variação dos conteúdos de Fe e Ti dos sedimentos marinhos da região costeira da Venezuela, apontou para diminuições abruptas de precipitação relacionadas com a migração para sul da ZCIT em 9.3, 8.2, 7.8 e 5.1 mil anos A.P. Apesar de Haug et al. (2001) não estabelecer qualquer relação entre seu registro e os eventos Bond propriamente dito, a identificação do evento 8.2 na Venezuela já é considerada um forte indicativo de que, apesar de mais brandas, as oscilações climáticas do Holoceno provavelmente teriam impactado os trópicos. A extensão desses eventos ficou mais evidente com o registro de paleopluviosidade publicados de Fleitmann et al. (2003) e posteriormente por Wang et al. (2005) baseado na variação de $\delta^{18} \mathrm{O}$ de estalagmites da caverna Qunf, em Omã e Dongge no leste da China, respectivamente. Em ambos os registros de paleopluviosidade, eventos abruptos de seca observados ao redor de 8.2, 5.2, 4.2, 2.7 mil anos A.P. são relacionados ao evento 8.2 ka e aos eventos Bond “4”, “3” e "2". Sobretudo, essa relação entre os eventos Bond e a variação de chuva nos trópico ficou mais evidenciado no registro isotópico da caverna Dongge.

Na comparação entre o registro de paleopluviosidade do Norte de Minas com os registros paleoclimáticos mais clássicos referentes aos eventos Bond, a exemplo do registro de IRD publicado por Bond et al. (1997) e a curva isotópica de $\delta^{18} \mathrm{O}$ de Wang et al. (2005) da caverna Dongge, é possível observar um claro acoplamento das anomalias positivas de precipitação do norte de Minas com as variações de TSM do Atlântico norte e a ocorrência de períodos secos no leste asiático. Como pode ser observado na Figura 8.13, durante os períodos de aumento de IRD, dado pelo índice de \% de HSG (hematite stained grain), ocorre abruptas quedas nos valores de $\delta^{18} \mathrm{O}$ das estalagmites LG3 e LG11 concomitante com o aumento dos valores de $\delta^{18} \mathrm{O}$ das estalagmites DA e D4 da caverna Dongge, no leste da China (Wang et al., 2005; Yuan et al., 2004).

Essa relação antifásica entre os trópicos do Hemisfério Sul e Norte confirma a hipótese de 
deslocamento para sul da ZCIT durante os eventos de resfriamento das águas superficiais de altas latitudes do Atlântico Norte associada à intensificação da alta dos Açores (Ruddiman, 2008; Wang et al., 2005). Outro fator importante deve ser levado em consideração é o fortalecimento do anticiclone subtropical sob o platô siberiano no caso do leste asiático, possivelmente gerado pela intensificação dos jatos polares, também conhecido como ventos de oeste (westerlies), de maneira semelhante com o que ocorre com a Alta do Açores. O fortalecimento dos anticiclones subtropicais do Hemisfério Norte intensifica os ventos alísios de NE, favorecendo o deslocamento para sul da ZCIT ao longo de toda a zona equatorial (Cruz et al., 2009b; Fleitmann et al., 2003; Ruddiman, 2008).

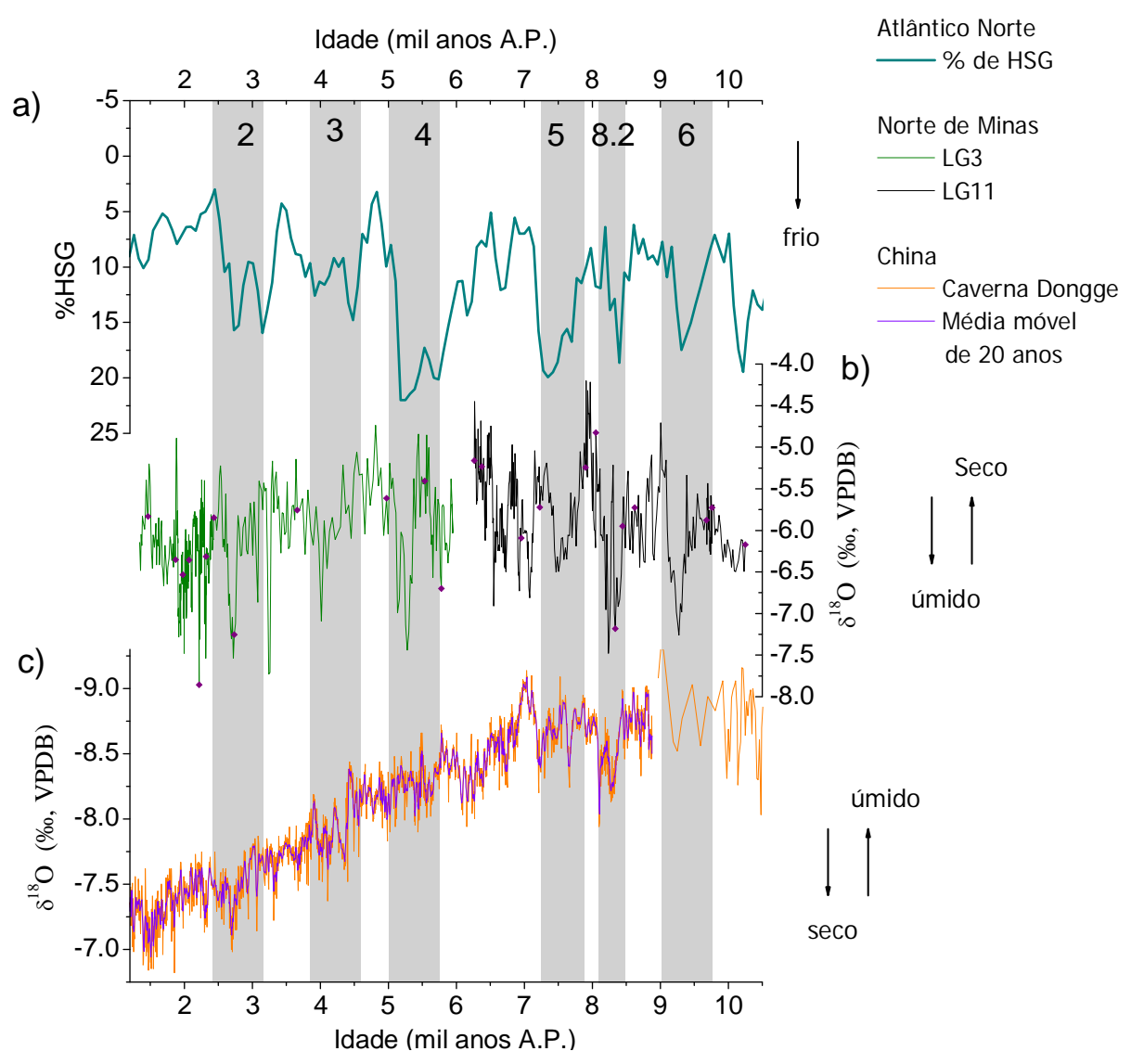

Figura 8.13 - Comparação entre: (a) variação do índice de HSG do testemunho marinho VM29-191 (Bond et al., 1997); (b) registro de $\delta^{18} \mathrm{O}$ das estalagmites LG3 e LG11 da caverna Lapa Grande; (c) curva do $\delta^{18} \mathrm{O}$ das estalagmites DA e D4 da caverna Dongge, leste da China (Wang et al., 2005; Yuan et al., 2004). A curva em roxo presenta a média móvel de 20 anos da estalagmite DA. As Barras em cinza marcam os eventos Bond 2, 3, 4, 5 e 6 e o evento 8.2 ky.

A relação entre as flutuações climáticas milenares observadas nos registros de paleopluviosidade de Cariaco com o registro do norte de Minas não é tão evidente quanto as observadas na comparação com o registro de espeleotemas do leste da China (Fig. 8.14). De fato, os registros de alta resolução de Cariaco não apresentam uma relação tão clara com os eventos abruptos detectados por Bond, ao contrário do que acontece na comparação com a curva de insolação. Enquanto os eventos de IRD conhecidos como Bond 6, 5, 4, 3 e 2 e o evento 8.2 ka, são 
concordantes com as variações de $\delta^{18} \mathrm{O}$ nos registros de espeleotemas do norte de Minas e da China, o registro de Cariaco apresenta relação apenas com os eventos Bond 6 e 2 e com o evento 8.2 ka (Fig. 8.14). Inclusive, alguns autores associam a excursão mais baixa de Ti observadas entre 4.5 e 2 mil anos A.P. nos registros de Cariaco com o aumento na intensidade dos eventos de El-Niño nesse período (Haug et al., 2001; Peterson et al., 2000; Peterson e Haug, 2006).

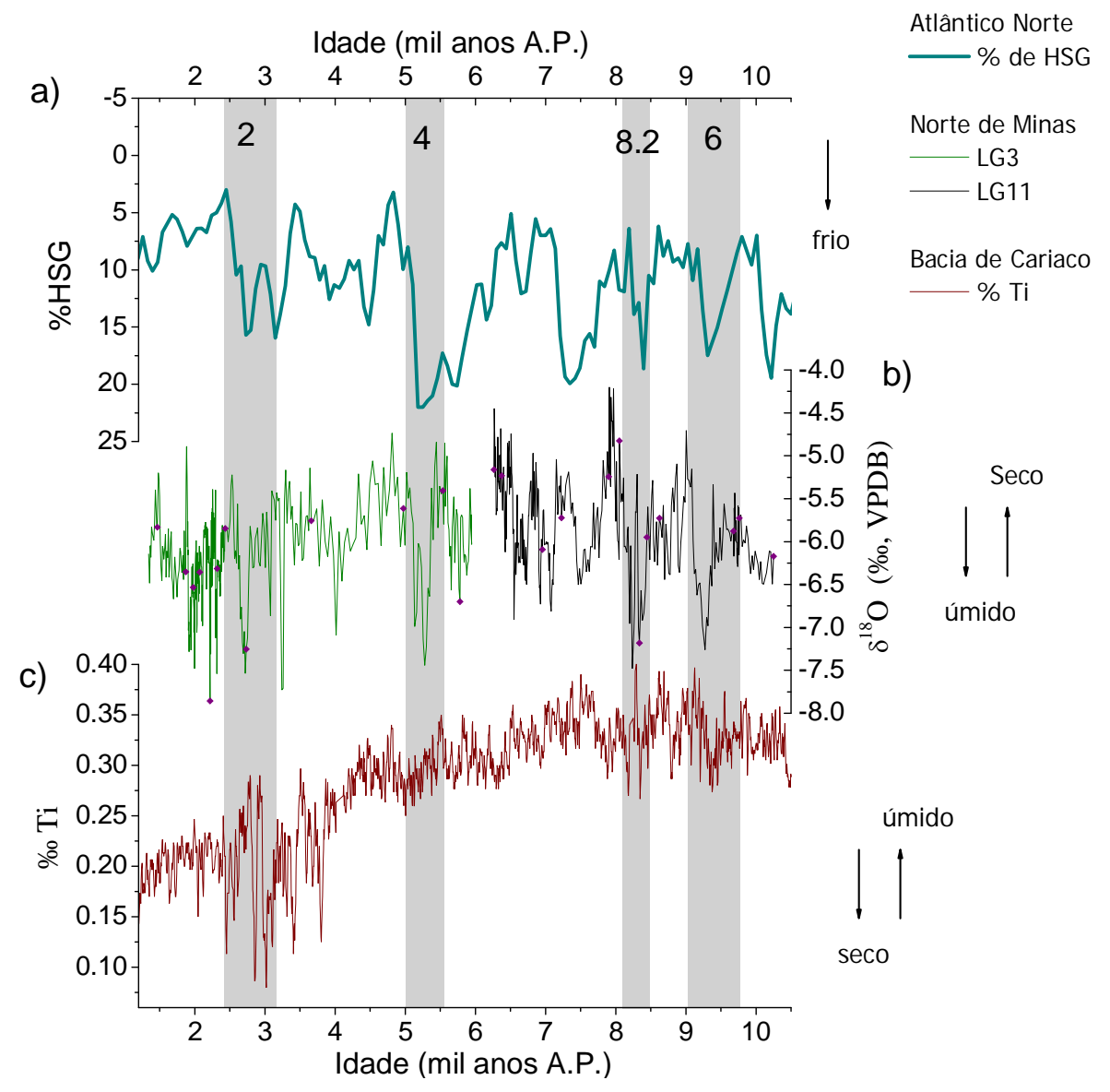

Figura 8.14 - Comparação entre os registros de paleopluviosidade de Minas e Cariaco e os registros de expansão de gelo do Atlântico norte. (a) Variação na cobertura de gelo do Atlântico norte com base no índice de HSG do testemunho marinho VM29-191 (Bond et al., 1997); (b) registro isotópico de $\delta^{18} \mathrm{O}$ do norte de Minas das estalagmites LG3 e LG11 da caverna Lapa Grande; (c) variação do conteúdo de Ti em \% dos sedimentos da Bacia de Cariaco, testemunho ODP1002 (Haug et al., 2001). As Barras em cinza marcam os eventos Bond 2, 4 e 6 e o evento 8.2.

Quanto à estrutura e a duração dos eventos abruptos do Holoceno no norte de Minas, nota-se variação na ocorrência dos eventos ao longo do tempo. Apesar da amplitude dos eventos serem aparentemente a mesma, variando entre 0.9 a $1.5 \%$ em todo o registro, o tempo de duração dos eventos muda consideravelmente. Ao passo que no Holoceno Inferior e Médio os eventos apresentam duração média de 300 anos, no Holoceno Superior esse período não passa de 100 anos. Com exceção do evento ocorrido a 2.7 mil anos A.P., a duração dos eventos não passa de 50 anos. Essa diferença na duração dos eventos sugere possíveis diferenças nos mecanismos responsáveis 
pelo desencadeamento dos diferentes eventos Bond no transcorrer do Holoceno.

De fato, diferentemente dos demais eventos ocorridos no Holoceno Médio e Superior, os eventos Bond 6 e o 8.2 ocorreram em uma época em que a quantidade de gelo sobre a América do Norte ainda era apreciável, reforçando a hipótese de que, introgressões de água doce durante o derretimento da geleira Laurentide teriam desativado a circulação termohalina esfriando o Hemisfério Norte (Carslon et al., 2008; LeGrande et al., 2006; Bernal et al., 2010; Fleitmann et al., 2007; Cheng et al., 2009). Já, o último evento Bond, conhecido como PIG tem sido cada vez mais relacionado à variação na atividade solar e vulcanismo (Haase-Schramm et al., 2005; Polissar et al., 2006; Yoshimori et al., 2006; Lozano-García, 2007).

Os dados isotópicos dos registros de Minas são consistentes com a série temporal de variação de $\delta^{13} \mathrm{C}$ dos sedimentos do lago Titicaca apresentados por Baker et al. (2005). Esses dados sugerem aumento no nível do lago coincidente, em parte, com a curva de variações de IRD de Bond et al. (1997), centradas em 9.5, 8.2, 7.6, 5.2 3.9, 3.2, 2.7 e 1.4 mil anos A.P. Quando comparados, os registros de variação de N-A do lago Titicada de Baker et al, (2005) com a reconstituição de paleopluviosidade do norte de Minas, nota-se uma grande relação positiva entre os períodos de abruptos de aumento de pluviosidade (Fig. 8.15). Pequenos desalinhamentos temporais entre esses registros, sobretudo durante o Holoceno Inferior, podem ser atribuídos a incertezas geradas nos dados geocronológicos, principalmente nos registros do Lago Titicaca, onde a resolução geocronológica é menor, a exemplo do período entre 10.8 e 6.9 mil anos, definido apenas por duas datações. Chama atenção na comparação entre os registros não apenas a sincronia dos eventos, mas também a estrutura dos mesmos, de fato muito semelhante.

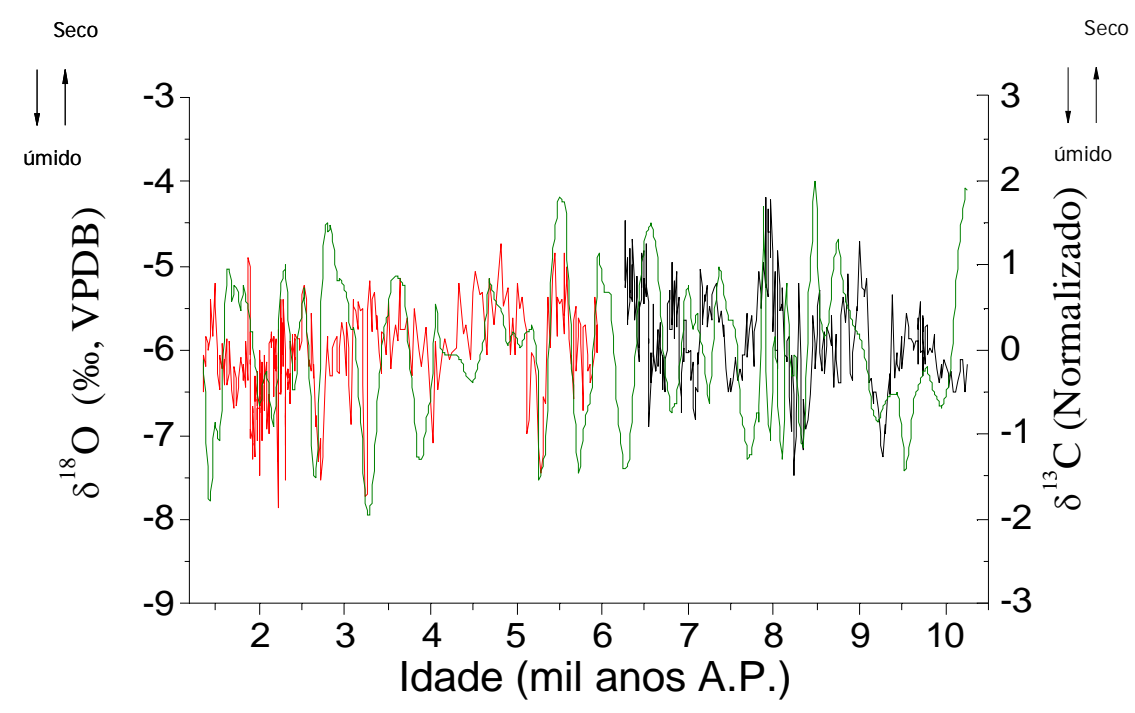

Figura 8.15 - Comparação entre os registros $\delta^{18} \mathrm{O}$ das estalagmites LG3 (vermelho) e LG11 (preto) com o registro de variação de N-A do lago Titica baseado nos valores normalizados de $\delta^{13} \mathrm{C}$ (verde) (Baker et al. 2005). 
O aumento de umidade em direção ao Holoceno Superior, caracterizado pelo decréscimo na ordem de $1.0 \%$ dos valores de $\delta^{18} \mathrm{O}$ em escala orbital, são compatíveis com as interpretações paleoclimáticas de Enters et al. (2010) para registros do lago Aleixo, também localizado no norte mineiro. Picos de valores mais negativos de $\delta^{13} \mathrm{C}$ dos sedimentos do lago Aleixo, associados com o aumento da produtividade primária são contemporâneos aos eventos abruptos de aumento de chuvas registrados nos espeleotemas da caverna Lapa Grande durante o Holoceno Médio e Superior.

Quando se compara a curva de HSG com a curva de variabilidade solar, estimada pela variação de $\Delta^{14} \mathrm{C}$ de anéis de crescimento de árvores, a exemplo do que fez Bond et al. (2001), vemos um ótimo acoplamento entre as flutuações de TSM do Atlântico norte com os períodos de redução atividade solar (Fig. 8.16). Como poder ser observado na Figura 8.16, os eventos abruptos de redução de TSM do Atlântico norte coincidem com o período de mínima atividade solar (alto $\Delta^{14} \mathrm{C}$ ), que por sua vez, ocorrem de maneira sincrônica aos períodos de aumento de chuvas no norte de Minas.

Van Geel et al. (1996) relaciona um evento de resfriamento abrupto ocorrido a 2.7 mil anos A.P. na Holanda à um súbito aumento no conteúdo de $\Delta{ }^{14} \mathrm{C}$ atmosférica, da mesma forma como O'Brien et al. (1995) relaciona períodos de aumento da intensidade dos jatos polares observados nos registros de poeira dos testemunhos de gelo GISP2 à períodos de mínima atividade solar. Comparações semelhantes realizadas por Fleitmann et al. (2003) nos registros isotópicos de espeleotemas de Omã e por Wang et al. (2005) com espeleotemas do leste da China apontam para a variação da atividade solar como um dos principais mecanismos desencadeadores dos eventos de enfraquecimento das monções asiáticas durante o Holoceno. 


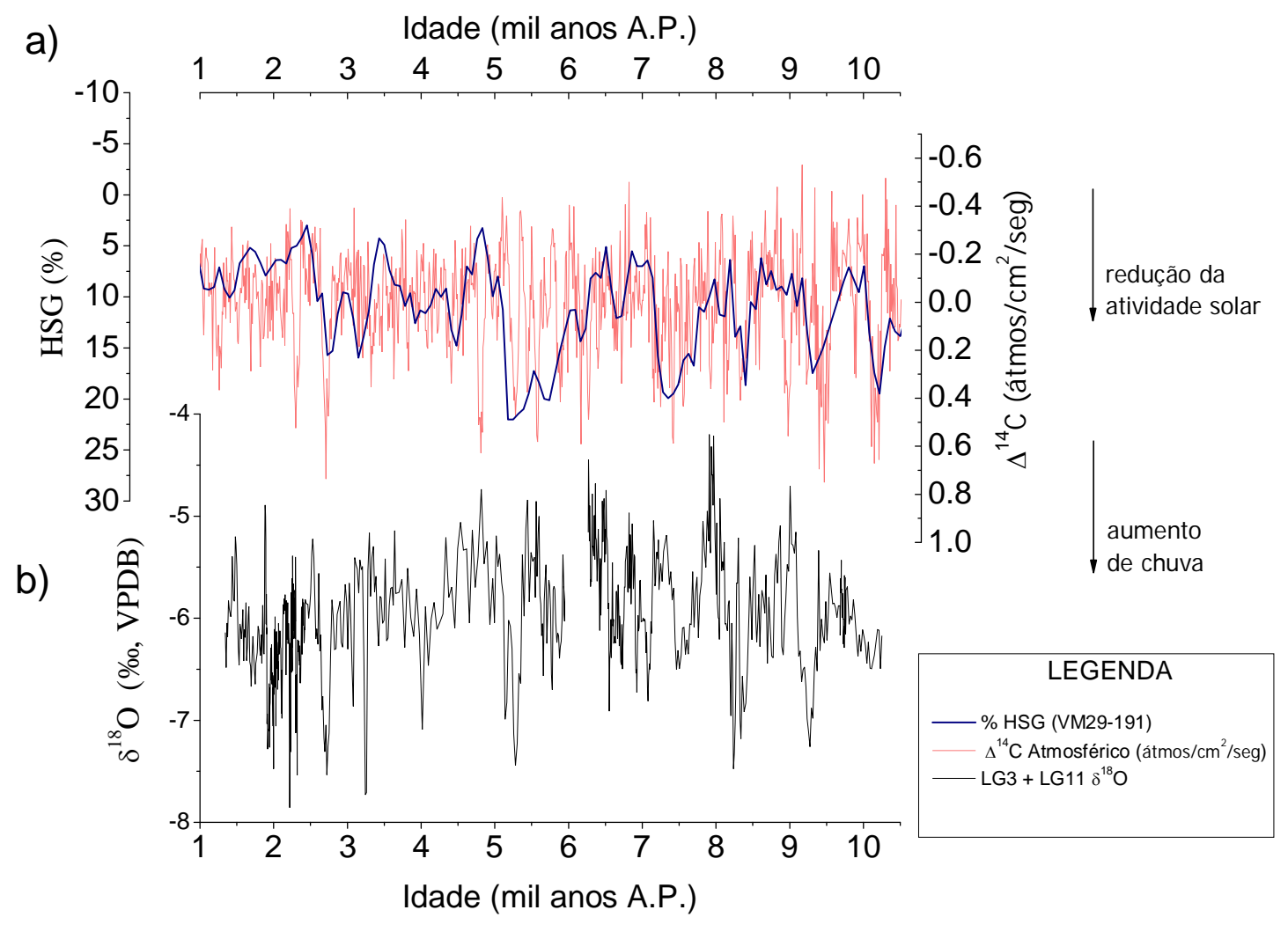

Figura 8.16 - Comparação dos registros paleoclimáticos de TSM do Atlântico Norte de Bond et al. (1997; 2001) e de paleopluviosidade do norte de Minas e da variação de atividade solar: (a) variação do conteúdo de IRD com base na porcentagem de HSG (hematite stained grain) em azul (Bond et al. 2001), com a curva de variação de irradiação solar baseada no registro destendenciado de $\Delta^{14} \mathrm{C}$ em átmos $/ \mathrm{cm}^{2} / \mathrm{seg}$ (vermelho claro) (Bond et al., 2001); (b) registro de $\delta^{18} \mathrm{O}$ das estalagmites LG3 e LG11, norte de Minas.

Numa comparação em maior detalhe, tanto os registros de paleopluviosidade de Minas, como os dados de $\delta^{18} \mathrm{O}$ da Chapada Diamantina (Barreto, 2010), mostram boa sincronicidade com a curva de $\Delta^{14} \mathrm{C}$, especialmente durante o evento 2.7 A.P. (Fig. 8.17). Entretanto, nem sempre os eventos de mínima atividade solar parecem repercutir tão bem nas curvas isotópicas como observado no evento 2.7, a exemplo do evento ocorrido a 2.3 mil anos A.P (Fig. 8.17). Da mesma forma, uma mínima solar expressiva ocorrida a 4.8 mil anos A.P. não encontra correspondência no registro isotópico do norte de Minas. 


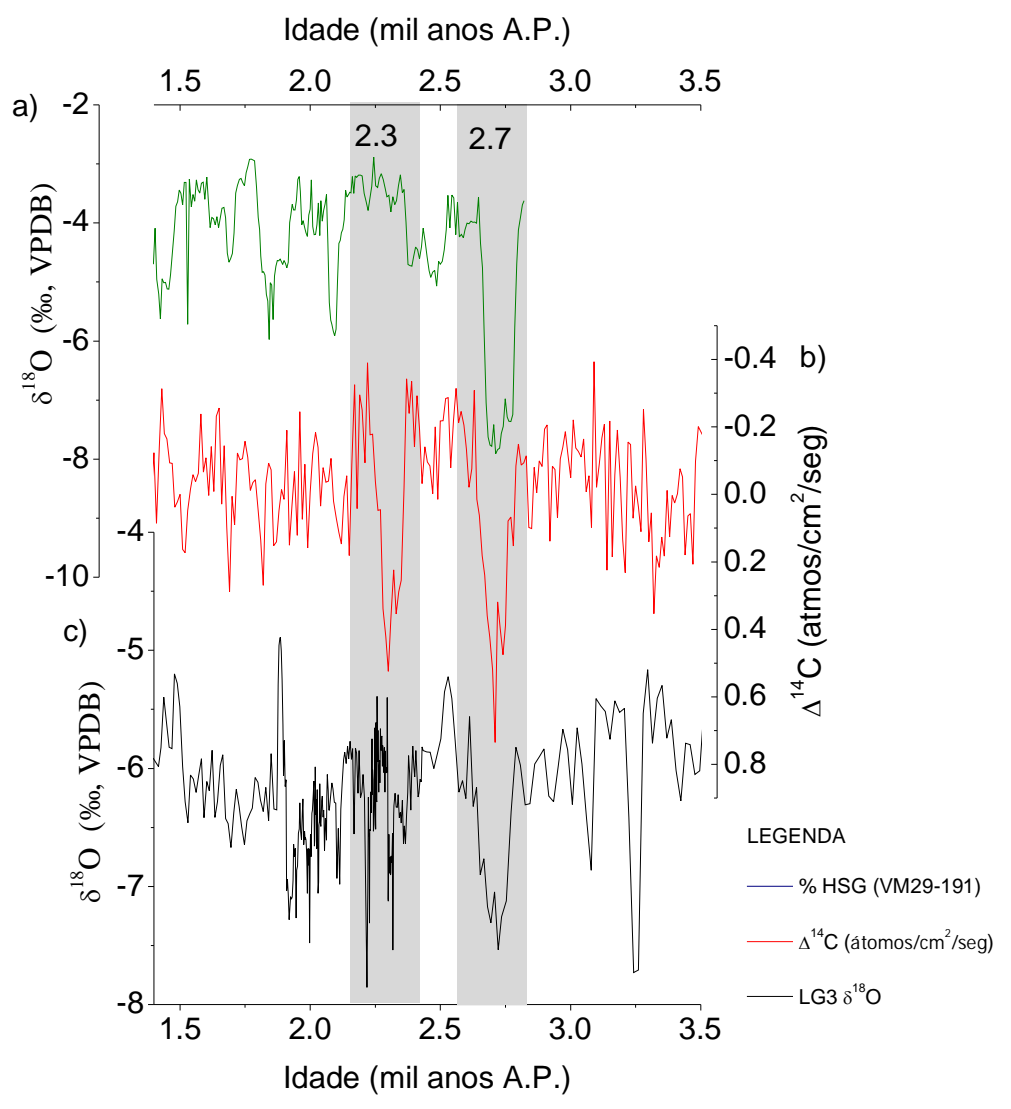

Figura 8.17 - Comparação entre (a) curva de $\delta^{18} \mathrm{O}$ da estalagmite DV2, Bahia; (b) curva de irradiação solar reconstituida a partir dos registros de $\Delta^{14} \mathrm{C}$ de anéis de crescimento de árvore (Bond et al., 2001) e (c) Curva de $\delta^{18} \mathrm{O}$ da estalagmite LG3.

De maneira geral, os eventos Bond apresentam uma periodicidade média de 1500 anos (Bond et al., 1997; Bond et al., 2001) comumente observada em registros de TSM de zonas tropicais e subtropicais do Pacífico e Atlântico norte (Isono et al., 2009). Baker et al. (2005) observa a mesma periodicidade de aproximadamente 1562 anos nos registros de flutuação do N-A do Lago Titicaca, cuja variação é diretamente relacionada a intensidade das monções Sulamericanas, influenciadas em última análise por variações de TSM do Atlântico Norte (Baker et al., 2001a; Baker et al., 2005; Ekdahl et al., 2008). Análises espectrais realizadas nas séries temporais de $\delta^{18} \mathrm{O}$ do testemunho de gelo GISP2 por Grootes e Stuiver (1997) apontam para a mesma ciclicidade ( 1470 anos), operante desde o início do MIS-3 a aproximadamente 50 mil anos A.P. até o Young Dryas, a 12.1 mil anos, a qual está relacionada ao período médio de ocorrência dos eventos Dansgaard-Oeschger (Grootes e Stuiver, 1997; Rahmstorf, 2003).

De acordo com as análises espectrais empregadas no tratamento estatístico das séries temporais do Holoceno, a periodicidade de 1500 anos ocorre de maneira pouco expressiva nos registros de paleopluviosidade do norte de Minas. Como pode ser observado nas Figuras 8.18B e D, a periodicidade de 1500 anos, descriminada na análise espectral de REDFIT (Fig. 8.18B), ocorre 
apenas durante o Holoceno médio. Dentre as frequências observadas nas análises das séries do Holoceno Inferior (estabelecida pela estalagmite LG11) e Holoceno Médio e Superior (estabelecida pela estalagmite LG3) chama a atenção a frequência de 820 anos, que é continua por quase todo o Holoceno Inferior e Médio, como pode ser observado nas análises de wavelets nas Figuras 8. 18C e 8.19 B. Outros eventos ocorem de forma não muito periódica com durações em torno de 170 e 200 anos, observados na estalagmite LG11 ( 178 anos) e na estalagmite LG3 (175 e 217 anos). Frquências similares também foram observadas por Baker et al. (2005) na análise da série de variação do N-A do lago Titicaca. Periodicidades coerentes com o AMO, $\approx 65$ anos, ocorrem com significância estatística nas análises espectrais e de wavelets, sobre tudo para no Holoceno Inferir próximo dos eventos abruptos de 8.2 ka e ao longo do Holoceno Superior (Fig. 8.18), sendo que a significancia dessa periodicidade mostrada nos gráfico podem estar prejudicadas devido a resolução do registro (em torno de 20 anos entre cada dado) (Knight et al., 2005, 2006). Eventos com periodicidade em torno de 120 e 180 anos podem na realidade serem resultados múltiplos da periodicidade próxima de 60 anos e, portanto estariam relacionados ao AMO.
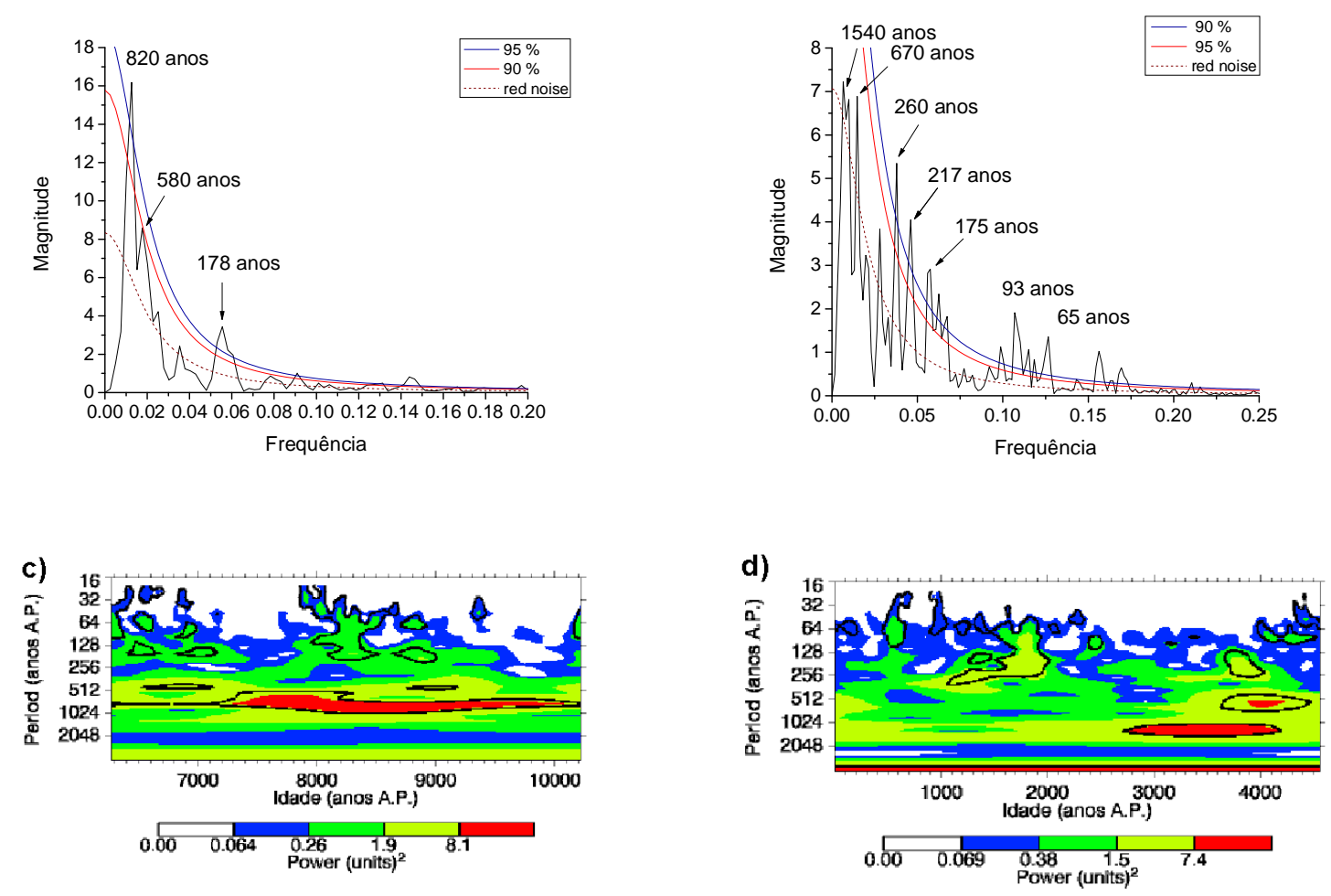

Figura 8.18 - (a) Análise de decomposição espectral de frequências dos dados de $\delta^{18} \mathrm{O}$ da estalagmite LG11. As linhas em vermelho e azul marcam os intervalos de confiança calculados para 90 e $95 \%$ respectivamente e a linha tracejada em cor vinho indica a curva de "red noise" calculada a partir do modelo AR1 (Shulz e Mudelsee, 2002; Thompson, 1990); (b) o mesmo que em "a" porém para a estalagmite LG3; c): Análise de wavelets das série temporal do $\delta^{18} \mathrm{O}$ da estalagmite LG11. As regiões contornadas em preto representam eventos estatisticamente significativos na faixa de $90 \%$ através da análise de "red noise". Os valores com a periodicidade dos eventos estão apresentados no eixo vertical, enquanto a sua intensidade espectral ao longo do tempo é indicada pelo índice de cor (Torrence e Campo, 1998); (d) o mesmo que em "c" porém para a estalagmite LG3. 
A fim de se obter um dado mais preciso para as oscilações de baixas frequências, a série temporal composta pelas estalagmites LG3 e LG11 foi integrada com os dados da estalagmite LSF17, de modo que o hiato entre 6.27 e 5.84 mil anos fosse coberto. Uma vez que os valores absolutos de $\delta^{18} \mathrm{O}$ das estalagmites da caverna Lapa Sem Fim apresentam-se mais enriquecidos em ralação aos da caverna Lapa Grande, a integração dos dados foi realizada com base nos valores de anomalia de $\delta^{18} \mathrm{O}$. O resultado das análises espectrais realizado para a série integrada é apresentado na Figura 8.19.

a)

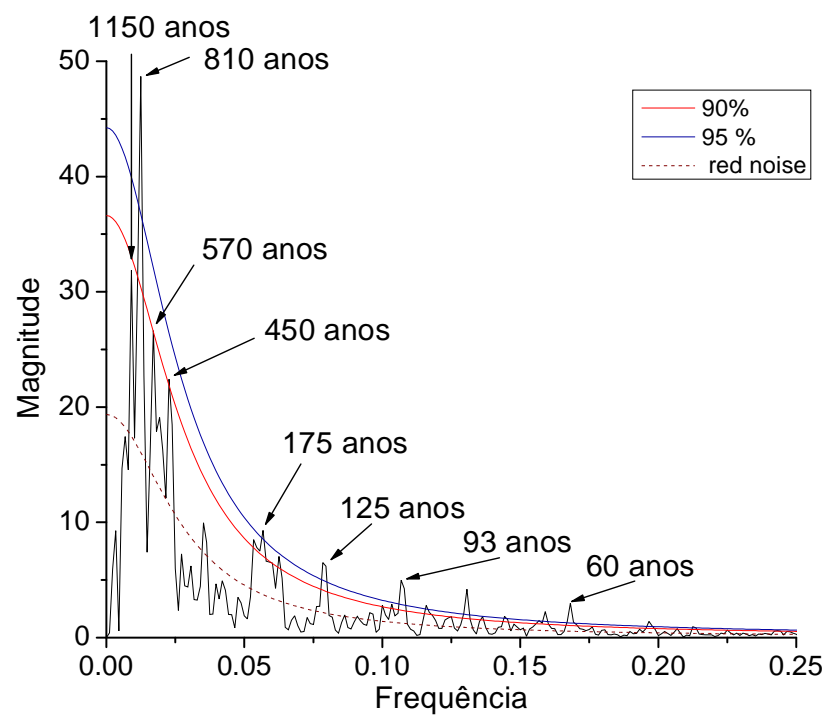

b)

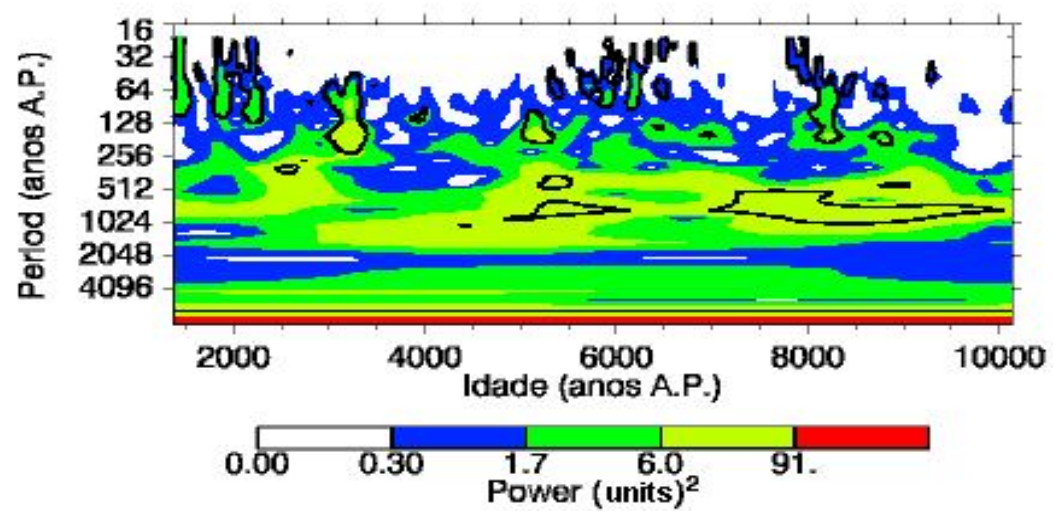

Figura 8.19 - (a) Análise de decomposição espectral dos dados de $\delta^{18} \mathrm{O}$ das estalagmites LG11, LSF17 e LG3. As linhas em vermelho e azul marcam os intervalos de confiança calculados para 90 e $95 \%$ respectivamente e a linha tracejada em cor vinho indica a curva de "red noise" calculada a partir do modelo AR1 (Shulz e Mudelsee, 2002; Thompson, 1990); (b) o mesmo que em (a) porém para análise wavelets. As regiões que apresentam contorno em preto representam eventos estatisticamente significativos na faixa de $90 \%$ através de "red noise". 
Para ressaltar a periodicidade de 820 anos, foi plotada uma curva senoidal com periodicidade de 820 anos sobre a série temporal de $\delta^{18} \mathrm{O}$ das estalagmites LG11 e LG3. Através da Figura 8.20, fica evidente que a série temporal de $\delta^{18} \mathrm{O}$ do norte de Minas se ajusta perfeitamente à periodicidade de 820 anos durante todo o Holoceno inferior e parte do Holoceno médio.

A mesma periodicidade foi observada por Bernal et al. (2010) nos registros isotópicos de $\delta^{18} \mathrm{O}$ da Cueva del Diablo, no sudeste do México, associado a variações das monções por oscilações da posição média da ZCIT e em registros de TSM do Pacífico equatorial leste (Marchitto et al., 2010). De acordo com o registro de TSM apresentado por Marchitto et al. (2010), durante os eventos Bond, o deslocamento para sul da ZCIT diminui a intensidade dos ventos alísios de nordeste sobre a costa Califórnia de modo a estabelece condições do tipo El-Niño no Atlântico tropical norte em virtude do consequente sobre-aquecimento das águas do Pacífico equatorial leste. Uma vez que o estabelecimento de condições do tipo El-Niño decorre do deslocamento para sul da ZCIT durante os eventos Bond, e este por sua vez poder ter sido intensificado por processos retroalimentativos associados à desativação da AMOC, é possível que o Atlântico module os eventos de ENOS em uma escala de tempo secular a multisecular.

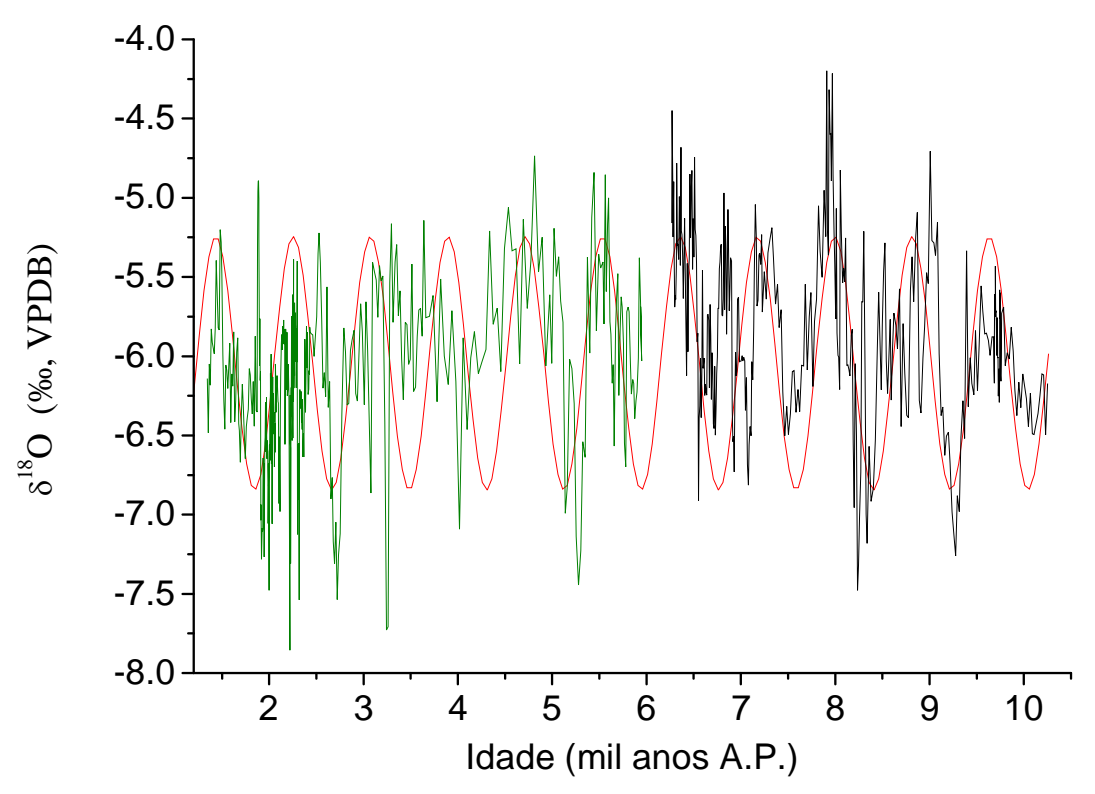

Figura 8.20 - Comparação das séries de $\delta^{18} \mathrm{O}$ das estalagmites LG11 (preto) e LG3 (verde) com uma função senoidal cuja periodicidade é de 820 anos (vermelho).

Outras periodicidades multidecenais a multisseculares localizadas entre as bandas de $128 \mathrm{e}$ 520 anos são significativas na análise espectral de wavelets durante os últimos 6 mil anos (Fig. 8.18D) e ocorrem de forma consistente com os períodos de 500, 250, 210 e 160 anos encontrados 
nas análises espectrais usando o REDFIT (Fig. 8.18B). Esse campo de frequência evidenciado pelas análises espectrais contribui para a hipótese de que, durante o Holoceno, a variabilidade climática do sistema de monções Sul-americanas pode ter sido influenciada pela variação da atividade solar, a exemplo dos ciclos solares de De-Vries-Suess que apresentam ciclicidade média de 512, 206 e 148 anos (Stuiver and Braziunas, 1989). 


\section{Considerações Finais}

A reconstituição da paleopluviosidade dos últimos 28 mil anos realizada no norte de Minas Gerais, obtido por meio de análises isotópicas de oxigênio em estalagmites das cavernas Lapa Grande e Lapa Sem Fim, representa uma importante contribuição na compreensão do comportamento do sistema climático Sul-americano frente às mudanças climáticas de escala global. A partir do registro isotópico de $\delta^{18} \mathrm{O}$ foi possível estimar como o sistema de monções Sulamericano afeta a região centro-leste do Brasil durante eventos abruptos frios e quentes registrados nas zonas de altas latitudes do Hemisfério norte e que, em última análise, são relacionados a alterações da circulação oceânica.

Por meio da comparação entre o registro paleoclimático da região estudada com os demais registros paleoclimáticos de alta resolução espalhados ao redor do globo, foi possível determinar que, independentemente do fator responsável pelo desencadeamento dos eventos abruptos, as mudanças na intensidade das monções sul americanas se dão principalmente por teleconexão estabelecidas diretamente com as zonas de altas latitudes do Hemisfério Norte, mais especificamente por alterações do gradiente de TSM do Atlântico.

No que tange as variações climáticas na escala orbital, a pluviosidade do norte de Minas descreve uma relação mais complexa com a curva de insolação em comparação o observado em outros registros de paleopluviosidade do Brasil, a exemplo dos registros de $\delta^{18} \mathrm{O}$ de estalagmites do sudeste (Cruz et al., 2005; a Cruz et al., 2006a; Wang et al., 2004; Wang et al., 2007) e no nordeste (Cruz et al., 2009a; Barreto, 2010).

Ao passo que durante os períodos glacial tardio e deglacial a variação da paleopluviosidade do norte de Minas se assemelha muito ao padrão antifásico observado no nordeste brasileiro por Cruz et al. (2009a) e Barreto (2010), durante o Holoceno a série histórica da paleoprecipitação do norte de Minas, descreve um padrão em fase com a insolação. O padrão nesse último período é o mesmo que ocorre no sudeste do Brasil, no entanto com um aumento menos pronunciado de pluviosidade em direção ao Holoceno Superior (Cruz et al., 2005a; Cruz et al., 2006a; Wang et al., 2004; Wang et al., 2007). Essa dualidade do registro mineiro por ser explicada pelo caráter de transição no qual se insere a região em termos influência do cavado do Nordeste na modulação da precipitação monçônica em escala orbital. Estando o norte de Minas situado numa distância muito próxima da região Nordeste, é possível que o fortalecimento da circulação zonal em altos níveis, estabelecida entre o cavado do Nordeste e a alta da Bolívia, tenha influenciado no deslocamento da Zona de Convergência do Atlântico Sul para sudoeste da área estudada. Nesse contexto, as condições de contorno empostas durante o glacial, principalmente durante o MIS 2, uma das fases 
mais frias da última glaciação, podem ter condicionado o deslocamento, ou mesmo expansão para sul da ZCAS, por intensificação do cavado do nordeste em altos níveis durante os períodos de máxima insolação de verão. Isso poderia explicar porque os resultados de estudos paleoclimáticos apontam clima mais seco durante o glacial tardio no nordeste (Cruz et al., 2009a) e norte de Minas e mais úmido nos Andes e a no sul e sudeste brasileiro (Baker et al., 2001a; Fritz et al., 2004; Baker et al., 2005; Cruz et al., 2005a; Cruz et al., 2006a; Ekdahl et al., 2008).

O norte de Minas experimentou fortes aumentos de precipitação diretamente relacionado a intensificação das monções Sul-americanas durante os eventos abruptos frios registrados nos testemunhos de gelo da Groenlândia e nas reconstituição de TSM do Atlântico norte, como os eventos Heinrich 1 e 2 e o Young Dryas, dada a resposta sincrônica com outros registros paleoclimáticos relacionados à variações de disponibilidade hídrica, espalhados pelo continente Sul-americano sobre áreas fortemente influenciadas pelo SMSA (Baker et al., 2001a; Baker et al., 2005; Barreto, 2010; Cruz et al., 2005a; Cruz et al., 2006a; Cruz et al., 2009a; Thompson et al., 1995; Thompson et al., 1998; Wang et al., 2004; Wang et al., 2007 entre outros). Da mesma, forma durante os eventos quentes, a exemplo dos eventos Dansgaard-Oescheger 2 e do Bølling-Allerød, foram registradas reduções da paleoprecipitação relacionadas ao deslocamento para norte da ZCIT, de modo a estabelecer uma perfeita relação antifásica com os registros de paleoprecipitação do Hemisfério norte, também influenciados pela circulação monçônica como, a exemplo dos registros de $\delta^{18} \mathrm{O}$ da caverna Dongge no leste da China (Wang et al., 2008; Wang et al., 2006; Yuan et al., 2004).

Ao longo do Holoceno, a curva isotópica de $\delta^{18} \mathrm{O}$ descreve uma tendência em fase com o ciclo de insolação e, portanto em fase com os registros do sudeste, o que sugere que, como o final das condições de contorno estabelecidas durante a glaciação, a circulação zonal responsável pelo cavado do Nordeste é menos atuante no norte de Minas. O registro do Holoceno é marcado, por fortes oscilações abruptas com amplitudes de variação da ordem de 3\%o, muito maiores que as variações comumente observadas nos registros de paleoprecipitação do Holoceno na China e sudeste do Brasil (que não ultrapassam 1\%o). De maneira geral, os períodos de aumento de precipitação apresentam uma boa relação com os e eventos Bond, sobretudo durante o Holoceno inferior nos eventos Bond 6, 5 e 4 e no evento 8.2. Isso sugere que as variações de temperatura do Atlântico norte promoveram siginificativas alterações na circulação monçônica da América do Sul, a exemplo do observado nas fases negativas da Oscilação Multidecadal do Atlântico.

A ocorrência de eventos abruptos de curta duração (entre 50 e 100 anos) durante o Holoceno superior, a exemplo do evento ocorrido a 2.7 mil anos A.P., apontam para possíveis diferenças nos mecanismos relacionados ao desencadeamento ou mesmo propagação das flutuações climáticas do 
Holoceno superior em relação ao Holoceno inferior. A semelhança entre o registro de paleopluviosidade do norte de Minas e a curva de variação de atividade solar em alguns eventos sugere que, possivelmente parte das flutuações climáticas do Holoceno de fato foram desencadeadas por reduções da atividade solar, como é especulado para o "little ice age" e para o eventos 2.7 mil anos A.P. (Haigh, 1996; Lee e Lee, 2007; Liu et al., 2009; Polissar et al., 2006; Stuiver e Braziunas, 1989; Usoskin e Kovaltsov, 2008; Yoshimori et al., 2006).

Os períodos de aumento abrupto na intensidade do SMSA registrado no norte de Minas durante o Holoceno são relacionáveis as fases de aumento das TSM do Pacífico equatorial leste dentro de um contexto de deslocamento para sul da ZCIT dada a relação antifásica estabelecida pelo registro mineiro com os registros de paleoprecipitação monçônica do Hemisfério Norte (Fleitmann et al., 2003; Marchitto et al., 2010; Wang et al., 2005). Tal relação sugere que, os eventos climáticos de redução de TSM do Atlântico norte aparentemente desencadeados por variações da AMOC são capazes de modular as condições de El-Niño tendo a vista que, em última análise, as condições da TSM do Pacífico Equatorial podem ser interpretadas em termos de condições do tipo El-Niño (TSM mais quentes) e tipo La-Niña (TSM mais frias) (Timmerman et al., 2007). 


\section{Referências}

AMBRIZZI, T.; SOUZA, E.B.; PULWARTY, R.S. The Hadley and Walker regional circulations and associated ENSO impacts on South American seasonal rainfall. In: DIAZ H.F.; BRADLEY R.S. (Eds.). The Hadley circulation: present, past and future. Amsterdã: Kluwer Publishers, Capítulo 7, p. 203-235, 2004.

AMUNDSON, R.; STERN, L.; BAISDEN, T.; WANG, Y. The isotope composition of soil and soilrespired $\mathrm{CO}_{2}$. Geoderma, v. 82, p. 83-114, 1998.

ANDERSON, D.E. Younger Dryas research and its implications for understanding abrupt climatic change. Progress in Physical Geography, v. 21, p. 230-249, 1997.

ARZ, H.W.; PÄTZOLD, J.; WEFER, G. Correlated millennial-scale changes in surface hydrography and terrigenous sediment yield inferred from last glacial marine deposits off northeastern Brazil. Quaternary Research, v. 50, p. 157-166, 1998.

ARZ, H.W.; PÄTZOLD, J.; WEFER, G. The deglacial history of the western tropical Atlantic as inferred from high resolution stable isotope records off northeastern Brazil. Earth and Planetary Science Letters, v.167 p. 105-117, 1999.

ARZ, H.W.; GERHARDT, S.; PÄTZOLD, J.; RÖHL, U. Millennial-scale changes of surface and deep-water flow in the western tropical Atlantic linked to Northern Hemisphere highlatitude climate during the Holocene. Geology, v. 29, p. 239-242, 2001.

AULER, A.S.; SMART, P.L. Late Quaternary paleoclimate in semiarid Northeastern Brazil from Useries dating of travertine and water-table speleothems. Quaternary Research, v. 55, p. 159-167, 2001.

AULER, A.S.; WANG, X.; EDWARDS, R.L.; CHENG, H.; CRISTALLI, P.S.; SMART. P.L.; RICHARDS, D.A. Quaternary ecological and geomorphic changes associated with rainfall events in presently semi-arid northeastern Brazil. Journal of Quaternary Science, v.19, p. 693-701, 2004.

AULER, S.A.; SMART, P.L; WANG X.; PILÓ, L.B.; EDWARDS, R.L.; CHENG, H. Cyclic sedimentation in Brazilian caves: Mechanisms and palaeoenvironmental significance. Geomorphology, v. 106, p. 142-153, 2009.

BABINSKY, M. Idades isocronicas $\mathrm{Pb} / \mathrm{Pb}$ e geoquímica isotópica de $\mathrm{Pb}$ das rochas carbonáticas do Grupo Bambui, na porção sul da Bacia do São Francisco. Tese (doutorado) Instituto de Geociências, Universidade de São Paulo, São Paulo, 1993.

BAKER, A.; ITO, E.; SMART, P.L., McEWAN, R.F. Elevated and variable values of ${ }^{13} \mathrm{C}$ in speleothems in a British cave system. Chemical Geology, v. 136, p. 263-270, 1997.

BAKER, P.A.; SELTZER, G.O.; FRITZ, S.C.; DUNBAR, R.B.; GROVE, M.J.; TAPIA, P.M.; CROSS, S.L.; ROWE, H.D.; BRODA, J.P. The history of South American tropical precipitation for the past 25,000 years. Science, v. 291, p. 640-643, 2001 a.

BAKER, P.A.; RIGSBY, C.A; SELTZER, G.O.; FRITZ, S.C.; LOWENSTEINK, T.K.; BACHER, N.P.; VELIZ, C. Tropical climate changes at millennial and orbital timescales on the Bolivian Altiplano. Nature, v. 409, p. 698-701, 2001 b. 
BAKER, P.A.; FRITZ, S.C.; GARLAND, J.; EKDAHL, E. Holocene hydrologic variation at Lake Titicaca, Bolivia/Peru, and its relationship to North Atlantic climate variation. Journal of Quaternary Science, v. 20, p. 655-662, 2005.

BALDINI, J.U.L.; McDERMOTT, F.; FAIRCHILD, I.J. Structure of the 8200-Year Cold Event Revealed by a Speleothem Trace Element Record. Science, v. 296, p. 2203-2206, 2002.

BARKER, S.; DIZ, P.; VAUTRAVERS, M.J; PIKE, J.; KNORR, G.; HALL, I.R.; BROECKER, W.S. Interhemispheric Atlantic seesaw response during the last deglaciation. Nature, v. 457, p. 1097-1103, 2009.

BAR-MATTHEWS, M.; AYOLAN, A. Late Quaternary Paleoclimate in the Eastern Mediterranean Region from Stable Isotope Analysis of Speleothems at Soreq Cave, Israel. Quaternary Research, v. 47, p. 155-168, 1997.

BARRETO, E.A.S. Reconstituição da pluviosidade da Chapada Diamantina (BA) durante o Quaternário Tardio através de registros isotópicos (O e C) em estalagmites. Dissertação (mestrado) Instituto de Geociências, Universidade de São Paulo, São Paulo, 2010.

BERGER, A.; LOUTRE, M. F. Insolation values for the climate of the last 10 million years. Quaternary Science Reviews, v. 10, p. 297-317, 1991.

BERNAL, J.P.; LACHNIET, M.; MCCULLOCH, M.; MORTIMER, G.; MORALES, P.; CIENFUEGOS, E. 2010, A speleothem record of Holocene climate variability from southwestern Mexico. Quaternary Research, v.75, p. 104-113, 2010.

BIASUTTI, M.; BATTISTI, D. S.; SARACHIK, E. S. Mechanisms controlling the annual cycle of precipitation in the Tropical Atlantic sector in an atmospheric GCM. Journal of climate, v. 17, p. 4708-4723, 2004.

BLUNIER, T.; BROOK, E.J. Timing of Millennial-Scale Climate Change in Antarctica and Greenland During the Last Glacial Period. Science, v. 291, p. 109-112, 2001.

BOCH, R.; SPÖTL, C.; FRISIA, S.; Origin and palaeoenvironmental significance of lamination in stalagmites from Katerloch Cave, Austria. Sedimentology, v.58, p. 508-531, 2011.

BOND, G.; BROECKER, S.J.; McMANUS, J.; LABEYRIE, L.; JOUZEL, J.; BONANI, G. Correlations between climate record from North Atlantic sediments and Greenland. Nature, v. 365, p. 143-147, 1993.

BOND, G.; LOTTI, R. Icebergs Discharges into the North Atlantic on Millennial Time Scale During the Last Glaciation. Science, v. 267, p. 1005-1010, 1995.

BOND, G.; SHOWERS, W.; CHESEBY, M.; LOTTI, R.; ALMASI, P.; DEMENOCAL, P.; PRIORE, P.; CULLEN, H.; HAJDAS, I.; BONANI, G. A Pervasive Millennial-Scale Cycle in North Atlantic Holocene and Glacial Climates. Science, v. 278, p. 1257 - 1266, 1997.

BOND, G.; KROMER, B.; BEER, J.; MUSCHELER, R.; EVANS, M.N.; SHOWERS, W.; HOFFMANN, S.; LOTTI-BOND, R.; HAJDAS, I.; BONANI, G. Persistent solar influence on North Atlantic climate during the Holocene. Science, v. 294, p. 2130-2136, 2001. 
BROECKER, W.S. Massive iceberg discharges as triggers for global climate changes. Nature, v. 372, p. 421-424, 1994.

BROECKER, W.S. Paleocean circulation during the last deglaciation: A bipolar seesaw? Paleoceanography, v. 13, p. 119-121, 1998.

BOUTTON, T.W. Stable carbon isotope ratios of soil organic matter and their use as indicators of vegetation and climate change. In: Boutton, T.W., Yamasaki, S.I. (Eds.), Mass Spectrometry of Soils. Marcel Dekker. New York, p. 47-82, 1996.

CARLSON, A.E., LEGRANDE, A.N., OPPO, D.W., CAME, R.E., SCHMIDT, G.A., ANSLOW, F.S., LICCIARDI, J.M., OBBINK, E.Rapid early Holocene deglaciation of the Laurentide ice sheet. Nature Geoscience, v.1, p.620-624, 2008.

CARVAlHO, L.M.V.; JONES, C. Zona de Convergência do Atlântico Sul. In. CAVALCANTI, I.F.A. et al. (Eds). Tempo e Clima no Brasil. São Paulo: Oficina de textos, 2009, 464 p.

CHENG, H., FLEITMANN, D., EDWARDS, L.R., WANG, X., CRUZ, F.W., AULER, A.S., MANGINI, A., WANG, Y., KONG, X., BURNS, S. J., MATTER, A. Timing and structure of the 8.2 kyr B.P. event inferred from $\delta^{18} \mathrm{O}$ records of stalagmites from China, Oman, and Brazil. Geology, v. 37, p. 1007-1010, 2009.

CHIANG, J.C.H.; BIASUTTI, M.; BATTISTI, D.S. Sensitivity of the Atlantic Intertropical Convergence Zone to the last glacial maximum boundary conditions. Paleoceanography, v. 18, p. 1094-1112, 2003.

CHIANG, J.C.H.; KOUTAVAS, A. Climate Change: Tropical flip-flop connections. Nature, v. 432, p. 684-685, 2004.

CHIESSI, C. M. ; MULITZA, STEFAN ; PAUL, ANDRÉ ; PÄTZOLD, JÜRGEN ; GROENEVELD, JEROEN ; WEFER, GEROLD. South Atlantic interocean exchange as the trigger for the Bolling warm event. Geology, v. 36, p. 919-922, 2008.

CHIESSI, C.M.; MULITZA, S.;PÄTZOLD, J.; WEFER, G.; MARENGO, J.A. Possible impact of the Atlantic Multidecadal Oscillation on the South American summer monsoon. Geophysical Research Letters, v. 36, L21707, 2009.

CLAUSSEN M.; GANOPOLSKI A.; BROVKIN V.; GERSTENGARBE, F.-W.; WERNER, P. Simulated global-scale response of the climate system to Dansgaard/Oeschger and Heinrich events. Climate Dynamics, v. 21, p 361-370, 2003.

CLARK, I.; P. FRITZ. Environmental Isotopes in Hydrology. CRC Press, Boca Raton, 1997, 328 p.

CLARK, P.U.; ALLEY, R.B.; POLLARD, D. Northern Hemisphere ice-sheet influences on global climate change. Science, v. 286, p.1104-1111, 1999.

CLEMENT, A.C.; M. A. CANE, A role for the tropical Pacific coupled oceanatmosphere system on Milankovitch and millennial timescale. Part I: A modeling study of tropical Pacific variability, in Mechanisms of Global Climate Change at Millennial Time Scales. Geophysical. Monograpg, v. 112, p. 363-371, 1999. 
CLEMENT, A.C.; PETERSON, L.C. Mechanisms of abrupt climate change of the last glacial period. Reviews of Geophysics, v. 46, RG4002, 2008.

CRISTALLI, P.S. Macrofitofósseis em tufos calcários quaternários do norte da Bahia como indicadores paleoclimáticos. Tese (Doutorado) - Instituto de Geociências, Universidade de São Paulo, São Paulo, 2006.

CRUZ, F.W.; BURNS, S.J.; KARMANN, I.; SHARP, W.D.; VUILLE, M.; CARDOSO, A.O.; FERRARI, J.A.; SILVA DIAS, P.L.; VIANA Jr., O. Insolation-driven changes in atmospheric circulation over the past $116 \mathrm{ky}$ in subtropical Brazil. Nature, v. 434, p. 63-66, 2005a.

CRUZ, F.W.; KARMANN, I.; VIANA Jr. O.; BURNS, S. J.; FERRARI, J. A.; VUILLE, M.; SIAL, A. N.; MOREIRA, M.Z. Stable isotope study of cave percolation waters in subtropical Brazil: Implications for paleoclimate inferences from speleothems. Chemical Geology, v. 220, p. 245-262, 2005b.

CRUZ, F.W.; BURNS, S. J; KARMANN, I.; SHARP, W.D.; VUILLE, M. Reconstruction of regional atmosphere circulation features during the late Pleistocene in subtropical Brazil from oxygen isotope composition of speleothems. Earth and Planetary Sciences Letters, v. 248, p.494506, 2006a.

CRUZ, F.W.; BURNS, S.J.; KARMANN, I.; SHARP, W.D.; VUILLE, M.; FERRARI, J.A. A stalagmite record of changes in atmospheric circulation and soil processes in the Brazilian subtropics during the Late Pleistocene. Quaternary Science Reviews, v. 25, p. 2749- 761, 2006 b.

CRUZ, F.W.; BARNS, S.; JERCINOVIC, M.; KARMANN, I.; SHARP, W.D.; VUILLE, M. Evidence of rainfall variations in southern Brazil from trace element ratios $(\mathrm{Mg} / \mathrm{Ca}$ and $\mathrm{Sr} / \mathrm{Ca})$ in a Late Pleistocene stalagmite. Geochimica et Cosmochimica Acta, v.71, p. 2250- 2263, 2007.

CRUZ, F.W.; VUILLE, M.; BURNS, S.J.; WANG, X.; CHENG, H.; WERNER, M.; EDWARDS, R.L.; KARMANN, I.; AULER, A.S.; NGUYEN, H. Orbitally driven east-west antiphasing of South American precipitation. Nature geosciences, v. 2, p. 1-5, 2009a.

CRUZ, F.W. ; WANG, X.; AULER. A.; VUILLE. M.; BURNS.; S.J.; EDWARDS, L.R.; KARMANN, I.; CHENG, H. Orbital and millennial-scale precipitation changes in Brazil from speleothem records. In FRANCOISE, V. et al. (Eds.). Past Climate Variability in South America and Surrounding Regions. Paris: Springer, 2009b.

CUTLER, K.B.; EDWARDS, R.L.; TAYLOR, F.W.; CHENG, H.; ADKINS, J.; GALLUP, C.D.; CUTLER, P.M.; BURR, G.S.; BLOOM, A.L. Rapid sea-level fall and deep-ocean temperature change since the last interglacial period. Earth and Planetary Science Letters, v. 206, p. 253-271, 2003.

DANSGAARD, W.; JOHNSEN, S.J.; CLAUSEN H.B.; DAHL-JENSEN, D.; GUNDESTRUP, N.S.; HAMMER, C.U.; HVIDBERG, C.S.; STEFFENSEN J.P.; SVEINBJORNSDOTTIR, A.E.; JOUZEL. J.; BOND, G.C. Evidence for general instability of past climate from a 250-kyr ice-core record. Nature, v. 364, p. 218-220, 1993.

DERRY, L.A.; KAUFMAN, A.J.; JACOBSEN, S.B. Sedimentary cycling and environmental change in the Late Proterozoic: Evidence from stable and radiogenic isotopes. Geochimica et 
Cosmochimica Acta, v. 56, p. 1317-1329, 1992.

DESMARCHELIER, J.M.; GOEDE, A.; AYLIFFE, L.K.; MCCULLOCH, M.T.; MORIARTY, K. Stable isotope record and its palaeoenvironmental interpretation for a late Middle Pleistocene speleothem from Victoria Fossil Cave, Naracoorte, South Australia. Quaternary Science Reviews, v. 19 , p. 763-774, 2000.

DORALE, J.A.; LIU, Z. Limitations of Hendy test criteria in Judging the paleoclimate suitability of speleothems and the need of replication. Journal of Cave and Karst Studies, v. 71, p. 73-80, 2009.

DORALE, J.A.; EDWARDS, R.L.; ITO, E.; GONZÁLEZ, L.A. Climate and vegetation history of the midcontinent from 75 to $25 \mathrm{ka}$ : A speleothem record from Crevice Cave, Missouri, USA. Science, v. 282, p. 1871-1874, 1998.

D'ORGEVILlE, M.; PELTIER, W.R. On the Pacific Decadal Oscillation and the Atlantic Multidecadal Oscillation: Might they be related?. Geophysical Research Letters, v. 34, L23705, 2007.

DREYBRODT, W. Evolution of the isotopic composition of carbon and oxygen in a calcite precipitating $\mathrm{H}_{2} \mathrm{O}-\mathrm{CO}_{2}-\mathrm{CaCO}_{3}$ solution and the related isotopic composition of calcite in stalagmites. Geochimica et Cosmochimica Acta, v. 72, p. 4712-4724, 2008.

DRYSDALE, R.N.; ZANCHETTAB, G.; HELLSTROMC, J.C.; FALLICKD, A.E.; ZHAOE, J-X.; ISOLAF, I.; BRUSCHIG, G. Palaeoclimatic implications of the growth history and stable isotope $\left(\delta^{18} \mathrm{O}\right.$ and $\left.\delta^{13} \mathrm{C}\right)$ geochemistry of a Middle to Late Pleistocene stalagmite from central-western Italy. Earth and Planetary Science Letters, v. 227, p. 215-229, 2004

EDWARDS, R.L.; CHEN, J.H.; WASSERBURH, G.J. 238U - 234U - 230Th - 232Th systemtics and the precise measurement of time over the past 500.000 years. Earth Planetary Science Letters, v. 81, p. 175-192, 1986.

EKDAHL, E.J.; FRITZ, S.C.; BAKER, P.A.; RISGBY, C.A.; COLEY, K. Holocene multidecadal-to millennial-scale hydrologic variability on the South American Altiplano: The Holocene, v.18, p. 867-876, 2008.

ENTERS, D.; BEHLING, H.; MAYR, C.; DUPONT, L.; ZOLITSCHKA, B. Holocene environmental dynamics of south-eastern Brazil recorded in laminated sediments of Lago Aleixo. Journal of Paleolimnology, v. 44, p. 265-277, 2010.

EMILIANI, C. Pleistocene temperatures. Journal of Geology, v. 63, p. 539-578, 1955.

FAIRCHILD I.J.; BORSATO A.; TOOTH A.F.; FRISIA, S.; HAWKESWORTH, C.J.; HUANG, Y.; McDERMOTT, F.; SPIRO, B. Controls on trace element (Sr-Mg) compositions of carbonate cave waters: implications for speleothem climatic records. Chemical Geology, v. 166, p, 255-269, 2000.

FAIRCHILD I.J.; BAKER, A.; BORSATO A.; FRISIA, S.; HINTON, R.W.; McDERMOTT, F.; TOOTH A.F. Annual to sub-annual resolution of multiple trace-element trends in speleothems. Journal of the Geological Society, v. 158, p. 831-841, 2001. 
FAIRCHILD, I.J.; SMITH, C.L.; BAKER, A.; FULLER, L.; SPÖTL, C.; MATTEY, D.; McDERMOTT, F. E. I. M. F. Modification and preservation of environmental signals in speleothems. Earth-Science Reviews, v. 75, p. 105-153, 2006.

FAIRCHILD, I.J.; TREBLE, P.C. Trace elements in speleothems as recorders of environmental change. Quaternary Science Reviews, v. 28, p. 449-468, 2008.

FLEITMANN, D.; BURNS, S.J.; MUDELSEE, M.; NEFF, U.; KRAMERS, J.; MANGINI, A.; MATTER, A. Holocene Forcing of the Indian Monsoon Recorded in a Stalagmite from Southern Oman. Science, v. 300, p. 1737-1739, 2003.

FLEITMANN, D., MUDELSEE, M., BURNS, S.J., BRADLEY, R.S., KRAMERS, J., MATTER, A., Evidence for a widespread climatic anomaly at around $9.2 \mathrm{ka}$ before present. Paleoceanography, v. 23, PA1102, 2007.

FORD, D.C.; WILLIAMS, P. Karst Hydrogeology and Geomorphology. Edição Revisada. Chichester, England: John Wiley \& Sons. 2007, 562 p.

FRITZ, S.C.; BAKER, P.A.; TIM, C.D.; LOWENSTEIN, K.; SELTZER, G.P.; RIGSBY, C.A.; DWYER, G.S.; TAPIA, P.M.; ARNOLD, K.K.; KU, T-H.; LUOH, S. Hydrologic variation during the last 170,000 years in the southern hemisphere tropics of South America. Quaternary Research, v. 61, p. 95-104, 2004.

GAN, M.A.; KOUSKY, V.E.; ROPELEWSKI, C.F. The South American monsoon circulation and its relationship to rainfall over West-Central Brazil. Journal of Climate, v. 17, p. 47-66, 2004.

GARREAUD, R.D., VUILlE, M., COMPAGNUCCI, R., MARENGO, J. Present-day South American climate: Palaeogeography, Palaeoclimatology, Palaeoecology, v. 281, p. 180-195, 2009.

VAN GEEL, B.; BURMANN, J.; WATERBOLK, H.T. Archaeological and palaeoecological indications of an abrupt climate change in The Netherlands, and evidence for climatological teleconnections around - 2650 BP. Journal of Quaternary Science, v. 11, p. 451-460, 1996.

GRIFFITHS, M.L., DRYSDALE, R.N., GAGAN, M. K., ZHAO, J.X., AYLIFFE, L.K., HELLSTROM, J.C., HANTORO, W.S., FRISIA, S., FENG, Y.X., CARTWRIGHT, I., PIERRE, E. S.T., FISCHER, M.J., SUWARGADI, B.W.. Increasing Australian-Indonesian monsoon rainfall linked to early Holocene sea-level rise. Nature, v. 2, p. 636-639, 2009.

GRIMM, A.M.; AMBRIZZI, T. Teleconnections into South America from the Tropics and Extratropics on Interannual and Intraseasonal Timescales. In FRANCOISE, V. et al. (Eds.). Past Climate Variability in South America and Surrounding Regions. Paris: Springer, 2009.

GROOTES, P.M.; STUIVER, M. Oxygen 18/16 variability in Greenland snow and ice with $10^{-3}$-to $10^{5}$-year resolution. Journal of Geophysical Research, v. 102, p. 26455-26470, 1997.

HAASE-SCHRAMM, A.; BÖHM, F.; EISENHAUER, A.; GARBE-SCHÖNBERG, D.; DULLO, W.-C.; REITNER, J. Annual to interannual temperature variability in the Caribbean during the Maunder sunspot minimum. Paleoceanography, v. 20, PA4015, 2005.

HAIGH, J. The Impact of Solar Variability on Climate. Nature, v. 272, p. 981-984, 1996. 
HAMMER, Ø., HARPER, D.A.T., RYAN, P.D. PAST: Paleontological Statistics Software Package for Education and Data Analysis. Palaeontologia Electronica v. 4, p.9 http://palaeoelectronica.org/2001_1/past/issue1_01.htm, 2001.

HAUG, G.H.; HUGHEN, K.A.; SIGMAN, D.M.; PETERSON, L.C.; RÖHL, U. Southward migration of the intertropical convergence zone through the Holocene. Science, v. 293, p. 13041308, 2001.

HEINRICH, H. Origin and consequences of cyclic ice rafting in the northeast Atlantic ocean during the past 130,000 years. Quaternary Research, v. 29, p. 142-152, 1988.

HELLSTROM, J.C.; McCULLOCH, M.T. Multi-proxy constraints on the climatic signiфcance of trace element records from a New Zealand speleothem. Earth and Planetary Science Letters, v. 179 p. 287-297, 2000.

HEMMING, S. R. Heinrich events: Massive late pleistocene detritus layers of the North Atlantic and their global climate imprint, Reviews of Geophysics, v. 42, RG1005, 2004.

HENDY, C.H. The isotopic geochemistry of speleothems. 1. The calculation of the effects of different modes of formation on the isotopic composition of speleothems and their applicability as paleoclimatic indicators. Geochimica et Cosmochimica Acta, v. 35, p. 801-824, 1971.

HENDY, H. D.; WILSON, A. T. Paleoclimatic data from spelethems. Nature, v. 219, p.45-51, 1968.

HUANG, Y.; FAIRCHILD, I.J. Partitioning of $\mathrm{Sr}^{2+}$ and $\mathrm{Mg}^{2+}$ into calcite under karst-analogue experimental conditions. Geochimica et Cosmochimica Acta, v. 65, p. 47-62, 2001.

IGLESIAS, M.; UHLEIN, A. Estratigrafia do Grupo Bambuí e coberturas fanerozóicas no vale do rio São Francisco, norte de Minas Gerais. Revista Brasileira de Geociências, v. 39, p. 256-266, 2009.

IMBRIE, J.; IMBRIE, J.Z. Modeling the Climatic Response to Orbital Variations. Science, v. 207, p. 943-953, 1980.

ISONO, D.; YAMAMOTO, M.; IRINO, T.; OBA, T.; MURAYAMA, M.; NAKAMURA, T.; KAWAHATA, H. The 1500-year climate oscillation in the midlatitude North Pacific during the Holocene. Geology, v. 37, p. 591-594, 2009.

JACOB, J.; HUANG, H.; DISNAR, J.R.; SIFEDDINE, A.; BOUSSAFIR, M.; ALBUQUERQUE, A.L.; TURCQ, B. Paleohydrological changes during the last deglaciation in Northern Brazil. Quaternary Science Reviews, v. 26, p. 1004-1015, 2007.

JAESCHKE, A.; RÜHLEMANN, C.; ARZ, H.; HEIL, G.; LOHMANN, G. Coupling of millennialscale changes in sea surface temperature and precipitation off northeastern Brazil with high-latitude climate shifts during the last glacial period. Paleoceanography. v. 22, PA4206, 2007.

JENKINS, G.; WATTS, D. Spectral Analysis and Its Applications, New York: Holden-Day, 1968.

JENNERJAHN, T.C.; VENUGOPALAN I.; ARZ, H.W.; BEHLING, H.; PATZOLD, J.; WEFER, G. Asynchronous terrestrial and marine signals of climate change during Heinrich Events. Science, v. 306, p. 2236-2239, 2004. 
JOHNSON, K.R.; HU, C.; BELSHAW, N.S.; HENDERSON, G.M. Seasonal trace-element and stable-isotope variations in a Chinese speleothem: The potential for high-resolution paleomonsoon reconstruction. Earth and Planetary Science Letters, v. 244, p. 394-407, 2006.

JOUZEL, J.; MASSON-DELMOTTE, V.; CATTANI, O.; DREYFUS, G.; FALOURD, S.; HOFFMANN, G.; MINSTER, B.; NOUET, J.; BARNOLA, J.M.; CHAPPELLAZ, J.; FISCHER, H.; GALLET, J.C.; JOHNSEN, S.; LEUENBERGER, M.; LOULERGUE, L.; LUETHI, D.; OERTER, H.; PARRENIN, F.; RAISBECK, G.; RAYNAUD, D.; SCHILT, A.; SCHWANDER, J.; SELMO, E.; SOUCHEZ, R.; SPAHNI, R.; STAUFFER, B.; STEFFENSEN, J.P.; STENNI, B.; STOCKER, T.F.; TISON, J.L.;WERNER, M.; WOLFF, E.W. Orbital and Millennial Antarctic Climate Variability over the Past 800,000 Years. Science, v. 317, p. 793-796, 2007.

KARMANN, I.; CRUZ F. W.; VIANA JR., O.; BURNS, S. J. Climate influence on trace element geochemistry of waters from Santana-Pérolas cave system, Brazil. Chemical Geology, v.244, p. 232-247, 2007.

KAUFMAN, A.J.; HAYESA, J.M.; KNOLLB, A.H.; GERMSC, G.J.B. Isotopic compositions of carbonates and organic carbon from upper Proterozoic successions in Namibia: stratigraphic variation and the effects of diagenesis and metamorphism. Precambrian Research, v. 49, p. 301327, 1991.

KAUFMANN, G.; DREYBRODT, W. Stalagmite growth and palaeoclimate: an inverse approach. Earth and Planetary Science Letters, v. 224, p. 529-545, 2004.

KNIGHT, J.R; ALLAN, R.J.; FOLLAND, C.K.; VELLINGA, M.; MANN, M.E. A signature of persistent natural thermohaline circulation cycles in observed climate. Geophysical Research Letters, v. 32, L20708, 2005.

KNIGHT, J.R.; FOLLAND, C.K.; SCAIFE, A.A. Climate impacts of the Atlantic Multidecadal Oscillation. Geophysical Research Letters, v. 33, L17706, 2006.

KNOX, J.C. Valley alluviation in Southwestern Wisconsin. Annals of the Association of American Geographers, v. 62, p. 401-410, 1972.

LABAT, D.; ABABOU, R.; MANGIN, A. Rainfall-runoff relation for karst springs. Part II: continuous wavelet and discrete orthogonal multi-resolution analyses. Journal of Hydrology, v. 238, p. 149-178, 2000.

LACHNIET, M. Climatic and environmental controls on speleothem oxygen-isotope values. Quaternaty Science Reviews, v. 28, p. 412-432, 2009.

LEA, D.W.; PARK, D.K.; Peterson, L.C.; Hughen, K.A. Synchroneity of Tropical and HighLatitude Atlantic Temperatures over the Last Glacial Termination. Science, v. 301, p. 1361-1364, 2003

LEDRU, M.P.; ROUSSEAU, D.D.; CRUZ JR., F.W.; RICCOMINI, C.; KARMANN, I.; MARTIN, L. Paleoclimate changes during the last 100,000 yr from a record in the Brazilian Atlantic rainforest region and interhemispheric comparison. Quaternary Research, v. 64, p. 444-450, 2005.

LEDRU, M.P.; CECCANTINI, G.; GOUVEIA, S.E.M.; LÓPEZ-SÁEZ, J.A.; PESSENDA, L. C.R.; RIBEIRO, A.S. Millenial-scale climatic and vegetation changes in a northern Cerrado (Northeast, Brazil) since the Last Glacial Maximum. Quaternary Science Reviews, v. 25, p. 1110-1126, 2006. 
LEDUC, G.; SCHNEIDER, R.; KIM, J.H-; LOHMANN, G. Holocene and Eemian sea surface temperature trends as revealed by alkenone and $\mathrm{Mg} / \mathrm{Ca}$ paleothermometry. Quaternary Science Reviews, v. 29, p. 989-1004, 2010.

LEE, E.H.; LEE, D.Y. Features of great minima in solar activity during the last 1000 years. Advances in Space Research, v. 40, p. 942-950, 2007

LEE, J-E.; JOHNSON, K.; FUNG, I. Precipitation over South America during the Last Glacial Maximum:

An analysis of the "amount effect" with a water isotope-enabled general circulation model. Geophysical Research Letters, v. 36, L19701, 2009.

LeGRANDE, A.N.; SCHMIDT, G.A.; SHINDELL, D.T.; FIELD, C.V.; MILLER, R.L.; KOCH, D.M.; FALUVEGI, G.; HOFFMANN, G. Consistent simulations of multiple proxy responses to an abrupt climate change event. PNAS, v. 103, p. 837-842, 2006.

LEWIS, S.C.; GAGAN, M.K.; AYLIFFE, L.K.; ZHAO, J-X.; HANTORO, W.S.; TREBLE, P.C.; HELLSTROM, J.C.; LEGRANDE, A.N.; KELLEY, M.; SCHMIDT, G.; SUWARGADI, B.W. High-resolution stalagmite reconstructions of Australian-Indonesian monsoon rainfall variability during Heinrich stadial 3 and Greenland interstadial 4. Earth and Planetary Science Letters, v. 303, p. 133-142, 2011.

LOZANO-GARCÍA, M. S.; CABALLERO, M. ORTEGA, B.; RODRÍGUEZ, A.; SOSA, S. Tracing the effects of the Little Ice Age in the tropical lowlands of eastern Mesoamerica. PNAS, v. 104, p. 16200-16203, 2007.

MANGIN, A. Pour une meilleure connaissance des syste`mes hydrologiques a` partir des analyses corre'latoires et spectrales. Journal Hydrology. V. 67, p. 25-43, 1984.

MARCHITTO, T.M.; MUSCHELER, R.; ORTIZ, J.D.; CARRIQUIRY, J.D.; VAN GEEN, A. Dynamical response of the tropical Pacific Ocean to solar forcing during the early Holocene. Science, v. 330, p. 1378-1381, 2010.

MECHOSO, C.R.; ROBERTSON, A. W.; ROPELEWSKI, C. F.; GRIMM, A. M. The American Monsoon Systems: an introduction. In: CHANG, B. et al. (Eds.). The Global Monsoon System: Research and Forecast. WMO/TD, n. 1266 (TMRP Report n. 70), p. 197- 206, 2005.

MELO, A.B.C.; CAVALCANTI, I.F.A.; SOUZA, P.P. Zona de Convergência Intertropical do Atlântico. In. CAVALCANTI, I.F.A. et al. (Eds.). Tempo e Clima no Brasil. São Paulo: Oficina de textos, 2009, $464 \mathrm{p}$.

MARTÍNEZ, M.I. Estratigrafia e tectônica do Grupo Bambuí, no Norte do estado de Minas Gerais. Dissertação (Mestrado), Instituto de Geociências, Universidade Federal de Minas Gerais, Belo Horizonte, 2007.

McDERMOTT, F. Palaeo-climate reconstruction from stable isotope variations in speleothems: a review. Quaternary Science Reviews, v. 23, p. 901-918, 2004.

McGILLEN, M.R.; FAIRCHILD, I.J. An experimental study of incongruent dissolution of CaCO3 under analogue glacial conditions. Journal of Glaciology, v. 51, p. 383-390, 2005. 
McMANUS, J.F.; FRANCOIS, R.; GHERARDI, J-M.; KEIGWIN, L.D.; BROWN-LEGER, S. Collapse and rapid resumption of Atlantic meridional circulation linked to deglacial climate changes. Nature, v. 428, p. 834-837, 2004.

MICKLER, P.; BANNER, J.L.; STERN, L.; ASMEROM, Y.; EDWARDS, R.L.; ITO, E. Stable isotope variations in modern tropical speleothems: Evaluating equilibrium vs. kinetic isotope effects. Geochimica et Cosmochimica Acta, v. 68, p. 4381-4393, 2004.

NGRIP members: High resolution Climate Record of the Northern Hemisphere reaching into the last Glacial Interglacial Period, Nature, 431, 147-151, 2004.

O'BRIEN, S. R.; MAYEWSKI, P. A.; MEEKER, L. D.; MEESE, D. A.; TWICKLER, M. S.; WHITLOW, S.I. Complexity of Holocene Climate as Reconstructed from Greenland Ice Core. Science, v. 270, p. 1962-1964, 1995.

OSTER, J.L.; MONTAÑES, I.P.; GUILDERSON, T.P.; SHARP, W.D.; BANNER, J.L. Modeling speleothem d13C variability in a central Sierra Nevada cave using ${ }^{14} \mathrm{C}$ and ${ }^{87} \mathrm{Sr} /{ }^{86} \mathrm{Sr}$. Geochemica et Cosmochemica Acta, v. 74, p. 5228-5242, 2010.

PESSENDA, L.C.R.; ARAVENA, R.M.; MELFI, A.J. The use of carbon isotopes (C-13, C-14) in soil to evaluate vegetation changes during the Holocene in central Brazil. Radiocarbon, v. 38, p. 191-201, 1996.

PESSENDA, L.C.R.; OLIVEIRA, P.E.; MOFATTO, M.; MEDEIROS, V.B.; GARCIA, R.J.F.; ARAVENA, R.; BENDASSOLI, J.A.; LEITE, A.Z.; SAAD, A.R.; ETCHEBEHERE, M.L. The evolution of a tropical rainforest/grassland mosaic in southeastern Brazil since 28,000 14C yr BP based on carbon isotopes and pollen records. QLuaternary research, v. 71, n.3, p.437-452, 2009.

PETERSON, L.C.; HAUG, GERALD H.; HUGHEN, K.A.; RÖHL, U. Rapid changes in the hydrologic cycle of the Tropical Atlantic during the Last Glacial. Science, v. 290, n 5498, p. 1947$1951,2000$.

PETERSON, L.C.; HAUG, G.H. Variability in the mean latitude of the Atlantic Intertropical Convergence Zone as recorded by riverine input of sediments to the Cariaco Basin (Venezuela). Palaeogeography, Palaeoclimatology, Palaeoecology, v. 234, p. 97-113, 2006.

PLAGNES, V. ; CAUSSE, C. ; GENTY, D. ; PATERNE, M.; BLAMART, D. A discontinuous climatic record from 187 to $74 \mathrm{ka}$ from a speleothem of the Clamouse Cave (south of France). Earth and Planetary Science Letters, v. 201, p. 87-103, 2002.

POLISSAR, P.J.; ABBOTT, M.B.; WOLFE, A. P.; BEZADA, M.; RULL, V.; BRADLEY, R.S. Solar modulation of Little Ice Age climate in the tropical Andes. PNAS, v. 103, p. 8937-8942, 2006.

RAHMSTORF, S. Ocean circulation and climate during the past 120,000 years. Nature, v. 19, p. 207-214, 2002.

RAO, V.B.; CAVALCANTI, I. F. A.; HADA, K. Annual variation of rainfall over Brazil and water vapor characteristics over South America. Journal of geophysical research, v. 101, p. 26,539$26,551,1996$.

RAILSBACK, L. B.; BROOK, G.A.; CHEN, J.; KALIN, R.; FLEISHER, C.J. Environmental controls on the petrology of a Late Holocene speleothem from Botswana with annual layers of 
aragonite and calcite:Journal of Sedimentary Research, v. A64, p. 147-155, 1994.

RAMIREZ, E.; HOFFMANN, G.; TAUPIN, J.D.; FRANCOU, B.; RIBSTEIN, P.; CAILLON, N.; FERRON, F.A.; LANDAIS, A.; PETIT, J.R.; POUYAUD, B.; SCHOTTERER, U.; SIMOES, J.C.; STIEVENARD, P. A new Andean deep ice core from Nevado Illimani (6350), Bolivia. Earth and Planetary Science Letters, v. 212, p. 337-350, 2003.

RICHARD, D.A.; DORALE, J.A. 2003. Uranium-series chronology and environmental applications of speleothem. In: BOURDON, B. et al. (Eds.), Uranium-series Geochemistry. Reviews in Mineralogy and Geochemistry, v. 52, p. 407-460, 2003.

ROBERTS, M.S.; SMART, P.L; BAKER, A. Annual trace element variations in a Holocene speleothem. Earth and Planetary Science Letters, v. 154, p. 237-246, 1998.

ROZANSKI, K,; ARAGUÁS, L. Spatial and temporal variability of stable isotope composition of precipitation over the South American continent. Bulletin de l'Institut Français d'Études Andines, v. 24, p. 379-390, 1995.

RUDDIMAN, W.F. Orbital changes and climate. Quaternary Science Reviews, v. 25, p. 3092-3112, 2006.

RUDDIMAN, W.F. Earth's climate: past and future. $2^{\mathrm{a}}$ edição. Nova Iorque: W.H. Freeman. 2008, $465 \mathrm{p}$.

RÜHLEMANN, C.; MULITZA, S.; . MÜLLER, P.J.; WEFER, G.; ZAHN, R. Warming of the tropical Atlantic Ocean and slowdown of thermohaline circulation during the last deglaciation. Nature, v. 402, p. 511-514, 1999.

SACHS, J.P.; LEHMAN, S. Subtropical North Atlantic temperatures 60,000 to30,000 Years Ago. Science, v. 286, p. 756-759, 1999.

SHACKLETON, N. Oxygen isotope analyses and Pleistocene temperatures re-assessed. Nature, v.215, p.15-17, 1967.

SHEN, C-C., EDWARDS, R.L., CHENG, H., DORALE, J.A., THOMAS, R.B., MORAN, S. B., WEINSTEIN, S.E., EDMONDS H.N. Uranium and thorium isotopic and concentration measurements by magnetic sector inductively coupled plasma mass spectrometry: Chemical Geology, v. 185, p. 165-178, 2002.

SHULZ, M.; MUDELSSE, M. REDFIT: estimatingred-noise spectra directly from unevenly spaced paleoclimatic time series. Computers \& Geosciences, v. 28, p. 421-426, 2002.

SIFEDDINE, A.; ALBUQUERQUE, A.L.S.; LEDRU, M-P.L.; TURCQ, B.; KNOPPERS, B., MARTIN; L., MELLO, W.Z.; PASSENAU, H.; DOMINGUEZ, J.M.L.; CORDEIRO, R.C.; ABRÃO, J.J.; BITTENCOURT, A.C.S.P. A 21000 cal years paleoclimatic record from Caço Lake, Northern, Brazil: Evidence from sedimentary and pollen analyses. Palaeogeography, Palaeoclimatology, Palaeoecology, v. 189, p. 25-34, 2003.

SILVA, M.T. et al. Domínios espeleogenéticos na Lapa Sem Fim (MG 973) Luislândia MG. In: Congresso Brasileiro de Espeleologia, 26., Januária. Anais. Januária: Sociedade Brasileira de Espeleologia, 2003, p. 180-183. 
SINCLAIR, D.J. Two mathematical models of $\mathrm{Mg}$ and $\mathrm{Sr}$ partitioning into solution during incongruent calcite dissolution Implications for dripwater and speleothem studies. Chemical Geology, v. 283, p. 119-133, 2010.

SINGARAYER, J.S.; VALDES, P.J. High-latitude climate sensitivity to ice-sheet forcing over the last 120 kyr. Quaternary Science Reviews, v. 29, p. 43-55, 2010.

SPÖTL, C.; FAIRCHILD, I.J.; TOOTH, A.F. Cave air control on dripwater geochemistry, Obir Caves (Austria): Implications for speleothem deposition in dynamically ventilated caves. Geochimica et Cosmochimica Acta, v. 69, p. 2451-2468, 2005

STUIVER, M., BRAZIUNAS, T.F. Atmospheric 14C and century-scale solar oscillations. Nature, v. 338, p. 405-408, 1989.

STUTE, M.; FORSTER, M.; FRISCHKORN, H.; SEREJO, A.; CLARK, J.F.; SCHLOSSER, P.; BROECKER, W.S.; BONANI, G. Cooling of tropical Brazil $\left(5^{\circ} \mathrm{C}\right)$ during the last glacial maximum. Science, v. 269, p. 379-383, 1995.

TIMMERMANN, A.; OKUMURA, Y.; AN, S.-I.; CLEMENT, A.; DONG, B.; GUILYARDI, E.; HU, A.; JUNGCLAUS, J.H.; RENOLD, M.; STOCKER, T.F.; STOUFFER, R.J.R. SUTTON, R.; XIE, S.-P.; YIN, J. The Influence of a Weakening of the Atlantic Meridional Overturning Circulation on ENSO. Journal of Climate, v. 20, p. 4899-4919, 2007.

THOMSON, D.J.. Time series analysis of Holocene climate data. Philosophical Transactions of the Royal Society of Londons, série A 330, v. 330, p. 601-616, 1990.

THOMPSON, L.G.; MOSLEY-THOMPSON, E.; DAVIS, M.E.; LIN, P-N.; HENDERSON, K.A.; COLE-DAI, J.; BOLZAN, J.F.;LIU, K-B. Late Glacial Stage and Holocene tropical ice core records from Huascarán, Peru. Science, v. 269, p. 46-50, 1995.

THOMPSON, L.G.; DAVIS, M.E.; MOSLEY-THOMPSON, E.;SOWERS, T.A.; HENDERSON, K.A.; ZAGORODNOV, V.S; LIN, P.-N.; MIKHALENKO, V.N.; CAMPEN, R.K.; BOLZAN, J.F.; COLE-DAI, J.; FRANCOU, B. A 25,000-Year Tropical Climate History from Bolivian Ice Cores. Science, v. 282, p. 1858-1864, 1998.

TORRENCE, C.; COMPO, G.P. A practical guide to wavelet analysis. Bulletin of the American Meteorological Society, v. 79, p. 61-78, 1998.

TREBLE, P.; SHELLEY, J.M.G.; CHAPPELL, J. Comparison of high resolution subannual records of trace elements in a modern (1911-1992) speleothem from southwest Australia. Earth and Planetary Science Letters, v. 16, p. 141-153, 2003.

USOSKIN, I.G.; KOVALTSOV, G.A. Cosmic rays and climate of the Earth: Possible connection. Comptes Rendus Geocience, v. 340, p. 441-450, 2008.

VAN BEYNEN, P.E.; SOTO, L.; PACE-GRACZYK, K. Paleoclimate reconstruction derived from speleothem strontium and $\delta^{13} \mathrm{C}$ in Central Florida. Quaternaty International, v. 187, p. 76-83, 2008.

VAN BREUKELEN, M.R.; VONHOF, H.B.; HELLSTROM, J.C.; WESTER, W.C.G.; KROON, D. Fossil dripwater in stalagmites reveals Holocene temperature and rainfall variation in Amazonia. Earth Planetary Science Letters, v. 275, p. 54-60, 2008. 
VELLINGA, M.; WOOD, R. Global climate impacts of collapse of the Atlantic Thermohaline Circulation. Climate Change, v. 54, p. 251-267, 2002.

VERA, C.; HIGGINS, W.; AMADOR, J.; AMBRIZZI, T.; GARREAUD, R.; GOCHIS, D.; GUTZLER, D.; LETTENMAIER, D.; MARENGO, J.; MECHOSO, C.R.; NOGUESPAEGLE, J.; SILVA DIAS, P.L.; ZHANG, C. Toward a unified view of the American Monsoon Systems. American Meteorological Society, v. 19, p. 4977-5000, 2006.

VIMEUX, F.; GALLAIRE, R.; BONY, S.; HOFFMANN, G.; CHIANG, J.C.H. What are the climate controls on $\delta \mathrm{D}$ in precipitation in the Zongo Valley (Bolivia)? Implications for the Illimani ice core interpretation. Earth and Planetary Science Letters, v. 240, p. 205-220, 2005.

VUILLE, M.; BRADLEY, R. S.; WERNER, M.; HEALY, R.; KEIMIG, F. Modeling $\delta^{18} \mathrm{O}$ in recipitation over the tropical Americas: Interannual variability and climatic controls. Journal of Geophysical Research, v.108, p. 4174, 2003.

VUILLE, M.; WERNER, M. Stable isotopes in precipitation recording South American summer monsoon and ENSO variability observations and model results. Climate Dynamics, v. 25, p. 401413, 2005.

WAINER, I.; CALUZET, G. Last Glacial Maximum in South America: Paleoclimate proxies and model results. Geophysical Research Letters, v. 32, L08702, 2005

WANG, Y. J.; CHENG, H.; EDWARDS, R. L.; AN, Z. S.; WU, J. Y.; SHEN, C.C.; DORALE, J. A. A high-resolution absolute-dated late Pleistocene monsoon record from Hulu Cave, China. Science, v. 294, p. 2345-2348, 2001.

WANG, X.; AULER, A.S.; EDWARDS, R.L.; CHENG, H.; CRISTALlI, P.S.; SMART, P.; RICHARDS, D.A.; SHEN, C. Wet periods in northeastern Brazil over the past 210 kyr linked to distant climate anomalies. Nature, v. 432, p. 740-743, 2004.

WANG, Y.; CHENG, H.; EDWARDS, R. L.; HE, Y.; KONG, X,; AN, Z.; WU, J.; KELLY, M. J.; DYKOSKI, C. A.; LI, X. The Holocene Asian Monsoon: Links to Solar Changes and North Atlantic Climate. Science, v. 308, p. 854-857, 2005.

WANG, X.; AULER, A.S.; EDWARDS, R. L.; HAI, C.; ITO, E.; MANIKO, S.; Interhemispheric anti phasing of rainfall during the last glacial period. Quaternary Science Reviews, v. 25, p. 33913403, 2006.

WANG, X.; AULER, A.S.; EDWARDS, R.L.; CHENG, H.; ITO, E.; WANG, Y.J.; KONG, X.G.; SOLHEID, M. Millennial-scale precipitation changes in southern Brazil over the past 90,000 years. Geophysics Research Letters, v. 241, p. 699-706, 2007a.

WANG, X.; EDWARDS, R. L.; AULER, A. S.; CHENG, H.; ITO, E. Millennial-scale interhemispheric asymmetry of low-latitude precipitation: Speleothem evidence and possible highlatitude forcing. Geophysical Monography Ser. p. 173, 279-293, 2007 b.

WANG, Y.; CHENG, H.; EDWARDS, R.L.; KONG, X.; SHAO, X.; CHEN, S.; WU, J.; JIANG, X.; WANG, X.; AN, Z. Millennial- and orbital-scale changes in the East Asian monsoon over the past 224,000 years. Nature, v. 452, p. 1090-1093, 2008. 
WELDEAB, S.; SCHNEIDER, R.R.; KÖLLING, M. Deglacial sea surface temperature and salinity increase in the western tropical Atlantic in synchrony with high latitude climate instabilities. Earth and Planetary Science Letters, v. 241, P. 699-706, 2006.

WILLIAMS, P.W.; KING, D.N.T., ZHAO, J.-X.; COLLERSON, K.D. Late Pleistocene to Holocene composite speleothem $18 \mathrm{O}$ and 13C chronologies from South Island, New Zealand-did a global Younger Dryas really exist? Earth and Planetary Science Letters, v. 230, p. 301-317, 2005.

WOHLFARTH, B. The chronology of the Last Termination: a review of radiocarbon-dated, highresolution terrestrial stratigraphies, Quaternary Science Reviews, v. 15, p. 267-284, 1996.

WRIGHT, J.D., Global climate change in marine stable isotope records, In NOLLER, J.S. et al. (Eds.). Quaternary Geochronology: Applications in Quaternary Geology, p. 671-682, 1999.

YOSHIMORI, M.; RAIBLE, C.C.; STOCKER, T.F.; RENOLD, M. On the interpretation of lowlatitude hydrological proxy records based on Maunder Minimum AOGCM simulations. Climate Dynamics, v. 27, p. 493-513, 2006.

YUAN, D.; CHENG, H.; EDWARDS, R.L.; DYKOSKI, C.A.; KELLY, M.J.; ZHANG, M.; QING, J.; LIN, Y.; WANG, Y.; WU, J.; DORALE, J.A.; AN, Z.; CAI, Y. Timing, Duration, and Transitions of the Last Interglacial Asian Monsoon. Science, v. 302, p. 575-578, 2004.

ZHANG, R.; DELWORTH, T.L. Simulated Tropical Response to a Substantial Weakening of the Atlantic Thermohaline Circulation. Journal of Climate, v. 18, p. 1853-1860, 2005.

ZHOU, J.; W. LAU, K.-M. Does a monsoon climate exist over South America?. Journal Climate, v. 11,p. 1020-1040, 1998. 
ANEXO I

(Mapas) 


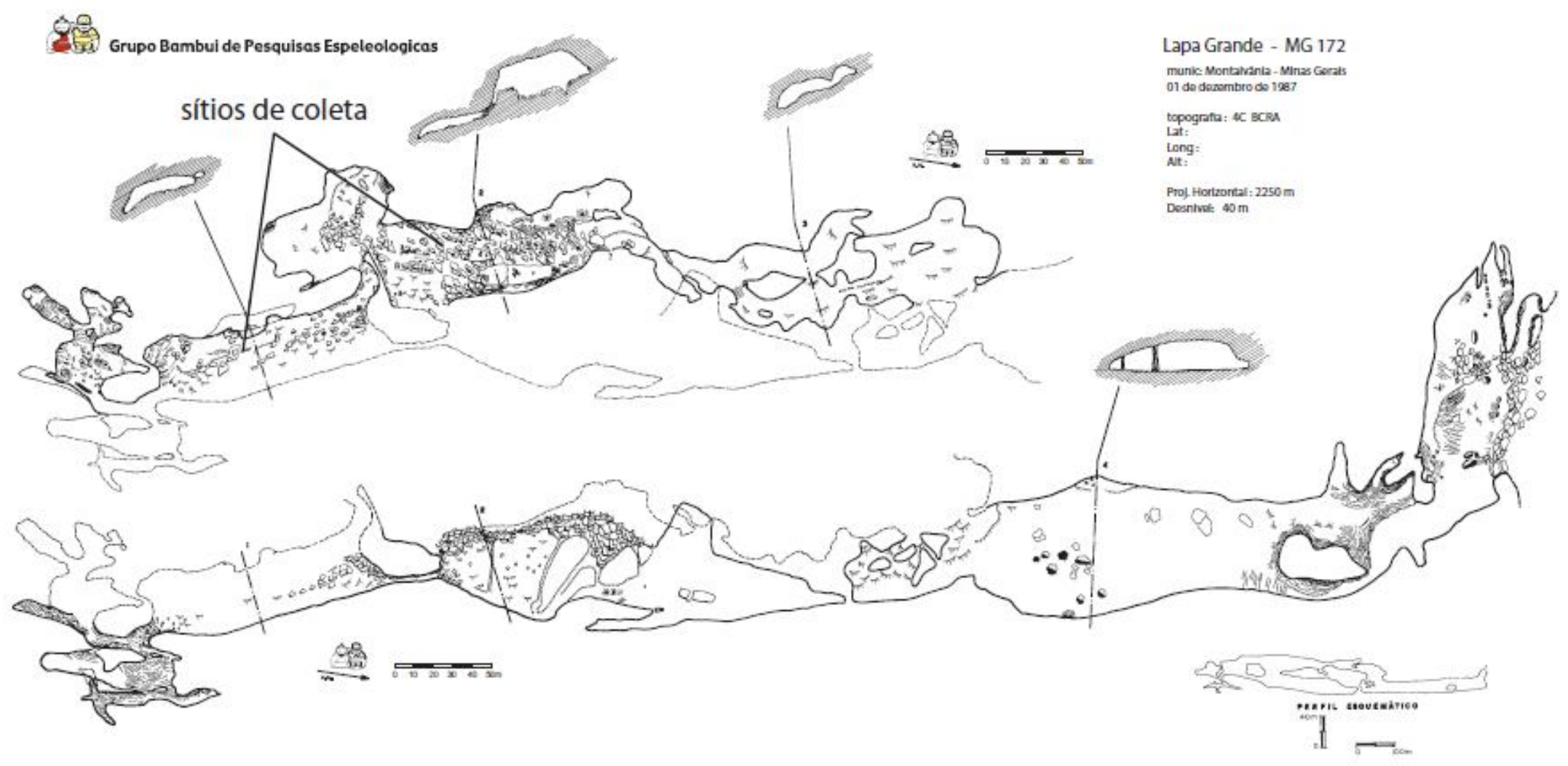




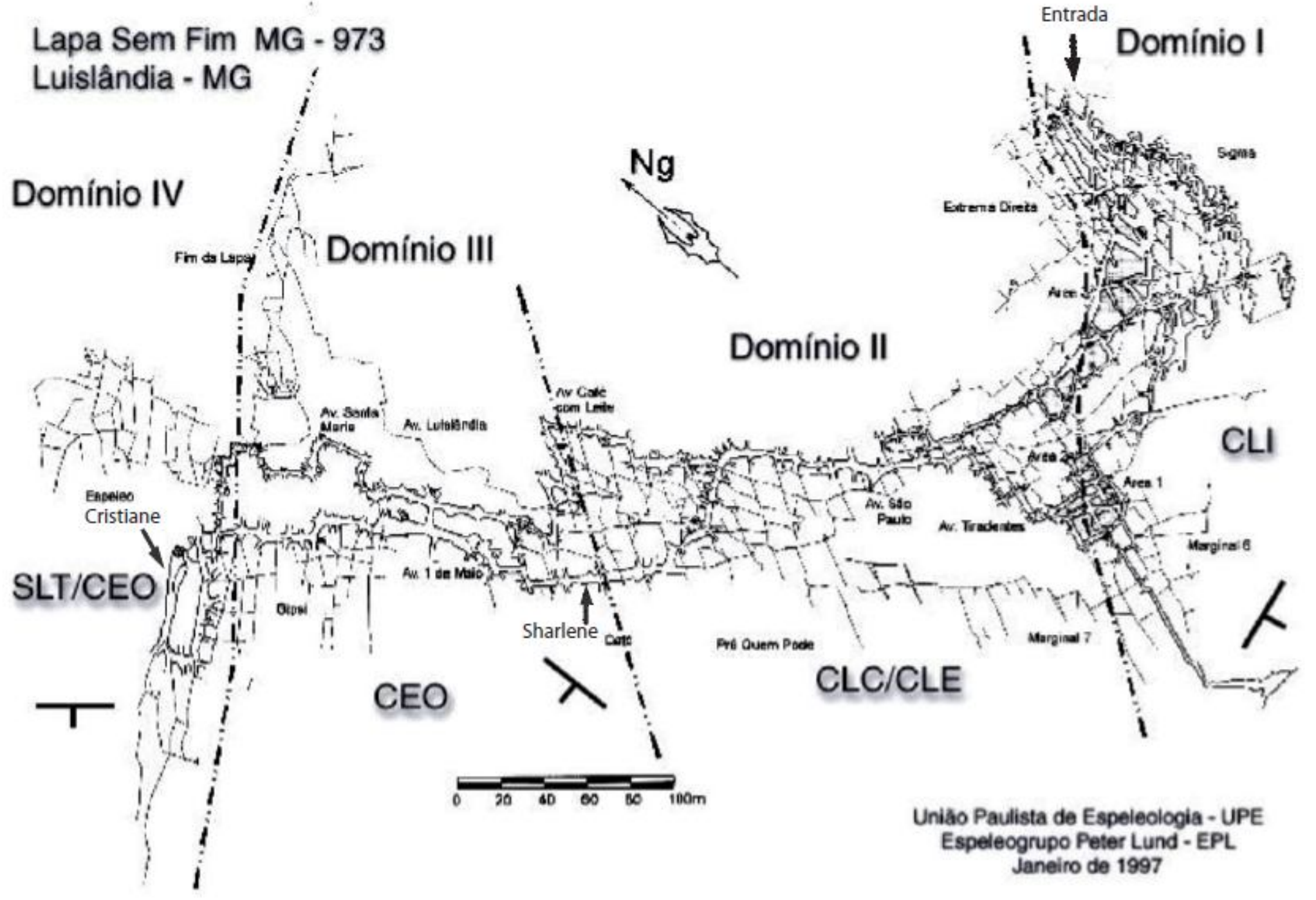


ANEXO II

(Dados GNIP) 
1061

Latitude: $15.85 \mathrm{~S}$ Longitude: $\quad 47.93 \mathrm{~W}$ Altitude: m.a.n.m.

\begin{tabular}{|c|c|c|c|c|c|}
\hline Ano & Mês & $\begin{array}{c}\text { precipitação } \\
(\mathrm{mm})\end{array}$ & Deutério & Oxigênio & $\begin{array}{c}\text { Temperatura } \\
\left({ }^{\circ} \mathrm{C}\right)\end{array}$ \\
\hline 64 & 12 & 291 & & & 20.4 \\
\hline 65 & 1 & 266 & & & 20.2 \\
\hline 65 & 2 & 163 & & & 21 \\
\hline 65 & 3 & 319 & -51.2 & -8.53 & 20.4 \\
\hline 65 & 4 & 166 & -25.1 & -4.85 & 20.4 \\
\hline 65 & 5 & 7 & & & 20 \\
\hline 65 & 6 & 32 & -21.7 & -4.2 & 17.6 \\
\hline 65 & 7 & 32 & 0 & -2.2 & 18.3 \\
\hline 65 & 8 & 5 & 26.1 & 1.4 & 20.5 \\
\hline 65 & 9 & 73 & 7.5 & -0.3 & 22.6 \\
\hline 65 & 10 & 361 & -16.8 & -4 & 20.2 \\
\hline 65 & 11 & 449 & -26.1 & -4.6 & 19.9 \\
\hline 65 & 12 & 121 & -5.6 & -2.2 & 21.4 \\
\hline 66 & 1 & 231 & -49.6 & -7.6 & 21 \\
\hline 66 & 2 & 352 & -52.1 & -7.7 & 20.9 \\
\hline 66 & 3 & 169 & -25.4 & -4.9 & 21 \\
\hline 66 & 4 & 107 & -22.7 & -4.9 & 20.1 \\
\hline 66 & 5 & 87 & 11.2 & 1.7 & 19 \\
\hline 66 & 6 & 0 & & & 17 \\
\hline 66 & 7 & 0 & & & 17 \\
\hline 66 & 8 & 0 & & & 19 \\
\hline 66 & 9 & 102 & 3.2 & -1.8 & 21.3 \\
\hline 66 & 10 & 137 & 6.4 & -0.5 & 21 \\
\hline 66 & 11 & 154 & & & 20 \\
\hline 66 & 12 & 348 & -78.9 & -11.6 & 21 \\
\hline 67 & 1 & 90 & -26.8 & -4.58 & 21 \\
\hline 67 & 2 & 171 & -19.3 & -3.52 & 21 \\
\hline 67 & 3 & 285 & -51.8 & -8.72 & 21 \\
\hline 67 & 4 & 218 & -24.7 & -4.59 & 20 \\
\hline 67 & 5 & 4 & & & 19 \\
\hline 67 & 6 & 0 & & & 18.7 \\
\hline 67 & 7 & 0 & & & 18 \\
\hline 67 & 8 & 0 & & & 20.2 \\
\hline 67 & 9 & 39 & 18.6 & 0.53 & 22 \\
\hline 67 & 10 & 64 & -3 & -1.77 & 22 \\
\hline 67 & 11 & 218 & -30.2 & -6.08 & 20.6 \\
\hline 67 & 12 & 180 & -44.8 & -7.86 & 20 \\
\hline 68 & 1 & 92 & -0.4 & -1.43 & 21 \\
\hline 68 & 2 & 57 & -107.6 & -14.73 & 19 \\
\hline 68 & 3 & 225 & -23.3 & -4.1 & 21.2 \\
\hline 68 & 4 & 149 & -22.6 & -4.97 & 20 \\
\hline 68 & 5 & 28 & 2.1 & -1.52 & 17 \\
\hline 68 & 6 & 0 & & & 16.6 \\
\hline 68 & 7 & 0 & & & 17.1 \\
\hline 68 & 8 & 7 & 7.2 & -0.79 & 19 \\
\hline 68 & 9 & 49 & 1.5 & -2.14 & 20 \\
\hline 68 & 10 & 88 & & & 21.7 \\
\hline 68 & 11 & 315 & -0.1 & -1.99 & 21.6 \\
\hline 68 & 12 & 272 & -41.9 & -6.83 & 20.1 \\
\hline 69 & 1 & 196 & & & 20 \\
\hline
\end{tabular}




\begin{tabular}{|c|c|c|c|c|c|}
\hline 69 & 2 & 139 & -38.5 & -5.38 & 22 \\
\hline 69 & 3 & 191 & & & 21.8 \\
\hline 69 & 4 & 62 & -20.8 & -4.82 & 21.3 \\
\hline 69 & 5 & 121 & -45.5 & -6.95 & 19.4 \\
\hline 69 & 6 & 0 & & & 18.5 \\
\hline 69 & 7 & 0 & & & 18.6 \\
\hline 69 & 8 & 0 & & & 21.2 \\
\hline 69 & 9 & 5 & 24.9 & 2.61 & 22.9 \\
\hline 69 & 10 & 196 & 0 & -1.63 & 21.8 \\
\hline 69 & 11 & 304 & & & 21.2 \\
\hline 69 & 12 & 278 & -42.9 & -7.35 & 20 \\
\hline 70 & 1 & 472 & 17.8 & 2.76 & 20.9 \\
\hline 70 & 2 & 233 & -64.8 & -9.46 & 20.8 \\
\hline 70 & 3 & 189 & -26.9 & -3.92 & 21.4 \\
\hline 70 & 4 & 99 & -10.6 & -1.14 & 20.4 \\
\hline 70 & 5 & 1 & -41.4 & -6.8 & 20 \\
\hline 70 & 6 & 0 & & & 19.5 \\
\hline 70 & 7 & 0 & & & 18 \\
\hline 70 & 8 & 0 & & & 19.3 \\
\hline 70 & 9 & 93 & 4.2 & -0.25 & 21.6 \\
\hline 70 & 10 & 207 & -1.5 & & 21.5 \\
\hline 70 & 11 & 229 & -38.5 & -6.13 & 21.3 \\
\hline 70 & 12 & 195 & & & 21.7 \\
\hline 71 & 1 & 201 & & 0.56 & 21.9 \\
\hline 71 & 2 & 122 & & 0.52 & 21.3 \\
\hline 71 & 3 & 191 & & -0.71 & 21.7 \\
\hline 71 & 4 & 126 & & -2.68 & 21.1 \\
\hline 71 & 5 & 33 & & -2.68 & 19.8 \\
\hline 71 & 6 & 34 & & -1.69 & 19.3 \\
\hline 71 & 7 & 62 & & -1.66 & 18.7 \\
\hline 71 & 8 & 1 & & & 19.6 \\
\hline 71 & 9 & 124 & & -2.71 & 20.4 \\
\hline 71 & 10 & 278 & & -7.32 & 19.7 \\
\hline 71 & 11 & 368 & & -8.38 & 19.8 \\
\hline 71 & 12 & 287 & & -4.44 & 20.7 \\
\hline 72 & 1 & 22 & & -7.64 & 21.4 \\
\hline 72 & 2 & 92 & & & 21 \\
\hline 72 & 3 & 106 & & -3.79 & 21.5 \\
\hline 72 & 4 & 142 & & & 20 \\
\hline 72 & 5 & 28 & & -4.97 & 19.6 \\
\hline 72 & 6 & 1 & & -0.9 & 19.3 \\
\hline 72 & 7 & 8 & & & 19.3 \\
\hline 72 & 8 & 2 & & & 21.2 \\
\hline 72 & 9 & 26 & 20.4 & 0.79 & 21.8 \\
\hline 72 & 10 & 237 & -11.8 & -3.2 & 22 \\
\hline 72 & 11 & 333 & & & 21.7 \\
\hline 72 & 12 & 474 & & & 21.5 \\
\hline 73 & 1 & 169 & -37 & -6.21 & 22.5 \\
\hline 73 & 2 & 185 & -7.6 & -2.37 & 22.1 \\
\hline 73 & 3 & 229 & -54.6 & -8.15 & 21.9 \\
\hline 73 & 4 & 85 & & & 21.8 \\
\hline 73 & 5 & 18 & -7.9 & -2.8 & 20.1 \\
\hline 73 & 6 & 24 & & & 20.4 \\
\hline 73 & 7 & 0 & & & 19 \\
\hline 73 & 8 & 0 & & & 22 \\
\hline 73 & 9 & 72 & & & 22 \\
\hline 73 & 10 & 311 & -38.5 & -6.09 & 20.4 \\
\hline
\end{tabular}




\begin{tabular}{|c|c|c|c|c|c|}
\hline 73 & 11 & 196 & -29.6 & -5.13 & 21 \\
\hline 73 & 12 & 162 & -28.3 & & 21.3 \\
\hline 74 & 1 & 91 & -22.4 & -4.29 & 21.3 \\
\hline 74 & 2 & 207 & -36.4 & -5.75 & 21.6 \\
\hline 74 & 3 & 260 & -94.5 & -13.48 & 20.4 \\
\hline 74 & 4 & 91 & -52.9 & -7.81 & 21 \\
\hline 74 & 5 & 44 & -24.2 & -4.11 & 19.5 \\
\hline 74 & 6 & 0 & & & 18.7 \\
\hline 74 & 7 & 0 & & & 17.5 \\
\hline 74 & 8 & 33 & 2.6 & -0.72 & 20.1 \\
\hline 74 & 9 & 0 & & & 22.7 \\
\hline 74 & 10 & 177 & 0 & -1.37 & 21.4 \\
\hline 74 & 11 & 186 & -39.9 & -6.33 & 21.5 \\
\hline 74 & 12 & 186 & -39.9 & -5.96 & 20.7 \\
\hline 75 & 1 & 233 & -17.6 & -3.84 & 21.2 \\
\hline 75 & 2 & 228 & -26.6 & -4.54 & 21.5 \\
\hline 75 & 3 & 53 & -7.3 & -2.35 & 22.2 \\
\hline 75 & 4 & 190 & -77.1 & -11.09 & 20.3 \\
\hline 75 & 5 & 59 & -13.1 & -3.06 & 19.1 \\
\hline 75 & 6 & 0 & & & 18.4 \\
\hline 75 & 7 & 23 & -5.4 & -1.73 & 17.2 \\
\hline 75 & 8 & 0 & & & 20.2 \\
\hline 75 & 9 & 30 & 11.4 & -1.18 & 21.8 \\
\hline 75 & 10 & 121 & -1.8 & -1.17 & 21.5 \\
\hline 75 & 11 & 155 & -17.1 & -3.53 & 20.9 \\
\hline 75 & 12 & 240 & -40.1 & -5.57 & 21.1 \\
\hline 76 & 1 & 138 & -5.9 & -2.47 & 21.6 \\
\hline 76 & 2 & 350 & -26.6 & -5.29 & 20.9 \\
\hline 76 & 3 & 170 & -10 & -2.98 & 21.1 \\
\hline 76 & 4 & 76 & -12.5 & -3.34 & 21 \\
\hline 76 & 5 & 77 & -2 & -1.86 & 19.8 \\
\hline 76 & 6 & 0 & & & 19 \\
\hline 76 & 7 & 13 & & & 18.5 \\
\hline 76 & 8 & 0 & & & 20.9 \\
\hline 76 & 9 & 74 & 1.5 & -1.54 & 20.8 \\
\hline 76 & 10 & 101 & & & 20.6 \\
\hline 76 & 11 & 244 & -37.9 & -6.64 & 20 \\
\hline 76 & 12 & 262 & -28.7 & -5.23 & 21.9 \\
\hline 83 & 1 & 347 & -64 & -9.2 & \\
\hline 83 & 2 & 292 & -57 & & \\
\hline 83 & 3 & 207 & -39 & -6.1 & \\
\hline 83 & 4 & 218 & -61 & & \\
\hline 83 & 5 & 54 & -17 & -3.3 & \\
\hline 83 & 6 & & -4 & -2.4 & \\
\hline 83 & 7 & 25 & -11 & -3.8 & \\
\hline 83 & 8 & & & & \\
\hline 83 & 9 & 73 & 4 & -1.2 & \\
\hline 83 & 10 & 177 & -15 & -3.6 & \\
\hline 83 & 11 & 316 & -30 & -5.7 & \\
\hline 83 & 12 & 283 & -27 & -5.1 & \\
\hline 84 & 1 & 137 & -17 & -4 & 21.7 \\
\hline 84 & 2 & 136 & -25 & -5.4 & 22.3 \\
\hline 84 & 3 & 160 & & & 21.6 \\
\hline 84 & 4 & 84 & -43 & -6.9 & 20.8 \\
\hline 84 & 5 & 2 & & & 21 \\
\hline 84 & 6 & 0 & & & 20.5 \\
\hline 84 & 7 & 0 & & & 20.1 \\
\hline
\end{tabular}




$\begin{array}{rrrrrr}84 & 8 & 87 & -32 & -4.4 & 20.1 \\ 84 & 9 & 59 & & & 16.9 \\ 84 & 10 & 214 & & -2.1 & 21.8 \\ 84 & 11 & 87 & & -2.3 & 21.8 \\ 84 & 12 & 135 & & & 21.5 \\ 85 & 1 & 318 & & & 20 \\ 85 & 2 & 158 & & & 22 \\ 85 & 3 & 178 & & & 21.4 \\ 85 & 4 & 114 & -21 & -3.2 & 20.7 \\ 85 & 5 & 59 & -20 & -2.6 & 20.2 \\ 85 & 6 & 0 & & & 20.3 \\ 85 & 7 & 0 & & & 17.6 \\ 85 & 8 & 15 & & -2.9 & 20.3 \\ 85 & 9 & 56 & -4 & -2.8 & 21.7 \\ 85 & 10 & 229 & -6 & -3.1 & 21.2 \\ 85 & 11 & 128 & 6 & -0.7 & 21.2 \\ 85 & 12 & 279 & -58 & -7.2 & 21 \\ 86 & 1 & 199 & -59 & -7.4 & 21.2 \\ 86 & 2 & 137 & -17 & -2.9 & 21.4 \\ 86 & 3 & 84 & -20 & -3.4 & 21.7 \\ 86 & 4 & 69 & -7 & -1.3 & 21.6 \\ 86 & 5 & 9 & 5 & -1.3 & 21 \\ 86 & 6 & 0 & & & 18.2 \\ 86 & 7 & 32 & 3 & -1 & 18.7 \\ 86 & 8 & 51 & 4 & -1.1 & 20.6 \\ 86 & 9 & 13 & -5 & -2.2 & 21 \\ 86 & 10 & 106 & -22 & -4.6 & 21.8 \\ 86 & 11 & 112 & -26 & -4.3 & 21.5 \\ 86 & 12 & 194 & -10 & -3.3 & 21.6 \\ 87 & 1 & 74 & -15 & -3.5 & 22.3 \\ 87 & 2 & 155 & -16 & -2.8 & 21.7 \\ 87 & 3 & 315 & -26 & -5.3 & 21.2 \\ 87 & 4 & 191 & -52 & -7.9 & 21.6 \\ 87 & 5 & 63 & -6 & -0.6 & 20.9 \\ 87 & 6 & 6 & 11 & -0.4 & 19.3\end{array}$




\section{ANEXO III}

(Datações $\mathrm{Th}^{230}$ ) 


\begin{tabular}{|c|c|c|c|c|c|c|c|c|c|}
\hline $\begin{array}{c}\text { Sample } \\
\text { ID }\end{array}$ & $\begin{array}{c}\text { Depth } \\
(\mathrm{mm})\end{array}$ & $\begin{array}{r}{ }^{238} \mathrm{U} \\
\text { ppb }\end{array}$ & $\begin{array}{c}{ }^{232} \mathrm{Th} \\
\text { ppt }\end{array}$ & $\begin{array}{l}{ }^{230} \mathrm{Th} /{ }^{232} \mathrm{Th} \\
\text { (atomic } \times 10^{-6} \text { ) }\end{array}$ & $\begin{array}{c}\delta^{234} U^{\star} \\
\text { (measured) }\end{array}$ & $\begin{array}{c}{ }^{230} \mathrm{Th} /{ }^{238} \mathrm{U} \\
\text { (activity) }\end{array}$ & $\begin{array}{l}{ }^{230} \text { Th Age (yr) } \\
\text { (uncorrected) }\end{array}$ & $\begin{array}{c}{ }^{230} \text { Th Age (yr) } \\
\text { (corrected) }\end{array}$ & $\begin{array}{l}\delta^{234} U_{\text {Initial }}{ }^{\star \star} \\
\text { (corrected) }\end{array}$ \\
\hline
\end{tabular}

\section{LG3 - Stal agmite}

\begin{tabular}{lc} 
LG3-a & 6. \\
LG3-b & 25. \\
LG3-c & 43. \\
LG3-d & 70. \\
LG3-e & 84. \\
LG3-g & 118 \\
LG3-h & 132 \\
LG3-i & 143 \\
LG3-J & 168. \\
LG3k & 185 \\
LG3-I & 197. \\
LG3-m & 207. \\
\hline
\end{tabular}

LG11 - Stalagmite

LG11-m
LG11a-3
LG11-b
LG 11B-5
LG 11B-5
REPLICATION
LG 11a-6

\section{LG 11a-6 \\ LG11-n}

LG 11B-158

LG11-p

LG 11B-7-2

LG11-d

LG 11B-8

LG11-B

LG12 - Stalagmite

LG12-1

LG 12A 18

LG12-a

$\begin{array}{rlrlrl}1,356 & \pm 4 & 1415 & \pm 5 & 349.3 & \pm 4.2 \\ 1,231 & \pm 2.4 & 258 & \pm 3 & 2224 & \pm 38 \\ 1,912 & \pm 4.8 & 390 & \pm 3 & 2387 & \pm 33 \\ 1,601 & \pm 3.6 & 324 & \pm 3 & 2510 & \pm 30 \\ 1,714 & \pm 4.4 & 219 & \pm 3 & 4256 & \pm 78 \\ 1,336 & \pm 2.8 & 75 & \pm 3 & 10302 & \pm 394 \\ 1,729 & \pm 3.2 & 115 & \pm 3 & 8664 & \pm 221 \\ 773 & \pm 3.9 & 125 & \pm 3 & 4071 & \pm 98 \\ 883 & \pm 2.3 & 97 & \pm 3 & 8215 & \pm 244 \\ 645 & \pm 1.7 & 170 & \pm 3 & 4384 & \pm 84 \\ 546 & \pm 1.1 & 163 & \pm 3 & 4169 & \pm 84 \\ 695 & \pm 1.4 & 147 & \pm 3 & 5841 & \pm 122\end{array}$

\section{Lapa Grande cave}

$630.9 \pm 3.1 \quad 0.02213 \pm 0.00027$ $655.8 \pm 2.2 \quad 0.02828 \pm 0.00036$ $636.4 \pm 2.0 \quad 0.02953 \pm 0.00034$ $632.1 \pm 1.9 \quad 0.03085 \pm 0.00024$ $633.1 \pm 2.1 \quad 0.03299 \pm 0.00041$ $660.4 \pm 2.2 \quad 0.03508 \pm 0.00030$ $583.6 \pm 1.6 \quad 0.03505 \quad \pm 0.00026$ $604.2 \pm 6.0 \quad 0.03987 \pm 0.00040$ $655.8 \pm 3.1 \quad 0.05482 \pm 0.00041$ $572.0 \pm 3.7 \quad 0.07039 \pm 0.00068$ $522.7 \pm 2.7 \quad 0.07574 \pm 0.00078$ $448.5 \pm 2.3$ $0.07508 \pm 0.00063$

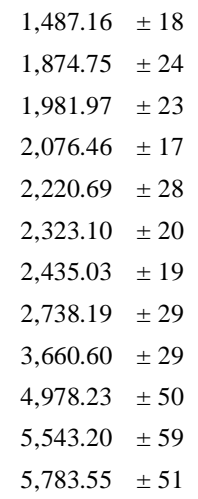

$0.07544 \quad \pm 0.00085$ $0.07657 \pm 0.00043$ $0.08041 \quad \pm 0.00040$ $0.08178 \pm 0.00097$

$0.08382 \pm 0.00672$ $0.08752 \pm 0.00045$ $0.08897 \pm 0.00100$ $0.09296 \pm 0.00064$

$0.09451 \pm 0.00062$ $0.09667 \pm 0.00081$ $0.10877 \pm 0.00065$ $0.10920 \pm 0.00065$ $0.11309 \pm 0.00134$

$7,366.73 \quad \pm 610$ $8,631.83 \pm 76$

$10,280.36 \pm 130$

$\begin{array}{llll}\mathbf{1 , 4 6 9} & \pm \mathbf{2 0} & 634 & \pm 3.08 \\ \mathbf{1 , 8 7 1} & \mathbf{2 4} & 659 & \pm 2.19 \\ \mathbf{1 , 9 7 8} & \pm \mathbf{2 3} & 640 & \pm 2.03 \\ \mathbf{2 , 0 7 3} & \pm \mathbf{1 7} & 636 & \pm 1.92 \\ \mathbf{2 , 2 1 8} & \pm \mathbf{2 8} & 637 & \pm 2.14 \\ \mathbf{2 , 3 2 2} & \pm \mathbf{2 0} & 665 & \pm 2.18 \\ \mathbf{2 , 4 3 4} & \pm \mathbf{1 9} & 588 & \pm 1.65 \\ \mathbf{2 , 7 3 5} & \pm \mathbf{2 9} & 609 & \pm 6.02 \\ \mathbf{3 , 6 5 9} & \pm \mathbf{2 9} & 663 & \pm 3.17 \\ \mathbf{4 , 9 7 3} & \pm \mathbf{5 0} & 580 & \pm 3.72 \\ \mathbf{5 , 5 3 8} & \pm \mathbf{5 9} & 531 & \pm 2.72 \\ \mathbf{5 , 7 7 9} & \pm \mathbf{5 1} & 456 & \pm 2.32\end{array}$

$6,266+74$ $6,375 \pm 40$ $6,956 \pm 42$ $7,228 \pm 89$ $7,355 \pm 610$ $7,901 \pm 51$

$8,055 \pm 96$

$8,338 \pm 61$

$8,446 \pm 61$

$8,622 \pm 76$

$9,680 \pm 67$

$9,763 \pm 65$

$10,252 \pm 131$

$352 \pm 1.83$ $349 \pm 2.43$ $301 \pm 4.04$ $276 \pm 1.67$ $286 \pm 1.75$ $250 \pm 2.40$ $250 \pm 2.32$ $264 \pm 2.10$ $271 \pm 2.62$ $274 \pm 1.99$ $281 \pm 3.41$ $276 \pm 2.14$ $260 \pm 3.39$
$6,277.48 \quad \pm 73$ $6,388.32 \pm 38$ $6,965.16 \pm 42$ $7,240.89 \quad \pm 89$ $7,934.94 \quad \pm 45$ $8,071.31 \pm 95$ $8,348.32 \quad \pm 61$ $8,450.58 \pm 61$ $9,699.25 \pm 66$ $9,785.73 \quad \pm 63$

$\begin{array}{rlllll}11,779 & \pm 154 & \mathbf{1 1 , 7 4 3} & \mathbf{\pm 1 5 5} & 400 & \pm 5.5 \\ 12109 & \pm 52 & \mathbf{1 2 , 0 8 3} & \mathbf{\pm 5 5} & 406 & \pm 1.9 \\ 12,861 & \pm 77 & \mathbf{1 2 , 8 2 1} & \pm \mathbf{7 9} & 398 & \pm 3.8\end{array}$




\begin{tabular}{|c|c|c|c|c|c|c|c|c|c|c|c|}
\hline LG12-b & & $179.0 \quad \pm 0.5$ & $111 \pm 2$ & $4141 \quad \pm 77$ & $358.0 \quad \pm 4.3$ & $0.15632 \quad \pm 0.00069$ & 13,254 & \pm 76 & 13,241 & \pm 76 & $372 \pm 4.4$ \\
\hline LG 12A 100 & & $75.9 \pm 0.1$ & $214 \pm 4$ & $1034 \pm 21$ & $384.5 \quad \pm 1.7$ & $0.1770 \pm 0.00074$ & 14825 & \pm 69 & 14,766 & \pm 80 & $401 \pm 1.8$ \\
\hline LG12-2 & & $45 \pm 0$ & $226 \pm 2$ & $599.6 \pm 9.7$ & $386.6 \pm 5.5$ & $0.18369 \pm 0.00276$ & $15,383.3$ & \pm 255.2 & 15,279 & \pm 260 & $404 \pm 5.7$ \\
\hline $\begin{array}{c}\text { Sample } \\
\text { ID }\end{array}$ & $\begin{array}{c}\text { Depth } \\
(\mathrm{mm})\end{array}$ & $\begin{array}{l}{ }^{238} \mathrm{U} \\
\text { ppb }\end{array}$ & $\begin{array}{c}{ }^{232} \mathrm{Th} \\
\text { ppt }\end{array}$ & $\begin{array}{l}{ }^{230} \mathrm{Th} /{ }^{232} \mathrm{Th} \\
\text { (atomic } \times 10^{-6} \text { ) }\end{array}$ & $\begin{array}{c}\delta^{234} U^{*} \\
\text { (measured) }\end{array}$ & $\begin{array}{c}{ }^{230} \mathrm{Th} /{ }^{238} \mathrm{U} \\
\text { (activity) }\end{array}$ & $\begin{array}{l}{ }^{230} \mathrm{Th} \\
\text { (uncor }\end{array}$ & $\begin{array}{l}\text { Age }(y r) \\
\text { rrected) }\end{array}$ & $\begin{array}{r}{ }^{230} \mathrm{Th} \mathrm{Ag} \\
\text { (correc }\end{array}$ & $\begin{array}{l}\text { e (yr) } \\
\text { ted) }\end{array}$ & $\begin{array}{l}\delta^{234} U_{\text {Initial }}{ }^{\star \star} \\
(\text { corrected) }\end{array}$ \\
\hline
\end{tabular}

\begin{tabular}{|c|c|c|c|c|c|c|c|c|}
\hline \multirow{2}{*}{\multicolumn{9}{|c|}{ LSF3 - Stalagmite }} \\
\hline & & & & & & & & \\
\hline LSF3-A & 62.1 & \pm 0.2 & 256 & \pm 2 & 1,626 & \pm 15 & 1712.1 & \pm 7 \\
\hline LSF3-B & 84.8 & \pm 0.3 & 158 & \pm 1 & 3,758 & \pm 41 & 1726.6 & \pm 8 \\
\hline LSF3-128 & 75.6 & \pm 0.1 & 759 & \pm 15 & 704 & \pm 14 & 1713.6 & \pm 4 \\
\hline LSF3-188 & 69.7 & \pm 0.1 & 139 & \pm 3 & 3,748 & \pm 77 & 1729.7 & \pm 4 \\
\hline LSF3-C & 69.7 & \pm 0.2 & 119 & \pm 1 & 4,578 & \pm 60 & 1713.8 & \pm 7 \\
\hline LSF3-253-REP & 80.9 & \pm 0.1 & 88 & \pm 2 & 7,408 & \pm 174 & 1683.7 & \pm 3 \\
\hline LSF3-306 & 88.7 & \pm 0.1 & 169 & \pm 3 & 4,373 & \pm 89 & 1690.6 & \pm \\
\hline LSF3-316 & 72.1 & \pm 0.1 & 118 & \pm 2 & 5,173 & \pm 107 & 1700.5 & \pm 4 \\
\hline LSF3-D & 51.1 & \pm 0.2 & 2003 & \pm 6 & 221 & \pm 1 & 1684.9 & \pm \\
\hline LSF 3B 340 & 85.7 & \pm 0.1 & 282 & \pm 6 & 2,627 & \pm 53 & 1617.2 & \\
\hline LSF 3B-I & 80.6 & \pm 0.1 & 371 & \pm 7 & 1,911 & \pm 38 & 24301 & \\
\hline LSF3B-II & 76.5 & \pm 0.1 & 927 & \pm 19 & 735 & \pm 15 & 24552 & \\
\hline LSF 3-1' & 105.3 & \pm 0.2 & 530 & \pm 11 & 1,763 & \pm 36 & 1593.0 & \\
\hline LSF3-415 & 91.0 & \pm 0.2 & 431 & \pm 9 & 1,991 & \pm 41 & 1630 & \pm 6 \\
\hline LSF 3-3' & 95.5 & \pm 0.2 & 1033 & \pm 21 & 872 & \pm 18 & 1602.3 & \pm 3 \\
\hline LSF3-E & 86.7 & \pm 0.3 & 298 & \pm 2 & 2,780 & \pm 22 & 1579.7 & \\
\hline \multicolumn{9}{|l|}{ LSF15- Stalagmite } \\
\hline LSF15-1 & 91.3 & \pm 0.1 & 406 & \pm 8 & 1069 & \pm 22 & 1751 & \pm 3 \\
\hline LSF15-4 & 71.9 & \pm 0.1 & 201 & \pm 4 & 1734 & \pm 35 & 1740 & \pm 3 \\
\hline LSF15-6 & 184.4 & \pm 0.2 & 33 & \pm 1 & 28101 & \pm 663 & 1782 & \pm 4 \\
\hline LSF15-8 & 82.1 & \pm 0.1 & 175 & \pm 4 & 2483 & \pm 50 & 1768 & \pm 3 \\
\hline LSF 159 & 74.1 & \pm 0.1 & 2055 & \pm 41 & 200 & \pm 4 & 1757 & \pm 3 \\
\hline LSF 159 REP & 76.9 & \pm 0.1 & 1975 & \pm 40 & 207 & \pm 4 & 1690 & \pm 3 \\
\hline LSF15-10 & 68.8 & \pm 0.1 & 273 & \pm 5 & 1394 & \pm 28 & 1697 & \pm 4 \\
\hline LSF15-11 & 53.1 & \pm 0.1 & 396 & \pm 8 & 776 & \pm 16 & 1722 & \pm 3 \\
\hline LSF15-12 & 57.4 & \pm 0.1 & 508 & \pm 10 & 663 & \pm 14 & 1715 & \pm 10 \\
\hline LSF15-13 & 83.7 & \pm 0.1 & 4009 & \pm 9 & 147 & \pm 0 & 2141 & \pm 4 \\
\hline LSF15-14 & 124.0 & \pm 0.1 & 275 & \pm 6 & 3269 & \pm 66 & 2096 & \pm 4 \\
\hline
\end{tabular}

$\begin{array}{llll}0.40557 & \pm 0.00282 & 17,397.88 & \pm 139 \\ 0.42261 & \pm 0.00277 & 18,075.01 & \pm 141 \\ 0.42837 & \pm 0.00103 & 18,409.34 & \pm 56 \\ 0.45220 & \pm 0.00116 & 19,385.45 & \pm 62 \\ 0.47263 & \pm 0.00325 & 20,488.03 & \pm 164 \\ 0.48931 & \pm 0.00148 & 21,502.44 & \pm 76 \\ 0.50579 & \pm 0.00115 & 22,227.03 & \pm 65 \\ 0.51160 & \pm 0.00124 & 22,413.55 & \pm 70 \\ 0.52601 & \pm 0.00361 & 23,281.53 & \pm 194 \\ 0.52431 & \pm 0.00121 & 23,831.22 & \pm 65 \\ 0.53349 & \pm 0.00104 & 24,300.93 & \pm 60 \\ 0.54041 & \pm 0.00118 & 24,552.36 & \pm 68 \\ 0.53826 & \pm 0.00153 & 24,781.80 & \pm 84 \\ 0.57242 & \pm 0.00218 & 26,104.24 & \pm 129 \\ 0.57181 & \pm 0.00169 & 26,380.78 & \pm 95 \\ 0.57888 & \pm 0.00343 & 27,040.19 & \pm 201\end{array}$

$12190 \quad \pm 33$

$0.2878 \pm 0.0007$

$0.2934 \pm 0.0010$

$0.3064 \pm 0.0007$

$0.3210 \pm 0.0008$

$0.3366 \pm 0.0008$

$0.3231 \pm 0.0011$

$0.3355 \pm 0.0010$

$0.3515 \pm 0.0013$

$0.3552 \pm 0.0019$

$0.4261 \quad \pm 0.0010$

$0.4391 \quad \pm 0.0011$

\begin{tabular}{|c|c|c|c|}
\hline 17,355 & \pm 141 & 1798 & \pm 8.0 \\
\hline 18,056 & \pm 141 & 1817 & \pm 9.0 \\
\hline 18,305 & \pm 92 & 1804 & \pm 4.3 \\
\hline 19,365 & \pm 64 & 1827 & \pm 4.4 \\
\hline 20,470 & \pm 164 & 1816 & \pm 7.9 \\
\hline 21,491 & \pm 76 & 1789 & \pm 3.5 \\
\hline 22,207 & \pm 66 & 1800 & \pm 4.1 \\
\hline 22,397 & \pm 71 & 1811 & \pm 4.5 \\
\hline 22,873 & \pm 281 & 1797 & \pm 9.6 \\
\hline 23,796 & \pm 70 & 1730 & \pm 2.7 \\
\hline 24,252 & \pm 69 & 1730 & \pm 3.1 \\
\hline 24,424 & \pm 113 & 1741 & \pm 3.6 \\
\hline 24,728 & \pm 93 & 1708 & \pm 3.5 \\
\hline 26,054 & \pm 134 & 1754 & \pm 6.6 \\
\hline 26,265 & \pm 125 & 1726 & \pm 3.8 \\
\hline 27,003 & \pm 202 & 1705 & \pm 8.8 \\
\hline
\end{tabular}

$\begin{array}{llll}\mathbf{1 2 , 1 4 3} & \mathbf{\pm 4 7} & 1751 & \pm 3.1 \\ \mathbf{1 2 , 4 6 8} & \mathbf{\pm 5 1} & 1740 & \pm 3.1 \\ \mathbf{1 2 , 8 8 4} & \mathbf{\pm 3 5} & 1782 & \pm 3.6 \\ \mathbf{1 3 , 5 9 6} & \mathbf{\pm 4 2} & 1768 & \pm 3.4 \\ \mathbf{1 4 , 0 9 5} & \mathbf{\pm 2 1 1} & 1757 & \pm 2.9 \\ \mathbf{1 3 , 8 5 8} & \mathbf{\pm 2 0 4} & 1690 & \pm 3.0 \\ \mathbf{1 4 , 6 5 0} & \mathbf{\pm 5 9} & 1697 & \pm 3.9 \\ \mathbf{1 5 , 2 2 0} & \mathbf{\pm 8 4} & 1722 & \pm 3.3 \\ \mathbf{1 5 , 4 2 6} & \mathbf{\pm 1 2 5} & 1715 & \pm 10.1 \\ \mathbf{1 5 , 7 1 3} & \mathbf{\pm 3 1 8} & 2141 & \pm 4.4 \\ \mathbf{1 6 , 9 6 0} & \mathbf{\pm 5 4} & 2096 & \pm 3.7\end{array}$


LSF16 - Stalagmite

\begin{tabular}{|c|c|c|c|c|c|c|c|c|c|c|c|c|c|c|c|c|}
\hline LSF16-1 & 61.7 & \pm 0.1 & 136 & \pm 3 & 2506 & \pm 51 & 1668.4 & \pm 3.3 & 0.3355 & \pm 0.00090 & 14457 & \pm 45 & 14,433 & \pm 48 & 1738 & \pm 3.5 \\
\hline LSF 162 & 73.1 & \pm 0.1 & 45 & \pm 1 & 9167 & \pm 198 & 1680.2 & \pm 2.4 & 0.3391 & \pm 0.00065 & 14550 & \pm 33 & 14,543 & $\pm \mathbf{3 3}$ & 1751 & \pm 2.5 \\
\hline LSF16-3 & 54.4 & \pm 0.1 & 15 & \pm 0 & 20349 & \pm 693 & 1573.1 & \pm 2.7 & 0.3299 & \pm 0.00100 & 14765 & \pm 50 & 14,762 & $\pm \mathbf{5 0}$ & 1640 & \pm 2.9 \\
\hline LSF16-4 & 52.2 & \pm 0.0 & 48 & \pm 1 & 6009 & \pm 129 & 1570.1 & \pm 2.4 & 0.3332 & \pm 0.00080 & 14939 & \pm 41 & 14,929 & \pm 41 & 1638 & \pm 2.5 \\
\hline LSF16-5 & 73.5 & \pm 0.1 & 354 & \pm 7 & 1184 & \pm 24 & 1613.5 & \pm 2.6 & 0.3454 & \pm 0.00118 & 15243 & \pm 58 & 15,191 & \pm 68 & 1684 & \pm 2.7 \\
\hline LSF16-6 & 68.4 & \pm 0.1 & 4542 & \pm 91 & 88 & \pm 2 & 1592.7 & \pm 2.9 & 0.3559 & \pm 0.00098 & 15869 & \pm 50 & 15,141 & \pm 518 & 1662 & \pm 3.9 \\
\hline LSF16-7 & 66.1 & \pm 0.1 & 60 & \pm 1 & 6580 & \pm 154 & 1646.3 & \pm 2.8 & 0.3612 & \pm 0.00132 & 15768 & \pm 64 & 15,758 & \pm 64 & 1721 & \pm 3.0 \\
\hline LSF16-9 & 76.3 & \pm 0.1 & 984 & \pm 20 & 497 & \pm 10 & 1685.1 & \pm 3.0 & 0.3889 & \pm 0.00100 & 16795 & \pm 50 & 16,659 & \pm 108 & 1766 & \pm 3.2 \\
\hline LSF16-10 & 34.5 & \pm 0.0 & 65 & \pm 1 & 3453 & \pm 73 & 1722.5 & \pm 3.4 & 0.3969 & \pm 0.00109 & 16909 & \pm 54 & 16,890 & \pm 56 & 1807 & \pm 3.6 \\
\hline LSF16-11 & 85.5 & \pm 0.1 & 393 & \pm 8 & 1442 & \pm 29 & 1715.2 & \pm 3.1 & 0.4021 & \pm 0.00108 & 17194 & \pm 54 & 17,146 & \pm 63 & 1800 & \pm 3.3 \\
\hline LSF 1612 & 124.7 & \pm 0.1 & 220 & \pm 4 & 3789 & \pm 77 & 1718.5 & \pm 2.4 & 0.4053 & \pm 0.00079 & 17318 & \pm 40 & 17,300 & \pm 42 & 1805 & \pm 2.6 \\
\hline LSF16-13 & 75.6 & \pm 0.1 & 725 & \pm 15 & 731 & \pm 15 & 1701.3 & \pm 2.3 & 0.4246 & \pm 0.00102 & 18328 & \pm 50 & 18,228 & \pm 86 & 1791 & \pm 2.4 \\
\hline \multicolumn{17}{|c|}{ LSF17 - Stalagmite } \\
\hline LSF 17-1 & 137.7 & \pm 0.2 & 221 & \pm 4 & 1808 & \pm 37 & 2965.9 & \pm 4.2 & 0.1764 & \pm 0.00047 & 4934 & \pm 15 & 4,922 & \pm 17 & 3007 & \pm 4.3 \\
\hline LSF 17-A & 137.9 & \pm 0.2 & 351 & \pm 7 & 1241 & \pm 25 & 2973.2 & \pm 4.4 & 0.1917 & \pm 0.00056 & 5361 & \pm 17 & 5,343 & \pm 21 & 3018 & \pm 4.5 \\
\hline LSF17-2 & 183.4 & \pm 0.2 & 135 & \pm 3 & 4718 & \pm 96 & 3027.5 & \pm 3.6 & 0.2104 & \pm 0.00043 & 5815 & \pm 13 & 5,810 & \pm 14 & 3078 & \pm 3.7 \\
\hline LSF17-B & 191.1 & \pm 0.3 & 338 & \pm 7 & 2114 & \pm 43 & 3133.2 & \pm 4.6 & 0.2267 & \pm 0.00060 & 6111 & \pm 18 & 6,099 & \pm 20 & 3188 & \pm 4.6 \\
\hline LSF17-C & 162.0 & \pm 0.3 & 211 & \pm 4 & 3033 & \pm 62 & 2967.5 & \pm 4.6 & 0.2399 & \pm 0.00096 & 6752 & \pm 29 & 6,743 & $\pm \mathbf{3 0}$ & 3024 & \pm 4.7 \\
\hline LSF 17-3 & 153.2 & \pm 0.2 & 298 & \pm 6 & 2216 & \pm 45 & 2883.8 & \pm 5.0 & 0.2616 & \pm 0.00067 & 7542 & \pm 22 & $\mathbf{7 , 5 2 7}$ & \pm 24 & 2946 & \pm 5.1 \\
\hline
\end{tabular}

$* \delta^{234} U=\left(\left[{ }^{234} U /{ }^{238} U\right]_{\text {activity }}-1\right) \times 1000 . * * \delta^{234} U_{\text {initial }}$ was calculated based on ${ }^{230}$ Th age $(T)$, i.e., $\delta^{234} U_{\text {initial }}=\delta^{234} U_{\text {measured }} \mathrm{X} \mathrm{e}^{\lambda 234 \times \mathrm{T}}$.

Corrected ${ }^{230} \mathrm{Th}$ ages assume the initial ${ }^{230} \mathrm{Th} /{ }^{232} \mathrm{Th}$ atomic ratio of $4.4 \pm 2.2 \times 10^{-6}$. Those are the values for a material at secular equilibrium, with the bulk earth ${ }^{232} \mathrm{Th} /{ }^{238} \mathrm{U}$ value of 3.8 . The errors are arbitrarily assumed to be $50 \%$.

***B.P. stands for "Before Present" where the "Present" is defined as the year 1950 A.D. 


\section{ANEXO IV}

(Artigo submetido à revista Geology) 
Abrupt variations in South American monsoon rainfall during the Holocene based on speleothem record from central-eastern Brazil.

Nicolás M. Stríkis ${ }^{1}$, Francisco W. Cruz ${ }^{1}$, Hai, Cheng ${ }^{2,3}$, Ivo Karmann ${ }^{1}$, R. Lawrence

Edwards ${ }^{3}$, Mathias Vuille ${ }^{4}$, Xianfeng Wang ${ }^{5}$, Marcos S. de Paula ${ }^{1}$, Valdir, F. Novello ${ }^{1}$, Augusto S. Auler ${ }^{6}$

${ }^{1}$ Instituto de Geociências, Universidade de São Paulo, Rua do Lago, 562, CEP 05508-080, São Paulo-SP, Brazil.

${ }^{2}$ Institute of Global Environmental Change, Xi'an Jiaotong University, Xi'an, Shaanxi 710049, China

${ }^{3}$ Department of Geology and Geophysics, University of Minnesota, Minneapolis, MN 55455, USA.

${ }^{4}$ Department of Atmospheric and Environmental Sciences, University at Albany, SUNY, 1400 Washington Ave, Albany, New York 12222, USA.

${ }^{5}$ Lamont-Doherty Earth Observatory of Columbia University.

${ }^{6}$ Instituto do Carste, Rua Barcelona, 240/302, Belo Horizonte, MG 30360-260, Brazil

( ${ }^{*}$ ) Corresponding author, e-mail: cbill@usp.br (Francisco da Cruz.) Tel.: 55-11-3091-4213; Fax: 55-11-3091-4207.

\section{ABSTRACT}

Well dated high resolution oxygen isotope record of speleothems in central-eastern Brazil spanning from 1.3 to $10.2 \mathrm{ky}$ B.P. revels that the occurrence of abrupt variations in monsoon precipitation is not random. Indeed, they show a striking match with Bond events and a significant pacing at about 800 years, a dominant periodicity present in sea surface temperature (SST) records from both the North Atlantic and equatorial Pacific Oceans and possibly related to periods of low solar activity (high ${ }^{14} \mathrm{C}$ based on atmospheric $\Delta^{14} \mathrm{C}$ record). The precipitation variations over central-eastern Brazil are broadly antiphased with the Asian and Indian monsoon during Bond events and show marked differences in duration and structure between early and late Holocene. Our results suggest that these abrupt multicentennial precipitation events are primarily linked to changes in the North Atlantic meridional overturning circulation (AMOC). Anomalous cross-equatorial flow induced by negative AMOC phases may have modulated not only the monsoon in South America but also affected El Niño-like conditions in the tropical Pacific during the Holocene. 


\section{INTRODUCTION}

Ever since Bond et al. (1997) published their paper on rapid climate change events in the North Atlantic region the Holocene has been recognized as a period marked by abrupt climate fluctuations on millennial to centennial time scales at high latitudes. Based on the striking correlation between ice-rafted debris (IRD) records in North Atlantic sediment cores and tropical rainfall, the Bond-IRD events have been used to link shifts in the intensity of the Atlantic thermohaline circulation to changes in sea surface temperature (SST) and related precipitation anomalies over regions affected by the Indian and Asian Monsoon (Fleitmann et al., 2003; Wang et al., 2005; Cheng et al., 2009).

Although the magnitude of millennial-scale cold events is much less pronounced during the Holocene (O'Brien et al., 1995; Bond et al., 1997), they nonetheless produce a large deficit in monsoonal rainfall over the Northern Hemisphere (N.H.). This is indicated by the striking match between the Bond events and less (sub)tropical precipitation over regions in Oman (Fleitmann et al., 2003), Asia (Wang et al., 2005) and northernmost South America (Haug et al., 2001). Despite strong evidence that intense cold conditions over the N.H. also produced wetter conditions within the South America monsoon system (SAMS) region during the $8.2 \mathrm{ky}$ event (Cheng et al., 2009) and the Little Ice Age (Haug et al., 2001; Licciardi et al., 2009), it is not clear whether other similar abrupt events during the Holocene, for example the events at 1.4, 2.7, 4.2, 5.9 and 9.2 ky exerted a similar influence on South American monsoon precipitation and glacial advances.

One of the first attempts to associate abrupt centennial to millennial-scale variations in SAMS precipitation with Bond events was published by Baker et al. (2001; 2005). They proposed that lake level fluctuations at Lake Titicaca were positively correlated with the record of IRD pulses over the North Atlantic during the Holocene. Ekdahl et al. (2008) showed that patterns of lake level variations inferred from diatom stratigraphy of lakes near Lake Titicaca are similar to those observed by Baker et al. (2001, 2005). The physical mechanism linking changes in the hydrologic cycle over the tropical Andes with climate variations in the North Atlantic, however, remains speculative. Over the tropical lowlands precipitation changes may result from variations in the latitudinal gradients of tropical SST primarily related to trade wind strength (Arz et al., 2001) and related changes in the intensity or core location of tropical convection. However, there are significant discrepancies in the timing and amplitude between the different records that make these assumptions somewhat inconclusive. This is particularly true for large regions directly affected by the SAMS in Brazil, where almost no data is available from high-resolution, well-dated paleoprecipitation records.

Our results are based on high-resolution speleothem isotope record that extends back to 10.5 ky from a cave located in the northern portion of Minas Gerais State (MG), where precipitation is 
exclusively due to SAMS activity. This new record allows us to reconstruct the spatiotemporal behavior of precipitation changes on multidecadal to centennial time scales and climatic forcings, in particular the impact of negative North Atlantic SST anomalies during Bond Events.

\section{SAMPLES AND METHODS}

Two stalagmites were collected from Lapa Grande cave (LG3 and LG11, hereafter Lapa Grande record), a $2200 \mathrm{~m}$ long cave, located in Northern Minas Gerais state (14² $25^{\prime} 22^{\prime}$ ' S; $44^{\circ}$ 21' 56" W), in the central-eastern part of Brazil (Fig. 1). The cave developed in low metamorphic grade limestones of the Meso- to Neo-Proterozoic Bambuí Group. The samples were collected at about $560 \mathrm{~m}$ distance from the entrance in a local with more restricted cave ventilation.

The present day climate at study site is tropical semi-humid according to Köppen-Geiger classification with a mean annual precipitation of $958 \mathrm{~mm}$, recorded from 1953 to 2005 at a meteorological station located $1 \mathrm{~km}$ from the cave (source: www2.ana.gov.br). The regional precipitation is due to activity of the South Atlantic Convergence Zone (SACZ), which is one of the main features of the SAMS during the austral summer, associated with intense convective activity in the Amazon region (Garreaud et al., 2009). The SACZ extends southeastward from the core of the continent to the South Atlantic (Vera et al., 2006) (Fig. 1). Once the monsoon season comes to an end, rainfall basically ceases from May to October.

The speleothems were dated by U-Th method using inductively coupled plasma-mass spectrometry (ICP-MS) technique at the University of Minnesota following the procedures

described by Shen et al. (2002). Most dates, 24 in total, present errors $(2 \sigma)<1 \%$ (Supplementary Table S1). Oxygen isotope ratios are reported as $\delta^{18} \mathrm{O}$, relative to the Vienna Peedee belemnite standard (for methods and analytical procedures, see the Supplementary material). The Lapa Grande record, which spans from 1.3 to $10.2 \mathrm{ky}$ B.P., is composed of $600 \delta^{18} \mathrm{O}$ samples, yielding a temporal resolution between 1 and 40 years (10 years on average) and present a large range of $\sim 4.5$ $\%$ o throughout the Holocene. 


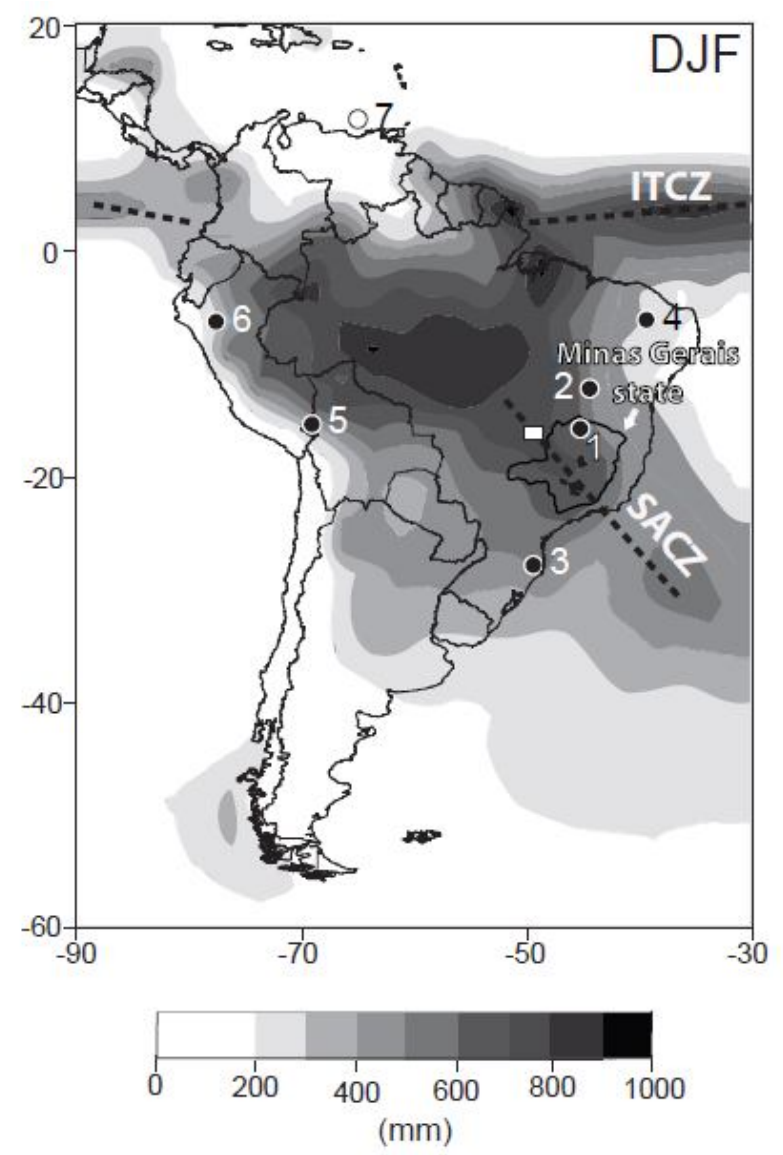

Figure 1. Long-term mean (1979-2000) precipitation (in mm) for December-February from Climate Prediction Center Merged Analysis of Precipitation (CMAP). The numbers in the map indicate the study site and other paleoclimate records: 1 - Lapa Grande cave in Minas Gerais state, central-eastern Brazil; 2 - Gruta do Padre (Wang et al. 2007); 3 Botuverá cave (Cruz et al., 2005); 4 - Caves sites in Rio Grande do Norte state (Cruz et al., 2009); 5 - Lake Titicaca (Baker et al., 2001); 6 - Cueva del Tigre Perdido (Van Breukelen et al., 2008); 7 - Cariaco Basin (Haug et al., 2001). The white square indicates the location of Brasília IAEA-GNIP station.

\section{RESULTS AND DISCUSSION}

Model experiments suggest that the $\delta^{18} \mathrm{O}$ in precipitation is primarily controlled by the "amount effect" over areas such as Northern Minas Gerais, where precipitation is fundamentally the result of SAMS activity (Vuille et al., 2003). Furthermore, this feature is confirmed by the strong negative correlation between monthly rainfall amount with monthly weighted mean $\delta^{18} \mathrm{O}$ at the IAEA-GNIP station in Brasília between 1963 to $1987\left(\mathrm{R}^{2}=0.64\right)$, where precipitation is climatologically identical to the study region (Supplementary Fig. S1 A). Relatively low correlation coefficients between $\delta^{18} \mathrm{O}$ and $\delta^{13} \mathrm{C}$ along the speleothems' growth axes suggest that stalagmites LG3 $\left(r^{2}=0.13\right)$, and LG11 $\left(r^{2}=0.24\right)$ were deposited in approximate isotopic equilibrium according to the Hendy test (Supplementary Fig. S1 B).

The main characteristics of this new record are abrupt fluctuations in $\delta^{18} \mathrm{O}$ punctuating the entire Holocene, with some differences in the structure and duration of events between the early and late Holocene. The Lapa Grande $\delta^{18} \mathrm{O}$ record shows strong events of increased precipitation 
centered at 9.2, 8.2, 7.4, 7.0, 6.4, 5.2, 3.7, 3.1, 2.7, 2.3 and 1.7 ky B.P. During the early and midHolocene the duration of these events was about 300 years with amplitudes varying from 0.9 to 1.5 \%o, with the lowest $\delta^{18} \mathrm{O}$ values corresponding to the $8.2 \mathrm{ky}$ event (Fig. 2). Just after the $8.2 \mathrm{ky}$ event, a dry event with similar amplitude $(\sim 1.5 \%$ o $)$ and duration $(\sim 0.3 \mathrm{ky})$, occurred at $7.8 \mathrm{ky}$ B.P., which is without any equivalent in the paleoclimate records from South America. These abrupt events recorded in Brazil present isotopic amplitudes that are two to three times larger than documented in the Dongge speleothem records, where the largest event took place at $8.2 \mathrm{ky}$ B.P. with only a $\sim 0.5 \%$ o shift (Wang et al., 2005).

Late Holocene abrupt events are equivalent to those observed in the early and mid-Holocene in terms of their amplitude; however they are much more short-lived, not lasting longer than 100 years. The longest event occurred at $2.7 \mathrm{ky}$ B.P. and lasted 100 years, followed by the events at 3.7 and 3.1 ky B.P which lasted around 50 years. The other events (3.0, 2.3, 2.2 and 1.7 ky B.P.) lasted about 20 years. These results suggest significant differences in the mechanism controlling multidecadal to centennial SAMS variability between early/mid-Holocene and late Holocene.

Fig. 2 presents a comparison of the Lapa Grande isotope record (LG) with IRD pulses in the North Atlantic expressed in terms of percentage of hematite stained grain (HSG) variations and with other paleo-monsoon records from South America and eastern China. Abrupt negative shifts of $\delta^{18} \mathrm{O}$ in Lapa Grande record show a striking match with Bond events during the early and mid-Holocene, consistent with the notion of a SAMS intensification during cold events in the N. H. (Baker et al., 2001; Baker et al., 2005; Ekdahl et al., 2008; Cheng et al., 2009). These abrupt decreases in $\delta^{18} \mathrm{O}$ values, associated with increased precipitation in central-eastern Brazil, closely correspond with an anomalously cold North Atlantic during Bond events 6, 5 and 4 and during the 8.2 ky event (Fig. 2). However, it is important to note that other significant wet events, albeit with shorter duration, occurred at 7.1 and $6.6 \mathrm{ky}$ at times of low IRD input to the North Atlantic, apparently unrelated to Bond events.

Conversely, the impact of these events seems to produce a different rainfall response over tropical South America during late Holocene. Even though negative excursions of $\delta^{18} \mathrm{O}$ in our speleothems are still coherent with Bond events 2 and 4, a change in the temporal structure of the events is apparent. For instance, the $\delta^{18} \mathrm{O}$ record suggests two wet phases of $\sim 300$ years duration, peaking at 5.8 and $5.2 \mathrm{ky}$ and dissected by a dry phase at $5.5 \mathrm{ky}$, which is also observed in Lake Tititaca (Baker et al., 2001; Baker et al., 2005). On the other hand, the Lapa Grande record shows no response to Bond events 1 and 3 which are marked by a stepwise decrease in the amplitude of the HSG pulses. 


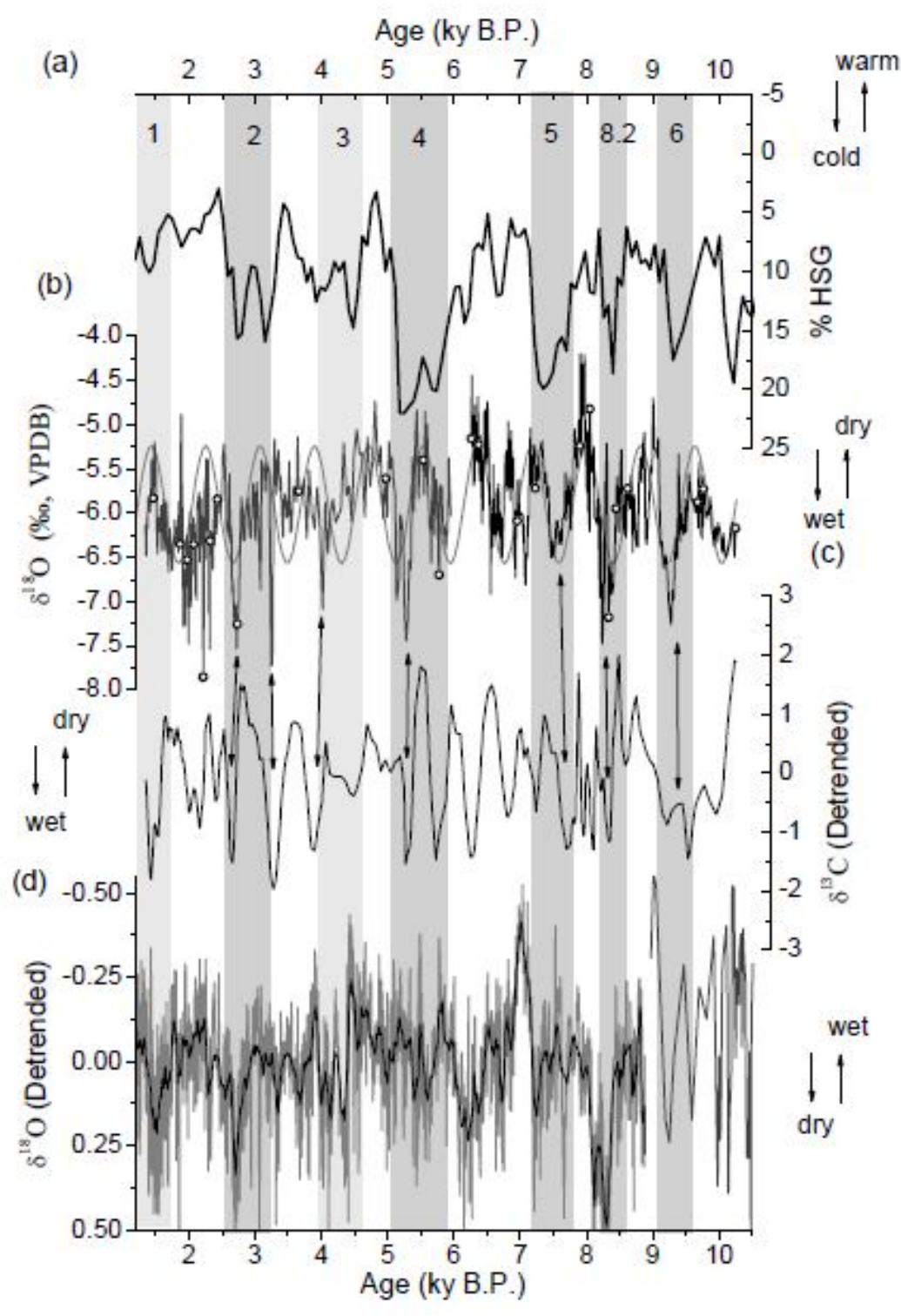

Figure 2. Comparison between (a) hematite stained quartz grain (HSG) record from North Atlantic of the VM 29-191 (Bond et al., 2001); (b) composite $\delta^{18} \mathrm{O}$ record from Lapa Grande cave with LG3 in gray and LG11 in black; A sine function in light grey is highlighting a cycle of 820 years observed in the spectral analysis of the $\delta^{18} \mathrm{O}$ time-series. The circles placed over the $\mathrm{L} 3$ and LG11 times series represent the dated portions; (c) detrended $\delta^{13} \mathrm{C}$ record from Lake Titicaca (Baker et al., 2005); (d) detrended DA (light gray) and D4 (dark gray) stalagmite $\delta^{18} \mathrm{O}$ record from Dongge cave, eastern China (Wang et al., 2005; Yuan et al., 2004). A 20-year running mean of the DA $\delta^{18} \mathrm{O}$ time series is presented in black. The Bond events 1 to 6 and the 8.2 ky event are indicated by the grey bars.

Anomalously cold conditions in the North Atlantic region are apparently affecting SAMS precipitation over part of the continent as indicated by the large coherence in both amplitude and duration of wet events in Brazil with periods of high lake levels of Titicaca inferred from $\delta^{13} \mathrm{C}$ of organic matter in sediments (Baker et al., 2005). The relationship also appears to hold during periods of strong reductions in SAMS paleo-precipitation, which again occurred synchronously in Bolivia and central-eastern Brazil within age errors. 
The Lapa Grande paleo-precipitation record shows a prominent antiphased relationship with Asian monsoon precipitation (AM) as recorded in the Dongge speleothem record (Wang et al., 2005) (Fig. 2). Low AM activity over eastern China during Bond events 6, 5 and 2 (9.2 ky, 7.4 ky and $3.1-2.7 \mathrm{ky}$ ) and the $8.2 \mathrm{ky}$ event coincides with an intensification of the SAMS over centraleastern Brazil (Fig. 2.).

Differences in the climate response to typical N.H. cold events throughout the Holocene might be the result of glacial boundary conditions that persisted until about 7 ky (Carlson et al., 2008). The longer duration of abrupt wet events recorded in central-eastern Brazil during the early Holocene is probably related to the rapid meltdown of the remaining Laurentide ice caps, potentially reducing the strength of the AMOC (Carlson et al., 2008; Fleitmann et al., 2007; Bernal et al., 2010). This mechanism may have exerted a strong influence on meridional SST gradients in the tropical Atlantic, thereby increasing monsoonal rainfall in southern South America.

Our record of variations in SAMS precipitation shows some consistencies but also significant discrepancies with the Ti record from the Cariaco basin, an extensively used proxy record for rainfall distribution within the area influenced by the ITCZ (Supplementary Fig. S2). The abrupt wet events recorded in Brazil at 3.7, 3.1 and 2.9 ky B.P. are approximately synchronous with dry events in the Cariaco basin, but this is not the case of the other events recorded during late Holocene in Lapa Grande cave. Nonetheless, the generally anti-phased pattern of tropical precipitation between hemispheres is evident when comparing speleothem records from Brazil and China, for instance at 2.7, 2.3, 1.9 and 1.7 ky B.P., suggesting an intrinsic control on SAMS precipitation activity through the mean latitudinal position of the ITCZ. It is likely that these incongruities between South and Central America are in part due to a stronger influence of ENSO in certain regions such as Central America and the Caribbean during late Holocene (Haug et al., 2001; Lachniet et al., 2004). In contrast, central-eastern Brazil is not significantly influenced by ENSO (Garreaud et al., 2009).

A spectral analysis of the composite LG3 and the LG11 stalagmite (Supplementary Fig. S3) shows a periodicity of $\sim 1540$ years for monsoon precipitation during the late Holocene, which is in agreement with Bond events (Bond et al., 2001). Nevertheless, the most prominent cycle observed in the Lapa Grande paleo-precipitation record during the early Holocene is about 820 years, the same periodicity as described in the Cueva del Diablo record, southwestern Mexico (Bernal et al., 2010) and for SST variations in the eastern equatorial Pacific (Marchitto et al., 2010), where warmer SST are observed during Bond events. In order to highlight the importance of this 820 year cycle during the early and middle Holocene, a sine function with a wavelength of 820 years is superimposed in Fig. 2. 
Multi-centennial periodicities within the 128 to 512 year band of the wavelet spectrum during the last $6.0 \mathrm{ky}$ are consistent with periods of 500, 250, 210 and 160 years pointed out by the spectral analysis (Supplementary Fig. S3). These spectral peaks support the idea that monsoon variability in South America may be sensitive to variations in solar irradiance such as the 210-year De Vries-Suess cycles or periodicities of 512, 206 and 148 years present in the $\Delta^{14} \mathrm{C}$ record (Stuiver and Braziunas, 1989). Bond et al. (2001) argue that most of the North Atlantic SST oscillations are likely tied to solar activity; hence, at least part of the Bond events could be driven by variations in solar activity. Indeed the events at 9.2, 8.2, 7.5, 5.2, 2.7 and 2.3 ky coincide with periods of low solar activity (high ${ }^{14} \mathrm{C}$ based on atmospheric $\Delta{ }^{14} \mathrm{C}$ and cosmogenic ${ }^{10} \mathrm{Be}$ deposition on the Greenland ice sheet) during 9.4, 8.2, 7.4, 5.3, 2.7 and 2.3 ky B.P. (Bond et al., 2001). On the other hand, variations in solar irradiance alone can not explain all these interhemispheric changes in monsoon rainfall. For example, none of the speleothem records from Brazil and China show a significant covariance with solar activity during the events at 3.1 and 3.7 ky B.P.

Abrupt increases (decreases) in SAMS (Asian and Indian) rainfall have been related to lower SST in the North Atlantic, an intensification of the northeast trade winds and a southward displacement of the ITCZ, invoking an intensification of cross-equatorial flow. At the same time of increase SAMS, warm SST is observed in east equatorial Pacific (Marchitto et al., 2010). These results may have important implications for the notion of the establishment of El Niño-like conditions in the eastern tropical Pacific because atmospheric circulation changes forced by negative anomalies of SST in Atlantic Ocean are partly controlled by the strength of the AMOC (Timmerman et al., 2007).

In this context, our results demonstrate that the slowdown of the AMOC associated with fresh water pulses in the North Atlantic can promote abrupt changes in monsoonal precipitation in South America, potentially influenced by feedback processes involving solar forcing.

\section{Supplementary Information}

Figure S1, S2 and S3; Table S1.

\section{Acknowledgements}

We thank M. H. Hollanda and L. Mancine for their support during the stable isotope data acquisition at the University of São Paulo. We are grateful to IBAMA/C. Mendes for permission to collect stalagmite samples. We thank Cristiano Chiessi for insightful scientific discussions. This work was supported by the Fundação de Amparo a Pesquisa do Estado de São Paulo (FAPESP), Brazil (grant to F.W.C and I.K.). 


\section{REFERENCES CITED}

Arz, H.W., Gerhardt, S., Pätzold, J., Röhl, 2001, U. Millennial-scale changes of surface- and deepwater flow in the western tropical Atlantic linked to Northern Hemisphere high-latitude climate during the Holocene: Geology, v. 29, n. 3, p. 239-242, doi: 10.1130/0091-7613.

Baker, P.A., Seltzer, G.O., Fritz, S.C., Dunbar, R.B., Grove, M.J. Tapia, P.M., Cross, S.L., Rowe, H.D., Broda, J.P., 2001, The history of South American tropical precipitation for the past 25,000 years: Science, v. 291, p. 640-643, doi: 10.1126/science.291.5504.640.

Baker, P.A., Fritz, S.C., Garland, J., Ekdahl, E., 2005, Holocene hydrologic variation at Lake Titicaca, Bolivia/Peru, and its relationship to North Atlantic climate variation: Journal of Quaternary Science, v. 20, p. 655-662, doi: 10.1002/jqs.987, doi: 10.1002/jqs.987.

Bernal, J.P., Lachniet, M., McCulloch, M., Mortimer, G., Morales, P., Cienfuegos, E., 2010, A speleothem record of Holocene climate variability from southwestern Mexico: Quaternary Research, in press, doi: 10.1016/j.yqres.2010.09.002.

Bond, G., Showers, W., Cheseby, M., Lotti, R., Almasi, P., deMenocal, P., Priore, P., Cullen, H., Hajdas, I., Bonani, G.A ., 1997, Pervasive millennial-scale cycle in North Atlantic Holocene and Glacial climates: Science, v. 278, n. 14, p. 1257 - 1266, doi: 10.1126/science.278.5341.1257.

Bond, G., Kromer, B., Beer, J., Muscheler, R., Evans, M.N., Showers, W., Hoffmann, S., LottiBond, R., Hajdas, I., Bonani, G., 2001, Persistent solar influence on North Atlantic climate during the Holocene: Science, v. 294, p. 2130-2136, doi: 10.1126/science.1065680.

Carlson, A.E., Legrande, A.N., Oppo, D.W., Came, R.E., Schmidt, G.A., Anslow, F.S., Licciardi, J.M., Obbink, E., 2008, Rapid early Holocene deglaciation of the Laurentide ice sheet: Nature Geoscience, v.1, p.620-624, doi: 10.1038/ngeo285.

Cheng, H., Fleitmann, D., Edwards, L.R., Wang, X., Cruz, F.W., Auler, A.S., Mangini, A., Wang, Y., Kong, X., Burns, S. J., Matter, A., 2009, Timing and structure of the 8.2 kyr B.P. event inferred from $\delta^{18} \mathrm{O}$ records of stalagmites from China, Oman, and Brazil: Geology, v. 37, p. 1007-1010, doi: 10.1130/G30126A.1.

Cruz, F.W., Vuille, M., Burns, S.J., Wang, X., Cheng, H., Werner, M., Edwards, L.R., Karmann, I., Auler, A.S., Nguyen, H., 2009, Orbitally driven east-west antiphasing of South American precipitation: Nature Geoscience, v. 2, p. 210-214, doi: 10.1038/NGEO444.

Ekdahl, E.J., Fritz, S.C., Baker, P.A, Risgby, C.A., Coley, K., 2008, Holocene multidecadal-to millennial-scale hydrologic variability on the South American Altiplano: The Holocene, v.18, p. 867-876, doi: 10.1177/0959683608093524. 
Fleitmann, D., Burns, S.J., Mudelsee, M., Neff, U., Kramers, J., Mangini, A., Matter, A., 2003, Holocene forcing of the Indian Monsoon recorded in a stalagmite from southern Oman: Science, v. 300, p. 1737-1739, doi: 10.1126/science.1083130.

Fleitmann, D., Mudelsee, M., Burns, S.J., Bradley, R.S., Kramers, J., Matter, A., 2007, Evidence for a widespread climatic anomaly at around 9.2 ka before present: Paleoceanography, v. 23, PA1102, doi:10.1029/2007PA001519.

Garreaud, R.D., Vuille, M., Compagnucci, R., Marengo, J., 2009, Present-day South American climate: Palaeogeography, Palaeoclimatology, Palaeoecology, v. 281, p. 180-195, doi:10.1016/j.palaeo.2007.10.032.

Haug, G., Hughen, K., Sigman, D.M., Peterson, L.C., Röhl, U, 2001, Southward migration of the Intertropical Convergence Zone through the Holocene: Science, v. 293, p. 1304-1308, doi: 10.1126/science.1059725.

Lachniet, M., Burns, S.J., Piperno, D.R., Asmerom, Y., Polyak, V.J., Moy, C.M., Christenson, K., 2004, A 1500-year El Niño/Southern Oscillation and rainfall history for the Isthmus of Panama from speleothem calcite: Journal of Geophysical Research, v. 109, D20117, doi:10.1029/2004JD004694.

Licciardi, J.M., Schaefer, J.M., Taggart, J.R., Lund, D.C., 2009, Holocene glacier fluctuations in the Peruvian Andes indicate northern climate linkages: Science, v. 325, p. 1677-1679, doi: 10.1126/science. 1175010 .

Marchitto, T.M., Muscheler, R., Ortiz, J.D, Carriquiry, J.D., van Geen, A., 2010, Dynamical response of the tropical Pacific Ocean to solar forcing during the early Holocene: Science, v. 330, p. 1378-1381, doi: 10.1126/science.1194887.

O’Brien, S.R., Mayewski, P.A., Meeker, L.D., Meese, D.A., Twickler, M.S., Whitlow, S.I., 1996, Complexity of Holocene climate as reconstructed from a Greenland ice core: Science, v. 270, p. 1962-1964, doi: 10.1126/science.270.5244.1962.

Shen, C-C., Edwards, R.L., Cheng, H., Dorale, J.A., Thomas, R.B., Moran, S. B., Weinstein, S.E., Edmonds H.N., 2002, Uranium and thorium isotopic and concentration measurements by magnetic sector inductively coupled plasma mass spectrometry: Chemical Geology, v. 185, p. 165-178, doi:10.1016/S0009-2541(01)00404-1.

Stuiver, M., Braziunas, T.F., 1989, Atmospheric ${ }^{14} \mathrm{C}$ and century-scale solar oscillations: Nature, v. 338, p. 405-408, doi:10.1038/338405a0.

Timmermann, A., Okumura, Y., An, S.-I., Clement, A., Dong, B., Guilyardi, E., Hu, A., Jungclaus, J. H., Renold, M., Stocker, T.F., Stouffer, R.J., Sutton, R. Xie, S.-P., Yin, J., 2007, The Influence of a Weakening of the Atlantic Meridional Overturning Circulation on ENSO: 
Journal of Climate, v. 20, p.4899-4919, doi: 10.1175/JCLI4283.1.

van Breukelen, M.R., Vonhof, H.B., Hellstrom, J.C., Wester, W. C. G., Kroon, D., 2008, Fossil dripwater in stalagmites reveals Holocene temperature and rainfall variation in Amazonia: Earth and Planetary Science Letters, v. 275, p. 54-60, doi: 10.1016/j.eps1.2008.07.069.

Vera, C., Higgins, W., Amador, J., Ambrizzi, T., Garreaud, R., Gochis, D., Gutzler, D., Lettenmaier, D., Marengo, J., Mechoso, C.R., Nogues-Paegle, J., Silva Dias, P.L., Zhang, C., 2006, Toward a unified view of the American monsoon systems: Journal of Climate, v. 19, p. 4977-5000, doi: 10.1175/JCLI3896.1.

Vuille, M., Bradley, R.S., Werner, M., Healy, R., Keimig, F., 2003, Modeling $\delta^{18} \mathrm{O}$ in precipitation over the tropical Americas: 1. Interannual variability and climatic controls: Journal Geophysical Research, v. 108, D6, 4174, doi: 10.1029/2001JD002038.

Wang, Y., Cheng, H., Edwards, R.L., He, Y., Kong, X. An, Z., Wu, J., Kelly, M. J., Dykoski, C. A., Li, X., 2005, The Holocene Asian Monsoon: Links to solar changes and North Atlantic climate, Science, v. 308, p. 854-857, doi: 10.1126/science.1106296.

Wang, X., Edwards, R.L., Auler, A.S., Cheng, H., Ito, E., 2007, Millennial-scale interhemispheric asymmetry of low-latitude precipitation: Speleothem evidence and possible high-latitude forcing: Geophysical Monograph, Ser. 173, 279-293.

Yuan, D., Cheng, H, Edwards, R.L., Dykoski, C.A., Kelly, M.J., Zhang, M., Qing, J., Lin, Y., Wang, Y., Wu, J., Dorale, J.A., An, Z., Cai, Y., 2004, Timing, Duration, and Transitions of the Last Interglacial Asian Monsoon: Science, v. 302, p. 575-578, doi: 10.1126/science.1091220. 


\section{SUPPLEMENTARY MATERIAL}

\section{Analytical Methods}

Age determinations were carried out at the Minnesota Isotope Laboratory (USA), using multi-collector inductively coupled plasma mass spectrometry technique (MC-ICP-MS, ThermoFinnigan NEPTUNE), according to the procedures described in Shen et al. (2002). Twenty four samples weighing between 150 and $300 \mathrm{mg}$ were dissolved and equilibrated with a ${ }^{236} \mathrm{U}_{-}{ }^{233} \mathrm{U}_{-}{ }^{229} \mathrm{Th}$ spike and then separated and purified using methods described in Edwards et al. (1987). Initial ${ }^{230} \mathrm{Th}$ values were corrected with a typical bulk earth ratio, i.e. atomic ratio of ${ }^{230} \mathrm{Th} /{ }^{232} \mathrm{Th}=4.4 \pm$ $2.2 \mathrm{ppm}$. U-Th isotopic data and ages are shown in Supplemental Table S1.

Oxygen isotope ratios are expressed in $\delta$ notation, the per mil deviation from the VPDB standard. For example for oxygen, $\delta^{18} \mathrm{O}=\left[\left(\left({ }^{18} \mathrm{O} /{ }^{16} \mathrm{O}\right)\right.\right.$ sample $\left.\left./\left({ }^{18} \mathrm{O} /{ }^{16} \mathrm{O}\right) \mathrm{VPDB}\right)-1\right] \times 1000$. For each measurement, approximately $200 \mu \mathrm{g}$ of powder was drilled from the sample and analyzed with an on-line, automated, carbonate preparation system linked to a to a Finnigan Delta Plus Advantage at the University of São Paulo. The speleothem reproducibility of standard materials is $0.1 \%$ o for $\delta^{18} \mathrm{O}$.

\section{SUPPLEMENTARY FIGURES}

\section{Supplementary Figure S1.}

(a)

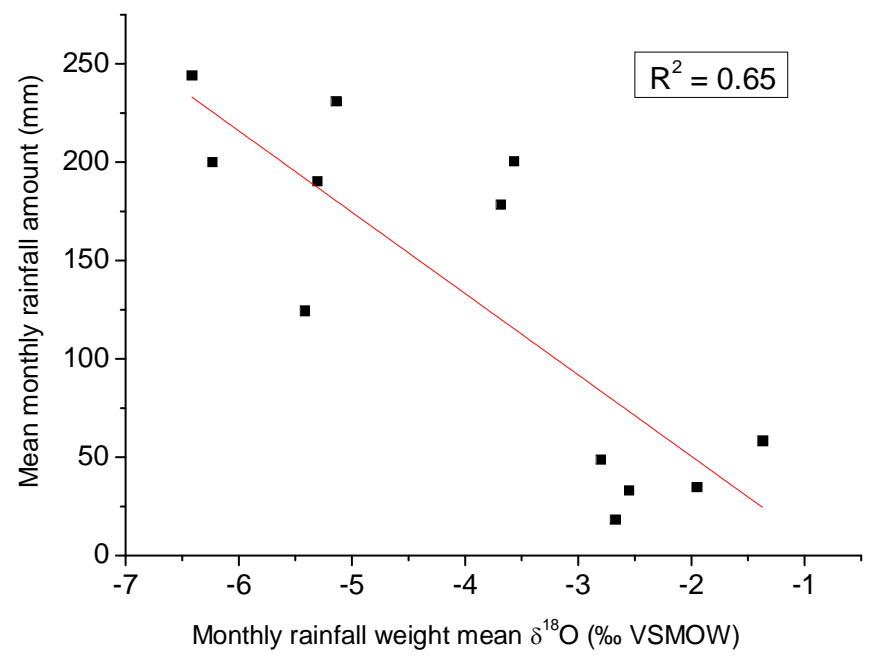


(b)

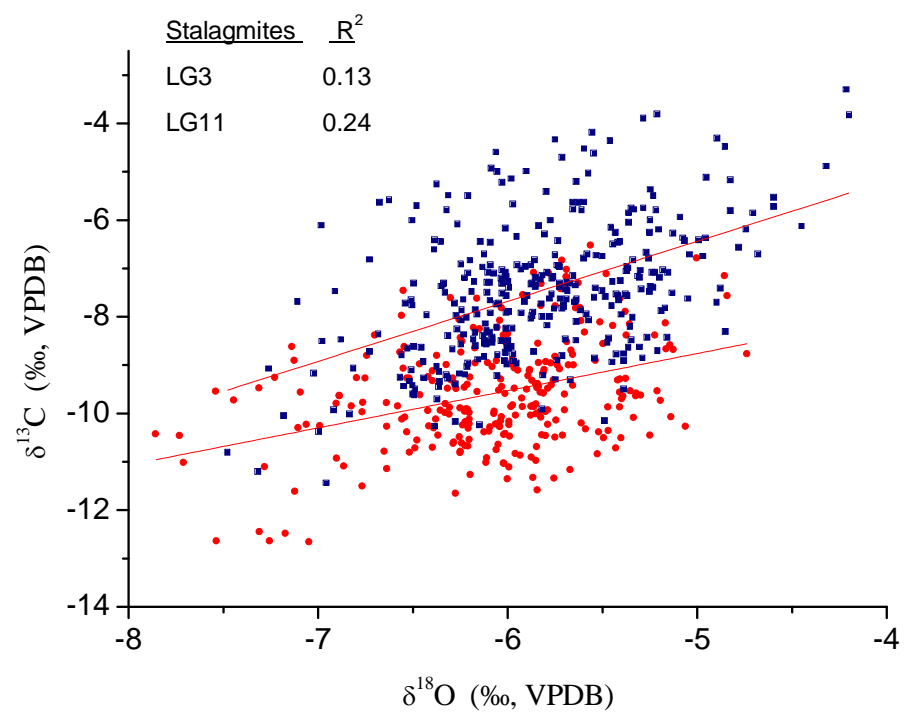

Figure S1. (a) The relationship between monthly rainwater $\delta^{18} \mathrm{O}$ weight mean values and monthly rainfall amount at the IAEA station Brasília (located about $400 \mathrm{~km}$ to the southwest from Lapa Grande cave). (b) Scatter diagram of $\delta^{18} \mathrm{O}$ versus $\delta^{13} \mathrm{C}$ values for each analyzed stalagmite: blue dots indicate LG11 stalagmite and red circles show LG3 stalagmite. The red lines mark the best linear fit. The time intervals covered by each stalagmite are: LG11 from 10.2 to $6.2 \mathrm{ky}$ for LG 11 and from 5.8 to $1.4 \mathrm{ky}$ for LG3. 


\section{Supplementary Figure S2.}

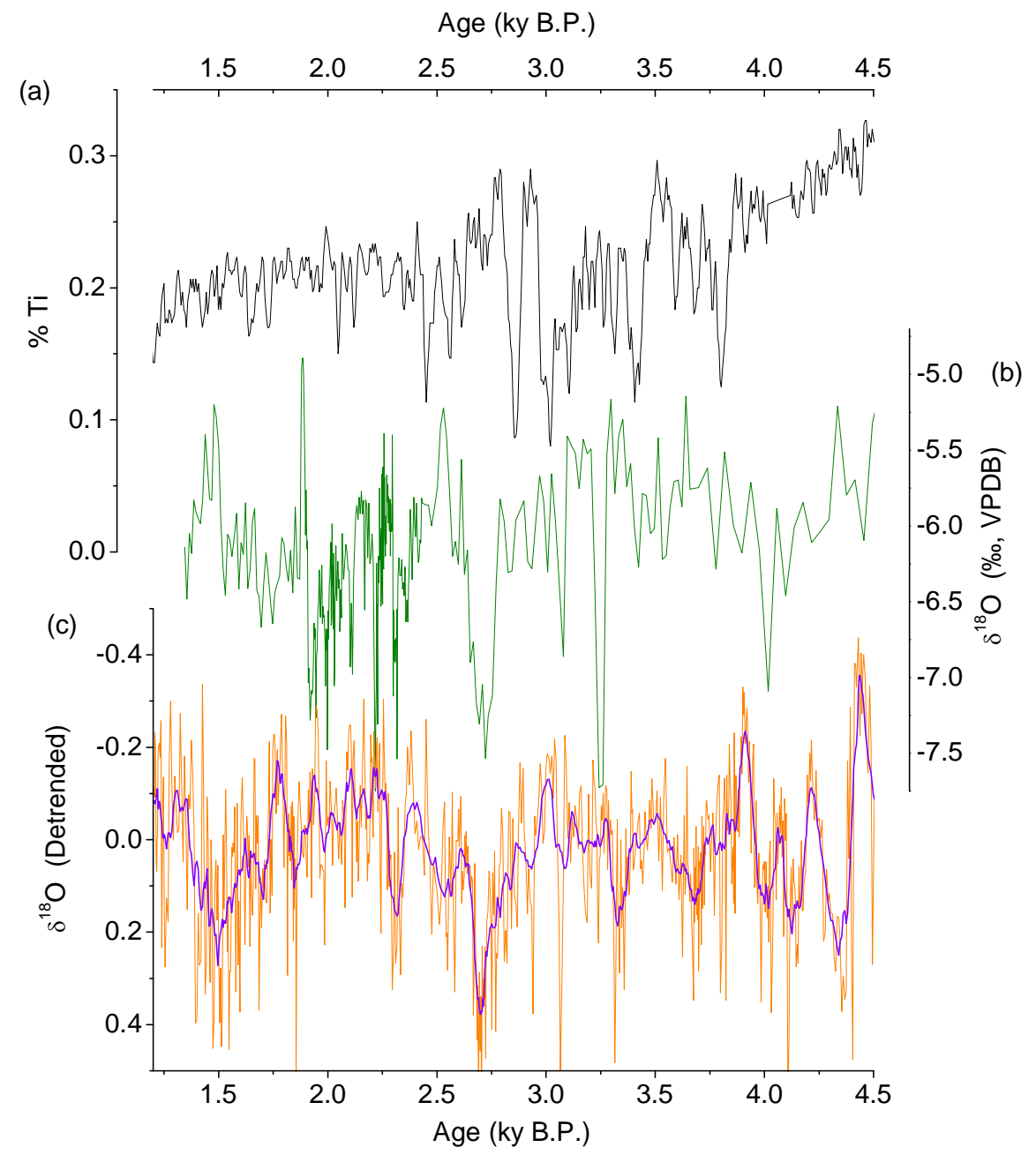

Figure S2. Comparison between (a) \% Ti from Cariaco basin (Haug et al., 2001); (b) Lapa Grande $\delta^{18} \mathrm{O}$ record from LG 3 stalagmites; (c) in orange: detrended DA stalagmite $\delta^{18} \mathrm{O}$ anomalies from Dongge cave, eastern China; purple line indicates a 10 year running mean (Wang et al., 2005). 


\section{Supplementary Figure S3.}

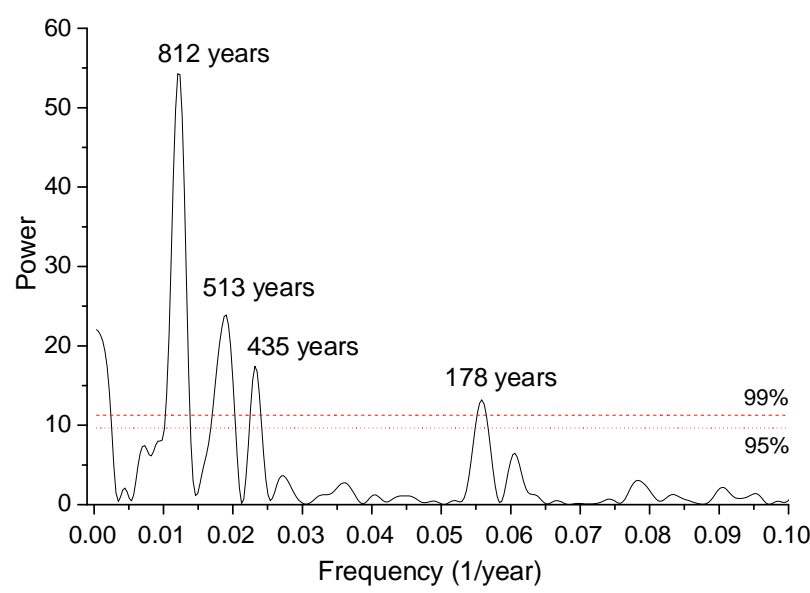

Early Holocene

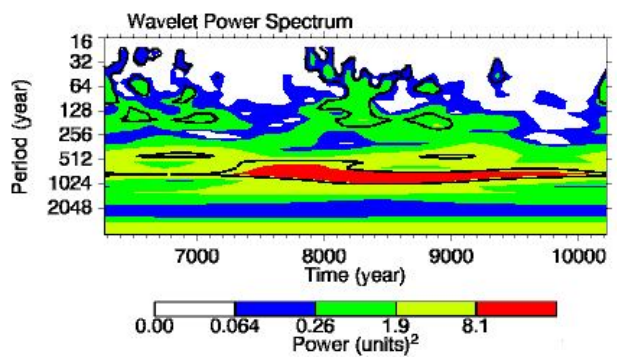

Early Holocene

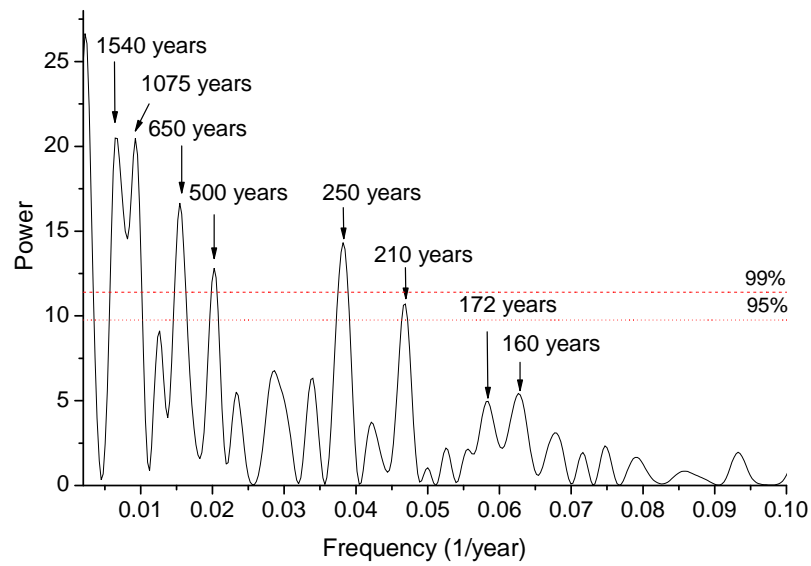

Late Holocene

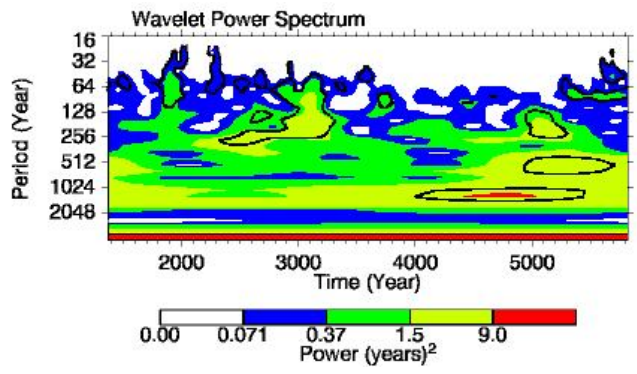

Late Holocene

Figure S3. Top: Spectral analysis of the $\delta^{18} \mathrm{O}$ time series during early and late Holocene. The dashed and dotted horizontal red lines mark the 99 and $95 \%$ confidence levels respectively (Torrence and Campo, 1998). The spectral analysis was obtained by Past software using the Lomb periodogram algorithm (Hammer et al., 2001). Bottom: as on top but for wavelet power spectrum analysis. The wavelet contours correspond to power levels above $75 \%, 50 \%, 25 \%$, and $5 \%$, respectively. Black contours on the wavelet power spectrum indicate the $90 \%$ confidence level, using a red-noise (autoregressive lag1) background spectrum. The data were equally spaced of 10 years. 


\section{Supplementary Table S1}

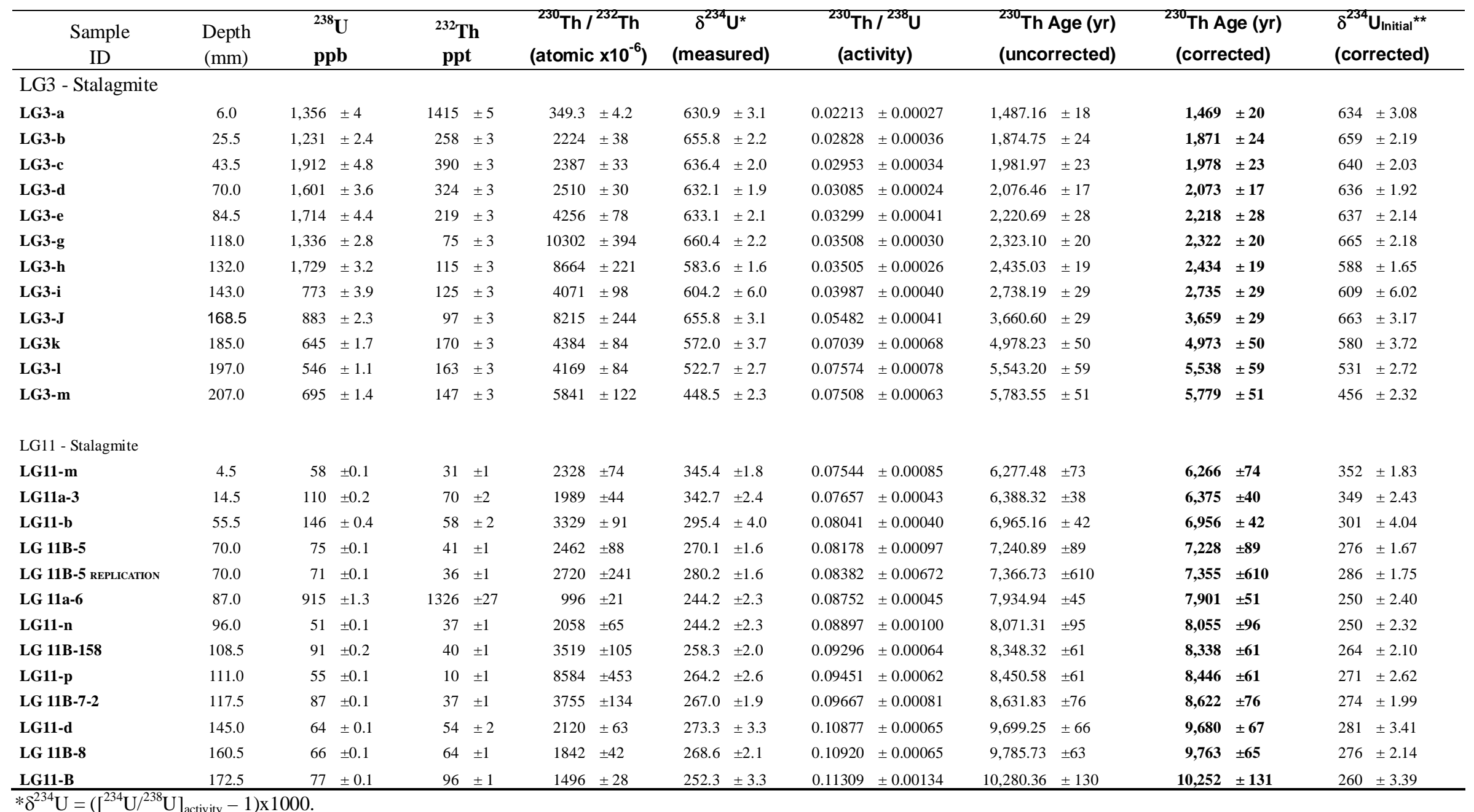

$* \delta^{234} U=\left(\left[{ }^{234} U /{ }^{238} U\right]_{\text {activity }}-1\right) \times 1000$.

$* * \delta^{234} U_{\text {initial }}$ was calculated based on ${ }^{230} \mathrm{Th}$ age $(\mathrm{T})$, i.e., $\delta^{234} \mathrm{U}_{\text {initial }}=\delta^{234} \mathrm{U}_{\text {measured }} \mathrm{X} \mathrm{e}^{\lambda 234 \mathrm{~T}}$

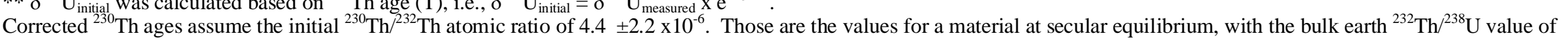
3.8. The errors are arbitrarily assumed to be $50 \%$. 


\section{References cited}

Edwards, R.L., Chen, J.H., and Wasserburg, G.J., 1987, 238U-234U-230Th-232Th systematics and the precise measurement of time over the past 500,000 years: Earth Planetary Science Letters, v. 81, p. 175-192.

Hammer, Ø., Harper, D.A.T., Ryan, P.D., 2001, PAST: Paleontological Statistics Software Package for Education and Data Analysis: Palaeontologia Electronica v. 4, 9pp. http://palaeoelectronica.org/2001_1/past/issue1_01.htm.

Haug, G., Hughen, K., Sigman, D.M., Peterson, L.C., Röhl, U, 2001, Southward migration of the Intertropical Convergence Zone through the Holocene: Science, v. 293, p. 1304-1308, doi: 10.1126/science.1059725.

Shen, C-C., Edwards, R. L., Cheng, H., Dorale, J. A., Thomas, R. B., Moran, S. B., Weinstein, S. E., Edmonds H. N., 2002, Uranium and thorium isotopic and concentration measurements by magnetic sector inductively coupled plasma mass spectrometry: Chemical Geology, v. 185, p. 165-178, doi:10.1016/S0009-2541(01)00404-1.

Torrence, C., Compo, G.P., 1998, A Practical Guide to Wavelet Analysis: Bulletin of the American Meteorological Society, v. 79, p. 61-78.

Wang, Y., Cheng, H., Edwards, R.L., He, Y., Kong, X. An, Z., Wu, J., Kelly, M. J., Dykoski, C. A., Li, X., 2005, The Holocene Asian Monsoon: Links to solar changes and North Atlantic climate, Science, v. 308, p. 854-857, doi: 10.1126/science.1106296. 